\title{
Early Cinema and the Supernatural
}

\author{
by \\ Murray Leeder
}

B.A. (Honours) English, University of Calgary, M.A. Film Studies, Carleton University

\author{
A thesis submitted to the \\ Faculty of Graduate Studies and Research \\ in partial fulfillment of the requirements for the degree of \\ Doctor of Philosophy \\ in Cultural Mediations
}

(C) Murray Leeder September 2011 
Library and Archives

Canada

Published Heritage

Branch

395 Wellington Street Ottawa ON K1A ON4 Canada
Bibliothèque et

Archives Canada

Direction du

Patrimoine de l'édition

395 , rue Wellington

Ottawa ON K1A ON4

Canada
Your file Votre référence

ISBN: 978-0-494-83208-0

Our file Notre référence

ISBN: $978-0-494-83208-0$
NOTICE:

The author has granted a nonexclusive license allowing Library and Archives Canada to reproduce, publish, archive, preserve, conserve, communicate to the public by telecommunication or on the Internet, loan, distribute and sell theses worldwide, for commercial or noncommercial purposes, in microform, paper, electronic and/or any other formats.

The author retains copyright ownership and moral rights in this thesis. Neither the thesis nor substantial extracts from it may be printed or otherwise reproduced without the author's permission.
AVIS:

L'auteur a accordé une licence non exclusive permettant à la Bibliothèque et Archives Canada de reproduire, publier, archiver, sauvegarder, conserver, transmettre au public par télécommunication ou par l'Internet, prêter, distribuer et vendre des thèses partout dans le monde, à des fins commerciales ou autres, sur support microforme, papier, électronique et/ou autres formats.

L'auteur conserve la propriété du droit d'auteur et des droits moraux qui protège cette thèse. $\mathrm{Ni}$ la thèse ni des extraits substantiels de celle-ci ne doivent être imprimés ou autrement reproduits sans son autorisation.
In compliance with the Canadian Privacy Act some supporting forms may have been removed from this thesis.

While these forms may be included in the document page count, their removal does not represent any loss of content from the thesis.
Conformément à la loi canadienne sur la protection de la vie privée, quelques formulaires secondaires ont été enlevés de cette thèse.

Bien que ces formulaires aient inclus dans la pagination, il n'y aura aucun contenu manquant.

\section{Canadä}




\begin{abstract}
This dissertation takes up the familiar notion of cinema as a magical or supernatural art and entertainment form through the examination of early cinema's links to contemporaneous practices in stage magic, spiritualism and psychical research. The use of supernatural scenarios by early filmmakers (including Georges Méliès and George Albert Smith) and the characterization of cinema as a haunted space in early commentaries (emblematized by but not limited to Maxim Gorky's famous “Kingdom of Shadows" essay) illustrate the extent to which supernatural metaphors made the grey, silent and immaterial medium of cinema legible to its first audiences. The project of this dissertation is to restore early cinema's forgotten supernatural contexts through a series of case studies. Besides exploring the effects on early cinema of contemporaneous understandings of the supernatural, the dissertation also challenges current conceptions of cinema as "ghostly" or "magical" by employing historical evidence to evaluate the theoretical and ontological claims advanced by film and media scholars today.

Chapter One examines the place of ghostliness in early and contemporary film theory through a focus on the ontology of cinema associated with the recent spectral turn in contemporary media studies, where a lack of sensitivity to the historical character of discourse on ghosts has led to hyperbolic claims about cinema's novelty. Chapter Two considers cinema within a longer history of the projected image and debates about illusionism and the supernatural, stressing cinema's continuities with prior media going back to the invention of the magic lantern, in order to correct mistaken assumptions about
\end{abstract}


early cinema's novelty. Chapter Three examines the trope of the panicking audience that features in accounts of Jean Eugène Robert-Houdin's 1856 magic shows before Algerian natives, and the "myth of the Grand Café," which held that cinema's first audiences fled before the appearance of a phantom train. Chapter Four considers how George Albert Smith's films drew on his prior careers as a stage mesmerist and a psychical researcher, and also pioneered cinematic double exposures, a standard technique for the depiction of cinematic ghosts. Chapter Five turns to cinema's close cousin the X-ray, which during the 1890 s was seen as exhibiting its own supernatural properties through its apparent ability to collapse surfaces into depths and expose death in life. Chapter Six traces a specific image through multiple media across a relatively long time span: the (typically female) skeleton. It illustrates the extent to which early cinema was one participant in a broader "skeleton vogue" that was at once continuous with centuries old danse macabre traditions and reshaped through the advent of the X-ray. The chapter connects the common scene of women transformed into skeletons in the trick film to the cult of the dead or dying woman that was prominent in the fin de siècle and remains so to this day. 


\section{Acknowledgments}

First and foremost, I must thank my supervisor, Charles O'Brien, for helping shepherd this project to completion, and for offering his unflagging enthusiasm and support. I would also like to thank my other second and third readers, Marc Furstenau and Franny Nudelman, for their invaluable contributions all through the process. In addition, I would like to give special thanks to various professors from Film Studies and Cultural Mediations, including André Loiselle, Mitchell Frank, Barbara Leckie, Barbara Gabriel, Mitsuyo Wada-Marciano, Paul Théberge, Zuzana Pick and Chris Faulkner for their help and support over the years. I would also like to thank those scholars from other institutions with whom I exchanged ideas and who imparted valuable advice over the process, such as Matthew Solomon, Frank Gray and Simone Natale. I would also like to thank my external examiners, Aboubakar Sanogo from Carleton University and Rob King from the University of Toronto, for their spirited engagement with this project. In addition I would like to acknowledge the contributions of both the Social Sciences and Humanities Research Council of Canada and the Ontario Graduate Scholarship for their important and substantial contributions.

My work has benefitted from the recent explosion in archival material from early cinema on DVD. Special credit must go to the Flicker Alley's wonderful boxed set Georges Méliès: First Wizard of the Cinema (1896-1913) (2008) and its subsequent follow-up Georges Méliès: Encore (2010) with newer discoveries - may there be many more "encores" to follow. Other films, especially those of George Albert Smith, I viewed at the British Film Institute in London, largely on $35 \mathrm{~mm}$ with a few on VHS. My research into print documents and rare books and periodicals took me to the archives of the Society for Psychical Research, housed in the Cambridge University library, the Harry Price Collection at the University of London, the reading room of the Magic Circle in London, and the American Society for Psychical Research in Manhattan. Many thanks to the archivists and librarians at these venues for their support and enthusiasm. I would also like to thank Donna Yates, who gave me a place to stay during the Cambridge leg of my research.

The intellectual community at Carleton has been immeasurably helpful in keeping me on track, so thanks goes to such fellow students as Steve Rifkin, Jessica Aldred, Marc Raymond, Ben Wright, Dan Sheridan, Margaret Rose, Sylvie and Paul Jasen, Heather Igloliorte, Matt Croombs, Jeremy Maron, Stacey Loyer, Anne de Stecher, Danielle Wiley, Tom Everett and Kyle Devine. I am sure I am forgetting people, and I hope none of those people read this and are appalled by their absence.

Finally, to Alana Conway who has helped me through these past years in ways I cannot begin to enumerate with her love and patience. 


\section{Table of Contents}

Introduction $\quad 1$

$1 \quad$ The Haunting of Film Theory 16

$2 \quad$ Light and Lies: Screen Practice and (Super-) Natural Magic 38

$3 \quad$ The Panicking Audience in Stage Magic and Early Cinema 61

4 The Strange Case of George Albert Smith: Mesmerism, Psychical Research

$\begin{array}{ll}\text { and Cinema } & 93\end{array}$

$5 \quad$ Aesthetics of Co-Registration: Spirit Photography, X-Rays and Cinema 124

$6 \quad$ Méliès's Skeleton: Gender and the Danse Macabre 154

$\begin{array}{ll}\text { Conclusion } & 188\end{array}$

Appendix I: "THOUGHT-READING EXTRAORDINARY" 194

Appendix II: A postcard from the Cabaret du Néant 195

$\begin{array}{ll}\text { Works Cited } & 196\end{array}$ 


\section{Introduction}

In the October 1896 issue of his quarterly journal Borderland, W.T. Stead, the well-known British spiritualist and "new journalist" who would later meet his fate aboard the R.M.S. Titanic, offered a dozen pages worth of "Suggestions from Science for Psychic Students: Useful Analogies from Recent Discoveries and Inventions." The Borderland to which the periodical's name referred lay between science and the supernatural, and "Suggestions from Science for Psychic Students" was meant to arm the faithful with analogies that they can use to convince people of the validity of spiritualist concepts about life and death, time and space. Stead's analogies come from electricity, the phonograph, the telephone, the photograph, and the camera obscura, but also from the X-ray and the kinetoscope (spelled "kinetiscope" by Stead), the early motion picture exhibition device that the Edison Manufacturing Company had debuted in 1894. The article begins:

The discovery of the Röntgen rays has compelled many a hardened sceptic to admit, when discussing Borderland, that "there may be something in it after all." In like manner many of the latest inventions and scientific discoveries make psychic phenomena thinkable, even by those who have no personal experience of their own to compel conviction. I string together a few of these helpful analogies, claiming only that they at least supply stepping stones that may lead to a rational understanding of much that is now incomprehensible. (400)

We see how clearly the spiritualist movement of the nineteenth century recognized its own peculiar relationship with new technologies and drew consciously on scientific rhetoric. ${ }^{1}$ Spiritualists argued that psychic powers and contact with the dead did not seem so far removed from the modern wonders of science and technology, cinema included.

\footnotetext{
${ }^{1}$ The "technological" character of modern spiritualism has been explored by numerous scholars, including Swatos (1990), Peters (1999 esp. 94-101, 137-44), Sconce (2000 21-58) and Noakes (2004). Martyn Jolly
} 
Stead's article contains sections called "The Kinetiscope of Nature" and "The Kinetiscope of the Mind." In the former case, Stead reproduces the story sent to him by "a lady in Bath" about a place in the Rocky Mountains that animals dare not approach and from which mysterious shrieks of pain are regularly heard. It was the site of the massacre of a group of Mexican men, women and children by "Red Indians," and the location of a terrible tragedy retains an impression of it and continues to reenact it. The trauma of massacre, it is understood, activated a force with the cinema-like ability to record and replay reality (401-3). Of the complementary "Kinetiscope of the Mind," Stead writes that, "The possibility of visualizing the phantoms of the imagination is possessed by some persons in such a high degree that they can compel clairvoyants and sensitives to see as if they were real persons the purely imaginary heroes and heroines of an unwritten romance" (403). He reports such anecdotes as that of a man possessed of an ability to "produce at will, as if his mind were a kinetiscope, living pictures of the past . . . [P]hantoms can be created by the power of the will, which, indeed, is a power which gives to the man who knows how to use it, the semblance of divinity" (Ibid,), and of a man living in a restored sixteenth-century chateau who was able to will the portraits on the wall into life. ${ }^{2}$

In both the Kinetiscopes of Nature and of the Mind, a recurrence of the past, a visitation by the dead, an apparitional conjuring or a overcoming of death are figured in cinematic terms. New exposure to kinetoscopes and related technologies of projection is

writes that "The spiritualists were modernists. They understood the phenomena they witnessed, and believed in, to be part of the same unfolding story of progress as science and technology" (2006 143). ${ }^{2}$ The homologies Stead draws between (proto-) cinematic form and the workings of human cognition forecast a major concern of early film theorists such as Hugo Münsterberg (1916), a connection bolstered by a knowledge of Münsterberg's own studies of spiritualism (1899; see Natale (2010)). 
understood to make the spiritualists' ghost world that much more tangible and plausible. ${ }^{3}$ In Stead's article we see the flipside of a better known phenomenon of the 1890s: the tendency of cinema's first observers to characterize it as a supernatural medium. The most famous instance of this, which I will discuss in length at my first chapter, is Maxim Gorky's declaration that cinema is "the kingdom of shadows," a sort of storehouse for the unhappy dead: "Noiselessly, the ashen-grey foliage of the trees sway in the wind, and the grey silhouettes of the people, as though condemned to eternal silence and cruelly punished by being deprived of all the colours of life, glide noiselessly along the grey ground" (407).

This dissertation locates the Victorian interest in supernatural phenomena as an important context for early cinema, ${ }^{4}$ but one that is underacknowledged and misunderstood. The overarching question explored in this dissertation is a broadly cultural one: why did such a compulsive desire to link cinema with the supernatural exist in the late 1800s? This was not only the case for outsiders like Gorky, struck by a first encounter with the apparatus. Such metaphors were also used by people within the nascent film industry. In fact, the kinetoscope's inventor, W.K.L. Dickson, used séance metaphors to describe cinema in his book The History of the Kinematograph, the Kinetoscope and the Kinetophonegraph (1895), ${ }^{5}$ and one early projecting process,

\footnotetext{
${ }^{3}$ Spiritualists would occasionally make claims for a special relationship with cinema for decades to come. Martyn Jolly writes that a spiritualist named Dr. Guy Bogart visited the set of The Bishop of the Ozarks (1923), a film with a pro-spiritualist theme, "and was convinced he saw a real spirit manifest itself on the set to complement the film's special effects" (143). ${ }^{3}$

${ }^{4}$ In the past few decades this term has largely displaced "primitive cinema" to describe cinema before roughly the mid 1910s and the standardization of the feature-length narrative films as the industry's key product. My focus here is largely on the years before 1900 .

${ }^{5}$ The book was co-authored with his sister Antonia. Matthew Solomon (2010) explores the rhetoric of the supernatural in the Dicksons' book, arguing that it borrows from exposures of spiritualism done by stage magicians (16-20). W.K.L. Dickson's employer, Thomas Edison, was himself a point of obsession for some spiritualists. An 1884 article in Light argued that Edison's feat of sending electricity through a
} 
premiered by Francis Jenkins and Thomas Armat at the Cotton States Exposition in Atlanta, October 1895, bore a name that would seem to promise ghost-viewing: "Phantoscope" (Rossell 1998 120-6). Supernatural scenarios allowed pioneering trick filmmakers like Georges Méliès in France and George Albert Smith in England, to show off the capacity of the medium for wonderful appearances and disappearances, animations and transformations. Nuanced attention to the Victorian conception of the supernatural allows us to better understand, for instance, the reception of cinema's apparent capacity to both arrest and reanimate life, its ghostly status as a half-present medium of projected light or its capacity to dematerialize and transform the human body through trick effects.

Few scholars have taken up the subject of early cinema and the supernatural in much detail, and too often the specifics of the Victorian supernatural are effaced in favour of larger, generalized and ahistorical invocations of "supernaturalness." Put simply, to speak of the supernatural in the 1890 s is not to speak of the supernatural today, and a concerted examination of just what the supernatural meant at the time of cinema's debut will illuminate many issues in early cinema, exposing connections that have been lost and obscured. In addition to excavating early cinema's links with the late Victorian supernatural, this dissertation has the secondary objective of examining what has come to be called the "spectral turn," the concerted interest in questions of the supernatural, ghostliness and haunting within cultural and critical theory during the last two decades, the most influential work of which is Jacques Derrida's Specters of Marx (1992, English

vacuum was great evidence of "how science is tending towards the spiritualism ... Spiritualists should be in the front ranks of learning in every department of knowledge in the great school of nature" (Allen 512) and a 1896 letter in Banner of Light insisted that Edison was a medium whose (perhaps unconscious) grand project was contacting the spirit world (Eggleston 1). 
translation in 1993). ${ }^{6} \mathrm{I}$ am indebted to this body of scholarship and the freedom it has promoted to engage with issues of ghosts and magic, but at the same time I express skepticism and caution about its claims, and especially the way it has tended to look to early cinema as a locus for proving ontological or essential claims about cinema as a "ghostly" or "supernatural" medium. It is my contention that the association of early cinema with the supernatural is an important subject, but that the trope of cinema in general and early cinema in particular as a haunted, spectral or magical space has been has been deployed laxly in scholarship, with too little attention to historical specifics. While the vogue for looking back to early cinema to understand media culture today often produces valuable insights, it can also produce misconceptions about early cinema, ${ }^{7}$ particularly where early cinema's links to the supernatural are concerned.

Roughly the half-century previous to cinema's debut, saw a major reconfiguration of the supernatural (here a term broad enough to encompass the popular experience of ghosts, the practices of stage magicians alongside the speculations of spiritualists and occultists $^{8}$ and the new "scientific" discipline of psychical research - I will further refine the definition later in the dissertation). It was modernized and even made scientific, ${ }^{9}$ and by 1895 , the year of cinema's public debut, that process was complete. Magicians

\footnotetext{
${ }^{6}$ The theoretical engagement with the supernatural to which the phrase "spectral turn" tends to be applied is largely contemporaneous with (yet, I believe, distinct from) a sustained cultural/historical interrogation of the supernatural by scholars like Roger Luckhurst, Pamela Thurschwell, Alex Owen, Richard Noakes, Steven Connor, Shane McCorristine and Srdjan Smajić, to name only a few. The most trenchant critiques of the spectral turn have come from some of these scholars.

${ }^{7}$ Notably, there is a tendency to overstate cinema's novelty and efface its place on a longer history of screen practice (which, as I argue in Chapter 2, has long been imbricated with the supernatural).

${ }^{8}$ The Victorian occult revival, conventionally dated to the foundation of the Hermetic Order of the Golden Dawn in 1888, plays only a background role in this dissertation. For excellent overviews, I would refer any reader to Washington (1996), Owen (2004), Gunn (2011) and Drury (2011).

${ }^{9}$ Among the scholarship that has influenced my thinking on the relationship of science and the supernatural in modern culture but is not otherwise mentioned in this introduction, I will give credit to Briggs (1977), Finucane (1982), Gunning (1995a), Grove (1997), Davis (1998), Marvin (1998), Vanderbeke (2006) and Morrisson (2007).
} 
reframed their tricks as "experiments," spiritualism (often pointedly calling itself "Modern Spiritualism") promoted itself as a scientific religion for a new rational era, and psychical researchers saw their grandest project as finding scientific evidence for the human soul and thus protecting religion from the agnostic likes of John Tyndall and T.H. Huxley (Blum 2006 263-4).${ }^{10}$ Amid these blurring boundaries of faith and science, the new wave of Gothic literature, including famous novels and short fiction by H. Rider Haggard, H.G. Wells, Robert Louis Stevenson, Oscar Wilde, Henry James and Bram Stoker, was itself heavily indebted to the new science of psychical research; in these works we often find that "science is Gothicized, and gothicity is rendered scientifically plausible" (Hurley 1996 20; see also Luckhurst 2005 xix).

This intimate relationship between science and the supernatural is observable in many of the early writings on cinema. One excellent example is V.E. Johnson's December 1896 article "The Kinematograph from a Scientific Point of View." Johnston writes:

The Kinematograph having literally at its birth been dragged into the service of the omnipotent music hall . . . its scientific value is likely to be obscured, if not temporarily lost - a misfortune which every earnest worker in science should, I think, do his utmost to avert ... In meteorology, isolated photographs of a storm or storm clouds, or the results of a whirlwind, are held in high esteem, but how much more valuable would be a series showing such a storm of whirlwind in action? ... Photographs of machinery at rest in all its diversified branches are of the greatest value both in business and in the education of students - how much more valuable will be photographs - faithfully representing its wonderful and oftentimes complicated movements? (25)

\footnotetext{
${ }^{10}$ This process is related to the professionalization of science that, according to John Limon, was complete by 1860 . Prior to that time, one could "drop everything and become a scientist" (1990 5), but in time science became an occulted process inaccessible to the average man. See also Knight (1986).
} 
Johnson endorses cinema's value as a mechanical tool for science's benefit in place of its status as a means of public entertainment, but nevertheless closes his article with a magical analogy:

When King Roderick first visited the necromantic tower of Toledo - or at least so runs legendary history - he beheld on the linen cloth taken by him from the coffer the painted figures of men on horseback of fierce demeanor; anon the picture became animated, and there at length appeared a depiction upon its magic surface a great field of battle with Christians and Moslems engaged in deadly conflict, accompanied with the clash of arms, the braying of trumpets, the neighing of horses. Can the imagination conceive that which the mind of science cannot execute? (25)

The identification of cinema as a valuable new technology and the understanding of it as the heir apparent to supernatural traditions coexist easily for commentators like Johnson. We might do well to recall Arthur C. Clarke's Third Law: "any sufficiently advanced technology is indistinguishable from magic" (qtd. in Bailey 2005 176). ${ }^{11}$ For the Victorians, cinema was one of the best feats of magic (or supernatural conjurations) to have ever come along.

Scholars have begun to explore the significance of magical and spiritualist practices to media history more broadly. Jeffrey Sconce's Haunted Media: Electronic Presence from Telegraphy to Television (2000) explores how supernatural, metaphysical and otherwise outré metaphors have served to help make new media technologies legible to their first users. More than this, Sconce argues that our very ideas about what constitutes the supernatural have everything to do with the media of the time, persuasively interpreting, for instance, the spiritualist movement as originating in the

${ }^{11}$ Clarke's famous words are quoted or paraphrased in a great many places, including within fictional narratives. Lex Luthor (Kevin Spacey) quotes them in Superman Returns (2006) (see Evans 2010 590), as does Jane Foster (Natalie Portman) in Thor (2011). A 2011 Star Trek tie-in novel by David A. McIntee bears the title Indistinguishable from Magic, and James Cameron once described the impact his special effects in The Abyss (1989) had on an audience by evoking Clarke's Third Law, stating that it represents "how it's supposed to be-for the audience. ... The sufficiently advanced technology had become magic to them" (1992 262). 
1840s as an unexpected child of the invention of the telegraph. Sconce focuses on such media of transmission as the telegraph, the radio, television and the Internet, but cinema too is a "haunted" medium, a fact recognized both by some of its first commentators and by a body of literature in film studies. Cinema is surely not the only supernatural technology, nor even the most supernatural, but, if, as John Durham Peters provocatively puts it, "[e]very new medium is a machine for the reproduction of ghosts" (1999 139), it must have supernatural particularities of its own. Of course, early cinema overlapped in fundamental ways with other media, and this dissertation will attend to some of these connections as well, most concertedly in relation to cinema's near-twin, the X-ray.

My project also shares a certain amount of intellectual space with Simon During's Modern Enchantments: The Cultural Power of Secular Magic (2002), which rests on the simple but profound premise that "magic has helped shape modern culture" (1). During proposes that "once we fully recognize magic's role as a cultural agent, our sensitivity to the play of puzzlement, fictiveness and contingency in modernity will be heightened" (2). Just as our understanding of modernity is transformed by attention to the supernatural, so will our understanding of cinema, so often understood as an emblematic technology of modernity. ${ }^{12}$ During's sweeping and ambitious book stretches back to antiquity in its considerations but largely concerns itself with the period from 1700 to 1900 , "when Europe was moving into modernity" (3); my study is concerned with the last years of that period, when cinema made its debut.

\footnotetext{
${ }^{12}$ Others would include the locomotive, phonograph, telegraph, typewriter, phonograph, telephone and automobile. Important sources on modernity not otherwise cited in this introduction include Kern (1983), Clark (1984), Crary (1992), Latour (1993) and Harvey (2003). For useful overviews on thinking about cinema and modernity, see Furstenau and Hasslöcher (1994) and Murphet (2008).
} 
But what place can the supernatural have in modernity? Alan Swingewood writes that modernity "is imbricated in Enlightenment reason, the belief in progress, empirical science and positivism. Modernity signifies a culture of innovation, a rational ethos challenging traditions and rituals in the name of critical thought, empirical knowledge and humanism" (1998 138). But the positivist face of modernity Swingewood describes is merely one aspect of the complex, contradictory character of modernity that some scholars have emphasized (Calinescu (1987), Pels (2003)). Writing about the "second phase" of modernity that encompasses the nineteenth century, Marshall Berman emphasizes both stabilizing and destabilizing facets:

This is a new landscape of steam engines, automatic factories, railroads, vast new industrial zones; of teeming cities that have grown overnight, often with dreadful human consequences; of daily newspapers, telegraphs, telephones and other mass media; of increasingly strong national states and multinational aggregations of capital; of mass social movements fighting these modernizations from above with their own modes of modernization from below; of an ever-expanding world market embracing all, capable of the most spectacular growth, capable of appalling waste and devastation, capable of everything except solidity and stability. (1983 19)

We should not be surprised that this tumultuous time was a fertile environment for speculations about the supernatural to flourish. As Marina Warner has written,

modernity did not by any means put an end to the quest for spirit and the desire to explain its mystery: curiosity about spirits of every sort ... and the ideas and imagery that communicate their nature have flourished more vigorously than ever, when the modern fusion of scientific inquiry, psychology, and metaphysics began. $(200610)^{13}$

If "modernity and enchantment have been perceived to be dichotomous in much of Western theory" (McEwan 2008 31), the counter-tradition described by During, Warner and others argue for more of a dialectical relationship, in which modernity is not so much

\footnotetext{
${ }^{13}$ Mladen Dolar makes a similar statement: "Ghosts, vampires, monsters, the undead dead, etc., flourish in an era when you might expect them to be dead and buried, without a place. They are something brought about by modernity itself' (1991 7).
} 
the "disenchantment of the world" described by Max Weber but, on the contrary, part of the world's re-enchantment.

The view of modernity as multifaceted and dialectical has recently been taken up by thinkers on early cinema, an area where the debates on the value of modernity have raged perhaps to the point of an impasse. ${ }^{14}$ In "Modernity and Cinema: A Culture of Shocks and Flows" (2006), Tom Gunning offers a significant revision of the formulation he first popularized in his "Cinema of Attractions" essay more than twenty years earlier. Gunning writes that his previous work tended to "[emphasize] what Marshall Berman might have called the 'dissolving' aspects of modernity: its discontinuity, its sense of confrontation and shock, its explosive nature, its speed and disorientation" (309). But such an emphasis, Gunning argues, marginalizes another dimension of modernity which emphasizes standardization, organization and rationalization. With both aspects under consideration, modernity emerges as Janus-faced, looking at once towards chaos and order - the titular shock and flow. Drawing on Wolfgang Schivelbusch (1986), Gunning uses the railway as an emblematic example. Railroad travel was rapid and comfortable. It was a much smoother means of transportation than the stagecoach, with its bumpy roads and unpredictable schedules. A train could handle many more passengers at once than its competitors, and allowed passengers to ride in comfort and class. A traveler could read and socialize. In many ways, rail was the representative modern form of transportation rational, systematic, fast and efficient. But passengers knew the ever-present danger of

\footnotetext{
${ }^{14}$ See Gunning (1995), Bordwell (1997), Singer (2001), Keil (2004) and Gunning (2006) for a back and forth between rival perspectives, a once-productive conversation giving way to a quarrel. For more accounts of modernity and cinema, see Gunning (1994, 1995a, 1997, 1998, 2000, 2005), Hansen (1991, 1999), Friedberg (1993), Doane (1993, 2002), Christie (1994, 2009), Cinema and the Invention of Modern Life (1995), Kirby (1997), Schwartz (1998) and Singer (2009). For critical views, see Carroll (2001) and Turvey (2008).
} 
railroad crashes that could inflict trauma on an enormous scale. The train ride embodies the dialectic between the forces of rationalization and organization and those of dissolution and chaos. Both are modern (310). ${ }^{15}$

How can it be that magicians, spiritualists, psychical researchers and so many others made such blatant appeals to science to explain, contextualize or justify ghosts, magic, telepathy and other such phenomena that can seem so irrational? If we understand modernity in the dialectical terms Gunning proposes, this dynamic seems not only unsurprising, but perhaps inevitable. Cinema, according to Gunning's revised formulation, is best understood as partaking of both the shock and the flow of modernity. If early cinema was dominated by shock effects of various kinds (Gunning's "Cinema of Attractions"), post-1910 cinema would become dominated by the rationalizing face of modernity, with narrative as a stabilizing force that ushers in the factory-style industrial mode of production and thus regularizes cinema's product. But that chaotic other face remains. Gunning ultimately argues that a nuanced conception of modernity needs to acknowledge both its dissolving and stabilizing faces. Ben Singer offers a similar revision of his understanding of modernity in the recent essay "The Ambimodernity of Early Cinema": "Modernity is better understood as a heterogeneous arena of modern and counter-modern impulses, yielding cultural expressions that reflected both ends of the spectrum, along with, and perhaps more frequently, ambivalent or ambiguous positions in between" (2009 38). ${ }^{16}$ These multifaceted conceptions of modernity suggest ways of

\footnotetext{
${ }^{15}$ The considerable significance of the train and early cinema has been explored by such scholars as Kirby (1997), Bottomore (1999), Loiperdinger (2004) and Blümlinger (2006). I will explore the specifics of what is sometimes called the "train effect" in my third chapter.

${ }^{16}$ This essay is one of the few to pay attention to supernatural thought as an expression of modernity in the cinema, a subject to which I will return.
} 
addressing why the most modern and rational societies always seem to have such a fascination the magical, the supernatural and the occult.

And what of modernism? Berman defines "modernism" as "any attempt by modern men and women to become subjects as well as objects of modernization, to get a grip on the modern world and make themselves at home in it" (5). By this definition, most of the personages dealt with in this dissertation qualify as modernists, be they magicians modernizing their acts by appealing to science, spiritualists delighted by the potential of new technologies to access invisible worlds, psychical researchers applying an experimental model to supernatural phenomena or early filmmakers drawing on the stock of supernatural concepts available to them to provide material for their new medium. They are all probably most readily allied with "popular modernism" (Daly 1999) or "vernacular modernism" (Hansen 1999), though many of the canonical figures of "high modernism," from writers like Ezra Pound, T.S. Eliot and Mina Loy, to artists like Max Ernst and Marcel Duchamp, to intellectuals like Sigmund Freud and Henri Bergson, had their own dabblings (and sometimes more) with spiritualism and occultism. The cultural reach of the supernatural went well beyond those who per se believed in it; as Helen Sword writes, "even confirmed sceptics such as [James] Joyce, D.H. Lawrence and Virginia Woolf, while shunning spiritualist practice, routinely filled their fiction, poetry and essays with mediums, ghosts, séances, disembodied voices, and other invocations of the living dead" (2002 x).

The entanglements of early cinema with the modern supernatural can be explored from any number of angles, and this dissertation does not claim to be exhaustive in this regard. It does, however, attempt to provide an important backstory to current debates 
about cinema's "magical" or "ghostly" properties, testing the claims of these theoretical debates against historical evidence. Chapter 1, "The Haunting of Film Theory," deals with the understanding of cinema as a haunted medium in such early film theorists as Ricciotto Canudo, Antonin Artaud and Béla Balázs and its revival in the aforementioned body of scholarship labelled the "spectral turn." I argue, however, that the spectral turn, which draws from the supernatural a set of powerful discursive metaphors, has tended to mistake historically contingent aspects of cinema for essential attributes.

Having established the theoretical contexts for its discussion of early cinema and the supernatural, the dissertation tries to reclaim its original context in a variety of ways, each chapter exploring a different element of that context. Chapter 2, "Light and Lies: Screen Practice and (Super-) Natural Magic," examines the entanglement of the supernatural and "screen practice" in a longer history leading up to the cinema. From the magic lantern, invented in the seventeenth century as a form of "natural magic" that used illusions to demystify spectators but that often served to mystify them instead, through the theatrical illusions of Pepper's Ghost and the ghost show in the latter half of the nineteenth century, the fascination with the supernatural implications of the projected image has a long history before cinema's debut, which helps illuminate cinema's own supernatural qualities.

Chapter 3, "The Panicking Audience in Stage Magic and Early Cinema," takes up questions of spectatorship, illusion and panic by considering two foundational narratives of competent versus incompetent spectatorship. One story comes from the history of stage magic, and tells of the great magician Jean Eugène Robert-Houdin going to Algeria to help undermine the influence of Muslim miracle-workers by demonstrating his own 
feats of illusion. The other is the persistent "myth of the Grand Café," which holds that cinema's first audiences fled in terror at the sight of a cinematic train. Both narratives imagine a naïve group of spectators erupting in panic on encountering a new form of illusion. Against them, the superior, trained spectator is constructed.

Chapter 4, "The Strange Case of George Albert Smith: Mesmerism, Psychical Research and Cinema," offers a biographical examination of the relationship of cinema and the supernatural by following the unique career trajectory of a pioneering British filmmaker. Smith started as a Brighton stage performer whose finely-honed thoughttransference act brought him the attention of the fledgling Society for Psychical Research (S.P.R.). After spending more than a decade working for the S.P.R. in a variety of capacities, he returned to Brighton and made some of most innovative films in the world at the time. In particular, he made a variety of trick films that clearly drew on his prior professions, and pioneered the double exposure aesthetics that would come to conventionally signify cinematic ghosts for decades.

Chapter 5, "Aesthetics of Co-Registration: Spirit Photography, X-Rays and Cinema," broadens its focus outward from cinema to examine the supernatural implications of two photographic practices adjacent to cinema. The chapter argues that both share an aesthetic principle whereby various layers of information are collapsed onto a single plane, which they share with cinematic double exposure techniques. The chapter closes with a consideration of trick films that borrow X-ray aesthetics, including Smith's The X-Ray Fiend (1897).

Chapter 6, "Méliès's Skeleton: Early Cinema, Gender and the Danse Macabre," focuses on the prominence of the figure of the skeleton in entertainment in the 1890s. 
Skeletons are a particularly common sight in early cinema, especially in the trick films of Georges Méliès beginning with The Vanishing Lady (1896). This visibility can be explained on one hand as a vestige of danse macabre traditions stretching back to the Middle Ages, and on the other as an offshoot of the X-ray's contemporaneous popularity. The chapter explains how both of these causes factored into the eroticization of the female skeleton in early cinema and the late Victorian cult of dead and dying women.

The central question of this dissertation may be phrased as something like "what conditions made early cinema's supernatural associations possible?" Why did early cinema inspire supernatural associations by commentators like Stead, Gorky and Johnson, and by filmmakers who gravitated towards supernatural scenarios? One way to explain any supernatural qualities that cinema was recognized as possessing in its first years is through recourse to its newness, its status as a novel and wondrous new medium. For instance, Stephen Bottomore quotes an account of an Englishman recalling a boyhood visit to the cinema as "yet another glimpse of the supernatural in a world half shrouded in a fog of myth." Bottomore notes that "One should not forget that the very fact of seeing one's own society, and, indeed, oneself reflected on the screen was in itself amazing. The cinema enabled a person to 'stand outside of himself' and see again an event he had already experienced - an extraordinary idea in the $19^{\text {th }}$ century" $(1999179)$. I do not discount this explanation for cinema's supernatural affinities entirely, but it does not fully satisfy me, any more than the more conceptual claims for cinema's "ghostliness" that I examine in Chapter 1. Rather, I suggest throughout the dissertation that we can understand cinema's supernatural qualities not only as flowing from its newness but rather as points of continuity with some of the innumerable technologies and 
practices that anticipated it: the Phantasmagoria and other displays of projected light, stage magic, mesmerism and psychical research, photography and the danse macabre. In my conclusion, I offer my thoughts on the parallel question of "why now?" What about the 1990s and 2000s nurtured both the spectral turn and the sustained interest in the supernatural in both academia and mass culture? 


\section{Chapter 1: The Haunting of Film Theory}

In his essay "Reflections on the Seventh Art" (1923), film theorist Ricciotto Canudo made the fascinating and puzzling statement that the famous polymath Camille Flammarion, "having witnessed a screening of a film illustrating a soul's survival after death, has once again expressed his faith in spiritism, adding to his new enthusiasm for cinema" (300). In this context, "spiritism" refers to the principally French branch of the spiritualist movement, distinguished mainly by its emphasis on reincarnation (a subject of little interest for British and American spiritualists). It is not clear to me whether Canudo means a fictional film, one documenting a séance, or perhaps even some sort of film made by spiritists for polemical purposes. I suspect that the reference is to a fictional film ${ }^{17}$ and that perhaps this anecdote reached Canudo through personal channels. Canudo was among the first advocates of cinema as an art form, one of a group of French film theorists of the 1910s and 20s who tried to identify the mystical, revelatory, transformative qualities specific to cinema, which went under the name photogénie. Cinema was understood as synthesizing all the other arts and still possessing qualities that set it apart from them, and for Canudo, ghostliness was one of the most significant of those qualities. ${ }^{18}$ I will demonstrate in this chapter that questions about cinema's "ghostliness," "spectrality" or "hauntedness" have been important for thinkers on cinema almost from the beginning, but possibly gain their greatest prominence in the 1990s and

\footnotetext{
${ }^{17}$ John Warne Monroe shared this opinion in an email dated May 27, 2010, telling me that, to the best of his knowledge, no such anecdote appears in Flammarion's own writings. I would further speculate that Canudo does not know the exact film to which the anecdote refers, given the specificity of the titles he cites elsewhere in his essay.

${ }^{18}$ For a cogent explanation of photogénie, see Willemen (1994 124-133). See Dalle Vacche (2008 95-99) for more on Canudo's life, writings and influence on early Italian cinema.
} 
beyond. Within the spectral turn that emerges in the $90 \mathrm{~s}$, we frequently find essential or ontological claims made about cinema as a "ghostly" medium. I will argue that the scholars of the spectral turn, in using haunting and ghostliness as powerful metaphors, risk ignoring the historical character of discourse on ghosts. ${ }^{19}$ I caution particularly against the frequent invocation of early cinema as a sort of locus of cinema's supernaturalness, a critical construction that conventionally requires a discussion (and perhaps misuse) of Maxim Gorky's "Kingdom of Shadows" essay.

Canudo's remarks on Flammarion appear in a section of "Reflections on the Seventh Art" called "Immateriality in Cinema." Here, Canudo proposes that cinema possesses a particular power for conveying immateriality and the dimensions of the soul or the unconscious (which are spoken of almost interchangeably). Canudo argues that cinema naturally is better at this than theatre, because:

Theatre is confined to concrete speech, and when an unconscious image is desired, it can play with light: it can throw a white mantle around Hamlet's father. But it will always remain within the exact proportions of every reality. Cinema permits, and must further develop, the extraordinary and striking faculty of representing immateriality. (300-1, original emphasis)

His examples are the supernatural psycho-dramas The Phantom Chariot $(1921)^{20}$ from Sweden and Earthbound (1920) from the United States. He spends a paragraph describing the latter film, which presents the story of a man murdered by his mistress's husband, his ghost lingering on earth until he receives forgiveness from his wife for his infidelity; his spirit embraces her, though she cannot feel or see him. Canudo writes: "Certain shots in the film, combining the real and the immaterial, the living and the dead,

\footnotetext{
${ }^{19}$ The difficulty of defining "ghost" in a way that is universally applicable is taken up by Potts (2006). See Finucane (1982) for a treatment of how European ghosts have changed substantially over the centuries and Collins (1996) on shifting aesthetics of the supernatural.

${ }^{20}$ Directed by Victor Sjöström as Körkarlen, it was also released as The Phantom Carriage.
} 
are often powerful and very troubling. We are reminded of the promise that man might photograph the total life of the unconscious, whose unknown rhythm might rule over our own!" (301). Canudo was neither the first nor the last commentator to see cinema's ability to depict immateriality or ghostliness as essential to its identity as an artistic medium; his observations here link cinema to occult speculations about photography that I will discuss in Chapter 5.

The Camille Flammarion referenced by Canudo was known as an astronomer, publisher (founder of Groupe Flammarion), novelist and psychical researcher. At the time Canudo wrote "Reflections on the Seventh Art," Flammarion was in his late seventies, and had witnessed the history of spiritism from the beginning. A committed spiritist early in the movement's history, Flammarion had even spoken at the 1869 funeral of the movement's founder, Allen Kardec. ${ }^{21}$ As a faith that blurred religion and science, spiritism held a strong appeal to mystical-minded scientists (or science-minded mystics) like Flammarion. John Warne Monroe writes, “For many, like Flammarion, who cherished the consolation and moral certainty religion could provide, but who also believed in the ultimate truth-determining power of experimental inquiry, Spiritism appeared to be a definitive solution to a deeply disturbing philosophical problem" (2002 127). ${ }^{22}$ Canudo states that "[Flammarion] was happily surprised to see the cinema confront the evocation (if no longer the representation) of immateriality. $\mathrm{Mr}$.

Flammarion's remarks confirm that the cinema, when understood and conceived of as art by artists, must develop in specific areas that are impossible in other arts" (300, original emphasis), including embracing its own ghostly potential.

\footnotetext{
${ }^{21}$ He would later distance himself from spiritism, so Canudo's remarks may allude to a late-life reaffirmation of Flammarion's spiritist faith.

${ }^{22}$ More on Flammarion's spiritism, see Canguilhem (2004).
} 
The appropriateness Canudo finds in the fact that Flammarion's return to spiritism should have happened through the medium of cinema remind us that cinema's powers and spiritist (or spiritualist) values share something important: an interest in immateriality. Canudo was by no means unique in locating cinema's specificity, its photogénie, in the supernatural; in fact, in 1921, Jean Epstein himself wrote that, "The cinema is essentially supernatural" (1988 246). In 1927, Antonin Artaud authored an article called "Sorcery and the Cinema," in which he describes the cinema as a magical device that bestows "a quasi-animal life" (1988 49) to the images it animates, and even exalts them into almost Platonic ideal versions of themselves. Artaud writes, "The cinema is essentially the revealer of a whole occult life with which it puts us into direct contact. . . A whole imperceptible substance takes shape and tries to reach the light. The cinema is bringing us nearer to this substance" (50). Ben Singer has recently argued that the supernatural rhetoric embraced by the photogénie critics represents a little-acknowledged counter-strain of early film theory:

Few people today would endorse the quasi-religious, spiritualist rhetoric of French Impressionist criticism, but it would be a mistake to dismiss it as nothing more than quaint and silly mystification ... Conceptualizing cinema in terms of the occult, the supernatural, the metaphysical realms of noumena, Impressionist criticism seems very far removed from the main dynamic thrust of the cinemaand-modernity discourse. It gravitated toward the half-light of Romantic spiritualism rather than the materialist glare of the contemporary urban industrial milieu. (2009 47)

Looking beyond the photogénie critics, one can also find parallel claims in Béla Balázs's early book The Visible Man (2010). In a segment called "Miracles and Ghosts," focusing particularly on the fairytale film, Balázs concludes that "[it] is certain . . . that no written or oral literature is able to express them ghostly, the demonic and the supernatural as well 
as the cinematic" (59). Further, in one of his later articles, "Art Today and the Film" (1966), Rudolf Arnheim wrote

it seems evident that what captures us in [Jacques-Yves Cousteau's Worlds Without a Sun (1964)] is a most impressive although surely unintentional display of what the most impressive films of the last few years have been trying to do, namely, to interpret the ghostliness of the visible world by means of authentic appearances drawn directly from that world. The cinema has been making its best contribution to the general trend I have tried to describe, not by withdrawing from imagery, as other arts have, but by using imagery to describe reality as a ghostly figment. (244)

It is evident that charting out a relationship between cinema and the supernatural was a very real concern in both early and classical film theory, ${ }^{23}$ but the spectral turn has made it a much more substantial area of inquiry. A significant strand of recent scholarship has sought to locate cinema as "magical" or "ghostly" or "spiritual" on an essential level. For instance, in an article called "The Crypt, the Haunted House, of Cinema" (2004), Alan Cholodenko states:

It is a key premise of this essay that not only is the spectre a privileged subject of film but that it would be the ur figure of cinema, if cinema could have an ur figure, a figure not only operating at every second at every level in every aspect of every film, but also at the level of the cinematic, or rather animatic, apparatus of film, hence at the level of film 'as such.' (100)

Some version of this claim is operative in many other works: that film has a special affinity with death or the world of the ghost. As Gilberto Perez writes, "The projector, the magic lantern, animates the track of light with its own light, brings the imprint of life to new life on the screen. The images on the screen carry in them something of the world itself, something material, and yet something transposed, transformed into another world:

\footnotetext{
${ }^{23}$ Also, Parker Tyler's remarkable "Supernaturalism in the Movies" (1945) states: "Movie-camera trickery is of a magic-carpet kind - but here this expression not only is a figure of speech but denotes an actual vision, albeit only an image recorded by one mechanism and thrown by another onto a screen - an image as insubstantial as a ghost itself. With this power to render the human substance into mere symbolic ectoplasm, the movie camera possesses a perambulation parallel to the movements supposedly initiated in actual Ghost Land" (363).
} 
the material ghost" (1998 28). These "supernatural" inquiries reflect the impact the spectral turn has had on film theory, so I will now offer a more general treatment of the spectral turn before moving on to its specific impact in film studies.

The Spectral Turn

"Spectral turn" is a phrase much used at present in cultural studies, assuming a moment when philosophy fixes on questions about of ghosts, haunting and spectrality like never before. Like many of the "Turns" currently being discussed (the Pictorial Turn, the Sensorial Turn, the Spatial Turn, the Historical Turn, etc.), the term is drawn from Richard Rorty's model of the history of philosophy as a series of "Turns," in which "a new set of problems emerges and the old ones begin to fade away" (1979 264). The spectral turn is generally agreed to have been inaugurated in the early nineties with the publication of Jacques Derrida's Specters of Marx. Complex and controversial even by Derridean standards, Specters of Marx is a meditation on the fall of the Soviet Union and on the nature of ghosts. To counter both the current neo-conservative self-congratulation and theoretical declarations of "the end of history," Derrida calls for the foundation of links between deconstruction and classic Marxism and declares a "New International" to maintain Marx's spirit as a sort of ghostly half-presence between life and death, presence and absence. ${ }^{24}$ For Derrida the ghost is an innately deconstructive figure that undermines logocentric thought with its category-bending interstitiality, particularly in terms of its ability to cut through linear histories by the simultaneity of its past, present and future. Derrida provides the neologism "hauntology": "It is necessary for us to introduce haunting into the very construction of a concept. Of every concept, beginning with the concepts of being and time. That is what we would be calling here a hauntology" (6).

\footnotetext{
${ }^{24}$ For other Marxist treatments of the ghost, see Clery (1995), Wayne (2004) and Smith (2010).
} 
Christine Berthin writes that, "Hauntology is the dark double of ontology. It deconstructs and empties out ontology, being and presence. Neither alive nor dead, the Derridean spectre hovers between presence and absence, making it impossible to assign definitive meanings to things" (2010 3). As we shall see, Derrida's conception of the ghost has strong implications for cinema, which received (not in Specters of Marx but in other places) a key place in his discourse on ghosts.

The reception of Specters of Marx among Marxist and left-leaning critics has been extremely mixed (Davis 2007 8), and the book even inspired critiques from within the deconstructionist ranks (notably Spivak 1995). The considerably more friendly reception it received in literary and cultural studies, however, triggered a new academic vogue for ghosts and the supernatural. When asked "are you a scholar who deals with ghosts?" Derrida's translator, Peggy Kamuf, answered, "Yes . . . although I'm not sure I would have said so with as much conviction before Specters of Marx" (qtd. in Luckhurst 2002 527). She was not alone in this, and though not all participants in the spectral turn draw directly on Derrida's book, they benefit from the intellectual openness to questions of ghosts and haunting fomented by it. Other prime contributions include Jean-Michel Rabaté's The Ghosts of Modernity (1996), Avery F. Gordon's Ghostly Matters: Ghosts and the Sociological Imagination (1997), Carla Jodey Castricano's Cryptomimesis: The Gothic and Jacques Derrida's Ghost Writing (2001), Ashok Kara's The Ghosts of Justice: Heidegger, Derrida and the Fate of Deconstruction (2001), Julian Wolfrey's Victorian Hauntings: Spectrality, Gothic, the Uncanny and Literature (2002), Helen Sword's Ghostwriting Modernism (2002), Gray Kochhar-Lingren's TechnoLogics: Ghosts, the Incalculable, and the Suspension of Animation (2005), Colin Davis's 
Haunted Subjects: Deconstruction, Psychoanalysis and the Return of the Dead (2007), David Appelbaum's Jacques Derrida's Ghost: A Conjuration (2009), Gabriele Schwab's Haunting Legacies: Violent Histories and Transgenerational Trauma (2010) and Christine Berthin's Gothic Hauntings: Melancholy Crypts and Textual Ghosts (2010). ${ }^{25}$ This list could go on, ${ }^{26}$ and the trend shows no signs of abating. Consider the titles of some recent collections: Spectral America: Phantoms and the National Imagination (2004), Magic, Science, Technology and Literature (2006), Technologies of Magic (2006), Ghost, Stories, Histories: Ghost Stories and Alternative Histories (2007), Uncanny Modernity (2008), The Re-Enchantment of the World: Secular Magic in a Rational Age (2009), Haunting Presence: Ghosts in French Literature and Culture (2009), Popular Ghosts: The Haunted Spaces of Everyday Life (2010). The first line of the latter collection is "It seems that ghosts are everywhere these days" (ix) ... indeed. Numerous journals did special issues on spectral topics: Space and Culture on "Spatial Hauntings" in 2001, Art History on photography and spiritualism in 2003, and Cultural Geographies on "Spectro-Geographies" in $2008 .^{27}$

Surveying this material, however, brings some frustrations. As Jo Frances Maddern and Peter Adey write: "A clear set of issues, which may benefit from the application of the currently dissonant collection of theories of spectrality, has yet to be

\footnotetext{
${ }^{25}$ Consult Auerbach (2004) and Gunn (2006) for surveys of much of the central material of this turn. For a take more focused on the study of horror, see Hills (2005 154-8).

${ }^{26}$ Excluded from this discussion for reasons of space are sources on ghosts and haunting in postcolonial and racial theory both in film studies (Lim 2009, Mimura 2009) and outside it (Goddu 1997, Brogan 1998, Bergland 2000, Del Villano 2007, Turcotte 2009, Khair 2009, Parham 2009, Althans 2010, the collection Unsettled Remains (2009)), as well as the importance of the ghost in avant-garde cinema (Skoller 2005, Cahill 2007).

${ }^{27}$ There is also a certain relationship with the body of philosophical thinking about photography that emphasizes the photograph's ability to capture and thus implicitly make dead its subject, and the photograph itself as a venue for meditation on death, grief and historicity. I will return to this subject in Chapter 5.
} 
defined. The words 'haunting' and 'spectrality' are also often used loosely and without clear definition. Furthermore, the current debate remains murky and disconnected" (2008 292). Even the phrase "spectral turn" is used with less specificity than one might hope: both Jeffrey Weinstock (2004) and Diane E. Goldstein, Sylvia Ann Grider and Jeanne Banks Thomas (2007) use the phrase to denote not a body of academic writing, but a cultural fascination emblematized by many supernaturally themed films and television shows at the dawn of the third millennium (perhaps "cycle of production" would suit better than "turn" in this context). Throughout the spectral turn one finds adjectives like "haunted," "supernatural," "spectral," "ghostly" and even "uncanny"28 used with a lack of clarification, even interchangeably, due to the uncertain semantic parameters of each term. ${ }^{29}$ The claims of the spectral turn theorists are also often regarded with scepticism by historians of the supernatural. The editors of the collection The Victorian Supernatural note in its introduction that, "for Derrida, history is structurally and necessarily haunted, but where is the supernatural to be found in this kind of haunting? The problem is that the ghost is only one in a series of deconstructive tropes" (2004 12). They argue that Derrida's conception of the ghost, though evocative, is necessarily an ahistorical one. It is not sensitive to how the supernatural means different things in different cultures and at different times, and is not well-suited to considerations of people's actual experience of the supernatural. In the essay which coined the phrase "spectral turn," "The Contemporary London Gothic and the Limits of the "Spectral Turn"” (2002), Roger

\footnotetext{
${ }^{28}$ Freud's 1919 essay on the uncanny received no special focus in scholarship until the 1970s and subsequently rose to the status of a founding text in the 1970s (see Jay 1998, Collins and Jervis 2008, Masschelein 2011). For sources on psychoanalysis's complex relationship with the supernatural, including Freud's own dabblings in psychical research, see Gay (1989 105-130). Luckhurst (1999) and Thurschwell (2001 115-150).

${ }^{29}$ Davis laudably delineates his use of "spectre," "phantom" and "ghost," using the first for Derrida's sense, the second for that of Nicholas Abraham and Maria Torok and the third for more general uses. He confesses, however, that he is imposing stricter terminological consistency than the original authors (160).
} 
Luckhurst makes a similar case, urging that we resist using a generalized structure of spectrality or "haunted modernity" instead of a historical interpretation lodged in issues of politics and ideology. He warns against the "generalizing economy of haunting" (2002 534) as ahistorical and limiting, producing a paradigm whereby the ghost is not a specific symptom singular to its time and place but rather is understood only within "the generalized structure of haunting [which] is symptomatically blind to its generative loci" (2002 528). Luckhurst is among the scholars whose attitude towards the spectral turn might be described as "cautious interest," his critique not designed to disparage the spectral turn outright but to point to its limits. In closing he states, "We surely have to risk the violence of reading the ghost, of cracking open its absent presence to answer the demand of its specific symptomatology and its specific locale" (2002 542).

I am not unsympathetic to the spectral turn or its applications within film studies, but, like some of these critics, believe that a sense of historical rigour brought to bear on the trope of "cinema as ghostly" is necessary to balance the more theoretical propositions by scholars like Alan Cholodenko by providing an important backstory. Like Luckhurst, I believe that the spectral turn needs to be saved from itself. As we have established, the idea that cinema has a special relationship with the supernatural is by no means a new one, but was a reasonably common proposition during cinema's early years. But I contend that it was not the case that early cinema's audiences were encountering a more essential or authentic version of cinema (as a romantic yet persistent construction of early cinema's spectators would have it), but rather that the association of cinema with the supernatural is reflective of the cultural role played by the ghost and the supernatural more broadly at the moment of cinema's emergence. 
The Hazards of Gorky: Film Studies, Early Cinema and the Idea of Ghostliness

If the understanding of cinema as troubling the binaries of life and death, presence and absence, does not begin with Derrida, he certainly played a considerable part in cementing its current vogue. As in most fields, the reception of hauntology in film studies has been a mixed one. At the 2008 Society for Cinema and Media Studies in Philadelphia, Steven Shaviro served as the respondent for a panel called "Untimely Bodies: Towards a Comparative Film Theory of Human Figures, Temporalities and Visibilities," featuring presentations by Tom Gunning, Brian Wall, Chika Kinotsha and James Prakash Younger. Shaviro began with a swipe at Derrida that nevertheless reaffirmed his usefulness: "In his massively disappointing book Specters of Marx, Jacques Derrida nonetheless has one marvellous invention." Shaviro went on to state: ... Deeper than any ontology, deeper than being, deeper than what $i s$, there is that which haunts being, spectrally, without being reducible to it. Derrida, as is his wont, presents hauntology as an absence which underlies, and disrupts, any assertion of presence. But, of course, this formulation is reversible; it just as well designates a continuing subsistence, or insistence, at the very heart of death and absence. Something that has died, something that is in the past, nonetheless refuses to go away. Or something that is not yet born, something that is in a potential future, casts its premonitory shadow even before it has arrived. In either case, something that is invisible and impalpable fails to be simply absent, simply not there...

The speakers on this panel all point, in one way or another, to the hauntological dimension of the movies. They testify to the ways that -- as Gilles Deleuze puts it in a different context -- the cinematic image is never simply in the present: for it contains, rolled up within it, virtual dimensions of pastness and futurity. But beyond this, they suggest that film is itself the hauntological art par excellence. It is not just that a certain practice of cinema might be described as hauntological; but more importantly that hauntology itself, in its evanescent yet more-than-real spectrality, is inherently cinematic. Film does not capture and reproduce the real, so much as it always already haunts reality, sapping its apparent solidity from within. 
I quote Shaviro's speech at some length because it illustrates the extent to which the ghostliness of cinema has become an acceptable, mainstream theoretical concept. Where ghosts in Derrida's sense should be present in every imaginable medium (indeed, he says that we need to introduce "haunting into the very construction of a concept" (6)), for whatever reason cinema seems unusually prone to inspire reflections on this fact. This was true for Derrida himself. In Ken McMullan's experimental film Ghost Dance (1983), Derrida appears as himself in several scenes. In the longest of these, lead actress Pascale Ogier asks Derrida if he believes in ghosts. Derrida says,

Here the ghost is me. Since I've been asked to play myself in a film which is more or less improvised, I feel as if I'm letting a ghost speak through me. Curiously, instead of playing myself, without knowing it I let a ghost ventriloquize my words, or play my role ... Cinema is an art of phantoms (phantomachia), a battle of phantoms. I think that's what the cinema's about, when it's not boring. It's the art of letting ghosts come back.

Implicitly positioning himself against Weber's disenchantment paradigm, he goes on to say, "I believe that modern developments in technology and telecommunication, instead of diminishing the realm of ghosts ... enhances the power of ghosts and their ability to haunt us ... I say, 'Long live the ghosts."' Ogier died a year after the film was released, the day before her twenty-sixth birthday, and Derrida later would describe the experience of watching the film again with the knowledge of her death:

I suddenly saw Pascale's face appear on the screen, and I knew it was the face of a dead woman. She was replying to my question: 'Do you believe in ghosts?' As if she were looking straight into my eyes, she was still saying to me on the big screen, 'Yes, now, yes.' Which now? Years afterwards in Texas. I had the overwhelming feeling of the return of her ghost, the ghost of her ghost, coming back to say to me, to me, here, now: 'Now...now....now, that is, in this darkened room, on another continent, in another world, there, now, yes, believe me, I believe in ghosts." (qtd. in Davis 2007 20) 
In an essay called "Cinema and the Meaning of Life" (2006) Louis-Georges Schwartz writes that "The cinema provides a succinct figure for hauntology as well as participating in the process of haunting which, by itself, deconstructs life/death, presence/absence and being/non-being" (13). Schwartz quotes Derrida's 2001 interview with the editors of Cahiers du Cinéma, where he stated that "cinematographic experience belongs to spectrality from beginning to end" (14). Schwartz provides a more nuanced and thorough understanding of Derrida's hauntology and the place cinema has within it than one generally finds. It includes a discussion of Derrida's belated encounter with the cinematic "ghost" of Pascal Ogier which links Derrida's reaction back to early cinema:

Instead of exercising Ogier's ghost by explaining her away as a mechanical illusion, even an absolute illusion, or as an effect of mourning whereby a mere appearance is invested with the energy the mourner had given to the lost object, Derrida writes a description of the experience in an attempt to think this haunting and hauntology in general. If in the accounts of the first Lumière projections, the moving image comes to restore life to the dead, in Derrida's writings, the cinematic ghost appears as neither living nor dead, an appearance that changes the very nature of the categories. (18)

Here (and in a reference in a footnote to the Maxim Gorky essay I will shortly discuss), Schwartz acknowledges Derrida as a being on a lineage with, yet not precisely duplicating, those early commentators.

Among those scholars claiming a supernatural specificity for the cinema, there is a strong tendency to appeal, however selectively, to early cinema and its commentators. A special pride of place often goes to Maxim Gorky's "Kingdom of Shadows" essay (a retrospective label), written under the pseudonym "I.M. Pacatus" upon seeing an 1896 screening of the Lumière programme in Nizhni-Novgorod. Gorky viewed the films at the theatre of Charles Aumont, which doubled as a fashionable brothel, a fact to which the review makes a few coy references. Rather than emphasizing shock or excitement the 
way many initial accounts of cinema did, Gorky described cinema as something drab and depressing, an unnerving netherworld:

Last night I was in the Kingdom of Shadows.

If you only knew how strange it is to be here. It is a world without sound, without colour. Everything there - the earth, the trees, the people, the water and the air is dipped in monotonous grey. Gray rays of the sun across the grey sky, grey eyes in grey faces, and the leaves of the trees are ashen grey. It is not life but its shadow, not motion but its soundless spectre. (407)

The review continues for three pages in this mode of intense gothic melancholy. Of the people on the screen, Gorky states:

... the grey silhouettes of the people, as though condemned to eternal silence and cruelly punished by being deprived of all the colours of life, glide noiselessly along the grey ground.

Their smiles are lifeless, even though their movements are full of living energy and are so swift as to be almost imperceptible. Their laughter is soundless, although you see the muscles contracting in their grey faces. Before you a life is surging, a life deprived of words and shorn of the living spectrum of colours - the grey, the soundless, the bleak and dismal life.

It is terrifying to see, but it is the movement of shadows, only of shadows. Curses and ghosts, the evil spirits have cast entire cities into eternal sleep, come to mind and you feel as though Merlin's vicious trick is being enacted before you. (407-8)

Gorky paints cinema as both a kind of Hades for grey and insubstantial shades and as the grand conjuration of an evil magician. Later, he describes Partie de Cartes (1895) in similar terms:

Three men seated at the table, playing cards. Their faces are tense, their hands move swiftly. The cupidity of the players is betrayed by the trembling fingers and by the twitching of their facial muscles. They play ... Suddenly, they break into laughter, and the waiter who has stopped at their table with bear, laughs too. They laugh until their sides split but not a sound is heard. It seems as if these people have died and their shadows have been condemned to play card in silence unto eternity. $(408)^{30}$

\footnotetext{
${ }^{30}$ The words of Gorky quoted here and in virtually all citations accounts of Gorky's review(s) come from a translation of the essay appearing in Jay Leyda's Kino: A History of the Russian and Soviet Film (1960), credited to "Leda Swan." Gorky also wrote a piece for an Odessa paper on the same events, which was
} 
Gorky's words have an evocative power and are cited in a great many places. In general, critical deployments of Gorky's essay fall into two (somewhat overlapping) categories.

One uses it to speak about how European intellectuals rejected cinema as lacking, as Noël Burch puts it, "the requirements of the naturalistic ideology of representation" (1990 23), invoking the metaphor of the shadow to describe cinema as insubstantial and incomplete. Gorky's article is thus understood as embodying an early scepticism towards cinema's grey, silent world, and also as anticipating later iconophobic theoretical formations that object to cinema's illusionism. ${ }^{31}$ The other category focuses on the fact that Gorky's intellectual scepticism does little to obscure the visceral impact he describes cinema as having had on him, and find suggestive potential to his characterization of cinema as a haunted space, "an encounter with the living dead" (Lowenstein 2010 124).

Gorky's essay has given a title to Colin Harding and Simon Popple's excellent collection of early writings on cinema, In the Kingdom of Shadows: A Companion to Early Cinema (1996), as well as the documentary The Kingdom of Shadows: Rise of the Horror Film (1998) about silent "horror" films, now available as part of Kino International's American Silent Horror collection. ${ }^{32}$ Gorky's is indeed an important essay, considerations of which have helped scholars develop a more nuanced and balanced understanding of early audiences' reactions to cinema than once prevailed. His

translated to English by Leonard Mins for the anthology New Theatre and Film 1934 to 1937 . Even though the translation appeared significantly earlier (Leyda himself cited it in an 1946 article in Hollywood Quarterly (37)), it is far less cited in scholarship than the essay translated in Leyda's book. While it makes references to shadows and ghosts akin to those found in the more familiar essay, the overall tone is less gloomy and poetic but comes somewhat closer to straightforward reportage. It has been suggested that the supernatural implications are created or at least amplified by the translation in the Leyda book (Ruffles 2004238 ), but to the best of my knowledge no alternative translation has emerged.

${ }^{31}$ For other examples, see, Polan (1982/3 131-2), Pence (2004 30-5), Richardson (2004 257), Marcus (2007 72-5), Baumbach (2009 379-80), Brown (2009 142), and Furstenau (2010 1-2).

${ }^{32}$ The term "horror film" and the recognition of horror as a cinematic genre did not take place until the $30 \mathrm{~s}$, a fact to which the documentary is not sensitive. 
gloomy response to the Lumière films has helped scholars to complicate the simplistic "Lumière $=$ Realism, Méliès $=$ Formalism" dichotomy that once dominated understandings of early cinema, since Gorky imagines a phantasmal world built around images that would otherwise seem to epitomize realism. Tom Gunning drew on Gorky to counter the then-dominant Metzian model of early spectators' reactions to cinema as "submitting passively to an all-dominating apparatus, hypnotised and transfixed by its illusionist power" (1995 32) with one that emphasizes the sophistication of the audiences, and their ability to recognize cinema's illusionary qualities and reflect intelligently upon them. The early cinema spectator, for Gunning, is closer to Gorky than a credulous rube like the one we meet in Uncle Josh at the Moving Picture Show (1902).

Gorky's early writings on cinema are seldom discussed within their Russian context; I will shortly discuss Yuri Tsivian as the key exception. Instead, Gorky's article has been taken as an ahistorical, or at least transcultural, proof of cinema's ghostly qualities, evidence for the generalizing economy of the supernatural against which Luckhurst cautioned. ${ }^{33}$ In both examples cited above, the Harding-Popple anthology and the horror film documentary of the same title, the phrase "the Kingdom of Shadows," is implicitly pressed into service of representing a certain period of filmmaking (early cinema or silent cinema as a locus for cinema's ghostliness, which presumably does not apply beyond the introduction of sound, or at least not as well).$^{34}$ Neither work is

\footnotetext{
${ }^{33}$ It can also be pressed into the service of cases made about cinema's nature, essence or ontology on terms slightly different from (though perhaps parallel to) the trope of ghostliness. For example, Daniel Frampton (2006) places a quote from Gorky alongside an anecdote from the DVD of Contact (1997) where Jodie Foster expresses an uncanny feeling about having her face manipulated (1). Both examples, from a century apart, combine to paint cinema as an artificial otherworld.

${ }^{34}$ Davies (2007) has a chapter called "Projecting Ghosts," which follows the creation of ghostly images from the sixteenth century on to a discussion of ghosts in cinema, but quits in the late silent period; it thus reflects an understanding that silent cinema (or frequently, only early cinema) is to be understood as ghostly, haunted, uncanny ... and the rest of cinema is not, or at least not as pointedly so. This is
} 
particularly about Gorky, or subjects his essay to sustained analysis (the documentary never even mentions him; presumably the label "Kingdom of Shadows" for silent horror is meant to speak for itself). Take also Lee Grieveson and Peter Krämer's The Silent Cinema Reader (2003), the introduction of which begins by citing Gorky's famous words, even though the entire book scarcely references Gorky again. In The Haunted Gallery: Painting, Photograph, Film c. 1900 (2007), Lynda Nead, after an excellent discussion of haunted paintings as a late Victorian trend that transitioned naturally into cinema, draws on Gorky only at the last minute, and then only as a means of shifting the argument which she has been making with respect to England and France to a seemingly universal one (104). This rhetorical strategy is repeated at the end of the next chapter (131), where Gorky serves once again as a rhetorical "kicker" to close out an argument, managing to avoid any consideration of Gorky in his own cultural context. The very words "Kingdom of Shadows" are in danger of becoming a mantra, estranged from their original context.

A similar objection can be raised with respect to Laura Mulvey's Death $24 x a$ Second: Stillness and the Moving Image (2006). For Mulvey, the ghostly qualities of cinema identified in writings like Gorky's are attributable to cinema's absolute newness:

It is impossible to see the Lumière films as simple demonstrations of a new technology; every gesture, expression, movement of wind or water is touched with mystery. This is not the mystery of the magic trick but the more disturbing, uncanny sensation of seeing movement fossilized for the first time. This uncanny effect was also vividly present for the cinema's first spectators; the images' silence and lack of colour added to the ghostly atmosphere. (36)

particularly short-sighted when one considers the ghostly implications that were produced by the coming of sound. Indeed, the practice of voice-faking was referred to as "ghosting" (Durovicová 2003 88). See Spadoni for an exploration of the uncanny properties of early film sound (2007 8-30), and Donnelly (2010) for more on the occult properties of film sound 
For Mulvey, these ghostly qualities of cinema were effaced through familiarity, at least until our present moment and the disruptions created by the digital image. "But now, after more than a hundred years ... The phantom-like quality observed by Gorky and his contemporaries returns in force. The inanimate images of the filmstrip not only come alive in projection, but are the ghostly images of the now-dead resurrected into the appearance of life" (36). ${ }^{35}$ For Mulvey, the digital makes us all Gorkian spectators once again, experiencing the "technological uncanny," but in this process the historical specifics of early cinema and its relationship to the supernatural as it was understood at the time get lost. An essay by Trond Lundemo in The YouTube Reader (2009) makes a similar case for the "spectral dimension of the Internet ... Cyberspace is a ghostly matter with important connections to the all-surrounding ether of modern media transmissions" (315). In Lundemo's essay, the spectral qualities of the Internet are delineated in relation to those of early cinema, which is becoming a radically overdetermined space available to be mined for metaphorical value by any scholar of spectrality. It should not be surprising Lundemo's essay bears the title "In the Kingdom of Shadows: Cinematic Movement and the Digital Ghost."

There is no shortage of examples of similar uses of "The Kingdom of Shadows." Peter S. Donaldson's "Cinema and the Kingdom of Death: Loncraine's Richard III" (2002) opens with an extensive quotation from Gorky's essay to help establish a privileged relationship between cinema and death. Having done so, Donaldson moves on to a discussion of death and cinematic self-reflexivity in Richard III (1995). For Donaldson, as for a great many other scholars, Gorky's essay has a distinct utility: with a few choice quotations, it establishes a generalized haunting of the cinema, which may

\footnotetext{
${ }^{35}$ See Rayner (2006 157) for a comparable example.
} 
then be deployed virtually anywhere. ${ }^{36}$ Only in Tsivian's Early Cinema in Russia and its Cultural Reception (2004) is Gorky's essay considered within the context of the place and time in which he wrote, and this yields rich insights. How fascinating to read that Gorky's description of the card players in Partie de Cards (1895) as condemned souls playing cards for all eternity is an allusion to a line from Pushkin (5-6), or that Gorky also wrote a short story inspired by the suicide of a chorus girl/prostitute at Aumont's, which Gorky attributed to seeing a happy family on the screen and realizing her life will never be as sweet (36-7). Tsivian's sustained inquiry into the culture of the magic lantern in Russia that predated cinema helps us understand that Gorky's reaction was not a timeless and acultural reaction of cinema's supernatural implications, but a culturally contingent and historically specific reaction to pre-existing associations between the projected image and the supernatural.

The spectral turn's embrace of early cinema can be viewed as symptomatic of an interesting reversal in attitudes towards early cinema and its spectators in the recent decades. It was once the case that early or "primitive" cinema was understood merely as a set of waystations on the road the classical model supposedly codified by D.W. Griffith, riddled with dead ends and wrong turns. This teleological model is also an oedipal one locating Griffith as the father of cinema and thereby relegating everything before him to him illegitimacy: you cannot predate your father, after all. Under this model, early spectators became characterized by ignorance, fear and panic, as I shall further discuss in

\footnotetext{
${ }^{36}$ If there is one mode of filmmaking with reference to which the film-as-ghostly motif is deployed nearly as frequently as early cinema, it is surely the German Expressionist cinema. We need think only of the title of Lotte Eisner's foundational text of German Expressionism, The Haunted Screen (1969). Anton Kaes cites Gorky in his discussion of Nosferatu (1922), stating: 'For Murnau, film is 'not life but its shadow,' just as it was for Gorky ... Nosferatu, a purely cinematic creature ... rules in the kingdom of shadows, which is none other than the kingdom of film" (2009 125).
} 
Chapter 3. Critics came along to counter this attitude, though it has scarcely been eliminated, but another notion has unfortunately emerged that is almost as insidious: early cinema as Edenic and innocent, existing in a state of grace, with both filmmakers and audiences more in touch with cinema's true nature. Tom Gunning once cautioned that the term "primitive cinema" connotes "an elementary or even childish mastery of form in contrast to a later complexity," adding parenthetically, "and need we add that this viewpoint often shelters its apparent reversal in the image of a cinema of a lost purity and innocence?" (1990b 96). When it comes to the trope of ghostliness, the latter attitude is very pervasive indeed. If cinema is and always has been ghostly or spectral, it is implicitly the case that early spectators simply knew the true nature of cinema better than we. This fact is "proved" by commentaries like Gorky's, as well as the choice of material of some early filmmakers. For instance, Cholodenko states:

In taking the spectre as the 'ur' figure of cinema ... I take a cue from the fact that the spectre is a privileged subject of film, even giving birth to its 'own' genre the ghost film - a staple of cinema from its earliest days to the most recent times. Between 1896 and 1907, a rash of haunted hotel, castle, inn, manor and chateaux films were made ... More recent examples of this genre include Poltergeist (1982), Evil Dead (1983), Ghostbusters (1984), Beetlejuice (1988), Ghost (1990), Ghost Dad (1990), Truly Madly Deeply (1991), Casper (1995) . . Then there are those films that acknowledge that special relation between film and the spectre by marking their titles with the sign of the ghost and the haunted house, for example, The Phantom of the Opera. (103)

But the cinematic ghost film is not without its roots in other media, especially literature and theatre, and it seems groundless to claim it as a "privileged subject" for cinema. We might raise the fact that ghosts as a theme come in and out of favour - between the heyday of the comic and romantic ghost films sometimes labeled film blanc (Valenti 1978) and new cycle of kicked off by Heaven Can Wait (1978) (Genelli and Genelli 1984, Fowkes 1998, 2004), ghosts stories are actually distinctly rare in Hollywood at 
least. ${ }^{37}$ The mere fact that films about ghosts were and continue to be made proves nothing about cinema's ontology (or hauntology), but may tell us something about the conditions of its emergence. Mandy Merck makes a similar claim for an innate affinity between cinema and the figure of the ghost (her argument also quotes Gorky, naturally):

As if in recognition of its own peculiar 'hauntology' as the medium of exchange which transforms the pro-filmic event into an apparition, the early cinema produced scores of 'phantom rides' in which cameras were mounted on gondolas, cars, balloons, funiculars, and especially trains, to provide the first eerily moving shots of the landscape; and it soon specialized in ghostly characters created by double exposure and superimposition. An entire comic genre was created to employ these effects, the 'trick film'... (1999 168)

In both cases, a single argument is implicit: ghosts were a common subject for early cinema (and perhaps even for cinema in general) because of an essential or ontological connection between cinema and the supernatural.

It is undeniable the supernatural has a profound presence in early cinema, but to explain this we need not look to ontology, but rather to contingent historical circumstance. I submit that it need not be the case that the essential ghostliness of cinema motivated the production of ghost themed films in early cinema or any other time, but is rather that a cultural conjunction of supernatural tropes operative in late Victorian culture caused cinema to be recognized through such a lens. The remainder of this dissertation is devoted to exploring the ways in which this was so.

\footnotetext{
${ }^{37}$ It only seems otherwise because of the production of masterpieces like The Innocents (1961) and The Haunting (1963) in that period.
} 


\section{Chapter 2: Light and Lies: Screen Practice and (Super-) Natural Magic}

As I have already mentioned, one way scholars have attempted to explain early cinema's supernatural qualities is through its newness. The "new" (a word for which we might substitute "novel," "astonishing," "wondrous," etc.) often appears to be unsettling and otherworldly, and new media can have these qualities in spades. ${ }^{38}$ As noted, Laura Mulvey proposes in Death $24 x$ a Second that there existed in early cinema a sense of "technological uncanny," defined as "the sense of uncertainty and disorientation which has always accompanied a new technology that is not yet fully understood" (27). I suggest in this chapter that we may actually reverse this formulation by proposing that any association of cinema with the supernatural came not (or at least not only) from its newness but from its continuities with older screen practices like the Phantasmagoria, Pepper's Ghost and the "ghost show." Examination of these practices will show us that the affinities of the supernatural with media of projected light existed long before cinema's debut and made the association of cinema with the supernatural not only understandable, but perhaps inevitable. Perhaps one need not choose one explanation over the other (a "newness thesis" versus a "continuity thesis," if you like), ${ }^{39}$ but when Mulvey makes statements like "This was the cinema that (like the twentieth century itself) left behind the morbid spirit of the Victorians to become an emblem of modernity" (37), I am forced to conclude that, like so many others, she fails to acknowledge the extent to which things supernatural are modern. This chapter explores the "continuity thesis" to locate cinema within a longer history of the supernatural and the projected

\footnotetext{
${ }^{38}$ For discussions of the idea of newness in media, see Onians (1994) and Gunning (2003b).

${ }^{39}$ I here echo Gunning's argument that the theme of animation in early cinema can be both seen as part of cinema's modernity and a link to older traditions with no necessary contradiction (2001 5).
} 
image. It focuses on the concept of the projected image as "natural magic," beginning in the seventeenth century, which held that illusions could be used for purposes of enlightenment and entertainment; this was a progressive idea in a period where visual illusion was heavily associated with witchcraft and the Devil, understood in medieval Christian tradition as a master of illusion who merely imitates the true miracles reserved for God (Warner 2006 123). But regardless of the enlightened purposes to which the projected image was put, its supernatural associations have never entirely vanished.

Before proceeding further, it may be prudent to interrogate what we mean by the term "supernatural" itself. This dissertation uses it broadly enough to encompass practices and discourses as far-ranging as spiritualism, occultism, psychical research and stage magic. ${ }^{40}$ I have chosen to embrace "supernatural" as my umbrella term in part because the meaning of the word shifted in a significant way with the advent of modernity. The word derives from the Latin supernaturalis, meaning "above or beyond nature," and was usually associated with religion the before beginning of the nineteenth century, when a more secular usage, associated with ghosts and the like, began to predominate. This shift in the meaning roughly corresponds to Terry Castle's constellation of the late eighteenth century as the period of the "invention of the uncanny" (1995). Castle locates the invention of the uncanny with the internalization of the supernatural into the mind, where once external forces were turned into phantasmatic "inner pictures" (132). The modern experience of the supernatural, then, often involves layers of intellectual hesitation, usually framed in optical terms - is what I am seeing

\footnotetext{
${ }^{40}$ I have ruled out "paranormal" as a viable substitute because it is of twentieth century coinage. I confess that it does some injustice to the complex term "magic" to subsume it under "supernatural."
} 
"real" or is it all in my head? - connected with a set of issues about illusionism in cinema and the centuries of screen practice before it.

"Supernatural" is also a controversial term. For instance, the journal Anthropological Forum devoted a 2003 special issue to tackling the question of whether "supernatural" is a viable term, in the process debating its relationship to such categories as "sacred," "holy," "divine," "spiritual," "mystical," “mysterious," "paranormal, "extrasensory," "miraculous," "transcendent," "religious," "magical" and "superstition," to borrow the lexicon assembled by Susan Sered in her afterword (2003 216-7). ${ }^{41}$ I find this journal's discussion of terminology and its implications quite useful; anthropologists seem to be among the only scholars concerned with defining the "supernatural" at all. Various scholars in this special issue come out for or against the continued value of "supernatural" as a term, and I am borrowing my working definition from one of the "pro" camp: "The term 'supernatural' defines an order of existence beyond what is pragmatically visible and observable, an order of existence that is paranormal in the sense that it supposedly defies the laws of nature" (Anderson 2003 125). I would place particular emphasis on the word "supposedly." One of the reasons for the contentiousness of the term "supernatural" within anthropology is its implicit validation of western superiority. Morton Klass writes of the

remorseless unavoidable ethnocentric judgment of supernatural: that there is on the one hand a natural-real-universe and on the other hand there are notions about aspects of the universe that are situated outside the natural and the real and are therefore labeled supernatural by the person who knows what belongs in which category. (1995 25, emphasis original)

The idea of the supernatural can indeed be imperialistic and reductive when belief in the supernatural is often consigned to those on the margins: women, children, "savages," the

\footnotetext{
${ }^{41}$ Conspicuously absent from this list are such terms as "occult" and "sorcery."
} 
superstitious lower classes, the rural, etc. Further complicating the terminology, advocates of supernatural concepts such as telepathy or the existence of ghosts or the human soul believe that these things are in fact not supernatural at all, but natural; for this reason, spiritualists frequently denounced the very word "supernatural" (Connor 1999 204). The word itself is thus problematic, but I believe still the best available.

Visual Trickery and Illusions

Reflecting simultaneously on the contentious meanings of terms like "supernatural" and the optical character of the concepts they signify, I am reminded of a line from one of the most famous Victorian ghost stories, Edward Bulwer-Lytton's "The Haunted and the Haunters, or the House and the Brain" (1859). Preparing to investigate a haunted house in London, the open-minded narrator says: "Now, my theory is that the Supernatural is the Impossible ... therefore, if a ghost rise before me, I have not the right to say, 'So, then, the supernatural is possible,' but rather 'So, then, the apparition of a ghost, is, contrary to received opinion, within the laws of nature; that is, not supernatural"" (315). Bulwer-Lytton's tale has been referred to as "the apogee of the naturalized supernatural in the Victorian age" (Milbank 2002 163), a ghost story that justifies its haunting with references to scientific or pseudo-scientific concepts like psychology, magnetism and mesmerism (Briggs 1977 58-9). The ghosts that the narrator sees are presented in terms that we might in hindsight describe as "cinematic": as "shadows," "both the male shape and the female, though defined, were evidently unsubstantial, impalpable - simulacra - phantasms" (316). He observes but does not interact with them, any more than a cinematic spectator interacts with the screen. 
Various studies of nineteenth century ghosts - both literary and "actual" emphasize visuality as the exemplary character of haunting phenomena (Smajić 2010, McCorristine 2010). Obviously, not every supernatural phenomenon is visual: the spiritualists' spectacular "full materializations" were preceded by a long period of predominantly auditory phenomena, and the annals of psychical research rarely contained anything as spectacular as a fully-fledged visible ghost (though visible "crisis apparitions" - the Phantasms of the Living named in the title of Edmund Gurney, F.W.H. Myers and Frank Podmore's 1886 study - were the subject of the early S.P.R.'s most exacting research). Nonetheless, ghosts loom in the cultural imagination first and foremost as things to be seen, although perhaps more by one's mind than by one's eyes: "Neither the advent of gaslight nor electric light could banish the ghost from the visual field for the ghost-sight had long been affirmed as being an interior visuality in both occultist and psychological discourses" (McCorristine 6). Or, as Johann N. Schmidt puts it, "Precisely at the intersection of science and magic was the image that functioned as the mediator between a reflection of reality and illusionistic deception" (2006 240).

In his discussion of the "modern optical uncanny," Tom Gunning stresses that not all uncanny experiences are optical (or sensory at all) and that the optical uncanny is not strictly modern. Nonetheless, he holds that "in modernity not only does the optical uncanny become crucial and dramatic (as evident in the development of Fantastic literature ${ }^{42}$ ), but the modern scientific and technological exploration of vision and optics (such as the proliferation of new optical devices) multiply and articulate the possibilities of the optical uncanny" (2008b 70). It is in this compulsive focus on seeing - on seeing

\footnotetext{
${ }^{42}$ The literary mode characterized by Tzvetan Todorov (1975) as depending on a vacillation between naturalistic and non-naturalistic explanations for the supernatural. Gunning also writes on vision and the supernatural in "To Scan a Ghost" (2007).
} 
things that may or may not be there - that we can recognize one powerful connection between the supernatural and early cinema. The advent of cinema found audiences facing images that were profoundly lifelike but which they understood as, some way that is often difficult to characterize, mere illusions. Issues of illusion dominated the experience of and discourse surrounding early cinema. Uncertainty over just what constituted illusion on the part of cinema's first practitioners produced debates over whether spectators should be made aware of the precise mechanisms that allowed the creation of moving pictures. Joe Kember draws attention to an 1898 review that helps illustrate the uncertain parameters of the word "illusion" as it applied to cinema at the time. The review stated: "The stage was a real stage, the girls were real flesh and blood specimens, and the whole was illuminated with an intermittently projected light in such a realistic fashion that the illusion was almost perfect." Kember writes, "The word 'illusion' seems especially heavily loaded in this context, since it reverses the already widely disseminated idea of film's imitation of life. Here, life was imitating the animated pictures' imitation of life, and audiences were seemingly left to decipher the spectacle of an illusion of an illusion" (2009 129).

It seems there was a general understanding that "illusion" was resident in cinema, but less consensus about what that word meant. As the verisimilar style of filmmaking was becoming established during the Transitional Era (roughly 1908-16), its advocates in the trade press freely used the word "illusion" to describe its recreation of reality, even as that illusion in reference was of a variety opposite to that of the fantastical illusions of in the trick film. Close-ups and other shifts in camera distance were regarded with suspicion, for their violations of cinema's sense of space were thought to disrupt 
cinema's all-important illusion of reality (Keil 2001 164-5, Brewster and Jacobs 1997

164-9). Indeed, the earliest works of what we now call film theory, including writings by scholars like Henri Bergson (1913) and Hugo Münsterberg (1916), were consumed by questions about how an audience can have its attention held by and be entertained by what is, ultimately, an illusion. The 1960 s and 70 s would see similar debates emerge around the apparatus theorists' conception of the interpolated spectator enthralled by cinema's dominance, a point to which I shall return at the end of this chapter.

\section{A Longer History of Ghosts and the Projected Image}

In the first chapter of The Emergence of Cinema: The American Screen to 1907 (1990), Charles Musser argues that we should stop looking for the fraught and slippery origins of cinema in the late nineteenth century and instead consider the invention of the cinematographic apparatus within a much longer history of "screen practice." This label describes practices dating back to the birth of the catoptric lamp and its successor, the magic lantern, in the mid-1600s. Musser places particular emphasis on the Jesuit Athanasius Kircher and his 1646 text Ars Magna Lucis et Umbrae, "The Great Art of Light and Shadow," which urged that the lantern be used for educational purposes only and stressed that the lantern itself must be in full view of the spectators, rather than hidden away. ${ }^{43}$ Writes Laurent Mannoni,

[Kircher] did not want to pass himself off as a sorcerer, and denounced the quacks who used optics to take advantage of the credulous. Kircher's aim in revealing all these illuminated and shadowy optical tricks was partly to enlighten the general public ... The spectacular effects of mirrors made his object lessons on "natural magic' all the more effective. (2000 23-4)

\footnotetext{
${ }^{43}$ Kircher was once generally named as the inventor of the magic lantern, though he was preceded by Christiaan Huygens and other experimenters. Brian Winston notes the Eurocentric bias of most accounts of the origins of the magical lantern, as similar devices existed in China and the Arab world significantly earlier (1996 16).
} 
The term "natural magic" appears to have been coined by the Italian polymath Giambattista della Porta (or John Baptista Porta) in Natural Magic (Magiae naturalis), the first version of which was published in 1558 , with a greatly expanded version following in 1589. The English translation that appeared in 1658 states:

There are two sorts of Magick: the one is infamous, and unhappie, because it hath to do with foul spirits, and consists of Inchantments and wicked Curiosity; and this is called Sorcery; an art which all learned and good men detest ... The other Magick is natural; which all excellent wise men do admit and embrace, and worship with great applause, neither is there anything more highly esteemed, or better thought of, by men of learning ... that Magick is nothing else but the survey of the whole course of learning. (qtd. in During 18)

Porta's book (and others of the time, including Reginald Scot's 1584 The Discoverie of Witchcraft) condemned witchcraft but defended natural magic as good and godly, just as long as it is put to the service of entertainment and enlightenment. We might think of Porta's natural magic as roughly equivalent to science, a category large enough to subsume subjects as diverse as cooking and metallurgy, optics and perfume, magnetism and poison. But in the Renaissance context this version of science is still a highly occult one, a "preternatural philosophy" (Daston and Park 1998 170-2). Michele Pierson writes that Porta "claimed to be privy to the secret workings of nature, to a knowledge glimpsed in the vast network of resemblances linking the natural world to divine" (2002 18). The goal of natural magic was to "emulate the wonders of the nature and glorify their 'wondrousness"' (Hankins and Silverman 1995 5), promoting an understanding of the world as innately magical that conflicted with the experimental model of science that would begin to take hold in the Enlightenment. As I will show shortly, the meaning of natural magic would shift significantly by the nineteenth century. 
By reaching back to Kircher and the advent of natural magic as the origin of screen practice, Musser ties cinema's roots to the demystification of magical practices: "The origins of screen practice .. can be traced back to the mid 1600s and the demystification of those magical arts in which observers confused the 'lifelıke' image with life itself" (16) Musser argues the seventeenth century's Scientific Revolution not only resulted in the technology of the magic lantern but also created the climate in which it could be appreciated as a wondrous illusion: "As belief in ghosts declined, as witch burnings ceased, the apparent logic and effectiveness of projecting apparatus as instruments of mystical terror also diminished" (19). Musser understanding of the origins of screen practice parallels During's definition of "secular magic" as "illusions understood as illusions" (2). ${ }^{44}$

Importantly, Musser's word "demystification" is one of the translations for the German Entzauberung, more commonly rendered as "disenchantment." This concept is most associated with Max Weber, who proclaimed in 1917 that "The fate of our times is characterized by rationalization and intellectualization and, above all, by the 'disenchantment of the world"' (155). ${ }^{45}$ According to Weber, the "mysterious incalculable forces" once present in the world have been chased away by a slowly evolving "intellectualist rationalization, created by science and by scientifically oriented technology" (139). Modern rationalism and science were now understood as sufficient to explain features of the world that were once mysterious, so belief in the supernatural was

\footnotetext{
${ }^{44}$ One question that Musser does not examıne is why demystıfication should only be necessary for screen media What is more "illusionıstic" about screen media than any other kind of mimetic representation? Why should the projected image alone be invested with special illusionistic powers?

${ }^{45}$ Weber's phrase "die Entzauberung der Welt" draws on a line written Friedrich Schiller over a century earlier "die Entgoterung der Natur " the "dis-goddıng of the world" (Berman 1981 69) See Cascardı (1992) for a useful discussion of Weber's disenchantment thesis locating it withın broader currents in contınental philosophy
} 
no longer required: "It is no longer necessary, as it was for the savage who believed in such forces, to resort to magic in order to control or supplicate the spirits. Instead, technical devices and calculation perform that function. This means that the world is disenchanted" (Ibid.). Many scholars have argued, however, that the disenchantment of the world has never been a total process, ${ }^{46}$ and as we have seen, the age of modernity and disenchantment actually sees a boost in interest in the supernatural. I would likewise suggest that the demystification process described by Musser is never complete: the projected image retains supernatural implications long after Kircher and the Scientific Revolution tried to put them to rest. In a footnote in The Virtual Window (2006), Anne Friedberg teases us with the question of whether or not, despite Kircher's enlightened goals, "[Ars Magna Lucis et Umbrae] trained a new legion of mystifiers" (2006 316) who did not disenchant the world but enchanted (or re-enchanted) it with their illusions. Indeed, many of Kircher's descendants paid lip service to education and demystification while exploiting the magic lantern's occult affinities, and something similar can be said for the first practitioners of cinema.

By the nineteenth century, Porta's phrase "natural magic" persisted but with a somewhat different inflection, shorn "of its early predilections for the preternatural and the occult" (Pierson 19). In 1832, David Brewster, the Scotsman who counted the kaleidoscope and the stereoscope among his inventions, authored Letters on Natural Magic. ${ }^{47}$ A Calvinist who positioned himself against deceit and deception of all kinds, Brewster was a scientific popularizer and debunker of the supernatural. He argued, in

\footnotetext{
${ }^{46}$ See for instance Jenkins (2003), Owen (2004), Murdock (2008) and the anthology The Re-Enchantment of the World: Secular Magic in a Rational Age (2009).

${ }^{47}$ See Burwick (1991) for more on Brewster.
} 
fact, that optical trickery has been responsible for all of the superstition and the false gods of history, and rallied science to prove it. The ancient priests, he suggests,

must have been familiar with the property of lenses and mirrors to form erect and inverted images of objects... There is reason to believe that they employed them to effect the apparitions of their gods; and in some of the descriptions of the optical displays which hallowed their ancient temples, we recognize all the transformations of the modern Phantasmagoria. (1883 93)

Brewster sought to overhaul the idea of natural magic, hoping to see it become "a term for distinguishing between the practices of illusion and spectacular display associated with popular scientific cultural and those associated with the supernatural" (Pierson 19). Brewster was an intellectual descendent of Kircher, not only because of the technological lineage connecting the magic lantern to the stereoscope, but because they shared the conviction that optical trickery should be deployed only in service of education and never to truly deceive. In his 1856 book The Stereoscope: Its History, Theory and Construction, Brewster says: "For the purposes of amusement, the photographer might carry us even into the regions of the supernatural" (205), explaining the techniques that would shortly be used by spiritualists to create spirit photographs. ${ }^{48}$ For Brewster, however, such trick photographs were meant to serve rationalism by demonstrating the inadequacy of human vision in distinguishing between the supernatural and mere scientifically-created illusion.

Like Kircher, Brewster saw himself as fighting a war against ignorance and superstition, and the fact that he needed to argue against the supernatural implications of illusions proves that they still existed in the purported age of disenchantment (or put differently, it illustrates the extent to which the disenchanted "natural magic" of the nineteenth century remains haunted by occult "natural magic" of Porta). His invocation

\footnotetext{
${ }^{48}$ Spirit photography was a branch of portraiture that used double exposures to produce pictures of sitters overlaid with purported images of the dead, often called "extras." I will speak further about spirit photography in chapter 5 .
} 
of the Phantasmagoria in the above quote helps demonstrate this fact, for he knew as well as anyone that the projected image has been bound up with the supernatural for centuries. The supernatural lantern spectaculars of the Phantasmagoria, in particular, have in recent decades been a productive topic of exploration for scholars like Theodore X. Barber (1989), Laurent Mannoni (2000), Tom Gunning (2004b), Mervyn Heard (2006) and the aforementioned Terry Castle (1995). The term "Phantasmagoria" describes a variety of lantern performance that began in the 1790 s, notable for its supernatural subject matter and its tendency to mystify the mechanism of projection.

Because it required darkness to operate, the magic lantern was sometimes called "the Lantern of Fear" and naturally tended to grotesque and ghostly images even before the Phantasmagoria (Vermier 2005 132-3). Johann Schröpfer, a Leipzig coffee shop owner and freemason, flagrantly violated Kircher's precepts by using lantern technology to present himself as a necromancer. He staged séances, even one for Prince Charles of Saxony, who was trying to communicate with his deceased uncle. Schröpfer committed suicide in 1774, supposedly because he began to suffer delusions of his own conjurations come to life (Heard 48-9). Where Schröpfer passed off his lantern tricks as legitimately supernatural, the men behind the Phantasmagoria presented themselves as capable showmen even as they exploited mass association of illusions with ghosts. The most famous of these exhibitors were the Étienne-Gaspard Robert (under the stage name "Robertson") and Paul de Philipstal (as "Philidor"). Beginning in the 1790s, Robertson famously staged gloomy Phantasmagorical spectacles in the crypt of an abandoned Capuchin convent near the Place Vendôme in Paris. His ingenious methods included a "fantascope," "a large magic lantern that could slide back and forth on a double track 
between fifteen and eighteen feet long. When this lantern was moved along its track, the images projected on the screen from behind would grow or diminish in size, depending on the distance from the machine to the screen" (Terpak 2001 301). He and other daring lanternists even conjured up the spectres of revolutionaries like Danton and Robespierre mere months after their executions.

Robertson would introduce his performances with rhetoric that described the persistence of supernatural ideas in the putative Age of Enlightenment:

This is a spectacle which man can use to instruct himself in the bizarre effects of the imagination, when it combines vigor and derangement: I speak of the terror inspired by the shadows, spirits, spells and occult work of the magician: terror that practically every man experienced in the young age of prejudice and which even a few retain in the mature age of reason. (qtd. in Musser 1990 24).

The Phantasmagoria's reliance imagery of ghosts, skeletons and demons was in keeping with earlier lantern traditions, and the insistence of its operators that it served enlightenment values may have constituted lip service at best. Castle notes that, "Producers of phantasmagoria often claimed, somewhat disingenuously, that the new entertainment would serve the cause of public enlightenment ... Ancient superstitions would be eradicated when everyone realized that so-called apparitions were in fact only optical illusions" (143). Like the shadowplayer (Alexander Granach) in Arthur Robison's Warning Shadows (1923), they manipulated people's senses with perverse glee, but ostensibly did so for strictly moral purposes. ${ }^{49}$ But any enlightened intentions were hampered by the illusionists' desire to conceal their techniques: "The illusion was apparently so convincing that surprised audience members sometimes tried to fend off moving 'phantoms' with their hands or fled the room in terror . . . the spectral technology

\footnotetext{
${ }^{49}$ See Guerin (2005 89-108) for a treatment of Warning Shadows emphasizing its play on the boundaries of realism and illusion.
} 
of the phantasmagoria mysteriously recreated the emotional aura of the supernatural" (Ibid. 144). The destinies of the supernatural and the technology of the projected image entwine in the Phantasmagoria, neither for the first nor the last time.

The nineteenth century saw an explosion of scientific interest in vision and the invention of many "philosophical toys" that mark the road to cinema: the phenakisticope, thaumatrope, stroboscope, tachyscope, zoetrope, viviscope, mutoscope, kineoptoscope and more. ${ }^{50}$ Magic lantern technology continued to improve throughout the nineteenth century, and one of its offshoots marked a new chapter in projected imagery, again with ghosts and the supernatural taking on a central, emblematic role. In England in the 1860s, engineer Henry Dircks devised a new method which would allow an actor to appear to interact with a ghost onstage. It called for a huge pane of glass separating the audience and the theatre, onto which the image of a highly illuminated actor, in a space beneath the stage concealed from the audience's view, could be projected through mirrors. The effect was that the actor on stage remained fully embodied and present while the ghost appeared two-dimensional and half-present, yet both seemed to share space and time. The actor could appear to interact with the ghost, and even to pass through it. Dircks initially had difficulty selling his invention. Jim Steinmeyer writes:

Like many inventors, Dircks saw only the advantages of his plan and ignored its inconveniences. In fact, his invention would have not only revolutionized stage productions, but it would have demanded that theatres be rebuilt. London playhouses recognized that Dircks's proposal was for a brand new construction, with the stage lying below the audience and all the seats in a raised balcony. Dircks also called for special windows installed into the ceilings and walls, insisting that it would take sunlight - and daytime performances - to witness that effect. And yet, matinees were not in favour, and London has never been able to bank on bright sunshine. (2003 26)

\footnotetext{
${ }^{50}$ Most famously chronicled by Crary (esp. 97-136)
} 
The fate of the "Dircksian Phantasmagoria"51 would lie with Brewster's disciple John Henry Pepper, who had been the director of London's Royal Polytechnic Institution since 1854. The Polytechnic, standing at 309 Regent Street, had opened in 1838 as a venue for "Practical Science," showcasing new feats of science and engineering. It evolved into a venue where modern science and technology was presented as modern wonders, and placed particular emphasis on the exotic and spectacular. As Brenda Weeden writes in her history of the Polytechnic, the displays ranged from

Lord Dundonald's steam engine which drove the power looms in the Hall of Manufactures, to a tin case of preserved mutton, a patent steam fountain coffee pot, a cottage beehive and a New Zealand Spear ... In the gallery around the Great Hall, a Rubens painting hung next to an iron rocking chair and a group of anatomical models, including a large papier-mâché model of the human ear. (23)

The implicit theatricality of its presentations would eventually incorporate a lantern theatre where "dissolving views" illuminated by oxyhydrogen (limelight), for lectures on subjects like geology, astronomy and microbiology, as well as views of faraway places (Ibid. 43-50). In an 1843 article in the Illustrated Polytechnic Review, the author describes the Polytechnic as being designed for high-minded educational (to say nothing of nationalistic) purposes, specifically rejecting the "vile phantasmagoria" of previous lantern shows:

We now behold them no longer administering to the vulgar and depraved appetite, alternately exciting the laughter and terror of the beholders; but, assisted by the genius of philosophy and the pencil of art, they picture forth the truthful representations of lovely and picturesque scenery, the holy temples of distant nations, and the heart-stirring scenes of our country's triumphs. (Ibid. 47$)^{52}$

\footnotetext{
${ }^{51}$ In a surviving fragment of the Ruth Roland serial Haunted Valley (1923), we learn that the titular valley is actually "haunted" hologram-like projections of ghostly human forms (cinematically realized with double exposures) which are diegetically described as the inventions of a character named "Dirks." ${ }^{52}$ For another take on the early life of the Polytechnic and the climate of Victorian natural magic as the birthplace of cinema, see McGrath (1996).
} 
Pepper, a lantern lecturer with a degree in chemistry, was just the mix of grand showman and distinguished scientist appropriate to the Polytechnic's emphasis on mass education and tasteful wonder. Pepper took Dircks's design and improved it, replacing the need for sunshine with the oxyhydrogen lamp, previously used with the projecting microscope that Pepper had used to display gigantic microbes on a 425-square foot screen (Steinmeyer 27-9). "Pepper's Ghost," as the new technique came to be known despite Pepper's dutiful crediting of Dircks, debuted on the Christmas Eve of 1862 during a Polytechnic presentation of one of Dickens's Christmas ghost stories, "The Haunted Man."53 The ghost, in keeping with the danse macabre imagery that I will discuss in Chapter 6, was envisioned as a glowing skeleton that seemed to slowly materialize out of midair, and who would disappear and reappear to torment the play's protagonist. The presentation was intended as a spectacular showcase for developments in the field of optics, and Pepper intended to make a presentation at the end explaining how the illusion was accomplished. But on witnessing the ecstatic reaction of the audience, so amazed and so terrified by the Ghost, Pepper declined explanation (Steinmeyer 30). Pepper's impulse towards showmanship trumped sober science where the Ghost was concerned, and the legitimate social phenomenon he would soon have on his hands testified to the continued power possessed by Phantasmagoric projections.

Pepper restaged "The Haunted Man" in the Polytechnic's main auditorium on June 1, 1863 and different scenarios followed to explore the Ghost's possibilities. Pepper's Ghost shows would be a mainstay on the Polytechnic stage for many years to come. It was a public sensation to the extent that a racehorse called "Pepper's Ghost"

\footnotetext{
${ }^{53}$ For examinations of the Ghost's early life, see Brooker (2007), Groth (2007), Lightman (2007 167-218) and Posner (2007).
} 
appeared at Ascot in 1864 and London cabmen adopted the name to describe customers who vanished without paying (Davies 2007 207). Heard suggests that the more general ghost craze in the 1850 s that accompanied the spiritualist boom played a role in Dircks and Pepper's interest in ghosts (229). If this were the case, the relationship with spiritualism proved reciprocal. Pepper received numerous letters from spiritualists claiming that he conjured real ghosts on his stage, no matter what he said. "Pepper, embarrassed to be drawn into these arguments, found that by ignoring the claims, he had only fuelled the debate. A percentage of his audience wouldn't have it any other way. There were ghosts on stage" (Steinmeyer 21). Pepper's 1890 memoir is strongly critical of spiritualism, and though he does not use the words "natural magic," Pepper foregrounds the idea that the Ghost's role was to confront people with the illusionary character of haunting phenomena, a fact that did not endear him to spiritualists: "I vigorously denounced the traders in spirits, founding my arguments on the belief that God was too merciful to us to add to the troubles of this world the fear and trembling brought about by pretended communication with the invisible world" (28). Pepper even purports that Polytechnic employees needed to escort him home when spiritualists threatened personal violence against him.

Despite Dircks's and Pepper's attempts to control their respective patents, copies proliferated and the Ghost would be a fixture of supernatural theatre for decades. Pepper's Ghost was staged more often in the fairground "ghost shows" than for the conventional stage, and was seized upon by numerous itinerant showman, often using names like the "Captain Payne's Ghost Show," "Wallser's Ghost Illusion" and "Phantaspectra Ghostodrama" (Davies 209). Writes Vanessa Toulmin, 
... the travelling showmen had a major advantage of over their static rivals who had to install the huge glass whenever the trick was required) as the glass needed for the effect of the ghost on the travelling shows could remain fixed in place in its own purpose-built box, protected from the rigours of the journey by two hinged doors which, like those of the later bioscope show, could be pulled out to form part of the stage. By the mid-1870s many fairground exhibitors had seen the advantages of this innovation and showmen such as Randall Williams, Harry Wall and Tom Norman were exhibiting 'The Ghost' at venues throughout the country. (1998 7)

Williams, called "the King of the Showmen," brought his ghost show to more than a dozen fairs a year, the biggest being the Hull Fair in October and the London's World's Fair, which ran six weeks beginning on Christmas Eve. Since the mid-century, these fairs had been squarely focused on entertainment and exhibition, from steam-powered carousels to menageries, wax museums to illusionists, shooting salons to kinetoscopes, and they granted a prominent place for the ghost show. Between 1873 and 1896, Williams's show displayed projected ghosts and goblins, anchored by Williams's own oration. Advertisements boasted that Williams offered "The Greatest Ghost Show in the World" and his press notices referred to him as a "next to Barnum the most successful showman" (Ibid. 15).

Near the end of the century, the ghost show seemed quaint and its illusions had lost their currency. Williams responded by unexpectedly shifting his show entirely to the exhibition of moving pictures at the 1896-7 World Fair, apparently the first fairground exhibitor to make this switch. Many would follow quickly. One press note for the World Fair said "Randall Williams's ghost show is again located here, but they have this year abandoned the spectral business and are giving an exhibition of animated pictures, an alteration that appears to meet with approval"' (Ibid. 24). Williams continued exhibiting cinema until his death from typhoid fever in 1898 . The fact that one of the first 
exhibitions of cinema in Great Britain occurred under the label of the "Phantascopical Exposition" and replaced a ghost show that employed a version of Pepper's Ghost shows the ease with which cinema was received as the next stage in a tradition of theatricalized depictions of the supernatural. Williams's initial exhibition included Loie Fuller's serpentine dances, footage of the Czar in Russia, and other non-supernatural subjects, yet Pepper's Ghost's legacy of blurring entertainment, science and the supernatural, as well the longer association of the projected image with natural magic, infuse the nascent cinema in so many important ways. The spectral thrills of the ghost show provided one of cinema's first exhibition venues, and many audiences first experienced it as the heir apparent to that fading practice.

\section{Phantoscopes}

The chronology of the supernatural and the projected image I have just offered takes us up to the traditional beginnings of cinema. The association of projections and the supernatural has a long history, as have debates about the moral, educational and religious ramifications of displaying such illusions to the public. In the introduction I made reference to an early cinematographic process called "Phantoscope," a counterpart to more "lively" names like Vitascope and Biograph. This name makes sense when we recognize cinema as the logical successor to the "ghost show" and the inheritor of the whole haunted history of projected media before it. "Phantascope" was earlier a name of the philosophical toy otherwise known as the phenakistiscope (Robinson 1996 36, 40), and may echo the Robertsonian Phantasmagoria method called the "fantascope." There was also "Grand Phantascope" among the English Ghost Shows (Davies 209). If the 
cinema is indeed a "ghost-viewer," it was understood as being only the latest on a lineage.

The use of the word "phantasmagoria" also occurs in Marxist theory, connoting something illusory and weightless which nonetheless masquerades as real and substantial, allows us to approach the question of cinema and illusion from a slightly different angle. In the first volume of Capital, published in 1867, Karl Marx would refer to the commodity-form as "the phantasmagoric form of a relation between things" (165), an unreal and deceptive simulation which conceals an essential absence. Following Marx, Theodor Adorno would use phantasmagoria metaphors to describe "the occultation of production" (Adorno 2005 74; see also Huyssen 1986 34-42, Crary 132-3, Buck-Morss 22-27), and Walter Benjamin argued that, in Rolf Tiedemann's words, "the fate of nineteenth-century cultural lay precisely in its commodity character, which Benjamin thereupon represented in 'cultural values' as phantasmagoria ... a deceptive image designed to dazzle, is already the commodity itself, in which the exchange value of valueform hides the use value" (1988 276, original emphasis). ${ }^{54}$ It is therefore something more than pure analogy to suggest a parallel between the advocates of natural magic, as far removed in time as Kircher and Brewster, and the apparatus theorists, the Marxistinfluenced body of theorists who tended to construct the spectator as a passive figure trapped within the ideological dominance of the apparatus. ${ }^{55}$ The apparatus theorists (Christian Metz, Jean-Louis Baudry, Jean-Louis Commoli, Paul Narboni and others) did not believe that cinematic spectators mistook the image for reality, but rather that the

\footnotetext{
${ }^{54}$ For more on Walter Benjamin's use of phantasmagoria metaphors, see Britzolakis (1999).

${ }^{55}$ See Baudry (1974) and Metz (1982). The apparatus theorists operated within an iconophobic tradition stretching back to Plato (see Jay 1993 329-80).
} 
illusionism of cinema gave the false impression of a transparent, ideology-free window onto reality. As Commoli puts it,

The most analogical representation of the world is still not, is never, its reduplication. Analogic repetition is a false repetition, staggered, disphased, deferred and different; but it produces effects of repetition and analogy which imply the disavowal (or the repression) of these differences and which thus make of the desire for identification, recognition, of the desire the same, one of the principal driving forces of analogic figuration. (1980 138, original emphasis).

Again, cinema is understood as being innately deceptive and untrustworthy. But where Kircher and Brewster saw the projections of light as reformable, even useful, when presented with a sense of openness and clarity, the apparatus theorists did not generally share such optimism, rather constructing a cinematic spectator akin to Peter (Ralph Michael) in the Robert Hamer-directed segment of Dead of Night (1945), inexorably absorbed and possessed by the haunted mirror. Cinema, for the apparatus theorists, is thus phantasmagoric in both Marx's sense and that of Robertson.

Musser's construction of demystification as central to, and indeed a precondition for, modern screen spectatorship was in no small part a rejection of the apparatus theorists' model of the spectator. For apparatus theorists, the burden of "demystification" belongs to the critic, to expose the ideological workings of the apparatus that are otherwise obscured. For Musser, it is rather the opposite: the defining characteristic of screen spectatorship is the ability of a spectator to construct an intellectual distance between what is present on the screen and what it signifies. In similar terms, Tom Gunning rejected the apparatus theorists' conception of

audiences submitting passively to an all-dominating apparatus, hypnotized and transfixed by its illusionist power. Contemporary film theorists have made careers out of underestimating the basic intelligence and reality-testing abilities of the average film viewer and have no trouble treating previous audiences with such disdain. (1995 115) 
In a later essay linking early controversies around cinema to a broader association of the image with evil in western society, Gunning added: "A suspicion of cinema, understood as a visually powerful medium rooted in an illusion of reality and exerting unconscious influences on the view, underlies both a conservative antimodern resistance to the new medium at the dawn of the twentieth century and a neo-Marxist ideological critique decades later" (2004a 26).

The supernatural implications of the projected image that have come down to cinema through the Phantasmagoria and Pepper's Ghost not only persist, but resonate in film theory. At least one scholar has explicitly linked misgivings about cinema's illusionistic character to natural magic. In his important monograph The Magician and the Cinema (1981), Erik Barnouw proposes that the art of stage magic led directly to, and was then sadly supplanted by, the cinema. In his conclusion, Barnouw frames this transition in terms of natural magic - where stage magic and the trick film were expressions of natural magic that declared themselves as illusions, the verisimilar mode of classical cinema is deceitful precisely because it naturalizes its magic. ${ }^{56}$ Painting a sort of "fall from Eden" narrative, Barnouw writes:

It may well be that a central element in the power is the astonishing fact that media images are no longer seen by the public as optical illusions offered by magicians, but as something real. The unawareness is equivalent to defenselessness. The new industrialized magic may be closer to "black magic" than "natural magic." (112)

Barnouw here echoes Georges Méliès himself, who later in life denounced the classical model of cinema on a similar basis, as magic that does not acknowledge itself as such

\footnotetext{
${ }^{56}$ To quote Gunning on this transition, "In parallel editing the 'magical' switches from one line of action to another are not the product of a Méliès-like prestidigitator, nor indications of a marvelous overturning of the laws of space and time... Griffith's 'trick work' is in the service of the drama, a narrativizing of the possibilities of filmic discourse" (1991 190).
} 
(During 170). Barnouw also, of course, strongly echoes the apparatus theorists in his distrust of cinema's illusions as dangerous and deceptive, creating a "defenseless" and thoroughly mystified audience. It is intriguing to find these familiar debates framed explicitly in the terms of "natural" versus "black" magic. Critical discussions about cinema's status as illusion and the ideological implications thereof continue to this day, ${ }^{57}$ but on some level they are permutations of debates that have been going on since at least the seventeenth century, when Athanasius Kircher allied the magic lantern technology with the idea of natural magic. Barnouw's remarks remind us of that fact that cinema is just one stage of a longer history of the projected image, so too are many of the classic debates of film theory rooted in debates about natural magic that go back centuries.

${ }^{57}$ For other key contributions to debates about cinema's "illusionism," see Carroll (1988 90-106), Allen (1993), Anderson (1996), Currie (1996), Kania (2002) and North (2008). 


\section{Chapter 3: The Panicking Audience in Stage Magic and Early Cinema ${ }^{58}$}

The relationship of stage magic and early cinema is in certain aspects well documented. It is commonly known that some of the most technically-minded and enterprising of the magicians became some of the first filmmakers, and that theatres associated with magic acts were among the first venues for cinema. The list of magicians who became involved with cinema goes far beyond Georges Méliès to include Émile and Vincent Isola, Félicien Trewey, Gaston Velle, David Devant, Carl Hertz, Leopoldo Fregoli, Alexander Victor, John C. Green ("Belsaz"), William N. Selig, Horace Goldin and William Charles Hughes. Many of these men contributed to cinema through exhibition rather than production: Hertz, for example, was an American magician who acquired one of R.W. Paul's Theatrograph projectors in London in 1896 and took it with him on a long sea voyage, becoming the first person to exhibit cinema in South Africa and Australia. Green was a Canadian magician who read in June 1896 about an announcement for the premiere of Edison's Vitascope in Ottawa, hosted by Ahearn and Soper, owners of the Ottawa Electric Railway Company. Despite never having seen a film before, he convinced Ahearn and Soper to retain his services as a lecturer (Morris 1978 12-3). As During has written, "Audiences experienced film as part of the magic assemblage" (169), which at other times had embraced displays as diverse as feats of strength, ventriloquism, automata, juggling, comic performances and puppet shows. Cinema, in effect, amounted to another ancillary medium that the stage-magic industry had brought into its fold.

\footnotetext{
${ }^{58}$ Portions of this chapter have been published as "M. Robert-Houdin Goes to Algeria: Spectatorship and Panic and Illusion and Early Cinema" in Early Popular Visual Culture.
} 
Magic's links with early cinema have been excavated by Erik Barnouw in the aforementioned The Magician and the Cinema and more recently by Matthew Solomon in Disappearing Tricks: Silent Film, Houdini and the New Magic of the Twentieth Century (2010). ${ }^{59}$ In this chapter I will explore a new dimension of the magic/early cinema interface by placing emphasis squarely on a familiar motif in motion picture spectatorship: the figure of the panicking audience. I have observed that a great many laypersons are familiar with the idea that cinema's debut was accompanied by shock and trauma, with audiences jumping to their feet and fleeing the auditorium ... and something about a train. They may not know that the event in question was the debut of the Lumière cinematographe late in 1895 or that the film was that purportedly provoked this reaction was called L'Arrivée d'un train en gare de la Ciotat or The Arrival of a Train at Ciotat Station, but the tale itself is next to omnipresent. My experience is that most people, when told that the story is not a historical fact, react with disbelief or at least disappointment. But why has it struck such a chord? I would argue that it is because of the modern mythology it serves: the superiority of the modern spectator to a naïve one who does not know how to properly react to something new and sensational, yet weightless and illusionary.

This story, which has been termed "the Myth of the Grand Cafe"" after the Paris locale where it purportedly occurred, has been written about by a number of film theorists but only put to serious historical scrutiny in recent decades. It is not well appreciated, however, that the story of the panicking audience does not begin with cinema, but has a

\footnotetext{
${ }^{59}$ The lines of inheritance between stage magic and cinema are discussed in a great many recent other works, including those by special effects specialists Pierson (2002) and North (2008). Appropriately, cultural histories of magic like those by During (2002 and Mangan (2007) also grant generous attention to cinema. See also Mcllhany (1996).
} 
significant history of its own. We find the Myth of the Grand Café anticipated in one of the most famous stories from nineteenth century stage magic, that of the trip to Algeria made by the great French magician Jean Eugène Robert-Houdin in 1856. Robert-Houdin was the single most important figure in the rise of magic to respectable entertainment in the 1800 s, and his career in magic is often understood as having been capped by his return from retirement to outdo desert mystics with his superior French illusions. The structure of each narrative is essentially the same: a set of credulous, naïve spectators erupting into panic on encountering a new, technically sophisticated form of illusion. Against them, a trained, incredulous modern spectator is constructed, who recognizes simple illusion where the credulous spectator sees sorcery.

The fact that magic emerged as one of the most popular entertainment forms of the last half of the nineteenth century was perhaps inevitable in an age characterized "by the prominence of fleeting, forceful visual attractions and contra-contemplative spectatorial distraction" (Singer 2001 102). Magic is based around a series of spatial and temporal disruptions: the production of something from nothing, the disappearance of something into nothing, the transformation or transposition of objects, and the intriguing category of "Natural Science Laws Disobeyed," which includes levitation, invulnerability, matter through matter and rapid germination (Pringle 2006 55). If urban modernity, as it is so often understood, is defined at least in part by shock, speed and transformation, then the magical stage offered a place where the disruptions of modern life are repackaged as entertainment and thus safely contained. Tricks became standardized by the middle of the nineteenth century and were on the whole designed to delight and astonish rather than outright shock. Entire venues were devoted solely to 
magic as it became a respectable form of middle-class entertainment largely through the reforms brought about by Robert-Houdin. But as shall see, when Robert-Houdin was deployed in a colonial setting, his inclinations swayed towards shock effects quite unlike the tasteful gentility that characterized his most famous tricks, and his observations of his Arabic audiences proved telling regarding the culture of modernity, anticipating important issues in early cinema about illusion, shock and spectatorship.

\section{Robert-Houdin Goes to Algeria}

In 1856, Robert-Houdin, the so-called "King of the Conjurers," took up an offer to travel to Algeria and perform some magic shows before tribal assemblies. He had been retired from public life for several years at this point and only after several offers did he accept the military's request. The military, which since 1852 had exercised direct administrative control over the French civil territory of Algeria, brought Robert-Houdin in to help discredit the Marabout, ${ }^{60}$ an order of Islamic mystics who were thought to hold considerable sway over some of the tribes and perhaps even to be fomenting rebellion. It was supposed that the Marabouts' authority came from their miraculous powers, like the ability to walk through hot coals, drink glass and lick hot metal. As Robert-Houdin wrote in his memoirs:

The government was, therefore, anxious to destroy their pernicious influence, and reckoned on me to do so. They hoped, with reason, by the aid of my experiments, to prove to the Arabs that the tricks of their Marabouts were mere child's play, and owing to their simplicity could not be done by an envoy from Heaven, which also led us very naturally to show them that we are their superiors in everything, and, as for sorcerers, there are none like the French. (1859 372-3)

\footnotetext{
${ }^{60}$ The word is a corruption of murabit. Julia A. Clancy-Smith writes: "In the nineteenth-century lexicon of eastern Algeria and Tunisia, it meant 'men, devoted to God's adoration and linked to Him, who enjoy a reputation of saintliness which conferred upon them the title of "waliy," friend of God." The French equivalent, marabout, "was used and misused through the colonial period, giving rise to considerable confusion regarding the precise social and religious identity of the marabout" (1994 278).
} 
Robert-Houdin's task was to dazzle the Arabs with his own tricks and reveal that they were not magical but mere illusion - as were those of the Marabouts. ${ }^{61}$

A rough parallel exists between this mission of education through illusion to the procedures advocated by thinkers on natural magic from Athanasius Kircher to David Brewster (and paid lip service by the Phantasmagoria practitioners). Robert-Houdin was the perfect candidate for such an undertaking. Not only a performer, he was also an accomplished inventor and scientist, and as magic's great legitimizer, he transformed it from a culturally trivial diversion largely performed on the streets into a tasteful display of technical skill that appealed to a respectable audience. His legacy was acknowledged most famously by the Hungarian-American magician (and occasional filmmaker) Ehrich Weiss, who would assume the stage name Harry Houdini in tribute. Though RobertHoudin died in 1871, he would have a powerful effect on the development of the new medium of the cinema. In 1888, his Théâtre Robert-Houdin on the Palais-Royale in Paris would be purchased by magician/impresario Georges Méliès; under Méliès's management it would reign as the most celebrated stage magic venue in the world and become an important early venue for cinema. ${ }^{62}$ For a time, the genre of trick films that Méliès pioneered based would be called "Houdin films" (Musser 1990 139).

Robert-Houdin's kind of magic was a modern art for the age of illusions understood as illusions. Joe Kember writes that

The magic theatre was the institution that most obviously formalized the pervasive discourses concerning trickery ... consistently encouraging audiences not only to enjoy the illusionistic spectacle of the show, but also to conjecture concerning the mechanism of the trick. In fact, for many of the most successful

\footnotetext{
${ }^{61}$ These events are chronicled in the last few chapters of Memoirs of Robert-Houdin: Ambassador, Author, and Conjurer, published in 1858 and widely distributed in a number of languages; even though this narrative takes a fairly small part of the book, it has such great importance as to get represented in the title. ${ }^{62}$ See Solomon (2010 40-59) for an excellent overview of Méliès's tenure at the Théâtre Robert-Houdin.
} 
stage conjurers, entering into public debate concerning the nature of their tricks was a vital component of a show's success. (2009 180)

Modern magic, in other words, creates a certain kind of knowing spectator that is allowed a limited complicity in the magician's technique. We tend to think that magicians operate according to rules of strict secrecy (and indeed, individual secrets were zealously kept), but Patricia Pringle has argued that the mechanics of magic were widely published and freely available in the nineteenth century. Magic's appeal lay in "the art and its applications, not the apparatus alone" (54). Indeed, magician David Devant would write approvingly of the specialist audience knowledgeable about at the principles, at least, behind a magician's tricks: "When a member of an audience knows that secret he ceases to be curious about it, and so devotes his whole attention to the way in which the conjurer presents his little fairy story" (1931 101). Devant valorizes the knowing spectator whose focus is clearly on appreciating the magician's individual skill. ${ }^{63}$

Modern magic must never too seriously purport to be anything other than an illusion rendered by a combination of individual skill and covertly-applied technology. To do otherwise is either to be a mountebank of the sort Robert-Houdin crusaded against, or worse, to traffic in sorcery and witchcraft, the things magic needed to set aside in order to emerge as respectable modern entertainment. Part of the fascination of the story of Robert-Houdin in Algeria is that it represents a closer-than-usual conjunction of what we might term "the two magics." One, allied with the Marabouts, is the magic designated by the conceptual field that includes (to borrow Peter Pels's list), "shamanism, fetishism, witchcraft, the occult, mana and taboo - that was predominantly made to define an antithesis of modernity: a product of illusion and delusion that was thought to recede and

\footnotetext{
${ }^{63}$ For an exploration of the idea of the expert audience in stage magic and film, see Kember (2010).
} 
disappear as rationalization and secularization spread throughout society" (2003 4, original emphasis). To Pels's list we might add "sorcery," the word favoured by RobertHoudin (or of his translator) to connote performers making claims of legitimate magical powers. Against this is the magic of which Robert-Houdin was the walking embodiment, labeled "conjuring," "legerdemain," "escamotage" or "prestidigitation." Robert-Houdin reminds his readers that the latter term comes from presto digiti (activity of the fingers) (151-2) and therefore connotes personal skill rather than supernatural power.

Algeria gave Robert-Houdin an opportunity to prove the superiority of his version of magic through contrast. But the crusade against the "other magic" that he and so many of his peers embarked upon exposes uncertainties about the state of their own art. The modern, credulous spectator demands a balancing incredulous one, who takes the magic for something truly supernatural. This is one reason why "entertainment magic came into the hands of white men ... belief in real magic was still ascribed to those in the margins" (During 107), especially the "savage," in Robert-Houdin's case, the Oriental savage. Edward Said defined Orientalism as "a way of coming to terms with the Orient that is based on the Orient's special place in European Western experience ... the Orient has helped to define Europe (or the West) as its contrasting image, idea, personality, experience" (1-2). Indeed, the colonial inflection of "modern" magic was pronounced; in significant ways it defined itself through and in reference to the Orient. Arabic (especially Egyptian), Indian and Chinese magicians performed in Europe with some frequency, and in addition to these legitimate colonial performers, a classic dynamic of colonial appropriation was at work. London's key magic theatre was called "Egyptian Hall" and was draped in quasi-Arabic trappings. The "Indian rope trick" practiced by Hindu fakirs 
inspired similar levitation acts by European conjurers and even the rabbit trick, magic's emblem, had its origins in Egypt (During 109).$^{64}$ The repeated references to RobertHoudin as a "French Marabout" reflects a structure of appropriation and impersonation, much as Victor Hugo wrote of Napoleon in his poem "Lui": "Sublime, he appeared to the dazzled tribes/Like a Mahomet of the Occident" (qtd. in Said 1977 83).

One unstated purpose of Robert-Houdin's expedition was surely a large-scale disavowal of magic's colonial roots; hence Robert-Houdin's repeated insistence that the Marabouts' tricks were not only deceptive but also bad, "inferior" tricks. In French colonial readings of the Marabouts' practices, illusion masqueraded as genuine religious experience, proof of the powers given to the Marabout by Allah. In calling the Marabout "false prophets," Robert-Houdin invokes the overarching Occidental conception of Islam as a religion based on false prophecy, with Mohammed as a counterfeit Christ preaching a false Revelation (Said 60-2) - a kind of Marabout writ large. All Muslims are understood as excessively credulous and committed to a fraudulent religion, so RobertHoudin's mission of modernization and westernization was more subtly one of Christianization as well. As Barnouw writes, “. . if officialdom could be served and won thereby, [the magician] was willing to wrap his science in a mantle of the occult. Was [Robert-Houdin] performing in Algeria as an entertainer - or serving an official priestly function, keeping the ignorant in line?" (109). ${ }^{65}$

\footnotetext{
${ }^{64}$ See Solomon (2008a) for one angle on magic's colonial implications. Also, Beckman notes that Indian Mutiny of 1857 filled the press with images of Indian men raping and murdering European women, with one result being that English conjurers abandoned the quasi-Indian garb that had previously been popular (2003 31-6).

${ }^{65}$ A rough parallel may be drawn with the use of cinema by imperial powers in Africa: "Contrasting the Western and African way of life, these films represented the former as an embodiment of 'civilization' and the latter as 'backward' and with 'superstitious' customs to be left behind" (Meyer 2003 204).
} 
In his account of his Algerian expedition, Robert-Houdin also draws a telling distinction between modern and non-modern, French and Arab, through attitudes towards spectacle. Before performing directly for the tribes, Robert-Houdin put on more conventional shows at the Bab-Azoun Theatre in Algiers, playing mostly to an audience of French colonials. Robert-Houdin observes that "the Arabs who came were very few; for these men, with their indolent and sensual temper, consider the happiness of lying on a mat and smoking far above a spectacle" (377). A few pages later, at the fête, RobertHoudin similarly remarks that, "these sons of the desert could not understand that they were boxed up thus, side by side, to enjoy a spectacle, and our comfortable seats, far from seeming so to them, bothered them strangely" (379). On some level, this is a fairly standard construction of the colonized subject as simple, pure and uncultured, but I would suggest that we may read Robert-Houdin's remarks in a slightly more complicated way, perhaps even as anticipating Walter Benjamin's famous statement that "During long periods of history, the mode of human sense perception changes with humanity's entire mode of existence" (1969 222). Robert-Houdin implies that the specifics of life in Algeria have led to entirely different sensual schemata on the part of the Arabic "sons of the desert" than those of contemporary France. An exemplary modern, Robert-Houdin comes down firmly on the side of spectacle, the increasing mass public appetite for which justified his profession. As Rae Beth Gordon writes, "Visual fascination is a need at the end of the nineteenth century ... there is a palpable craving for optical illusion in particular, and this can be seen in the proliferation of toys like the kaleidoscope ... the stereoscope ... and the trompe-l'oeil designs ... in Art Nouveau, and in the art of the Nabis" (2001 198, original emphasis). To this list we may of course add the magical 
stage. It is particularly fascinating to find Robert-Houdin drawing the distinction between the modern and non-modern, and the accompanying trained and untrained forms of spectatorship, along the fault line of spectacle.

The Mysterious Clockmaker: Robert-Houdin and his World

Before further interrogating the specifics of Robert-Houdin's trip to Algeria, there is more to be said about the man himself and his contributions to the field of stage magic. Many of his specific claims have been disputed, most famously by Harry Houdini, who, in a rather oedipal move, subjected his idol to a sustained ad hominem attack in his book The Unmasking of Robert-Houdin (1908). It is clear that many of the tricks RobertHoudin claimed to originate had earlier versions that he improved upon, but his legacy lies less with individual tricks than with the revolution of taste he brought about. As During writes, he "negated the triviality and cultural nullity of magic by bringing to the stage the prestige of the inventor and scientist" (120). Robert-Houdin's Soirées Fantastiques placed magic firmly in the drawing room, where it had once taken place largely on the street, and he formalized the convention of magicians wearing evening dress instead of the older conical cap and flowing robes. Robert-Houdin's modernized magic parallels those qualities Baudelaire famously praised in Constantin Guys, "The Painter of Modern Life" who dressed subjects in modern clothes rather than ancient togas (1982 23-5). ${ }^{66}$ Robert-Houdin's revolution in magic was a revolution of class, allying magic with middle- and upper-class tastes. As Michael Mangan writes, Robert-Houdin aligned "the conjurer with the theatre rather than with the fairground, the circus or the street; with the 'art' of the drama rather than the mere 'entertainment' of the street

\footnotetext{
${ }^{66}$ This is irrespective of Baudelaire's negativity about the Algeria episode. He coined an epithet: "It was appropriate that an unbelieving society should send Robert-Houdin to the Arabs to turn them away from miracles" (Metzner 1998 205).
} 
performer; with high culture rather than with popular culture" (102-3). Some French magicians of today resent him for this, regarding him as responsible for turning magic into "commercially 'safe' but culturally vacuous entertainment - not art" (Jones 2008 34). Either way, Robert-Houdin stands as a towering figure in the emergence of modern magic and a significant figure in the prehistory of cinema as well.

The legitimization of magic was achieved in no small part through an embrace of the rhetoric of science. Even before Robert-Houdin, magicians resorted to quasi-scientific language with some frequency. Writes Paul Metzner,

the tricks were called 'experiments' (expériences), the performers 'physicists' (physiciens) and the performances 'scientific amusements' (physique amusante). This terminology was adopted by conjurers who had no particular interest in recent discoveries in physics and whose acquaintance with science went no further than a practical psychology of deception. $(1998199)^{67}$

More legitimately science-minded than most magicians, Robert-Houdin's clockmaking background allowed him to apply a mechanistic worldview to conjuring. By the end of his career, among his patents would number an electric clock, an electric bell for clocks, a battery, a current regulator, a current interrupter, and a current distributor; he also won a first-class medal at the 1855 Exposition es Produits de l'Industrie (Ibid. 208). A representative early invention is his "Mysterious Clock," displayed at the 1839 Exposition. Its completely clear face implying that it worked without gears, it was a clever mechanical device that hid its operations while making no claims of being supernatural, but merely "mysterious." As Joshua Landy argues, Robert-Houdin played a role in the secular re-enchantment of the world after the decline of religion, precisely by promoting science as magical (2009 102-110). Generally (though not in Algeria, where one assumes transportation would have been prohibitively difficult), Robert-Houdin's act

${ }^{67}$ See also Lachapelle (2008). 
leaned heavily on the automata, the mysterious devices for which the Mysterious Clock provides a structural model - they too mystify and create debate because it is not clear how they function. One of his automata, the Fantastic Orange Tree, has enjoyed renewed exposure in Neil Burger's The Illusionist (2006). ${ }^{68}$ When Robert-Houdin retired from public life to Blois, it was to pursue scientific experiments in electricity and ophthalmology. He invented a device called the iridoscope, which "enabled RobertHoudin to peer deep into his own eyes and produce a sketch of his iris's neural structure" (During 124-5), even producing watercolours based on what he saw.

Robert-Houdin's crusade against mountebanks played a role in his elevation of magic to respectability. A microcosm of this process appears early in Memoirs, where Robert-Houdin describes his youthful self watching a conjurer named Carlosbach perform in the streets of Orléans. After doing a number of tricks, he tells the crowd about a balm he has invented: "Taking my balsam is a mode of embalming one's body prior to death; man is thus rendered immortal" (30). But as the naïve crowd prepares to buy this miracle product, Carlosbach suddenly laughs and reveals that it is a fake: "Do not be angry with me for the little trick I have played on you; I wished thus to put you on your guard against those charlatans who daily deceive you, just as I have done myself. I am no doctor, but simply a conjurer, a professor of mystification" (31). Rather, Carlosbach is peddling a book of magic, from which Robert-Houdin learns his first tricks. Other micronarratives throughout the book contribute to this tension between "competent and incompetent spectatorship" (Jones 2008 48) that pays off in the final chapters on Algeria. Robert-Houdin's shows in Algeria are superficially an extension of this project of

\footnotetext{
${ }^{68}$ For an account of the CGI Orange Tree at the juncture of magic and cinema, see Solomon (2008c 77-81). For more on the automata, see Schaffer (1999), Riskin (2003) and Wetmore (2009).
} 
countering deception: "These false prophets and holy Marabouts, who are no more sorcerers than I am, and indeed even less so, still contrive to influence the fanaticism of their co-religionists by tricks as primitive as are the spectators before whom they are performed" (372). Robert-Houdin's opposition of mountebanks would lead a number of magicians, including John Nevil Maskelyne, Harry Kellar and Harry Houdini, to famously oppose and expose the spiritualist mediums that they saw as new incarnations of the mountebank. ${ }^{69}$ Georges Méliès would ridicule them onscreen in films like $U p$-ToDate Spiritualism (1900), and this was only a portion of a much larger campaign against spiritualist waged by Méliès and a great many other magicians that had a strong presence in early cinema (Solomon 2010 24-27).

In his biography of Robert-Houdin, Christian Fechner stresses that Robert-Houdin "did not have a major influence on the conquest [of Algeria], in which moreover, he refused to participate twice, but on the contrary, was a major figure in the return to peace and reconciliation" (2002 39). Be that as it may, the Algerian episode of Robert-Houdin's career is often treated in grandiose terms by magic historians: "So, that's how one retired magician averted a war" (Rutter 2004 3). The documentary series Grand Illusions: The Story of Magic (1998) goes one step farther: "how a magician ended a war." Again and again, historians of magic make grandiose claims of this sort, which Robert-Houdin himself, egregious self-promoter though he was, never makes in Memoirs..$^{70}$ They like to

\footnotetext{
${ }^{69}$ Robert-Houdin was an early participant in the exposés of spiritualism, giving the subject coverage in his later book The Secrets of Stage Conjuring (1900, esp. 111-18 and 160-228). For an excellent source on anti-spiritualist activity in the late nineteenth century, see Natale (2010). For treatments of more recent magicians acting as debunkers, see Pankratz (1978) and Hill (2010 esp. 128-50).

${ }^{70}$ Actually, in the only overt reference to a rebellion, a revolt in Kabylia, Robert-Houdin describes his role more in the vein of bread and circuses. Staying behind in Algiers, he puts on spectacles at the Bab-Azoun Theatre to distract the masses. As Colonel de Neveu says, "By employing the minds of the Algerians, we prevent them from speculating on the eventualities of the campaign, which might be very injurious to the government" (375).
} 
imagine that the Marabouts were on the verge of influencing the native Algerian population into open warfare against their French masters (or that there was already a war going on), and that Robert-Houdin pacified their followers by revealing the Marabout as frauds. In Grand Illusions, Greg Brown summates: "The point is that Robert-Houdin stopped a great deal of bloodshed with a single magic show. That's a miracle." It was more like two magic shows, plus some subsequent smaller performances for tribal chiefs, but no matter; Brown's blinkered lack of consideration for the colonial context of RobertHoudin's mission shows how blatantly keen modern-day magicians and magic historians are on preserving Robert-Houdin's status as the man who legitimized their discipline and positioning the Algerian expedition as the crowning moment of his career, or even the crowning moment of magic itself. Not for nothing does Henning Nelms's Magic and Showmanship: A Handbook for Conjurers (1969), designed as an introductory guide for the aspiring magician, begin with a discussion of Robert-Houdin's exploits in Algeria. The insistence that what occurred in Algeria constitutes a miracle elevates Robert-Houdin posthumously to what he claimed not to be: a true miracle-worker. The most egregious case might be the account of these events by Milbourne and Maurine Christopher (2006). These authors are canny enough to emphasis the colonial implications of RobertHoudin's tricks before the Algerian natives ("He produced cannonballs from an empty hat-visual evidence of France's limitless armaments ... The invisible passage of silver coins from his hands to the interior of a closed, suspended crystal chest implied that the strongest fort could be penetrated by French ingenuity" (148)), but do so in stubbornly unreflexive way. 
This discourse resembles one coming from another time and place entirely, also borrowing Robert-Houdin in service of triumphalism. General Desvaux is supposed to have said: "The two men who have done most for the pacification of Algeria are Jules Gérard, the famous lion-tamer, and above all Robert-Houdin" (1983 Sharpe 34). In December, 1905, the Algerian newspaper Les Nouvelles made the following comment on Robert-Houdin's performances five decades earlier: "He has remained in grateful memory of the Algerians as an extraordinary man who spared France much bloodshed and moved colonization forward twenty years" (qtd. in Stahl 2004 5). Robert-Houdin represents good publicity for magicians and colonial powers alike. The following account appeared in Le Moniteur universel on October 9, 1857:

The arrival of an extraordinary man working miracles had been announced in advance to the Arabs. When everything had been prepared for his experiences, the Marabouts were not the least prompt to arrive. The efforts they had made to discredit this formidable competitor in the minds of their dupes would make the surprising things that were about to confound their understanding even more impressive.

It was no longer a matter of diverting and refreshing a curious and benevolent public; it was necessary to strike hard and true on crude imaginations and prejudiced minds ...

Today, the Marabouts have fallen into complete disrepute among the natives. On the other hand the celebrated prestidigitator is an object of admiration for them. (qtd. in Metzner 237)

It is difficult to imagine that either of these claims was true to any significant extent, but that does not really matter. As Metzner comments, Robert-Houdin's exploits 'illustrate the presence of both publicity of a spectacle but also ... the publicity power inherent in spectacle" (236, original emphasis). One wonders, in fact, just how Robert-Houdin best served the empire - by discrediting the Marabout in Algeria, or by subsequently writing and publishing the story in his memoirs for French consumption? The narrative allowed 
Europeans to confirm their own modern advancement by casting Algerian natives in the inferior role, and also continues to allow magicians the same sense of superiority.

The Marvel of the Moment and the Age: Robert-Houdin's Algerian Performances

One simple point to make about the Algerian segment of Robert-Houdin's Memoirs is that it places a greater emphasis on verisimilitude than the rest of the book. In the opening chapter Robert-Houdin says, "I possessed at the time a quality, which, I trust, I have not lost since, and that is extreme frankness" (24), but a magician can seldom be held at his word, and large portions of the book are as fraudulent as the last seventeen minutes of Orson Welles's $F$ for Fake (1973), the difference being that Welles acknowledges them as such. ${ }^{71}$ The baldest invention in Memoirs is Torrini, RobertHoudin's mentor. Nearly a quarter of the book deals with Torrini's sensational narrative, wherein it transpires that Torrini was really Edmond, Comte de Grisy, who spent a year in prison after accidentally shooting his son while doing a William Tell act. The whole Torrini episode is winkingly prefaced by an incident in which Robert-Houdin falls ill from food poisoning. "I was in a raging fever; my dreams were frightful, and I suffered from the most dreadful hallucinations" (53), he tells us, and even when he comes out of his sickness, he wonders, "How could I help fancying I was still dreaming?" (54). Almost immediately after this, Torrini appears on the scene. Indeed, Torrini and his assistant Antonio eventually leave the narrative almost without trace. James W. Cook observes that the fictional Torrini, an itinerant carnival magician with noble lineage, allowed Robert-Houdin to locate himself as a part of a shining tradition despite the "low" nature of his entertainments (2001 188-90).

\footnotetext{
${ }^{71}$ The opening sequence of $F$ for Fake has Welles quoting Robert-Houdin's famous dictum than a magician is an actor playing the part of a magician. For more on Welles and magic, see Solomon (2010 125-7).
} 
The unreality of Torrini has been lost on many. ${ }^{72}$ In the history of magic by Henry Ridgely Evans that opens Magic: Stage Illusions, Special Effects and Trick Photography (1897), a collection of articles from Scientific American edited by Albert A. Hopkins, almost as much space goes to Torrini/de Grisy as to Robert-Houdin. Even more embarrassing is the case of Harry Houdini, whose The Unmasking of Robert-Houdin rails at Robert-Houdin for everything under the sun, from purporting to invent tricks with prior antecedents to going through Memoirs without ever stating his second wife's name (41), raises no questions about Torrini's veracity. Writes Jim Steinmeyer, “The Torrini chapters, wildly coincidental and unsubstantiated in any other sources, should never have gotten past Houdini, who boasted about holding every element of the story to his expert magnifying glass" (2003 155). One wonders if Robert-Houdin would have enjoyed the irony of his illusion continuing to fool people after his death. What the device of Torrini tells us is that Robert-Houdin's pretense to absolute frankness and transparency is a thin veneer, that his motivations ran more to utilizing powers of trickery on a credulous audience. We shall see this impulse play out in Algeria.

In comparison to Torrini, the Algeria episode is grounded in convincing details.

Robert-Houdin is much more interested in making his own account at least appear factual. ${ }^{73}$ It is full of specific dates: June 1856 for his first meeting with Colonel de François-Edouard de Neveu, September $27^{\text {th }}$ for his arrival in Algiers (and even September $10^{\text {th }}$ for his departure from St. Gervais), October $28^{\text {th }}$ for his first performance

\footnotetext{
${ }^{72}$ It appears to have been a historian named Jean Chavigny who first questioned Torrini's reality in print in 1943. For another half-century, many in the world of magic persisted in believing that Torrini was real. In 2002, Robert-Houdin biographer Christian Fechner lamented and conceded that Torrini was a fiction (Jones 2008 42).

${ }^{73}$ This is doubly true of "A Course in Miracles," the closing chapter of Memoirs, an exposé of the Sufi mystics the Aïssaoua, based on a ritual he witnessed in Algeria. Robert-Houdin's scholarship is immaculate here, citing scientific journals and books both contemporary and from centuries earlier, and even reveals the workings of some of his own tricks in order to show that the Aïssaoua miracles are mere illusion.
} 
before the Arab chiefs and so on. Seldom does such specificity appear in the rest of the Memoirs. Robert-Houdin vocally welcomed the opportunity to serve France with his magic: "I was very much influenced in my determination by the knowledge that my mission to Algeria had a quasi-political character. I, a simple conjurer, was proud of being able to render my country a service" (372). He even reportedly refused 10,000 francs payment (Sharpe 34).

Robert-Houdin may insist that he is no true sorcerer, but he describes feeling like one, and even masquerading as one, when he first performs for an audience of sixty native Algerian chiefs at an autumnal fête. Drawing a distinction between French and Arabic audiences, he writes, "I was here not merely to amuse a curious and kind public [but] must produce a startling effect upon coarse minds and prejudices, for I was enacting the part of a French Marabout" (381). One striking feature of Robert-Houdin's narrative is how he paints his mission as one of enlightenment and education, as demystifying the miraculous, but in fact seizes every opportunity to "terrify them by the display of a supernatural power" (383), taking an undisguised glee in this task. "From what you have witnessed, you will attribute a supernatural power to me," he tells his audience, "and you are right" (383). He uses the light-and-heavy box trick, which employs the cooperation of a magnetized stage floor; a scientific principle unknown to his audience furnishes him with his trick. An extremely strong Arab, a "Hercules" (384), emerges from the audience to pick up the box. Then Robert-Houdin "magically" strips his strength away, and the Arab finds it impossible to lift the box. In time, Robert-Houdin signals for an electric shock through the handle, and the Arab undergoes a spectacular muscular contraction and 
screams in agony. "It "It would have been cruelty to prolong this scene" (385), RobertHoudin writes, a phrasing that emphasizes spectacle over the man's actual pain. The physical superiority of the savage colonial, we learn, is no match for French intelligence and ingenuity, and the act has more than a hint of technologized colonial violence behind it. Robert-Houdin's repeated descriptions of the audience members cowering, wailing and praying to Allah work to emphasize the volatile and credulous character of the Algerian natives.

The narrative becomes more sensational when an actual Marabout emerges from the audience threatening to kill Robert-Houdin. Robert-Houdin provides him a pistol for this purpose, as well as the bullets (so the Marabout will be convinced that the gun has not been doctored), and holds an apple before his heart. We know from early chapters that the bullets are actually pewter balls that look just like bullets but detonate harmlessly. The Marabout's gun goes off and a bullet appears to lodge into the apple. The amazed Marabout grabs the apple away from Robert-Houdin, "thrust[s] it into his waistbelt, and could not be induced to return it, persuaded as he was that he possessed in it an incomparable talisman" (387-8). Some weeks later, deeper in the desert, Robert-Houdin repeats this bullet catch act with another Marabout and outdoes it by appearing to catch the bullet in his teeth. Further, he filled one of his false bullets with his own blood so that when fired against a white wall it leaves a red smear that astonishes the Marabout: "It was evident that for the moment he doubted everything, even the Prophet" (412). Islam is again mocked and the gunplay of the bullet catches provides an implicit commentary on France's arsenal and status as "bulletproof."

${ }^{74}$ Carolyn Marvin briefly discusses this sequence (58-9). 
Robert-Houdin concludes the show at the fête with a disappearing act. He invites up from the audience "a young Moor, about twenty years of age, tall, well built, and richly dressed . . Bolder and more civilized, doubtlessly, than his comrades ..." (388). Robert-Houdin directs him to a small table in the center of the stage, raises a cloth cone over top of him, and lowers it - the Moor vanishes without a trace. In its earlier life, such vanishing acts were principally done with male subjects: Robert-Houdin was conventionally assisted by his sons, and it was one of them whom he made to vanish under a cone. But from the 1880 s on, vanishing tricks would be conventionally performed on women almost exclusively, and as such they have been examined at considerable length by feminist scholars, especially Lucy Fischer (1979) and Karen Beckman (2003). Fischer notes several implications of the convention of the vanishing woman, among them the demonstration of male power over the female sex, reducing her into a function of male will, the transformation of woman to a decorative object, and a tendency to "dematerialize and decorporealize the female sex - to relegate women to the level of 'spirit' ... magical practice literalizes the notion of woman as 'Other,' as unfathomable mystery" (34, original emphasis). Fischer argues that the underlying register is not woman's weakness but her strength, with the vanishing trick reflecting a cultural need to contain her. ${ }^{75}$ Fischer's points take on a curious new resonance in the colonial context. Elements of the same power dynamic that commentators have found in the male magician-female assistant duo are still at play here. The subject of the disappearance is a strong, rich Algerian native, surely the sort the French would love to have as an ally or hate to have as a foe. That is, one who needs to be placed in the feminine position of subjugation, the language of which runs through the Algeria

\footnotetext{
${ }^{75}$ I shall discuss the vanishing woman trick in more detail in Chapter 6.
} 
segment of Memoirs: the chiefs at this show are described as "clothed in their red mantles ... the symbol of their submission to France" (380). The man's disappearance triggers a fantastic fit of mass hysteria:

Immediately there began a spectacle which I shall never forget.

The Arabs were so affected by this last trick, that, impelled by an irresistible feeling of terror, they rose in all parts of the house, and yielded to the influence of a general panic ... it could be seen, from the agility and confusion of these high dignitaries, that they were the first to wish to leave the house

Vainly did one of them, the Caid of the Beni-Salah, more courageous than his colleagues, try to restrain them by his words: "Stay! stay! we cannot thus lose one of our-coreligionists. Surely, we must know what has become of him, or what has been done to him! Stay! stay!" (388-9)

Outside of the theatre, they find the "resurrected Moor" (389) waiting for them. With an impulse towards tactility, the Arabs want to feel his body to confirm his materiality, but the Moor is afraid of their examination and races into the desert.

Following another magic show the next night, which Robert-Houdin says nearly duplicated the same effects, he concludes with: "The blow was struck: henceforth the interpreters and all those who had dealings with the Arabs received orders to make them understand that my pretended miracles were only the result of skill, inspired and guided by an art called prestidigitation, in no way connected to sorcery" (389). He was presented with a tribute from the chiefs, a translation of which appears in Memoirs. Part of it reads:

Generous-handed destiny has sent down from above, in the midst of lightning and thunder, like a powerful and fertilizing rain, the marvel of the moment and the age, him who cultivates the surprising arts and marvelous sciences - the SidRobert-Houdin.

Our century has seen no one comparable to him. The splendor of his talent surpasses the most brilliant productions of past ages. Our age is the more illustrious because it has possessed him. (392) 
In Graham M. Jones's fascinating in-depth analysis of the proclamation, he observes that the translation Robert-Houdin relates is a selective one that omits several lines and distorts certain key implications found in the Arabic. Writes Jones, "The overall connotation [of the Arabic original] is that Robert-Houdin's act was seen as a prodigiously amusing curiosity of knowledgeable performance - not terrifying sorcery as the magician's narration implies" (2010 77).

Michael Mangan writes that

The deeper purpose of Robert-Houdin's performance ... is to effect a major ideological shift by advancing the claims of western material rationalism over those of the folk rituals of the Marabout, and, by association, over the claims of Islam itself. Its function is to construct a clear opposition between rationalism and "superstition" and convince the Arabs that the rationalism is superior. The magician is engaged in that most essential of colonial enterprises: that of establishing the validity of the colonialists' world-view over that of the subject people. (112)

Mangan is correct, but another register needs probing as well. For there is a fantastic disconnection between the errand of rationalism described above and Robert-Houdin's actual description, where he takes an obvious pleasure in transforming himself into just that kind of sorcerer, fully capable of inspiring real supernatural, even religious, terror in an audience, complete with quasi-religious artifacts like the protective apple. One gets the impression not of an eroding of the power of sorcery so much as a reshaping of its object; the Arabs now are no longer to be afraid of the Marabout but rather of a Frenchman (a "French Marabout," no less), and by extension, France itself. It is strange indeed to find the conjurer noted for his taste and gentility electrocuting his patrons and taking a professional pride in practically producing riots. The setting allows Robert-Houdin to take a considerable break from his usual persona, enacting a literal "shock treatment" on his audience. Robert-Houdin is a privileged European allowed to fulfill cultural and 
professional fantasies in a colonial Neverland, enthusiastically playing a role of power impossible in Europe. Perhaps any magician, no matter how "modern," craves the primal power of the sorcerer and is willing to impersonate one when the occasion presents itself. ${ }^{76}$ Perhaps this is what led the magicians to cinema, which presented boundless opportunities to enact "real" magic using cinema's resources for trickery. But as I have noted, the story of Robert-Houdin's performances in Algeria resonate with early cinema in another important way - as the backstory for the myth of the Grand Café.

\section{The Panicking Audience in Early Cinema}

It is tempting to position Robert-Houdin, the paradigmatic modern showman, conjurer, inventor and entrepreneur in one, as a sort of spiritual godfather to early cinema. The numerous magicians who became filmmakers were all, if in ways less literal than Méliès (or even Houdini), Robert-Houdin's disciples; all almost certainly would have been familiar with Robert-Houdin's books, which were seminal texts for generations of magicians. Émile and Vincent Isola, two magicians who ultimately pursued careers in filmmaking, were even French Algerians for whom "the legend of Robert-Houdin's exploits in Algiers held special fascination" (Barnouw 48). The merger of illusion with spectacularized science and technology that was so important to RobertHoudin's vision of the magician must have seemed to reach its apotheosis in cinema.

Dan North writes that

By the late nineteenth century, the word illusionist had come to be used instead of conjurer, to connote the use of large apparatus in a trick, but also to stress the

\footnotetext{
${ }^{76}$ Robert-Houdin displays a willingness to masquerade as a sorcerer on other occasions, too, when faced with the naïve and foolish. In a lighthearted incident that takes place back in France, a high-class lady comes to visit him wanting him to put a curse on a man who has abandoned him. She calls him a sorcerer, and he tells her, "Unfortunately, madam, you give me a title I never possessed" (261). But she will not relent, so he invents a magic spell on the spot and thrusts a pin through a lighted candle, telling her that he has placed a curse on her former paramour. The gender-coding is unmistakable here, and related to RobertHoudin's need to place his Algerian audience in the feminine position of hysteria.
} 
spectatorial subjectivity on which the illusion was dependent . . . The distinction puts the emphasis on the way in which the spectator perceived the trick, as opposed to what the magician actually does. (45)

We can see many of the same issues playing out within the debates about cinema and illusion at the same time (see pages 44-5 of this dissertation). Paul S. Moore writes that: "Motion pictures, although no less illusory an entertainment than fortune-telling or magic shows, could be normalized and permitted because of the technological apparatus of the electric projector" (2008 70-1), and indeed, cinema would in time be regarded as the kind of safe, tamed illusion ${ }^{77}$ that Robert-Houdin's tasteful stage magic had been. But this conception developed against a conception of film producing wild, chaotic spectatorship, still familiar to us through the Myth of the Grand Café, which for many decades was repeated as fact by film historian after film historian as fact (Loiperdinger 2004 90-2). Says Tom Gunning:

The first audiences, according to this myth, were naïve, encountering this threatening and rampant image with no defenses, with no tradition by which to understand it. The absolute novelty of the moving image therefore reduced them to a state usually attributed to savages in their primal encounter with advanced technology of Western colonialists, howling and fleeing in impotent terror before the power of the machine ... Credulity overwhelms all else, the physical reflex signaling a visual trauma. (2004 863)

Now, compare the following description, part of Robert-Houdin's account:

"Allah! Allah!" he exclaimed, full of terror; then wrapping himself up quickly in the folds of his burnous as if to hide his disgrace, he rushed through the ranks of the spectators and gained the front entrance ... my audience had become grave and silent, and I heard the words "Shaitan!" "Djenoum!" passing in a murmur round the circle of credulous men, who, while gazing on me, seemed astonished that I possessed none of the physical qualities attributed to the angel of darkness. (385)

\footnotetext{
${ }^{77}$ I can scarcely make this statement without evoking Tom Gunning's famous description of special effects as "tamed attractions" (1990a 61), but I am also thinking of a line from Colin Bennett's 1913 Handbook of Cinematography: "There are no tame ghosts, even in the most up-to-date film production studios" (89). This line appears in a discussion of how to create ghostly effects using double exposures.
} 
Common to Robert-Houdin's Algerian episode and the Myth of the Grand Café is an understanding that spectatorship is a major fault line along which the modern and the non-modern are divided.

Like most founding myths, the Myth of the Grand Café is fundamentally specious. Martin Loiperdinger's article "Lumière's Arrival of a Train: Cinema's Founding Myth" (2004) shrewdly demolishes all claims for a factual basis for the story: it has no credible firsthand witnesses, as there surely would have been since journalists were present at these screenings, and no film of a train appeared in the first Lumière programme (104). There are a host of other reasons why the story is not credible, and one of the most profound is that it does not match our understanding of these first spectators. In an "Aesthetic of Astonishment" (1989), Gunning accepts a certain kind of reality to the myth of the Grand Café insofar as audiences did experience a sensual astonishment from the unfamiliar images, even if they did not jump to their feet and flee the building. For Gunning, their astonishment was consistent with the sensational visual training the Victorian spectator received in both life and entertainment, feeding in turn into the shockdriven mode of exhibition that is the Cinema of Attractions. For Gunning, the spectator's reaction is not driven by mistaking the image for reality and therefore fearing disaster, but rather is an exciting thrill like that of a patron of a carnival or a magic show. ${ }^{78}$ For Christian Metz, the Grand Café narrative persists because it allows us to assert the value of our own incredulity against an Other. He draws on an anthropological

\footnotetext{
${ }^{78}$ Rae Beth Gordon's understanding of the myth of the Grand Café is similar but distinct. She argues that the involuntary reactions provoked in the spectators by the image are consistent with symptoms of hysteria and mental illness: "What does create anxiety in the spectator are the implications attached to experiencing the same dislocations and convulsive agitation, perceptual disturbances (optical illusions, intense afterimages, hallucinations) as an hysteric" (132). Indeed, the gendering of hysteria opens up another set of issues, whereby the myth of the Grand Café transforms the superior, European audience into a set of feminized hysterics. See also Kirby (1998).
} 
analogy from Octave Mannoni, who tells us of cultures where masks are used to deceive children. At the point of their initiation to adulthood, however, they learn that behind the masks were adults in disguise. Donning the self-definition as of a knowing, incredulous spectator requires an imaginary Other, a credulous spectator to feel superior to:

Mannoni compares these switches of belief with those the ethnologist observes in certain populations in which his informers regularly declare that 'long ago we used to believe in these masks' (these masks are used to deceive children, like our Father Christmas, and adolescents learn at their initiation ceremonies that the 'masks' were in fact adults in disguise)... This 'long ago' is childhood, when one really was duped by the masks; among adults, the beliefs of 'long ago' irrigate the unbelief of today ... (1982 73)

This incredulous spectator takes a range of different forms: a child, a savage, or a country rube not yet trained to the shocks of modern life. A wonderful example of "rube spectatorship" appears in Béla Balázs's The Theory of the Film (1970) in the anecdote of a girl raised on a Siberian collective farm, who is intelligent and well-educated but has never seen a motion picture. She is visiting her urban cousins in Moscow and is left alone at the pictures to watch a burlesque. She comes home pale and grim, and her cousins ask her how she liked the film.

She could scarcely be induced to answer, so overwhelmed was she by the sights she had seen. At last she said: "Oh it was horrible, horrible! I can't understand why they allow such dreadful things to be shown here in Moscow!"

"Why, what was so horrible then?"

"Human beings were torn to pieces and the heads thrown one way and the bodies the other and the hands somewhere else again." (34-5)

The conventions of the close-up elude the Russian peasant girl and she interprets the cinema as a sick horror show. Trauma, again, is the default reaction whenever one is understood as facing something outside of an established sensorial inventory. 
There was an entire genre of "rube films" in early cinema featuring a country bumpkin getting into hilarious situations in the modern urban world. The most discussed is Edwin S. Porter's Uncle Josh at the Moving Picture Show.$^{79}$ In this case, Uncle Josh attends a movie theatre and watches a short series of films but confuses them for reality and tries to interact with them. He is perplexed by title cards, tries to join a dancer on the screen, is shocked by a barreling locomotive, tries to break up a kissing couple by picking a fight with the man, and climactically brings down the screen in the end, earning himself a beating from the projectionist. It is a copy of a British film of the year before, Robert W. Paul's The Countryman and the Cinematograph, and would itself inspire further copies (Loiperdinger 90, Bottomore 1999 184-6). According to Simon Popple and Joe Kember, rube films allowed filmmakers to "[give] spectators a reflection of their own viewing strategies, demonstrating that excessive naïveté or misbehavior during the show were to be ridiculed and rejected by the accomplished spectator" (2004 66). Nicholas Hiley argues that the story of the untrained viewer was initially placed onto a figure of Otherness like the rube, but by 1920 or so, it was relocated onto the entire cinematic audience of twenty-five years earlier (qtd. in Bottomore 1999 184).

Thomas Elsaesser finds a slightly more complex dynamic of spectatorship and discipline at work in the rube films. He asks:

Do the rube films not discipline their audience by allowing them to enjoy their own superior form of spectatorship, even if that superiority is achieved at the price of self-censorship and self-restraint? The audience laughs at Uncle Josh, who is kept at a distance and ridiculed, and thereby it can flatter itself with a selfimage of urban sophistication ... the rule is 'you may look, but you may not touch.' (2009 16)

\footnotetext{
${ }^{79}$ The Uncle Josh character figures in other films and goes back to the 1870 s on the vaudeville stage (Mayer 2009 52-4).
} 
In Elsaesser's shrewd analysis, the rube film plays an important role in helping to establish the (self-regulated) rules of behaviour on the part of cinema patrons. These films are teaching texts for the proper way to receive cinema, just as one function of Robert-Houdin's writings, especially concerning Algeria, is to reinforce the proper way to regard stage magic. Yet even as the pleasures of transgression are restricted, they are emphasized and perhaps even made desirable: as Miriam Hansen writes "Uncle Josh's transactions with each film spell out distinct aspects of spectatorial pleasure - mimeticnarcissistic, kinaesthetic, voyeuristic" (1991 28). We (the civilized, trained spectators) are not Uncle Josh, but do we not still crave the purity of his interactions with the image? Or the ability to experience magic so innocently as Robert-Houdin's Arabic audience are purported to have? In this way, we can see in these panicking audience narratives an expression of Gunning's "culture of shocks and flows," simultaneously moving towards shock and disorientation and regulation and discipline.

Though the rube would become the paradigmatic figure of incredulous spectatorship, the untrained viewer can also be a savage or primitive. Even Metz's analogy requires a "savage" context. In his article "The Panicking Audience?: Early Cinema and the "Train Effect"' (1999), Stephen Bottomore draws conclusions contrary to Loiperdinger and (to a lesser extent) Gunning to make the case that panicking early cinema audiences were a historical reality, albeit on a smaller scale than in legend and certainly not in the Grand Café. Having assembled his evidence, he states:

Let us grant that, in the early days of the cinema some people may have had a very real perceptual shock [to films such as the Lumière train films]. Some may even have jumped back in alarm. But whole audiences panicking? Is there any evidence of this? The answer seems to be "yes, occasionally, but only in audiences of a rather special kind." (1999 196) 
These "special" audiences include a screening at a mental asylum, and more often, nonWestern peoples. Bottomore identifies several versions of this narrative that take place in a colonial milieu, including Africa, Peru, the Philippines and India, as well as a group of Hopis in the American southwest. Bottomore states that "These reports may well be exaggerated and clearly the motive ... of belittling country dwellers, 'rubes' and 'primitives' might have applied. However, given the psychological effect of looming and other perceptual factors ... such reactions are surely not implausible" (1999 197). My point in raising this evidence is not to amass support for Robert-Houdin's account of his Algerian audience, but rather to locate in that account a prehistory for the "panicking savage" narratives that works to lay bare their unpleasant colonial implications, which are present whether or not these narratives are factually true.

The colonial or "primitive" subtext of early film theory has been taken up at length by Rachel O. Moore in her book Savage Theory (2000), with special focus on Balázs, Sergei Eisenstein and Vachel Lindsay. ${ }^{80}$ However differently, all of these scholars are fascinated by ideas of primitive rituals and magic, alongside narratives of the first encounters with cinema that implicitly cast spectators as primitives. ${ }^{81}$ She also draws attention to depictions of "savage" encounters with superior technology, from Nanook of the North (1921) to Too Hot to Handle (1938) to Dances with Wolves (1990): "Such persistent reenactments of naïve spectatorship, whether by viewers of cinema's first films or by people who have not yet been exposed to the movies because they are savages, serve ... a distinctly modern cosmology" (4). Such scenes are a point of evolution of the

\footnotetext{
${ }^{80}$ See also Bear (2008).

${ }^{81}$ Similarly, Tom Gunning notes that "the terrorized spectator of the Grand Café still stalks the imagination of film theorists who envision audiences passively submitting to an all-dominating apparatus, hypnotised and transfixed by its illusionist power." (1995 115).
} 
rube film; one of the most startling examples (startling to see such an outmoded brand of racism in a prestige picture) is a sequence in the middle of The Piano (1993) where a Maori confuses a shadow play of the Bluebeard story for reality and, like a colonial Uncle Josh, leaps on the stage to disrupt the performance. ${ }^{82}$ An example still closer to the context of magic comes at the end of Harry Houdini's film Terror Island (1920), when Houdini's character, inventor Harry Harper, terrifies a group of Polynesian natives into submission with a feat of modern trickery. "Not a white can be spared," Harper says, "unless we can play on their fears." The natives believe that they have drowned Harper and the heroine Beverley (Lili Lee) but they have survived thanks to Harper's submarine and his feats of escapology. A title card informs us that "To the superstitious natives the reappearance of their two victims rising from the sea is nothing short of a miracle." The tribal warriors bow before him and their threat is neutralized. If all of these scenes are essentially recastings of the myth of the Grand Café, Terror Island does one better in evoking the tale of Robert-Houdin in Algeria in the same motion: the magician averting violence through a clever use of modernity's resources to exploit "savage" superstitions, producing panicking, cowering, and ultimately subjugated natives. Houdini is playing a character who is not literally a magician but whose affiliation with invention and individualistic ingenuity very much marks him as a techno-magician; Houdini never stops being Houdini. As an embodiment of modern white American masculinity (Kasson 2003) and now a movie star, he becomes the train to provoke to simultaneously panic and tame the restless natives - another conquest by spectacle possibly inspired by that of his namesake, now filtered through to cinema.

\footnotetext{
${ }^{82}$ See Dyson (1995 273) and Gordon (1996 200-1).
} 
These "first encounter with modernity" narratives emerge on examination as a complex mesh of the anodyne and the alarmist. I have noted that Robert-Houdin's trip to Algeria has the axiomatic status of a founding myth, parallel to the status the myth of the Grand Café (defined broadly enough to include the rube film and other incarnations) enjoys in cinema, and for many of the same reasons. They are narratives of illegitimate or naive spectatorship that simultaneously exist to promise growth and adaptation, the overcoming of childhood or "savage" illusions (while simultaneously hinting at but curtailing the pleasures that lie in over-indulgence in the image). ${ }^{83}$ At the same time, however, they warn that modern superiority is capable of vanishing in a flash when faced with new forms of spectacle not yet tamed and regimented. Jean Epstein wrote in 1926 that "the young black who used to kneel in worship before the headlights on explorers' cars is now driving a taxi in Paris and New York. We had best not lag behind this black" (17), and from this racist sentiment we might extrapolate a major message buried in these stories of panicking audiences: as the modern subject is confronted with the novel and spectacular, he must take care to avoid becoming Uncle Josh, or a member of RobertHoudin's Algerian audience. Here again, a "primitive" example proves useful: in the 1960s, anthropologist Edmund Carpenter found that natives of New Guinea were terrified of mirrors, photographic images and film, but also that they took very little time to normalize the presence of these devices and even started making films themselves (Bottomore 1999 22-3). Even if this is not necessarily a representative example, it begins

\footnotetext{
${ }^{83}$ We see a narrativization of this dynamic in Ann Hu's Shadow Magic (2000). Lia Jinglun (Yu Xia) is astonished by his first encounter with cinema and is told by the fictional English exhibitor Raymond Wallace (Jared Harris) that it is too complicated to explain, but discerns how it functions by examining a zoetrope and other optical toys. Installed as a lecturer to help sell the new western novelty of cinema to his countrymen, he witnesses a panicked reaction to The Arrival of a Train and insists "Don't panic! It's only an illusion." The audience's quick recovery is a microcosm for the film's larger construction of the introduction of cinema into China. For a useful take on this film, see Mak (2002).
} 
to explain why Robert-Houdin, despite his mission of education, must withhold the key to becoming truly modern: understanding illusion as illusion. The magician who so carefully held himself up as a man of science and rationalism happily played a sorcerer when the place and circumstances allowed him to do so, and in so doing not only cemented the standing of stage magic and its patrons but helped prepare for the construction of the cinematic spectator. Just as the trained and educated spectator needs to imagine the naïve and untrained one to define himself against, "civilized" spectator needs the savage, feminized, pathologized panicking audience. 


\section{Chapter 4: The Strange Case of George Albert Smith: Mesmerism, Psychical}

\section{Research and Cinema}

There is only one name with a prominent place in the histories of both Victorian investigations into the supernatural and of early cinema. ${ }^{84}$ This is George Albert Smith, a Brighton stage mesmerist who participated in an important (and still contentious) set of early telepathy experiments and was a longstanding employee of the Society for Psychical Research before becoming one of the loose-knit group of film pioneers known as the "Brighton School" or "Hove School." The eccentric circuits of Smith's careers help us explore industrial and cultural affinities between the supernatural and cinema on more of a biographical level, and in this chapter I will explore this one man's strange case. Film historians have described Smith as a pioneer with key contributions to editing, ${ }^{85}$ the close-up, ${ }^{86}$ colour ${ }^{87}$ and the double exposure. Smith outlived virtually every other cinema pioneer, and though he lived in obscurity for decades, he did live to see his work garner new interest in the 40s and 50s. He gave interviews to film historians like Georges Sadoul and Rachael Low, and in 1955 he was elected a Fellow of the British Film Academy. On October 16, 1957, he attended the opening of the National Film

\footnotetext{
${ }^{84}$ With a few exceptions, his place in each set of histories is rarely acknowledged by the other. For example, in his history of parapsychology, John Beloff merely states that "During the 1890 s . . . Smith became interested in cinematography" (1993 87). References to Smith's career in psychical research are even scanter in the literature on cinema, with the exception of Frank Gray's excellent works (esp. 1996, 1998, 2000).

${ }^{85}$ His $A$ Kiss in the Tunnel (1899) has been called the first edited film in England (Gray 2004). See also Fairservice (2001 18-22, 32-3).

${ }^{86}$ Georges Sadoul praised Smith as inventor of the close-up as early as 1946, a claim generally made with respect to his films Grandma's Reading Glass (1900), As Seen Through the Telescope (1900) and A Sick Kitten (1903). For more on Smith and the close-up, see Bordwell and Thompson (1979 147), Brewster (1982 6), Burch (1990 89), Hansen (1991 33), Fairservice (2001 21), Chapman (2003 55), Popple and Kember (2004 103).

${ }^{87}$ Working for Charles Urban, Smith invented Kinemacolor, the first economically viable colour process. However, a lawsuit would nullify his patent in 1914. See Thomas (1983), Urban (2003), O'Brien (forthcoming).
} 
Theatre under Waterloo Bridge in London. A group photograph taken that night shows him alongside H.R.H. Princess Margaret, Gina Lollabrigida, Laurence Olivier, René Clair, John Ford, Vittorio de Sica and Akira Kurosawa, ${ }^{88}$ with Smith serving as a living embodiment of Britain's proud cinematic tradition. He would die two years later at the age of ninety-five.

Less than a decade after his death, a book would cast Smith in a rather different light, as a fraudster and cheat with a measure of responsibility for the suicide of the prominent late Victorian psychologist and psychical researcher Edmund Gurney. The Strange Case of Edmund Gurney (1964) was one of several scathing books about the founders of psychical research written by a disgruntled ex-S.P.R. member named Trevor H. Hall. The fact that the S.P.R. of the time meticulously collected reviews of and responses to Hall's books (still present in their Cambridge archives) speaks to the depth of their interest in or embarrassment at his claims, especially those relating to the death of S.P.R. co-founder Gurney. ${ }^{89}$ Following historians of psychical research, such as Fraser Nicol, C.D. Broad, John Beloff, Alan Gauld, Janet Oppenheim and Gordon Epperson, would provide more sympathetic and balanced treatments of the early S.P.R. and often disputed Hall's claims; Epperson calls The Strange Case of Edmund Gurney "mainly a work of fiction" in scholarly trappings (1994 142). Hall's most sensational claim was that the death of Gurney from an overdose of chloroform in a Brighton Hotel on July 22, 1888 was a suicide, inspired by learning that the Blackburn-Smith telepathy experiments he had conducted in 1882-3 had been faked by their participants, Douglas Blackburn and

\footnotetext{
${ }^{88}$ Reproduced in Gray (1996 31). Trevor Hall briefly mentions this event in Smith's life, including the detail that he was given a picture of the theatre by Lord Hailsham (1964 173).

${ }^{89}$ The popularity of The Strange Case of Edmund Gurney was such that BBC adapted it under the name The Magicians: Edmund Gurney and the Brighton Mesmerist, which aired in October 1967. Smith was portrayed by Ray Brooks, Gurney by Richard Todd.
} 
none other than George Albert Smith, whom Gurney had retained as a secretary and assistant in the years since. Hall further alleged that the S.P.R. leadership of the time concealed the facts of Gurney's suicide and passed it off as an accidental death in order to avoid bringing unwanted scrutiny to their still-fledging organization..$^{90}$

The matter of whether or not Gurney committed suicide is thoroughly marginal to the considerations of this chapter, except insofar as it is unfortunate that the best known source on Smith's early life (still useful for its biographical details) is also one that paints him as a hoaxer who played a substantial part in Gurney's death. I submit that it is not most productive to understand Smith as a fraud but rather as a figure uniquely positioned between two (at least two) worlds, whose life and careers can tell us something about their connections. I have mentioned Smith's status as a pioneer of double exposure aesthetics, and this is a place where the connection between the supernatural and cinematic technique reveals itself tangibly; Smith was one of the first filmmakers, if not the very first, to bring the ghostly aesthetic inherited from the spirit photograph to cinema. He thus inaugurated a strategy for the visualization of the supernatural that would remain standard for many decades. His diverse output as a filmmaker includes some early trick films reflective of his former careers, much of it utilizing double exposures. Paul Virilio notes that the "ghost industry" of spirit photography "had a huge impact on the aesthetic and technical vocabulary of the cinema" (1989 38), and though he is speaking particularly about the WWI era and Germany, his words probably apply even better to early cinema, and to the case of Smith in particular. The spiritualist dimensions of early cinema even extended to the inclusion of photographs borrowing the aesthetic of

\footnotetext{
${ }^{90}$ Whether or not Gurney had facial neuralgia and used chloroform to calm it, thus opening the possibility of an accidental overdose, is a particular issue of contention. See Coleman (1993) for one attempt to debunk Hall's claims about Gurney's death.
} 
the spirit photograph in W.K.L. Dickson's History of the Kinematograph (Solomon 2010 18-9). In spite of these strong associations, there never was a properly cinematic equivalent of spirit photography which would display proof of the existence of ghosts on screen, though such "Spirit-Cinema" was indeed craved by various writers (Ibid. 24-5). But if Spirit-Cinema was not to be, ${ }^{91}$ the use of the double exposure to envision the supernatural would be standard in cinema for decades, and at the beginning of that tradition is George Albert Smith, who reflects the entanglement of cinema and the supernatural on both personal and professional levels perhaps better than any other person.

\section{Smith the Mesmerist}

Various sources that describe Smith's early career as a theatrical performer have called him a magician, a mesmerist, a hypnotist, a spiritualist and a mentalist. In a sense, this array of labels is not unwarranted and reflects the close conjunction of these various practices in the stage entertainments of the time. Nevertheless, this confusion and lack of historical precision has led to what I believe to be several misreadings and misuses of Smith especially by film scholars; I shall detail these later in the chapter. In the meantime, my ambition is to bring more precision to the discussion of Smith's various careers and how they fit within the culture of the day. In this, I follow in the footsteps of Frank Gray (esp. 1998, 2000), whose writings on Smith are the best available.

Smith was born in East London in 1864 and his family moved south to Brighton at some point during his childhood. By 1881 , his father was deceased and his mother operated a seaside boarding house (Hall 1964 92-3), while the seventeen-year-old Smith

\footnotetext{
${ }^{91}$ The proliferation of documentary paranormal investigation series like Most Haunted reminds us that this dream is far from dead. See Williams (2010), Burger (2010), O'Hara (2010) and Hill (2011).
} 
worked as a seaside entertainer, honing an act that blended mesmerism, thoughttransference and stage spiritualism. To understand the significance of Smith's act, we must briefly examine the history of mesmerism, especially in England. Though it was never used in his lifetime, the practice takes the name of Franz Anton Mesmer, the German physician who began his studies into what he called "animal magnetism" (from the Latin animus, spirit) in the 1770s. Mesmer proposed that souls are electromagnetic constructions and theorized the existence of a kind of spiritual fluid which could flow from person to person, which was responsible for health and illness. Writes John Durham Peters, "Mesmer and his disciples considered themselves neither occultists nor a circus sideshow but the latest stride in the march of reason. They were offering a unified field theory of the material and moral forces. As gravitation held the planets in orbit, so animal magnetism kept souls in love and health and communication" (90). Mesmer's experiments were centered on the way in which a doctor/magnetizer could place a patient en rapport and effect cures by manipulating animal magnetism. ${ }^{92}$ The "mesmeric" rapport between doctor and patient was fraught with sinister, sometime sexual, implications related to the apparent abdication of will on the patient's part. Roger Luckhurst notes that "the first wave of the Gothic coincided with Anton Mesmer's theories of animal magnetism in the 1780s" (2002 204) and the exploration of dream, distraction, reverie and trance throughout Gothic art and literature was fuelled in large

\footnotetext{
${ }^{92}$ Peters characterizes Mesmer as a Columbus who "discovered a new world (the continent of the unconscious and the peninsulas of neurosis and hypnosis) yet remained mistaken about its identity to his dying day" (91).
} 
part by Mesmer's theories. Mesmeric themes figured significantly in the supernatural throughout the nineteenth century and beyond, as I shall discuss later in this chapter. ${ }^{93}$ Mesmerism reached Britain in 1837, well after its boom in popularity in continental Europe. The distinguished doctor John Elliotson began doing mesmeric experiments with patients at the University College Hospital in London and presenting public demonstrations before members of London society. Along with W.C. Engledue of Brighton, Elliotson founded the Zoist, A Journal of Cerebral Psychology \& Mesmerism, which ran from 1843 to 1864 . Elliotson's experiments and claims inspired widespread debate and ushered in an enormous vogue for mesmerism in English. Alison Winter writes that "Mesmerism could be seen almost everywhere and was practiced by individuals of virtually all professions and classes" (1998 16), with mesmeric imagery commonplace in political cartoons and other similar social satires of the day. Terry Parssinen explains that, while mesmerism and debates surrounding it defused through the printed word to a degree, it was the "small army" of itinerant mesmeric performers through which mesmerism truly spread (1997 89). Many of the mesmeric performers were of low social origins but achieved widespread audiences of mixed social standing, blurring the already hazy lines between scientist and performer, professional and amateur.

In 1842, the Scottish surgeon James Braid developed hypnosis, in part from the examination of purportedly mesmerized subjects. Even his rejection of animal magnetism in favour of psychophysiological explanations for mesmeric states did not inure Braid from criticism: "Braid's success in ridding his practice of some of mesmerism's

\footnotetext{
${ }^{93}$ Additional sources on mesmerism/hypnotism and nineteenth century literature include Kaplan (1975), Tatar (1978), Pick (2000), Thurschwell (2001 37-64), Melechi (2008 75-97) and the collection Victorian Literary Mesmerism (2006).
} 
controversial features was one factor in hypnotism's survival, although in the 1840s he was regarded as only one of many controversial practitioners, and drew his share of attacks" (Winter 1998 184). It would take many decades of debate within the psychological establishment before hypnotism reached the status of generally accepted scientific fact. But mesmerism's story did not end with the establishment of hypnotism. It continued as a stage practice, "transformed from a doctrine which made serious medical and scientific claims into an amusement to be placed in a category with conjuring or fortune-telling, and mesmeric performers were transformed from scientific lecturers and healers into entertainers" (Parssinen 104). Further, spiritualists and occultists were far too invested in Mesmer's ideas about animal magnetism and his fluidic model of the universe to let them go when the scientific orthodoxy did. Journals like Light and Borderland regularly printed pieces on mesmeric healing and mesmeric clairvoyance in the $1880 \mathrm{~s}$ and 1890s, and the new field of psychical research had mesmerism on its intellectual lineage, even as it officially allied itself with hypnotism and established science.

A September 1882 review in the Brighton Herald emphasized how the youthful

George Albert Smith's act drew rhetorically on the (by then heavily discredited) Mesmeric model of animal magnetism:

Mr. Smith cited numerous proofs of the existence in the human body of a magnetic force, remarking that he considered it was some such force which, emanating from the brain and acting through the nerves, contracted the muscles and produced motion; and that it was through the medium of magnetism that impressions were also received. Proceeding then to consider whether the magnetism of one person could be affected by that of another, he contended that we had under the control of our will a subtle magnetic force, and that it as possible to make other people feel that force. The effect it produced corresponded very closely with that of sleep, in which, the voluntary action of the brain being suspended, the involuntary action gave rise to dreams, and sometimes to somnambulism. By means of mesmerism, it was possible to suspend the voluntary action of the brain of the subject; and then, by inducing in them certain mental 
impressions, to produce such phenomena as he had demonstrated upon the platform. (2)

As part of the act, Smith would give a mesmerized baker named Fred Wells a candle and tell him it was sponge-cake, not stopping him until he had eaten half of it (Hamilton 2009

124-5). A July 1882 review from the Brighton Herald carried the following description:

Mr. Smith professes to show how some of his subjects, whilst retaining consciousness, are, nevertheless, unable to move or to refrain from moving, as the case may be except at his bidding. At other times the audience is asked to believe that the mental as well as the physical faculties of the subjects are wholly subjugated to the mesmerist's will, when he seems able to produce any impression upon their minds, including the sensations of heat and cold. (3)

Smith would soon adopt a thought-reading act ${ }^{94}$ in partnership with local journalist

Douglas Blackburn. Blackburn found Smith doing a mesmerism act in a small Brighton

hall and discovered that his own office-boy, Mahoney, was one of Smith's shills,

pretending to be put under the influence and subject to Smith's will (Hall 1964 93).

Blackburn took to shilling Smith in another sense, writing a series of articles about him

for The Brightonian throughout 1882, all written with unbridled enthusiasm. A July 22 article read:

Mr. G.A. Smith's concluding appearance at the Aquarium on Saturday evening was an event in the history of the institution. The crowd was simply enormous, and the excitement and enthusiasm proportionate. Someone calling himself a doctor seized one of the subjects whilst under control and administered sundry brutal kicks and prickings, and the boy still remaining unconscious the sceptic had the audacity to denounce him as a fraud. This was too much for the audience, so they threw the interrupter out.

The engagement has proved the most successful ever made by the Aquarium management, and throws Crowther, Little Louie and the Midgets far into the shade. Mr. Smith has received an offer for a re-engagement in a fortnight, but he proposes giving a series of select high-class séances for the popularizing of the science. (qtd. in Hall 1964 94)

\footnotetext{
${ }^{94}$ We know that Smith continued acting as a stage mesmerist as well through at least 1889 , well into his tenure with the S.P.R. (Gray 2000 172))
} 
It is not known whether the promised séances were ever performed, but this announcement does much to remind us how porous the worlds of magic, mesmerism and stage spiritualism were at the time.

By September 1882, Blackburn would join Smith onstage as his partner, having already been a "silent partner" stoking public interest in his performances. Smith would be blindfolded on stage while the audience produced various objects, the identity of which Blackburn would "telepathically" convey to Smith, allowing him to identify them. Smith and Blackburn adapted the methods of the American mentalist Washington Irving Bishop, who had proved a success in London the year prior. Bishop was the star of "muscle reading," a technique where the mentalist grips a subject's hand and purports to read his or her thoughts through subtle and involuntary responses on his or her part. Bishop was born of spiritualist parents and became the manager of the stage spiritualist Anna Eva Fay, but went through a remarkable reversal in 1876 , publishing a book exposing Fay's methods and hawking it at his own anti-spiritualist magic show (During 161). Despite his anti-spiritualist posture, Bishop came into conflict with the important English magician John Nevil Maskelyne; Maskelyne even successfully sued Bishop over a libelous newspaper article in which Bishop had accused Maskelyne of colluding against him. To Maskelyne, people like Bishop were little better than the spiritualists, exploiting the credulity of audiences; they represented a breed of new magic that clashed with the mechanized and secularized Robert-Houdin-influenced version of magic nurtured at London's Egyptian Hall.

Bishop, Stuart Cumberland and other early mentalists played an important part in triggering the scientific investigation of thought transference, which would shortly be 
redubbed "telepathy." Despite the fact that Bishop attributed his powers to muscle reading and not anything supernatural, and even published a guide to memorizing the mnemonics used by stage clairvoyants (Luckhurst 2002 63), he and other performers like him became rallying points for those eager to promote telepathy as a scientifically verifiable. Writes Luckhurst, “[Bishop] invited scientific observers to help explain his mysterious sensitivity ... and this left a space for supernatural accounts of these performances" (2002 65). Scientific investigators looked to stage performers as subjects for study, and stage performers embraced such opportunities for free publicity. Smith and Blackburn's relationship with the S.P.R proved a classic example of this symbiosis. The pair solicited scrutiny for their act through a letter Blackburn had printed in the spiritualist periodical Light on August 26, 1882, entitled "THOUGHT-READING EXTRAORDINARY" (see Appendix I). It boasts of Smith's abilities and solicits "a visit from any Spiritualist or scientific inquirer who may be at Brighton" (392). This letter would shape the direction of the rest of George Albert Smith's life.

Smith and the S.P.R.

The notice published by Blackburn in Light did indeed attract the attention of the fledgling Society for Psychical Research in the persons of S.P.R.-cofounders Frederic William Henry Myers and Edmund Gurney. The S.P.R. was founded earlier in 1882 to provide scientific scrutiny to claims of mediumship, telepathy, haunted houses and the like. Its principle players were a group of well-educated, mostly Cambridge, psychologists, philosophers and scientists, largely disenchanted with mainstream Christianity but hopeful that science would yield fresh evidence in support of God and the human soul. The S.P.R. carefully constructed a rationalist, empiricist posture, and 
would come to host an impressive number of Victorian intellectuals and scientists on its membership list. ${ }^{95}$ The S.P.R. initially formed a series of committees to investigate different psychic phenomena, among them the Committee on Mesmerism, the Committee on Haunted Houses and the Committee on Thought-Reading, swiftly renamed with the less-invasive sounding "Thought-Transference." Myers and Gurney were representing the latter when they came to Brighton to investigate Blackburn and Smith. Justifying telepathy was the S.P.R.'s grand project at the time, and it promoted theories that enfolded other supernatural phenomena within it. The S.P.R. offended spiritualist sensibilities by generally offering "a retheorization of the ghost as a telepathic phantasm" (Luckhurst 2002 182), denying the existence of the intelligent and motivated spectre representing a human being's surviving consciousness in favour of theories relating ghost phenomena to telepathic projections and psychic resonances.

In 1883, F.W.H. Myers coined the word "telepathy" from the Greek for "feeling at a distance." The adoption of such scientific (some would say pseudo-scientific) language was designed to help separate psychical research from spiritualism, theosophy, astrology and the rising interest in Eastern magic. There was a strong drive to promote the S.P.R. as legitimate, mainstream group of researchers, and for a time this worked well, thanks in large part to wide appeal of the idea of telepathy. The S.P.R.'s overarching project in its early existence was to turn telepathy into what Roger Luckhurst calls a "black box," borrowing language from Bruno Latour to describe a concept in science the substance of which is no longer disputed. Writes Luckhurst, "The transformation of thought-reading into telepathy shifted the locale of unaccountable

\footnotetext{
${ }^{95}$ The S.P.R. initially attracted many spiritualists as members but most left in 1886 after a set of exposés of mediums, including the prominent slate medium William Eglinton (Thurschwell 2001 17-8).
} 
transmission from the séance, the parlour, and the stage, to a site they intended to resemble a laboratory" (2002 70). Among the prominent thinkers who quickly became interested in telepathy were physicists like William Barrett, Oliver Lodge and Balfour Stewart and Harvard psychologist/ philosophers Charles Sanders Peirce ${ }^{96}$ and William James. ${ }^{97}$ The S.P.R.'s leadership seemed highly optimistic that telepathy would soon achieve legitimacy. Despite the empirical bearing the S.P.R. chose for itself, the very fact that Myers and Gurney were willing to take the bait of publicity-seeking stage performers like Smith and Blackburn shows how thin the separation between the worlds of science and entertainment truly was.

Blackburn and Smith would be the subject of the second major set of experiments in telepathy conducted by the S.P.R. The first was done with the Creery sisters, Mary, Alice and Maud, the teenage daughters of Reverend Creery of Buxton, Derbyshire. In June 1882, a paper jointly authored by Barrett, Gurney and Myers appeared in Nineteenth Century, entitled "Thought-Reading." It details the results of three-hundred and eightytwo experimental trials with the Creerys, where words or playing cards were transferred from room to room. Writes Luckhurst:

The results exceeded chance, and the statistical probabilities of guessing five or even eight playing cards in a row, as the children occasionally achieved, seemed impossible without further explanation. Since the investigation was of a private middle-class family of a priest, the investigators excluded trickery, collusion, or the vulgar pursuit of notoriety. None of the children exhibited a "morbid state of mind" and they always played in a "perfectly normal" state of consciousness, unconnected to any form of mesmeric trance. Given the exclusion of these possibilities, Barrett argued that this was evidence of thought-reading 'without physical contact or anything approaching it." (2000 68)

\footnotetext{
${ }^{96}$ For an assessment of Peirce's writings on the supernatural, see Braude (1998).

${ }^{97}$ In 1885, James became a founding member of the American Society for Psychical Research. His enthusiastic commitment to psychical research is the major subject of Blum (2006).
} 
The lack of physical contact distinguished these experiments from the "muscle reading" of performers like Bishop. Writes Violet Thurschwell, "The 1881 successes with the Creery girls became the basis for a firm belief by [the S.P.R.] that thought transference was a proven phenomenon" (2001 24). In the flush of this success they looked for more experimental subjects, taking them to Blackburn's letter in Light. Testing on the Creery sisters continued, but the results became less impressive as the test conditions tightened. In October 1887, the sisters were caught cheating during an experiment conducted in Cambridge and confessed to have been employing a set of codes all along (Oppenheim 1985 359-60); this was one of the events that severely damaged the S.P.R.'s quest for credibility in its promotion of the scientific reality of telepathy. We shall see elements of this narrative play out again with Blackburn and Smith.

The first Blackburn-Smith Experiments in thought-transference began in December 1882 in a Brighton hotel room rented by Gurney and Myers. Additional experiments took place in January and April of the following year in London, at the Society's premises in Dean's Yard, Westminster (Beloff 1993 86). The experimental setup (more or less - each source on these experiments varies slightly on minor details) had Smith under a blanket with his eyes bandaged. In a neighbouring room, a word, number or image would be shown by Myers to Blackburn. Blackburn would pace, impressing the figure on his mind, for ten minutes or so. Blackburn would then stand behind Smith and "telepathically" impart the image to him ... whether or not they had any physical contact during this process varies depending on the account. Smith would then take up the pencil and write whatever impressions entered his mind. The most dramatic results were a set of images published in the Proceedings of the Society for 
Psychical Research of pictures shown to Blackburn which were then reproduced by

Smith under the blankets in a rough, inchoate form, but unmistakably as copies of the original images. On other occasions, Blackburn was pricked in various parts of his body and Smith was asked to recognize, via their telepathic rapport, the location of the pain.

Latter-day writers have been extremely critical of the Blackburn-Smith experiments. According to Robert Henry Thouless,

There were various defects in the experimental design, including the fact that Blackburn and Smith were in the room together at the time of the reproduction and could, therefore, have been communicating by means of some code. ESP experiments in which a friend or relative of the percipient knows the right answer before the response is given can never be sound evidence of ESP. (1972 41)

Likewise, Herman Spitz cites the experiments as an example of how "eminent, respected and highly achieving professionals can become deeply enmeshed in obvious fraud and nonsense" (1997 80). At the time, however, Myers and Gurney deemed the experiments a success, and according to Charles Edward Mark Hansel, the experiments "might well have gone down in the history of parapsychology as one of the conclusive investigations providing irrefutable evidence for telepathy" (1996 32) ... were it not for Blackburn's claims, in a series of magazine articles between 1908 and 1911, that he and Smith had faked them. ${ }^{98}$ Apparently Blackburn was under the mistaken impression that all the principles of the events were dead; Gurney and Myers were, but Smith was not. Blackburn claimed that he and Smith took no pleasure in their prank and in fact that:

\footnotetext{
${ }^{98}$ Blackburn published a book called Thought-Reading, or, Modern Mysteries Explained in 1884, disclosing some of their secret of their act. He often gets painted as a duplicitous figure who seduced Smith into their joint fraud: "He was bad, dishonest, treacherous and vicious" (Nicol 1996 25). In the 1890s, Blackburn would relocate to South Africa and have a distinguished literary career there. Stephen Gray, the author of a 1999 book about writing in South Africa, describes Blackburn as "one of South Africa's great writers, and certainly the best of the many colonial Englishmen who recorded life in South Africa at the turn of the century" (13). Gray expresses amazement at discovering that Blackburn "has often been cast a villain and a blackguard, notably by the .. . Society for Psychical Research" (20). Like Smith, Blackburn's multiple careers seem radically removed from each other.
} 
Within three months of our acquaintance with the leading members of the Society for Psychical Research Mr. Smith and myself heartily regretted that these personally charming and scientifically distinguished men should have been victimized; but it was too late to recant. We did the next best thing. We stood aside and watched with amazement the astounding spread of the fire we had in a spirit of mischief lighted. (1)

Later in the article, Blackburn seems to contradict himself, claiming that they saw Gurney and Myers as the same sort of credulous dupes, "spiritualistic cranks," who attended their shows. He states that he and Smith felt a moral obligation to expose them, and found that Gurney and Myers left much to be desired as impartial examiners:

too anxious to get corroboration of their theories to hold the balance impartially. Again and again they gave the benefit of the doubt to experiments that were failures ... They allowed us to impose our own conditions, accepted without demur our explanations of failure and, in short, exhibited a complaisance and confidence which, however complimentary to us, was scarcely consonant with a strict investigation on behalf of the public. (2)

Blackburn describes his and Smith's successful fraud as a mix of luck and the employment of touch-codes such as those pioneered by Bishop. Additionally, he describes them working out a method where he would secretly draw an extra copy of the image he was to "telepathically" transfer on cigarette paper and then slip it into the brass protector of the pencil he slipped to Smith.

For his part, Smith always claimed that the experiments were genuine, first when the S.P.R. dispatched Alice Johnson to Brighton in 1908 to question him about Blackburn's confession, ${ }^{99}$ then again in a piece in the Daily News dated September 4, 1911, and finally towards the end of his very long life when visited by Dr. E.J. Dingwall in 1954 (Hall 1964 173). In the 1911 instance, Smith told an interviewer:

Mr. Blackburn's story is a tissue of errors from beginning to end. In the first place, I most emphatically deny that I ever, in any degree, any way, when

\footnotetext{
${ }^{99}$ This according to C.D. Broad's unpublished manuscript The Life, Death and Work of Edmund Gurney, contained in the S.P.R. archives in Cambridge.
} 
working with Mr. Blackburn, attempted to bamboozle Messrs. Myers, Gurney and Podmore. These gentlemen, long before they met us, had spent years in investigating psychic phenomena, and were aware of every device and dodge for making sham phenomena; they were watch not only for premeditated trickery, but for unconscious trickery as well. You could not deceive them, and the quack mediums hated them in consequence. It makes my blood boil to see them held up to ridicule ... (1)

Smith lists a litany of errors he finds in Blackburn's account, and reaffirms that the experiments were bona fide; in particular he denies that he and Blackburn ever had any physical contact during the experiments that could have allowed a muscle code of the Bishop type. The Smith of 1911 characterizes himself as a rational, sceptical sort but stresses his belief in telepathy, having witnessed and experienced it.

Accounts of the Blackburn-Smith experiments take on a Rashomon quality, with so many conflicting and disputed details of what happened in those Brighton hotel rooms. Did Blackburn and Smith touch hands or not? Did Blackburn pass Smith a pencil or did Smith have his own? Was Blackburn's confession, or Smith's counter to it, in earnest? Most claims of fraud rest on such simple details. The truth will never be known, and perhaps for our purposes it is less important than where these experiments took Smith. He would ultimately prove himself to be useful to the S.P.R. in ways far beyond any supposed telepathic powers. For one, Smith's talents as a hypnotist made him a strong asset. Fraser Nicol says that, "It may well be that in the long history of psychical research Smith was the most gifted hypnotist ever known" (1966 26). He was the usual hypnotist for the Committee on Mesmerism, and among the first experiments was done with the same Brighton baker Fred Wells who was a feature of Smith's stage mesmerism act (Nicol 38), further showing the continuity between stage and laboratory. 
In addition to his hypnotism, Smith had many less sensational skills that made him invaluable to the S.P.R. In his 2009 biography of Myers, Trevor Hamilton terms Smith the S.P.R.'s "factotum" (118), an appropriate term given the number of diverse roles he played for them. He became private secretary to Edmund Gurney, then the Honourary Secretary of the S.P.R., in 1883, a position he held until Gurney's contentious death in 1888, following which he would hold the same position for Myers. Gurney assigned Smith, alongside Frank Podmore, with checking facts for his massive book compiling people's experiences of visual hallucinations, Phantasms of the Living (1886). Smith also interviewed subjects reporting supernatural experiences, and in 1886 he was sent as far as Florida to interview a train driver named Mr. Skilton, whose life was saved by a premonition (Hamilton 249). The S.P.R. used him as a covert investigator too; on one occasion he was tasked with investigating the medium Leonora Piper for evidence of fraud, including searching her luggage and correspondence, an assignment that lead to Smith being beaten (Ibid. 206). So trusted was he that Gurney wrote in a letter to William James on April 16, 1886:

Smith's bona fides is quite beyond all doubt to anyone who knows him. I know him, I believe, quite completely. He has been acting as my private secretary for more than a year - with me for hours a day, \& I believe I know his character as well as, say, you have known that of any one of your pupils. He has been my pupil in a sense. He is blameless \& acute, perfectly steady and self-respecting, devoted to the work, \& excellent at tracing impostures. (Gauld 1968 181)

Articles occasionally appeared under Smith's byline in the S.P.R.'s periodicals, and these give one impression of a Smith as level-headed and sceptical observer. In an 1895 article in the Journal of the Society for Psychical Research, he recounts a performance by American stage mesmerist (or "somnomancer," a term of his own coinage) Samri 
Baldwin. ${ }^{100}$ Smith's account concludes with: "The whole business was most cleverly and successfully carried out here; but careful observers agreed that there was no good proof of occult or psychic powers, whilst, on the other hand, the proofs of conjuring and trickery were abundant" (228). Earlier, the March 1885 issue of the P.S.P.R. contained an account of his visiting a reputedly haunted house on " Road" in Norwich at the behest of its inhabitant, a clerk and his wife whom Smith only refers to as "Mr. and Mrs. X." They claimed to have both heard strange noises (including a voice stating "Hark! the master of this house has returned; we must depart" (314)) and to also have witnessed the apparition of an old gentleman. Smith says of his time there:

I, myself, heard strange sounds, but could account for nearly all of them. They were caused by the next door people going up and down stairs, by their fire being poked, by their voices, by passers in the street, and by the vibrations of distant carts. In addition to these there were some sounds which I could not exactly localise or account for, but they only consisted of such creaks and strains as one is almost sure to hear in a completely empty house, or, indeed, in any other house if intently listened for. (316)

He goes on to relate the opinion of friends and family of Mr. and Mrs. X. that the apparition was a dream image (Mr. X is described by Smith as "imaginative and somewhat excitable" (316) and the wife as "a young woman, very voluble, and fond of ventilating her religious creed" (317)). Smith concludes that "self-deception was at work to a very considerable extent" (316) in this case and the tone of his report suggests he puts next to no stock in supernatural explanations for this particular haunted house.

Likely due to his experiences in Norwich or dealing with similar haunted houses, in 1888, the S.P.R. paid Smith and his new bride to live for nearly a full year in a reputedly haunted house in Brighton. In a touch of morbid irony, Smith's benefactor

\footnotetext{
${ }^{100}$ Baldwin, known as "the White Mahatma," was also a pioneer of handcuff escape tricks. He was one of the interesting performers who both performed spiritualist exposés and professed a belief in psychic powers himself(Hansen 1990 53).
} 
Gurney visited this house to meet with the landlord about the lease during the trip to Brighton on which he died (Smith was away on his honeymoon when this happened). Writes Fraser Nicol, "[during the year of their occupancy] thirty-nine investigators slept in the house on 137 nights. Some of the researchers had mildly odd experiences, but no apparitions were seen. Once, while young Mrs. Smith was kneeling on the hearthrug saying her prayers, a guitar on the wall twanged repeatedly" (14). Hamilton wonders "just what the new Mrs. Smith thought about this as an introduction to married bliss" (249). Difficult to say, but soon enough Laura Eugenia Smith (née Bayley) would be the star of a great many of his films, including some with supernatural themes. She would even enact the role of a ghost herself, which perhaps she was equipped to do, having managed to get more "firsthand" experience with supernatural than most S.P.R. members ever did.

\section{Smith the Filmmaker}

A picture emerges of Smith as a dependable middle-class everyman, well liked by and loyal to his employers, good at picking up new skills and equal to a diverse range of tasks. No doubt these qualities served him in good stead once he and the S.P.R. parted ways and he took up the mantle of an enterprising businessman. In 1892, he acquired St. Ann's Well and Wild Garden in Hove, which had been a park, spa and local tourist attraction for over one hundred and fifty years. Under Smith's management it would expand and improve, offering a wide range of entertainments, including gypsy fortune tellers, monkey houses, productions of Shakespeare and magic lantern presentation. Smith's lantern skills, honed through the 1890s, appear to be a key factor in his transition into filmmaking (Gray 1998 15). In 1897, St. Ann's would become a site for the filming 
and production of films, and Smith would join James Williamson, Esme Collings and Alfred Darling in the "Brighton School." Michael Chanan describes this loose-knit group as middle-class technicians quite removed from the fairground showmen who represented another set of British film pioneers:

not only socially removed from working-class culture, but . . . hardly any closer to the world of high culture, and certainly totally removed from ferment which had come to grip the avant-garde in the closing years of the century, in the struggle against the restrictions of the late Victorian bourgeois mentality . . . For them, artistic culture was essentially decorative and inoffensive. (1996 157)

The extent to which this description fits Smith is debatable, but what is noteworthy here is that nowhere in Chanan's book does he demonstrate any awareness of Smith's showman roots, nor his tenure with the S.P.R. I believe that, on the contrary, Smith's background - theatrical and psychical - is of great importance in assessing his filmmaking.

A tendency exists to describe Smith as a tinkerer and technician and his films as empty mechanical exercises, but in fact his films are frequently clever and playful, with a special interest in using cinema's resources to depict altered states of consciousness and reality. Take Let Me Dream Again (1900), a two-shot film where a man is flirting with an attractive young lady, only to wake up and realize that he is in bed with his fat and unattractive wife. The transition between these two shots is accomplished by allowing the camera to go out of focus and then back in, representing the transition between dream and reality. The effect is unostentatiously achieved and the scenario was innovation enough to be copied by Ferdinand Zecca the following year as Rêve et Réalité. Also in 1900, Smith made The House that Jack Built. It shows a little boy and girl are playing with building blocks, and the boy maliciously topples the elaborate structure the girl has created. But 
then the film is reversed, causing the structure to be magically rebuilt. These films and others through Smith's career display a willingness to explore the technical qualities of cinema to overturn space and time. If Smith is often discussed as a pioneer of linkages that seem proto-classical in character (of editing, close-ups and cut-ins), I think it is equally possible to discuss him as a director fascinated by cinematic disruptions, especially in his trick work. This aspect of Smith's work must owe something the extreme possibilities he was exposed to during his tenure with the S.P.R; as Shane McCorristine states, "the type of films he made ... attest to the interest which the [supernatural] still held for Smith, and also shows the extent to which such subject-matter could be at home both in the S.P.R. scientific experiments on telepathy and the new mass entertainment of ghostly films" (2010 188).

Smith has been called the "English Méliès," a label that is reductive insofar as Georges Méliès and Smith had a reciprocal influence on each other. The two were apparently in regular correspondence in the late 1890s (Salt 1982 282), and John Barnes states that "If Smith was influenced by Méliès, it is equally true to say that Méliès owed a little to Smith" (1983 35), a point he demonstrates by listing a number of scenarios used by Smith before Méliès, including several based on mesmerism and spirit photography. It is documented that Smith purchased a copy of Méliès's The Haunted Castle (1896) in 1898 (Barnes 35), but also that Smith's use of double exposures precedes that of Méliès. Most of Smith's trick films are known to us only from catalogue descriptions, with the odd exception like The X-Ray Fiend, to be discussed in the following chapter, and the charming Santa Claus (1898). The latter film features a complex uses of stop motion and double exposures, which Frank Gray argues constitutes an early form of crosscutting in 
itself (2004 53): ${ }^{101}$ a circular appears insert against a black background to represent the sleeping children's dreams of the arrival of Santa Claus. It then vanishes as Santa himself arrives, fills the children's stockings and vanishes.

Some of Smith's trick films draw clearly on his experiences as a stage performer and at the S.P.R. Perhaps the most obvious is The Mesmerist, or, Body and Soul (1898), displaying a fantastic version of his prior trade. Its catalogue description reads:

"Professor Fluence" in his study is visited by old lady who wishes to see some "Mesmerism." Professor mesmerises little girl and proceeds to draw her "spirit" from her body. Little girl's spirit leaves body and walks over the furniture. "Spirit," which is quite transparent, is finally conducted back to the body, and the mesmerist awakens his subject, much to the relief of the old lady. (Barnes 32)

Smith uses cinematic means to materialize the most outlandish claims invested in mesmerism by its devotees, with the old lady as a figure of the credulous audience. Frank Gray notes that the film:

offers only a parody of the mysterious and wonderful parodies of the mesmerist . . . The mesmerist's power is realized as unworldly, having the ability to contact a spirit through the magnetic fluid and make it visible. Smith presents a comic thoroughly incredible portrait of the work of a mesmerist. The fiction, however, may easily have been interpreted by contemporary spiritualists as a portrait of the possible. As such, Smith's film becomes a projection of what might happen when contact is made with the "other side." (2000 173)

I would add that the film also comically narrativizes of one of the S.P.R.'s central claims: telepathy as a justification for ghost phenomena. Smith's The Mesmerist, despite its comic tone and the fact that it features in Professor Fluence a rather more benign mesmerist than Svengali or Dracula, is perhaps the first cinematic iteration of a tradition

\footnotetext{
${ }^{101}$ Sergei Eisenstein would later refer to double exposures as a technique that materializes cinema's basic ability to create the impression of simultaneity, which Eisenstein largely pursued through the linkage of different shots in montage (1947 79-80).
} 
that would ultimately include Drs. Caligari and Mabuse. ${ }^{102}$ Stefan Andriopoulous's fascinating book Possessed: Hypnotic Crimes, Corporate Fiction, and the Invention of Cinema (2008) deals with the hypnotic criminal in the decades to come, and in those films, as in Smith, we often find double exposure used to represent hypnotic powers. In Fritz Lang's The Testament of Dr. Mabuse (1933), for instance, we see the deceased Dr. Mabuse's projected will envisioned through double exposures as the half-present spectre that steps forward to possess Professor Baum (Otto Beregi, Sr.). As the phantom Mabuse straddles the line between hypnotic projection and supernatural ghost, we witness the survival of conventions that Smith played a significant role in establishing.

Another lost film, Photographing a Ghost (1898), has been the subject of considerable interest. One description reads "Photographer tries to take a picture of a ghost but it won't keep still and finally vanishes" (Barnouw 89), while another says:

Scene: A Photographer's Studio. Two men enter with a large box labeled "ghost." The photographer scarcely relishes the order, but eventually opens the box, when a striking ghost of a swell steps out. The ghost is perfectly transparent, so that the furniture, etc., can be seen through his "body." After a great deal of amusing business with the ghost, which keeps disappearing and reappearing, the photographer attacks it with a chair. The attack is amusingly fruitless, but the ghost finally collapses through the floor. (Barnes 33)

The scene is obviously rooted in the worlds of spiritualism and psychical research with which Smith was intimately familiar. In particular it pokes fun at spirit photography, a practice which will be given more attention in the following chapter. The description's special mention of the ghost's transparency was probably designed to emphasize Smith's signature use of double exposure. In a June 30, 1900 article in Chamber's Journal described Smith as having "introduced several cunning little devices in spirit-raising,"

\footnotetext{
${ }^{102}$ There are other mesmeric scenes in early cinema as well, such as the 1899 Edison film The Mesmerist and the Country Couple, which is also a version of the rube film.
} 
and as a kind of new medium, a specialist in "raising" ghosts (95). At the same time, it alludes to exactly the way ghosts appear in spirit photographs: semi-transparent, halfpresent wisps only nominally belonging to the image that they contain them, resembling (and created via) double exposures. Smith's later Mary Jane's Mishap (1903) - itself a subject of attention for scholars from Sadoul to Barnes, and which Jean Mitry praised as "possessing some very precise action cuts outstanding for its time" (2000 5) - also uses the powers of the double exposure to visualize the spectral in a comic vein. Four minutes long and featuring an impressive twelve shots, including a number of cut-ins, Mary Jane's Mishap stars Smith's wife Laura as the low-class housewife who makes the fatal error of pouring paraffin into her stove and is blown up (up the chimney, in fact). Her headstone reads, "Here Lies Mary Jane Who Lighted the Fire with Paraffin. Rest in Pieces," and mourners are terrified by her ghost stepping from the grave (paraffin bottle in hand), courtesy, again, of Smith's mastery of double exposures.

In H.G. Wells, Modernity and the Movies (2007), Keith Williams observes that the insubstantial ghost in Smith's Photographing a Ghost is echoed in H.G. Wells's short story "The Inexperienced Ghost" (1902), the titular spectre of which resembles a double exposure in the sense that you can see directly through it (40), and that it also has certain resonances with Wells's Invisible Man (52). This is not to suggest that Smith's double exposure ghosts influenced Wells directly, so much that a broader "photographic" understanding of a ghost found expression in the work of both Smith and Wells. Karen Beckman describes Smith's Photographing a Ghost as a meta-commentary on cinema's relationship to photography as means of depicting the supernatural. She says that the film: 
stages a quiet exposure of the inadequacies of the medium of photography in order to assert to supremacy of film in relation to insubstantial matters. As the photographer fails to capture the ghost because of its refusal to stay still, the moving picture delights in the spirit's mobility ... declaring itself the new master of the insubstantial, ectoplasmic body. (73)

Armed with this interpretation, we can understand the film itself as anticipating the claims that Ricciotto Canudo would make decades later, that cinema does indeed have a special capacity for depicting the spectral that goes beyond other media. ${ }^{103}$

Other lost trick films by Smith have the titles that speak for themselves: The Haunted Castle (1897), Faust and Mephistopheles (1898), Cinderella and the Fairy Godmother (1898), Aladdin and his Wonderful Lamp (1899). The Gambler's Wife (1899) has a gambler on the verge of suicide saved by the appearance of his dead wife, perhaps anticipating the moralistic haunting narratives common in the 1920s. In 1899, Smith produced The Haunted Picture Gallery, a version of the pervasive nineteenth century trope of paintings coming to life, blurring the lines between animate and inanimate. Lynda Nead locates this Pygmalionesque fantasy in locations as diverse as the tableaux vivant, Gilbert and Sullivan's Ruddigore, magic acts staged at the Egyptian Hall and an 1894 ad campaign for Dewar's Scotch whisky where a deceased Scotsman emerges from a painting to claim his descendant's beverage. Nead refers to Smith's film as "the ultimate nineteenth century version of The Haunted Picture Gallery" (80) because cinema itself is the full realization of the urge to see pictures come to life. How appropriate that Smith, who had such acquaintance with the world of the supernatural, should be the one to deliver the haunted picture gallery to its "ultimate" medium.

\footnotetext{
${ }^{103}$ Rigby (2006) also briefly mentions Photographing a Ghost as an early use of trick cinematography in England, implicitly positioning it as the first English horror film (14); the film receives similar references in Gifford (1973 14) and Dixon (2010 5).
} 
In 1900, Smith also directed the first cinematic version of The Corsican Brothers.

The 1844 novella by Alexandre Dumas, père, tells the story of two Siamese twins separated at birth who retain a psychic link that lasts beyond death. Dion Boucicault's 1852 stage adaptation included a sensational appearance by the ghost of the murdered brother; the trap door devised to facilitate the ghost's appearance used "counterweighted platforms and slatted shutters to allow an actor to rise gradually through the floor while simultaneously traveling across it" (Jackson 2004 6), became known as "the Corsican Trap." 104 A catalogue description of Smith's The Corsican Brothers reads as follows:

One of the twin brothers returns home from shooting in the Corsican mountains, and is visited by the ghost of the other twin. By extremely careful photography the ghost appears quite transparent. After indicating that he has been killed by a sword thrust, and appealing for vengeance, he disappears. A 'vision' then appears showing a fatal duel in the snow. To the Corsican's amazement, the duel and death of his brother are vividly depicted in the vision, and finally, overcome by his feelings, he falls to the floor just as his mother enters the room. (Heard 258, original emphasis)

There would be numerous cinematic adaptations of The Corsican Brothers with movie stars from Douglas Fairbanks, Jr., to Cheech and Chong, but Smith was first, transposing perhaps the premier ghost melodrama of the nineteenth century stage to cinema with the help of his well-honed ghost effects that could make a man quite transparent and effortless stage visions and other altered states of reality. It is reasonable to suggest, as Gray does (2000 175), that Smith was attracted to this material because of the role psychic rapport plays in The Corsican Brothers, which obviously resonated with a man who played a direct part in the history of telepathy experimentation. A similar case can be made that most of his trick canon, both in terms of subject matter and filmic technique,

\footnotetext{
${ }^{104}$ One might suspect that The Corsican Brothers was an excellent candidate for Pepper's Ghost, but this was not the case, since it called for a ghost who delivers dialogue.
} 
contains echoes of his earlier life as a stage mesmerist, mentalist and as a psychical researcher.

\section{The Uses of Smith}

This chapter has not exhausted Smith's numerous lives; I have paid little attention, for instance, to his roles as a lanternist or astronomer. ${ }^{105} \mathrm{I}$ wish to conclude by paying attention to the uses to which he has been put in film studies. The scholar to have written the most on him is certainly Frank Gray, who has brought admirable historical rigour and insight. Gray's 2000 essay “George Albert Smith's Visions and Transformations: The Films of 1898" pays particular attention to the culture of the supernatural as it manifests in Smith's filmmaking. He speaks of a need to locate Smith

within a broader cultural history of the supernatural in which it was actively investigated and sought ... As a full participant in this history across the $1880 \mathrm{~s}$ and 1890 s, Smith was actively involved in various means to alter the perception of an audience, either through a mesmerist's live performance, or by creating the fantastic through film production. (178)

My debt to Gray's article is clear, and I hope to have extended his insights by locating Smith's fascinating career and filmmaking within the late Victorian culture of the supernatural.

One contentious question around Smith's filmmaking is motivation: when Smith reached back into his history as a mesmerist and a psychical researcher in his filmmaking, what were his intentions? Here we find an interesting difference of opinion. During imagines him still in the persona of the charlatan who, partnered with Blackburn, defrauded Gurney and the entire S.P.R. For During, Smith's trick films continue to mock his gullible old employers. Describing Photographing a Ghost, he says "Smith's

\footnotetext{
${ }^{105}$ The latter is surely relevant to the shifts of perspective provided by his close-ups in films like Seen Through the Telescope.
} 
deceptions—his confidence tricks, if you like—have become mere illusions, which mock his old employers ... In Smith's case, a quasi-political resentment was probably at work . .. Relatively uneducated assistants like himself were dependent on, and even seduced into fraud by, idealistic and naive 'swells' like Gurney" (276). This is a substantial change from the usual narrative, where if Smith is understood as having been "seduced" by anyone, it is Blackburn, but no matter - During seems to have uncritically taken his impression of Smith's character from Trevor Hall. I see absolutely no basis for the claim that Smith is mocking the S.P.R. in his films and in fact I believe the evidence is against it, because Smith repeatedly and consistently refused to admit fraud even when given the opportunity to do so. ${ }^{106}$ True, his supernaturally-themed films are light-hearted and frivolous, as are those of Méliès, and do not carry the weightiness with which the prime movers of the S.P.R. approached supernatural matters, but this light touch does not make for mockery. Unlike Méliès, who staged anti-spiritualist scenarios on both the stage and the screen (Solomon 2010 25-6), Smith refrained from any formal "exposures."

For the opposite viewpoint, we can look to Stacey Abbott. In a footnote to her article "Spectral Vampires: Nosferatu in the Light of New Technology" (2004), Abbott suggests that exposure to the S.P.R.'s way of thinking did much to prepare Smith for filmmaking. She writes that

Smith embodied a more ambiguous relationship between stage performance, film technology and genuine spiritualism [than Méliès] ... the way in which he seamlessly moved between the scientific world of study and analysis of the supernatural to the technological world of stage performance and film magic ... suggests an affinity between these worlds. Many of Smith's films ... explore his own fascination with the occult and use dissolves, superimpositions and other trick effects in order to convey these supernatural phenomena. (228)

\footnotetext{
${ }^{106}$ Tellingly, During briefly mentions the Blackburn confessions but does not mention Smith's rejection of Blackburn's claims.
} 
I welcome Abbott's claim that Smith's choice of supernatural subject matter is rooted in his experiences with the S.P.R. and, less directly, that a familiarity with the claims of psychical researchers helped lead him to filmmaking itself (though the latter claim is obviously more speculative). But I take exception to the implication that Smith is to be understood as a spiritualist "true believer" making films to express a belief in genuine supernatural phenomena. Even though Smith certainly did perform stage séances early in his career (as did a great many performers of the time, Houdini included), I do not understand Abbott's claim of Smith's connection to "genuine spiritualism," whatever that might be, and am forced to wonder if she is conflating spiritualism with psychical research. Performing sceptical investigations of mediums like Leonora Piper and Samri Baldwin was probably the closest Smith ever got to the spiritualist community.

It is worth noting the rhetorical use to which Abbott puts Smith in her article. He is mentioned only in a footnote to the statement that "[in A Spiritualist Photographer (1903)] Méliès uses the dissolve in order to convey the magical process of spirit photography but it also effectively demonstrates how the supernatural can be stimulated through the mastery of technology" (12-3), within an article where F.W. Murnau's masterpiece Nosferatu (1922) is understood as a self-reflexive recognition of cinema's ghostly qualities. For example, Abbott describes Murnau "draw[ing] upon the supernatural potential of editing to suggest the uncanniness of the modern conception of space and time" (18). ${ }^{107}$ Abbott's argument is largely persuasive one, though weakened by her rhetorical strategy of establishing the spectrality of cinema with respect to early cinema and the trick film in particular, but then hopping to a film of 1922 made in a

\footnotetext{
${ }^{107}$ Cinematic vampires are also identified as having a special relationship to cinema's ghostliness by Michaels (1998 67-82) and Thomas (2000).
} 
vastly different industrial and cultural context. Abbott uses Smith as one example among many (including Gorky's "Kingdom of Shadows," of course) to establish an understanding of cinema as ghostly or spectral.

Michael Punt (2006) deploys Smith in a similar way, arguing that early spectators perceived cinema as a "“cinematographic séance' ... [which] confronts not realism but the expectations of scientific naturalism by presenting the believable as inexplicabledespite explanation - in exactly the way that G.A. Smith and the raft of mesmerists, telepathists, and clairvoyants did" (52). Punt's points about the parallels between early cinema spectatorship and the credulous/incredulous patrons of séances have merit, ${ }^{108}$ but his treatment of Smith is riddled with errors. He describes him as stage medium (Smith was principally a stage mesmerist and mentalist) who "began making films in Brighton some time after he was exposed as a fraud" (53); as we have seen, the only event that resembles a public exposure of Smith occurred more than a decade after his turn to filmmaking. ${ }^{109}$ The very fact of Smith's career trajectory and choice of filmic subject matter (and let us not forget that, unlike Méliès, the supernatural-themed trick films represent a tiny minority of his overall output) is turning into something equivalent to Gorky's essay - a proof of cinema's hauntedness that scholars may deploy without closer examination. This is not a tendency limited to scholarship on cinema; in several recent scholarly books on the supernatural, we find Smith mentioned briefly, perhaps for a paragraph or so as part of a cursory treatment of the supernatural qualities of early

\footnotetext{
${ }^{108}$ For a similar approach, see Herman (2006 437).

${ }^{109}$ Punt also refers to Smith's "amusement park," as he terms the pleasure gardens, as "Anne's Wells" instead of "St. Ann's Well."
} 
cinema (Davies (2007 211-2), Warner (2006 270-1)), citing Frank Gray but bringing little of his historical insight and rigour. ${ }^{110}$

Gray has remarked that "History has been unkind to Smith" (2000 178), and this is true insofar as most of his films are lost to the ravages of history. Ghost texts unto themselves, they can be speculated about and extrapolated upon but never studied directly. If the ninety-three year old Smith was there at the opening of the National Film Theatre in 1957 as the standard-bearer for the history of English cinema, "the Father of the British Film Industry" that Michael Balcon termed him (Gray 1996 31), he signified an absence too: not only the loss of so many of his own films, but the loss of a set of effaced histories that entangled mesmerism, psychical research, spiritualism, magic with filmmaking. He needs to be rescued from the reputation hung on him by Trevor Hall, as the fraudster responsible for inspiring the suicide of the Edmund Gurney, as well as from the attitude among too many film historians that he was an inventor, technician and entrepreneur, but in no way a film artist. Finally, he needs to be protected from the rising tide of scholars who would transform him into the human equivalent of the "Kingdom of Shadows" essay, wrenched from historical materiality to become a proof of cinema's ghostliness.

\footnotetext{
${ }^{110}$ In a footnote, Warner states "I have not been lucky enough to see any of Smith's films, and my account is taken from Gray's invaluable article" (411). But it is not a matter of luck: with the exception of Santa Claus (which anyone so inclined may now view on YouTube), none of the films Gray discusses in that article are known to exist.
} 


\section{Chapter 5: Aesthetics of Co-Registration: Spirit Photography, X-Rays and Cinema}

This dissertation has argued that the supernatural qualities of early cinema in part represent points of continuity with the practices from which cinema descended. Thus far, I have constructed versions of this argument with respect to the projected image, with stage magic and (in G.A. Smith's case) with mesmerism and psychical research, and in this chapter, I will make a similar argument with respect to photography. Early cinema's roots in photography are often traced through the chronophotography of Eadweard Muybridge and Étienne-Jules Marey (Braun 1992, 2010, Doane 2002), but instead my approach will relate cinema to spirit photography and X-ray photography. The former used double exposures to represent contact with the spirit world, and the latter, which made its debut almost at the exact same time as cinema, carried profound supernatural implications in its seeming ability to transform living flesh into a memento mori. This chapter explores deep aesthetic and cultural links that spirit photography, X-rays and cinema share through what I dub "co-registration," the depiction of different spatialities and temporalities simultaneously, seemingly collapsed onto a single plane. This discussion follows in part from the previous chapter's work on the double exposure techniques pioneered by G.A. Smith and others, which would become a privileged form for cinematic representations of ghosts, dreams, angels and so on. I have already alluded to the links between cinematic double exposures and the spirit photograph, where the "extras" appear as half-present and insubstantial figures alongside (but not interacting with) the sitters. The major aesthetic feature of most spirit photographs are multiple levels of information displayed together on a photographic surface, the spirit world and 
the human world of matter coming together in a single image but remaining visibly disconnected. ${ }^{111}$ This aesthetic of co-registration provides a concrete visualization of the world view embraced by many spiritualists and occultists: the spirit world ("Summerland" or "the Seventh Heaven" in spiritualist parlance) as another world largely coterminous with our own but invisible and inaccessible except to those specially equipped, either through mediumship or, as in spirit photography, with technology.

In an article called "The Life and Death of the Superimposition" (1946), André Bazin argued that the cinematic use of double exposures to signify dreams or hallucinations is pure convention:

Superimposition on the screen signals: "Attention: unreal world, imaginary characters"; it doesn't portray in any way what hallucinations or dreams are really like, or, for that matter, how a ghost would look... Superimposition can, in all logic, only suggest the fantastic in a conventional way; it lacks the ability to actually evoke the supernatural. The Swedish cinema [such as The Phantom Chariot] probably couldn't get the same results from it today as twenty years ago. Its superimpositions wouldn't convince anyone anymore. $(199774,6)^{112}$

Bazin was correct to the extent that double exposures, so common in the silent era, would on the whole come to represent the supernatural only in comic scenarios, from Here Comes Mr. Jordan (1941) and The Canterville Ghost (1944) to Alice (1990) and Ghost $\operatorname{Dad}(1990)$. But contrary to what Bazin says, there is plenty of evidence to suggest that, in the nineteenth and early twentieth century, the use of double exposure to signify the ghost was more than conventional: people actually believed that ghosts looked that way.

\footnotetext{
${ }^{111}$ Solomon draws attention to use of double exposures to represent disembodied spirits in Houdini's The Man from Beyond (1922) as a point of continuity with the spirit photograph and as evidence of Houdini's ambiguous position relative to spiritualism (2010 104).

${ }^{112}$ A similar sentiment was expressed by Curtis Harrington in 1952: "a man double-exposed so that he can be seen through looks not so much as we imagine a ghost might, but rather as a man double-exposed" (2000 9). For an intriguing discussion of superimpositions, Bazin and Godard, see Morgan (2011).
} 
A 1903 issue of the magician's journal Sphinx ran an article by E.H. Thornton entitled "Ghosts Have No Thickness." It tells us that

A real ghost has only two dimensions. He may be long or short, or wide or narrow, but he will not be either thick or thin. In fact, he will be so thin that it will not be thinness at all. It won't be anything. This is one of the results of investigations undertaken by the Society for Physical (sic) Research. The society does not affirm that much is known about ghosts and does not explain how the dimensions of ghosts have been established ... The real ghost, the one of two dimensions, is a harmless individual. He looks more like a magic lantern picture than anything else and is about as vicious ... (111)

So entrenched, it seems, was the relationship between the photograph and the supernatural that even ghosts were understood as possessing the qualities of photographs. Also striking are the number of ghost stories in the nineteenth century ${ }^{113}$ that either narratively involve photography or photographers (like Nathaniel Hawthorne's The House with Seven Gables (1851)) or use photographic imagery to describe ghosts. Allen W. Grove uses the example of the governess in Henry James's The Turn of the Screw (1898) seeing the evil ghost Quint "as definite as a picture in a frame," and later seeing him reveal his face against a glass like a portrait subject (1997 155). An early X-ray scientist named Silvanus Thompson prophesized that "we shall now be able to realize Dickens's fancy when he made Scrooge perceive through Marley's body the two brass buttons on the back of his coat" (Pamboukian 2001 58), using a metaphor of spectral insubstantiality drawn from a prominent ghost story to characterize the X-ray's powers. ${ }^{114}$

\footnotetext{
${ }^{113}$ And well beyond. See Curtis (2008 123-37) for a discussion of photographic imagery in ghost films, as well as more general thoughts about the relationship of photography and haunting. The Thai film Shutter (2004) is a particularly good example.

${ }^{114}$ We might reflect here too that Pepper's Ghost, which appeared on a pane of glass to the amazed audience, must have had a two-dimensional appearance as well as a wispy, half-present figure seeming to interact and yet be apart from the theatrical space. It no doubt had aesthetic connections to the spirit photograph, which debuted at almost the same time across the Atlantic.
} 
The X-ray, discovered by Wilhelm Conrad Röntgen on November 8, 1895, would quickly become entangled with cinema in ways that went far beyond the historical accident of having debuted in the same year. ${ }^{115}$ Röntgen's discovery triggered what one scholar has termed "the most immediate and widespread reaction to any scientific discovery before the explosion of the first atomic bomb in 1945" (Henderson 1988 324). Even as the X-ray was heralded as a new tool for science that seemed to realize the fantasy of objective, mechanical representations apart from human agency (Daston and Galison 1991, Knight 1996), its gloomy aesthetic fueled supernatural speculations. The most shocking quality of X-ray images of humans seems not to have been that they showed bones but that they appeared to turn bodies inside out, co-registering depths and surfaces together. Bones appear most prominently in X-ray images of human forms because they are the densest part of our bodies, but they appear surrounded by shadowy impressions of skin and tissue. Writes Akira Lippit:

The erasure of the surface (which paradoxically renders the world and its depths and interiorities superficial), the disappearance of a discernible interiority, plunges the subject into a 'universal depth.' A total and irresistible depth, everywhere. The world is no longer only outside, but also within, inside and out . .

In the X-ray image, the body and the world that surrounds it are lost. No longer inside nor out, within nor without, body and world form a heterogeneous one ... You are in the world, the world is in you. The X-ray can be seen as an image of you and the world, an image forged in the collapse of the surface that separates the two. (43)

In addition to the bodily and spatial collapse that Lippit indicates, we might understand the X-ray as a powerful form of temporal collapse as well. It presents in co-registration

\footnotetext{
${ }^{115}$ For treatments of early cinema's relationship with the X-ray, see Cartwright (1995), Crangle (1998), Jülich (2000, 2008), Tsivian (2004), Lippit (2005), Tosi (2005), Natale (2006), and Elder (2008). The Xray and cinema shared presentation venues and personnel, and were so linked in the public mind that it is common to find them mentioned the same breath by commentators of the time. If anything, the X-ray's initial profile was superior: it, not cinema, was dubbed "The New Photography" by the press.
} 
the lively present and the "fate that awaits us all" (as Robertson described the image of a skeleton in his Phantasmagoria shows (Barnouw 19)), showing us life and death, now and the deathly "later," in a single image. Like the spirit photograph and the double exposure aesthetic in cinema, it brings to the fore the deathly and supernatural subtexts that haunted photography from its inception.

\section{Photographs of the Invisible}

A pair of historical anecdotes will help illuminate the hold supernatural photographs had on the cultural imagination around the time of cinema's debut. On June 18, 1896, the New Zealand Journal printed an article with the suggestive title "Edison and Röntgen Outdone." The article shows a photograph of a field that seems to show a pair of shadowy ghost horses and riders jumping over a fence. It was taken in Waipawa, New Zealand by Mr. W.S. Russell, an employee of the Bank of New Zealand. The article explains that a pair of jockey boys died in a jumping accident on the same site, and that the pictures were taken on July 13 , the anniversary of the tragedy. A provocative subheadline reads, "The ghost question settled"; the photograph is understood as presenting positive and indisputable proof of the supernatural. Five months later, however, the article would be reprinted in W.T. Stead's spiritualist journal Borderland (445-6) alongside a letter from another New Zealand photographer dismissing the photo as an accidental double exposure that any photographer might explain. The image is captioned, somewhat uncharitably, "A 'faked' spirit photograph" (446). By Stead's time, the spirit photographs pioneered in the 1860 s seemed antiquated and unconvincing, and discussions of photography's supernatural powers now centered on more exotic images, including "dorchagraphs," images produced by ghosts directly onto photographic plates 
without a camera, "luminous light photographs" produced from photographic plates left in a darkened séance room, and images purporting to document human thought itself. Desire for the latter led directly to one of science's most famous hoaxes. In September 1896, Popular Science Monthly carried an article by scientist David Starr Jordan entitled "The Sympsychograph: A Lesson in Impressionist Physics." Jordan was one of the most respected scientists in the United States at the time and the president of Stanford University. The article purported that the Sympsychograph was an image recorded directly onto undeveloped photographing film by human brain waves. It was produced, the article claimed, by the "Astral Camera Club" that, inspired by Röntgen's discovery, set out about its own experiments to prove the superiority of thought over matter. The experiments, the article indicates, have "proved" that "[j] ust as one sensitive mind at a distance receives an image sent out from the psychic retina, so too could the same image be concentrated on a photographic plate" (597). They conclude that "the invisible rays of Röntgen are not light in the common sense, but akin rather to the brain emanations, or odic $^{116}$ forces, which pass from mind to mind without the intervention of forms of gross matter as a medium, and to which gross matter in all its forms is subject" (598).

The seven members of Jordan's Astral Camera Club, the article tells us, performed an experiment (on April $1^{\text {st }}$ ) in combining multiple brain emanations onto a single photographic plate by thinking about a cat: "They were not to think of any particular cat, but of a cat as represented by the innate idea of the mind or ego itself" (600). The article reproduced the image that purportedly resulted from: a set of double exposures melding several images of different cats into a murky grey blur. The article

\footnotetext{
${ }^{116}$ The odic or odylic force, also sometimes called the von Reichenbach force after its purported discoverer, Baron Carl von Reichenbach, was a hypothetic life force often used to justify mesmeric rapport.
} 
goes on to say that, "This achievement, like the earlier ones of Odin, Röntgen, Rogers, and Lee, opens great vistas for future scientific research. The next experiment will be by similar means to photograph the cat's idea of man" (601). Jordan's hoax was, if anything, too effective. The next issue acknowledging the falsity of what its perpetrators believed was an obvious joke, but by then Popular Science Monthly had received many letters from credulous readers. Jordan would recall in his autobiography that "One clergyman even went so far as to announce a series of six discourses on 'The Lesson of Sympsychography,' while many others said they welcomed the discovery as verifying what they had long believed"' (Lindskoog 1992 173). To understand the willingness of the public to be fooled by amazing new photographic techniques, we can look to the title of the New Zealand Journal article: "Edison and Röntgen Outdone." The photograph of the ghost horses outdoes both cinema and the X-ray; new forms of photography were so sensational that supernatural photography seemed plausible, even likely. It is no wonder that spiritualism held such an important place for photography in its rhetoric.

Recent scholarship has done much to excavate the significance of spiritualism in the development of modern culture. ${ }^{117}$ Spiritualism staked its appeal, as Ann Braude writes, on its ability to "provide empirical proof of the existence of the soul," and “"scientific' evidence of religious truth," asking people to "become 'investigators,' to observe 'demonstrations' of the truth of Spiritualism produced under 'test conditions' in the séance room" (2001 6). Be they phantom knocks, the voices in séances, phantom writing on slates, mysterious trumpet sounds, full materializations, ectoplasm or any other strange practices mediums attempted in their long history, spiritualism always

\footnotetext{
${ }^{117}$ Useful sources on spiritualism not otherwise cited in this dissertation include Owen (1989), Cottom (1991), Pimple (1995), Morita (1999), Weinstein (2004), Weisberg (2004), Tromp (2006), Blum (2006) Bennett (2006, 2007), Gomel (2007), McGarry (2008) and Vinitsky (2009).
} 
invited spectators to judge the evidence personally. Spirit photography provided more tangible and lasting evidence for the supernatural than most practices:

Nothing appeared more objective, after all, than an image captured through the camera's lens. Telekinesis, automatic writing, trance speech, and levitation could be ascribed to the medium's own powers of mind, but the ghostly images in these photographs, which sitters often identified as deceased loved ones, seemed incontrovertible evidence of disembodied souls. (Monroe 2002 162)

Spirit photographs and other forms of paranormal photography ${ }^{118}$ have received considerable attention of late, including numerous gallery exhibitions, a 2003 special issue of Art Journal, and books by Martyn Jolly (2006), John Harvey (2007) and Louis Kaplan (2008). ${ }^{119}$ Nancy M. West describes the spirit photograph as "a kind of selfreflexive commentary - a means of bringing to the surface photography's uncanny subtexts. Bizarre and often grotesque, these images flaunted the implicit questions the medium has raised about representation and death" (1996 173). West's observations help locate spirit photography within the history of photography, and in particular the relationship of photography to mortality and loss. This subject has been explored by Roland Barthes in Camera Lucida (1981), of course, but also by Rosalind Krauss (1978), Lynne Kirby (1995), Tom Gunning (1995a), Eduardo Cadava (1997), Geoffrey Batchen (1999), Jean Ma (2008) and others. "In fixing or immobilizing the object," writes Mary Ann Doane, "transforming the subject of its portraiture into dead matter, photography is always haunted by death and historicity" (Doane 1990 223). The idea that photography "is a mode of bereavement [that] speaks to us of mortification ..." (Cadava

\footnotetext{
${ }^{118}$ This expanded label would include ectoplasm photography (see Schoonover 2003), aura photography, Kirlian photography, thoughtography, Nensha, and so on. Krauss (1995) is likely the most broad and inclusive treatment of paranormal photography available.

${ }^{119}$ Additional sources on spirit photography include Jay (1991 7-29), Gunning (1995a, 2003a, 2008a), Monroe (2002 esp. 162-8, 171-3, 180-5), Cox (2003 112-35), Tucker (2005 159-93), Leja (2006 21-58), Cadwallader (2008), Wojcik (2009), and Arias (2010).
} 
11) has considerable heritage: consider Balzac's assertion in Cousin Pons (1847) that the photograph has proved that "a man or a building is incessantly and continuously represented by a picture in the atmosphere, that all existing objects project into it a kind of spectre which can be captured and perceived" (131), and Jules Michelet's reaction to seeing his portrait for the first time in 1850: "The daguerreotype. It saddens me, not to see myself thus with respect to form, but to see myself a corpse, without my inner fire or my spirit" (qtd. in West 174). The photograph, like the X-ray many decades later, was interpreted as supporting long-held occult speculations and seen as a powerful new tool for those who endorsed the supernatural.

In addition, photographs had a long history of creating blurred and half-present images through the exposure and development processes. While most photographers sought to mitigate these technical shortcomings, others embraced them; Julia Margaret Cameron made slightly blurry, ethereal portraits her signature style (Grove 148-50, Hill 2002). From at least the 1840 s, images of transparent ghosts sharing space with living subjects was considered a major challenge for amateur photographers and were often used in magic lantern images. As I noted in Chapter 2, the novelty ghost photograph was even endorsed by David Brewster in his 1856 book The Stereoscope: Its History, Theory, and Construction. The photographer's art, Brewster wrote, "enables him to give a spiritual appearance to one or more of his figures, and to exhibit them as 'thin air' amid the solid realities of the stereoscopic picture" (205). ${ }^{120}$ If Brewster stressed these double exposures as effects for the purpose of amusement only (within his broader understanding of optical trickery in service of enlightenment values), the techniques he outlined were

\footnotetext{
${ }^{120}$ See Kaplan (2008 27-31), Tucker (71-3) and Gunning (2007 112) for the relationship of spirit photograph to other novelty photographic techniques.
} 
nonetheless those used for spirit photography. Popularized (if not precisely invented) in the early 1860 s by New York photographer William Mumler, ${ }^{121}$ spirit photography would be a spiritualist practice for many decades, not fully dying out until after World War I.

By the 1897 publication of Albert Hopkins's guide Magic: Stage Illusions, Special Effects and Trick Photography, the term "spirit photography" was generic enough to refer to a class of trick photography; anyone may produce a "spirit" photograph that does not claim actual supernatural origins. Hopkins's guide denounces spiritualists as frauds and baits them at every occasion, but this was only necessary because there were indeed still spiritualists producing spirit photographs and claiming them as evidence of a world beyond. The practice would still have devotees in the first decades of the twentieth century, notably Ada Deane, William Hope and the "Crewe Circle" in England, though it may be fair to say that the photographs themselves now served more as ritual objects among the faithful than evidentiary documents meant to convert outsiders to spiritualist values. ${ }^{122}$ Owen Davies has suggested that the X-ray and cinema helped put an end to spirit photography as a serious practice (2007 204), and to some extent this may be true. I do not think, however, that it is most productive to conceive of cinema and the X-ray as having usurped the spirit photograph's status as supernatural photography, but rather to regard of the three of them as united through the aesthetic of co-registration.

Seeing Your Own Grave: The X-Ray, Death and the Supernatural

${ }^{121}$ For Mumler's predecessors, see Krauss (1995 99-101). The heyday of the spirit photograph was in the $1860 \mathrm{~s}$ and $1870 \mathrm{~s}$, when they were at the centre of extensive debates about authenticity and even legality. William Mumler was acquitted after a sensational trial in 1869 due to lack of evidence, but his French equivalent, Edouard Buguet, would not be so lucky, and received a year in prison and a stiff fine after confessing to fraud (Monroe 2002 180-5).

${ }^{122}$ For a thorough treatment of the "later life" of spirit photography, see Jolly (90-139). 
On November 8,1895 , a month and a half before the Lumière cinematograph would make its public debut at the Grand Café in Paris, German physicist Wilhelm Conrad Röntgen made a fortuitous discovery. Working in his home laboratory in Würzburg, Röntgen was experimenting with running electrical charges through a variety of vacuum equipment. Running a charge from a Ruhmkorff coil through a Crookes tube in a room that was kept dark to test the opacity of its cardboard cover, Röntgen discovered, quite by accident, a fluorescence left on a nearby bench that "look[ed] like faint green clouds ... Highly excited, Röntgen lit a match and to his great surprise discovered that the source of the mysterious light was the little barium platinocyanide screen lying on the bench. He repeated the experiment again and again" (Glasser 1934 9). Röntgen named his discovery " $x$ Strahlen," "X-rays," a designation that he never expected to outlive their status as "unknown." 123 The persistence of the label in at least some languages speaks to the extent to which a popular understanding of Röntgen's discovery was and remains supernaturally tinged. Biographer Otto Glasser argues that Röntgen initially conducted his experiments in secret because of his awareness of the supernatural implications of the rays made him fear for his professional reputation (38). The first widely distributed X-ray image was a picture of Röntgen's wife's hand, produced on December 22, 1895. Its most prominent feature is a wedding ring, denser than bone; this image would be widely imitated as fashionable women had their own

${ }^{123}$ Seventeen years would pass before the nature of X-rays were firmly determined to be waves like light waves but with a shorter wavelength than visible light. Prior to that there were several competing theories. Other terms used for X-rays images included "shadowgraphs," "skiagraphs" and the slightly more general "radiographs." 
hands X-rayed. ${ }^{124}$ As Lippit puts it, "Berthe Röntgen's X-rayed hand in 1895, marked by the exteriority of her wedding band, signaled the entry of light into the human body and the illicit marriage, as it were, of radiation and photographic culture" (83).

Where most scientific discoveries spread via trade journals and evade major public interest at first, news of the X-ray spread through the popular press and public exhibition, creating great demand in the late Victorian audience hungry for spectacle and novelty (Schedel 1995 342-3, Mussell 2007 78). In his non-fiction book Profiles of the Future (1974), Arthur C. Clarke separates scientific discoveries into "the expected" and "the unexpected," with the X-ray as a quintessential example of the latter: "No one had ever imagined or predicted such a thing; that one would be able to peer into the interior of the human body ... was something even the most daring prophet had never suggested" (35-6). Anything could be X-rayed, and, in the first years of the X-ray craze, a great many things were. But the X-rays images that attracted the most widespread interest were those of human bodies: "The sensation of 'seeing one's own death' was probably the most immediate reaction to X-ray images, and, morbid as it is, it was also responsible for the general fascination with X-ray as spectacle" (Tsivian 1996 84).

Scholars like Grove (1997) and Harvey (2007) have drawn direct connections between X-ray photography and spirit photography. To quote the latter:

Early radiographic images bore an uncanny resemblance to the soft, milky and translucent apparitions in spirit photographs. Like spirit photographs, radiographs revealed reality beyond the surface of the physical: things that were previously and normally out of sight could now be perceived ... Each represented a vision of our mortality: the radiograph shows a skeletal image (the intimation of our final physical state), which we carry around inside ourselves, even as we live; the 'extra' portrays a depth of being that not even X-rays could fathom - the

\footnotetext{
${ }^{124}$ An 1896 article in Pearson's Magazine features the X-rayed hand of the wife (unnamed) of Professor Spies of the Urania Institute of Berlin, reflecting the pervasiveness of the image of female hands (Dam 413), and, as I shall explore in the subsequent chapter, female skeletons.
} 
psychical state, the soul or spirit that, it was supposed, survived physical death. (74)

Aware of these parallels and accustomed to appealing to new technologies and scientific discoveries, spiritualists and occultists found a special value to the X-ray. James Coates's 1911 book Photographing the Invisible states:

To say that the invisible cannot be photographed, even on the material plane, would be to confess ignorance of facts which are commonplace - as, for instance, to mention the application of X-ray photography to the exploration of the muscles, of fractures of bones, and the internal organs. Astronomical photography affords innumerable illustrations of photographing the invisible. $(2)^{125}$

Photographs of inner and outer words are equally available to the rhetoric of spiritualists and occultists, who claimed that the X-ray confirmed of some of their basic premises, including the inadequacy of unaugmented human vision to assess the invisible world that lies around us. ${ }^{126}$ Camille Flammarion wrote in his 1900 work $L$ 'Inconnu:

The late discovery of the Röntgen rays, so inconceivable and so strange in its origins, ought to convince us how very small is the field of our usual observations. To see through opaque substances! to look inside a closed box! to see the bones of an arm, a leg, a body, through flesh and clothing! Such a discovery is, to say the least, quite contrary to everything we have been used to consider certainty. (qtd. in Henderson 326)

Likewise, W.T. Stead held that the X-rays represented "the latest inventions and scientific discoveries [that] make psychical phenomena thinkable" (qtd. in Luckhurst

\footnotetext{
${ }^{125}$ Similarly, the article entitled "Psychic Photography" written by Andrew Glendinning for the July 1896 issue of Borderland contains subheadings like "From the Roentgen Rays to the Existence of the Soul" and "The Faith of Science in the Invisible."

${ }^{126}$ The occult implications of the X-ray may be understood within a new climate of "modern alchemy," to borrow the title of Mark S. Morrisson's excellent 2007 study of the role occultism played in the emergence of atomic science. Occultist thought converged with several exciting scientific discourses in the late nineteenth century. Within months of Röntgen's discovery, Henri Becquerel would discover radiation. The Curies would discover radium the following year, and within the next decade, modern physics and atomic science would begin to take shape. These new discoveries gave fuel to the already thriving modern occult revival, a fact that the scientists were not unaware of. Morrisson states that: "the broad revival of interest in alchemy in the late nineteenth and early twentieth centuries ... gave chemists a trope that influenced its public reception and its sense of its own identity and contributed to its early understanding and portrayal of radioactivity's significance" (9). The scientists ultimately owed the occultists quite a lot, with their outré rhetoric doing part of the work of preparing the public for the modern world of scientific wonders.
} 
2002 139), and French spiritist and scientist Hippolyte Baraduc was inspired by the Xrays to investigate what he called "soul photography" (West 194, Monroe 2002 249). ${ }^{127}$ Others extended the concept of X-rays by postulating "V-rays" (Krauss 1995 61-4) and "X"-rays" (Ibid. 80-6), or tried to retroactively tether X-rays to existing mystical hypotheses: an article entitled "Röntgen's Vindication of Reichenbach" that appeared in an 1897 issue of the Borderland argued that X-rays were in fact the discredited Odic or Odylic force postulated by Baron von Reichenbach forty years earlier.

Approached from another angle, the supernatural heritage of the X-ray comes legitimately because of the role played by the early vacuum tube called the "Crookes tube" in its invention (Grove 164). Its inventor, William Crookes, was a famed chemist, the discoverer of the element thallium and the inventor of the radiometer. He was also a spiritualist and an early proponent of psychical research (I will discuss his notorious reports on mediums in the next chapter). The Crookes tube and radiometer were invented as part of his profoundly spiritualist scientific investigation into "the fourth state of matter," "Radiant Matter." In an August 22, 1879 speech before the British Association for the Advancement of Science, Crookes's language was draped in exalted mysticism:

We have actually touched a border land where Matter and Force seem to merge into one another, the shadowy realm between Known and Unknown which for me has always had peculiar temptations. I venture to think that the greatest scientific problems of the future will find their solution in this Border Land, and even beyond, where it seems to me, lie ultimate Realities, subtle, far-reaching, wonderful. (Raia-Grean 2008 71)

As his biographer William H. Brock has noted, Crookes's real and lasting contributions to science were to a considerable degree products of his occult explorations (2008 209). In 1896, Crookes became president of the S.P.R. and in his presidential address he framed

${ }^{127}$ See also Gibbons (1981 139-40) and Krauss (1995 51-7). 
the discovery of the X-ray as a crux moment in the history of science that will allow it to proceed in supernatural directions (Gunning 2008a 63). Crookes was the living embodiment of the supernaturalized Victorian science, and so his indirect contribution to the X-ray's discovery was appropriate.

As advocates for the scientific character of the supernatural, Coates, Crookes, Stead, Baraduc and Flammarion all received the X-ray warmly as a tool in their rhetorical arsenal. For others, the register of the X-ray's supernatural qualities was much less positive: it was seen as a disturbing and potentially terrifying portent of death. The most famous invocation of the X-ray image as a spectre of death comes from Thomas Mann's The Magic Mountain, with the famous lines “Spooky, isn't it? Yes, there's no mistaking the whiff of spookiness" (216). This is said by sanatorium director Behrens just after the protagonist, Hans Castorp, has looked at an X-ray image of his own hand, the paradigmatic X-ray image, bedecked by an heirloom ring:

Hans Castorp saw exactly what he should have expected to see, but which no man was ever intended to see and which he himself had never presumed he would be able to see: he saw his own grave. Under that light, he saw the process of corruption anticipated, saw the flesh in which he moved decomposed, expunged, dissolved into airy nothingness - and inside was the delicately turned skeleton of his right hand and around the last joint of the ring finger, dangling black and loose, the signet ring his grandfather had bequeathed him: a hard thing, this ore with which man adorns a body predestined to melt away beneath it, so that it can be free again and move on yet other flesh that may bear it for a while. $(215-6)^{128}$

Though Mann's eloquence is unmatched, the sentiment is not sui generis. When Berthe Röntgen saw the X-ray of her left hand, she is said to have shuddered at the image presaging her own death (Glasser 399); the skeletal hand that Castorp encounters harkens back, of course, to the first widely distributed X-ray image. A newspaper editor in Graz

${ }^{128}$ See Danius (2000 196-202) for a thorough discussion of Mann's use of X-ray imagery. 
allowed Professor P. Czermak to make an X-ray image of his head, "and later, after he had seen the picture, he 'absolutely refused to show the picture to anybody but scientists.' 'He has not closed an eye,' the report continued, 'since he saw his own death"' (Ibid. 40). Another 1896 account of the X-ray appearing in Transactions of the Colorado Medical Society said: "As the skeletal fingers came gradually forth from the blank plate, he felt a sort of creepy sensation, as though it was some ghostly hand beckoning him from another world - and it was another world; a new scientific world" (qtd. in Howell 1995 138), and a Life magazine cartoon from February 1896 shows a photographer taking the picture of the image of a farmer holding his scythe before a rising sun. The image is friendly and bucolic, but in the inset marked "Röntgen," it becomes a figure of death instead, a skeleton holding a scythe (Glasser 42). ${ }^{129}$ Mann's novel (and perhaps even more strongly, Roger Corman's minor classic $X$ : The Man with X-Ray Eyes (1963)) ${ }^{130}$ is also anticipated by a hack story called "Röntgen's Curse" by C.H.T. Crosthwaite that appeared in Longman's Magazine in 1896. In this tale, a scientist gives himself X-ray vision that he cannot switch off, and is faced by such horrible visages as his wife:

Instead of the comely face with its loving smile, a grinning skull, all the more dreadful because it was alive. Instead of the shapely figure, a ghastly skeleton, whose bony hands were outstretched to touch me. In the most tragic events there is sometimes an element of the ludicrous, so there was something of the ridiculous in this horrible travesty of life. There were hairpins hovering, as it were, over the skull, and a necklace of gold floating round the bones of the neck, moved by breathing, yet appearing to touch nothing ... The rings she wore encircled

\footnotetext{
${ }^{129}$ Of course, the "deathly" qualities of the X-ray would take on a different inflection once it became clear that the rays were in fact dangerous, capable of inscribing themselves on the bodies of their subject in unexpected ways, causing nausea, hair loss, skin peeling and burning and equally unpleasant symptoms. Most early experimenters would display these symptoms to some degree or another. The victims of the Xray were numerous, and became recorded in the annals of medical history as martyrs who suffered or even died to further the cause science (Herzig 2005 85-100).

${ }^{130}$ Fantasies of X-ray vision circulated long before Superman's 1938 debut: an 1899 article in the Aberdeen Weekly Journal claimed that a Massachusetts boy named Afley Leonel Brett has gained the power to see "with all the wonderful faculties of the Röntgen Rays" (6), but only for fifteen minute intervals when hypnotized by his father.
} 
without touching the bones of her fingers. It was a skeleton masquerading in the skeleton of a dress. (478)

Even when these takes on the X-ray are facetious, pulpish or comical, they narrativize the very real anxiety that many people seemed to feel with respect to the X-ray's amazing power to co-register depths and surfaces, life and death, on a single surface, the property it shares with the spirit photograph before it and the cinematic double exposures that followed.

\section{X-Ray Aesthetics in Magic and Theatre}

Given the sensational public reactions they provoked and their occult affinities, it seems only natural that X-rays would find a place in the magician's arsenal as well as that of the spiritualist. The aforementioned Hopkins guide contains a section called "The Neoöcultism" that states: "The X rays, after becoming the indispensable coadjutors of surgeons, and even of physicians, are now competing with the most noted mediums in the domain of the marvelous" (1897 96). The author suggests that a new form of theatricalized imitation of a séance could be rigged utilizing the X-ray. It calls for a Ruhmkorff coil and Crookes tube hidden from the audience's immediate view behind a wall or curtain, as well as a skeleton covered with zinc sulphide hidden beneath a black curtain (as well as a set of props similarly treated). The trick is described thus:

... a diner (who is doubtless near-sighted, since he wears eyeglasses) is about to do justice to his breakfast. Armed with a knife and fork, he attacks his beefsteak; but he is assuredly a greater eater than drinker, since he contents himself with water, while his light consists of a single candle ... Let us now put out the light and set the Ruhmkorff coil in action. What a surprise! A plate, a glass, a water bottle, and a candle shine in space with the light of glow-worms. A sinister guest in the form of a skeleton sits opposite the place occupied by the near-sighted gentleman, who has disappeared, and whose eyeglasses alone have held their own before this ghastly apparition. (99) 
Whether or not the Neoöcultism was ever put into practice on the stage, or even could be, is uncertain; it would be very elaborate, expensive, and deleterious to the health of the unfortunate actor bombarded with radiation. Nonetheless, the Neoöcultism indicates how the figure of the skeleton that had existed in the hands of magicians and lanternist for so long becomes newly relevant and justifiable through the context of the X-ray (a point to which I will return next chapter). Hopkins's guide states that "such scenes may naturally be varied to infinity, and the spirit of invention is so fertile, there is no doubt that before long ladies will be giving a place in the programme of their soirées to this up-to-date spiritualism" (99), displaying the complex links between X-rays, stage magic and spiritualism.

More often, magic acts did not use actual X-rays but borrowed X-ray aesthetics in service of amazement. In 1897, an X-ray themed act called "Les Rayons Röntgen" was staged at the Théâtre Robert-Houdin under Georges Méliès's management. A striking poster survives, reproduced by Tsivian (1996 90), which consolidates many key tropes associated with the $\mathrm{X}$-ray (perhaps most pointedly, its gendering). It shows a giant $\mathrm{X}$ radiating rays towards a well-dressed woman, who also has an $\mathrm{X}$ hovering above her head and string of X's along her middle. A man in evening wear stands nearby and points at her with both hands in a highly theatrical fashion. Some glowing scientific apparatus behind him further links the male figure with the magical technology, marking him as an amalgam of scientist and magician. The woman serenely points upwards to the giant $\mathrm{X}$ in the upper left corner; she is simultaneously the subject of the X-rays and their personification. Meanwhile, the omnipresent image of a skeletal hand is displayed on an easel at the front of the image. 
Possibly the most elaborate use of X-ray aesthetics for entertainment in the $1890 \mathrm{~s}$ occurred elsewhere in Paris, at the Cabaret du Néant, a sort of up-to-date Phantasmagoria. ${ }^{131}$ Its success in Montmartre was such that a chapter opened in New York City, and this venue was the subject of an article in Scientific American on March 7, 1896. ${ }^{132}$ As the article explains, spectators followed an attendant dressed like a monk to a black-walled restaurant with coffins as tables, the waiters in funeral garb and a chandelier that appeared to be made of bones of skulls. The room was decorated with

pictures to which the spectator's attention is called by the lecturer. Seen by the light of the room these pictures are ordinary scenes, but a new aspect is given to each when lights directly behind it are turned on; the figures in it appear as skeletons, each picture being in fact a transparency giving a different effect as it is lighted from the rear or as seem simply by reflected light. (152)

This is a common register of the X-ray's redefinition of the human body: the dirty secret of bones hiding beneath the facade of flesh cannot be maintained long. In the second chamber, which the spectators would enter to the sounds of a funeral march and tolling bells, an even more dramatic exposure along these lines would occur.

The second chamber, the account tells us, was very dark, the walls painted black, and smoking was not allowed because the trick that transpired within depended on an extremely clear atmosphere. A coffin stood at the back of a small stage. One of the audience members was requested to stand in it. Then, in view of the audience, he would to fade away, his image replaced by that of a skeleton. Scientific American captions their illustration of this feat with "An X Ray Illusion upon the Stage—Conversion of a Living Man into a Skeleton." The skeleton was in fact a painting of a skeleton kept just offstage,

${ }^{131}$ The Cabaret fits with the gloomy character of fin de siècle Paris described by Schwartz (1998 esp. 4488).

${ }^{132}$ See Pierson for a treatment of Scientific American's significance in the late nineteenth century (33-46), including a brief treatment of the Cabaret du Néant article (43). For a description of the Paris chapter, see Morrow (1899 264-76). 
illuminated by a set of Argand burners and reflected onto a pane of glass that separates the coffin and the audience. By carefully lowering one burner and increasing the other, one image appeared to replace the other:

The illusion is perfect to the outer audience; the one in the coffin sees absolutely nothing out of the common. His interest, if he knows what is going on, is centered in watching the changing expression of the spectators, being increased by the fact that at their period of greatest astonishment, he is absolutely invisible, although directly before them and seeing them more plainly than ever. After the restoration to life one or more auditors are put through the same performance, so that the recent occupant of the coffin can see what he has gone through. (Ibid. 152)

The Cabaret du Néant coffin trick used a technique derived from Pepper's Ghost and therefore might be said to have as close affinities with (pre-) cinema as with the $\mathrm{X}$-ray. The third chamber also had an audience member pulled onto the stage, where he would sit at a chamber and, unbeknownst to him, would appear alongside a sheeted ghost. The Scientific American article closes by observing that "The Röntgen rays are utilized in the advertising matter also, although John Henry Pepper, of the old London Polytechnic, may lay some claim to discovering the full utilization of the rays actually used in the Cabaret du Néant" (153). Through clever new applications of Pepper's Ghost, simple light rays now masquerade as X-rays in the service of entertainment within the Cabaret's morbid attractions. $^{133}$

If the Cabaret du Néant is little remembered today, it has received at least one interesting cinematic reference. In Francis Ford Coppola's Bram Stoker's Dracula (1992), there is sequence where Mina Murray (Winona Ryder) and the romantic aspect of Count Dracula (Gary Oldman) visit the London Cinematograph. ${ }^{134}$ In the Cinematograph, the den of invention that so fascinates the Count, we see a variety of transformation trick

\footnotetext{
${ }^{133}$ For other discussions of the Cabaret du Néant, see Nadis (2005 15-6) and Simon (2004 277-8).

${ }^{134}$ For more on this much-discussed sequence, see Gelder (1994 88-9), Stewart (1999 241-4), Thomas (2000 303-7), Moore (2000 48-9), and Joyce (2007 105-7).
} 
films, a backlit puppet show and other modern marvels; posters with the names of inventors, filmmakers and magicians adorn the walls, and one stage is even labeled "Pepper's Ghost." But the place erupts with panic, echoing the myth of the Grand Café, at the appearance of Dracula's wolf Bersicker. The Count's predatory approach towards Mina is framed against the 1901 Biograph film The Ghost Train, a negative image of a train approaching; ${ }^{135}$ Coppola thus represents the Count, a creature of negation, as another such ghost train pulling into the heart of modernity. In this dense, fast-cut sequence there is a brief symbolic intercut of the figure of Mina standing within the white outline of a vertical coffin, shaped exactly like those in the Scientific American illustrations of the Cabaret du Néant. A skeleton is superimposed on her, never fully replacing her but lingering over her as a sort of ghostly palimpsest. This image foreshadows Mina's own encounter with death as she is infected with Dracula's inhuman blood; it also echoes an earlier sequence where the Count first encounters Mina and we see, from his perspective, blood pumping all through her body like an anatomical model.

Coppola's choice to stage these encounters with mortality within the idiom of the $\mathrm{X}$-ray is in keeping with the film's fin de siècle setting and also testifies to the continuing power of these images to disquiet. Whether or not Coppola and his collaborators knew it, skeleton imagery has a strange link with Stoker's Dracula. In Stoker's initial notes for the writing project that would become Dracula, dating from around 1890, the vampire (called "Count Wampyr" before Stoker came across an evocative name linked to a fifteenth century tyrant in some literature on the history of Transylvania) could not be photographed: "could not Codak [sic] him - comes out black or like skeleton corpse"

\footnotetext{
${ }^{135} \mathrm{~F}$.W. Murnau famously used negative film to convey the vampire's unnatural and inverted status in Nosferatu. Hans Richter put it to more playful supernatural uses in Ghosts Before Breakfast (1927).
} 
(Stoker 2008 21). Stacey Abbott writes that "Stoker, drawing upon the language of modern technology, [rewrites] the characteristics of the vampire to embody the increasingly ambiguous relationship between science and the occult" (2007 17), and the Count's inability to be photographed, even if it does not reach the final draft of the novel, is certainly in keeping with this. Perhaps it is not so much that Dracula's supernatural nature precludes him being photographed so much as that that the camera, potentially a supernatural device in its own right, reveals his nature more clearly than the naked eye, whether exposing him as a skeleton or as pure absence ("comes out black"). The idea that only bones would be shown in a photograph remarkably forecasts the X-ray, and helps confirm that figure of the skeleton had an occult power in the years immediately before Röntgen's discovery; this perhaps helps us understand why the X-ray mania took the shape it did. Stoker's phrase "skeleton corpse" is curious, reminding one of the Xray's ability to expose of the (even living) body as a skeleton and "corpse" at once, visible on the same photographic surface through an aesthetic of co-registration.

\section{Camera Fiends and X-Ray Fiends}

In the 1890 s, X-rays and cinema were linked as rival novel forms of photography that jointly participated in a certain reconfiguring of the public understanding of materiality and insubstantiality, presence and absence, and life and death. They shared a common exhibition context: Richard Crangle notes that early in 1896, London variety venues exhibited R.W. Paul's Theatrograph and the X-ray side by side, along with new bicycles, military hardware and horseless carriages (1998 139). Numerous itinerant exhibitors also showed both X-rays and cinema. A notable example is William Paley, who would become known as the "Kinetoscope Man" for the films he made in Cuba 
during the Spanish-American War, under contract from the Edison Company (Musser 1990 167). ${ }^{136}$ Prior to this, he was an X-ray exhibitor who abandoned this field after a bout with radiation sickness, a problem that numerous experimenters with X-rays would face (Brecher and Brecher 1969 81-90). Other exhibitors of both X-rays and cinema included William Friese-Greene and Jasper Redfern in Britain, Mark Blow in Australia and Yokota Einosuke in Japan (Condon 2008 50). ${ }^{137}$

Throughout 1896, commentators often spoke of cinema and the X-ray in the same breath. In his aforementioned "The Kinematograph from a Scientific Point of View," V.E. Johnson indicated that "medicine in all of its branches has, or will very shortly have, three very powerful assistants in the X-rays, the Kinematograph, and the photochromoscope" (6), the latter being an early colour photography process. In the remarkable article by that appeared in New Review in February 1896, the pseudonymous (and never identified (Loiperdinger 116)) "O. Winter" draws cinema into his caustic critique of literary naturalism. "Is not Zola the M. Lumière of his art?" asks Winter. "It is the favourite creed of the realists that truth is valuable for its own sake, that the description of a tiresome hat or an infamous pair of trousers has a merit of its own closely allied to accuracy. But life in itself is seldom interesting ..." (15). Cinema, for Winter, sharply demonstrates how banal life is when it is simply represented realistically, and thus reminds us of that art needs unreality to sustain interest (Winter similarly indicts the chronophotography of Eadweard Muybridge). Winter suddenly turns to the X-ray at the close of his essay:

\footnotetext{
${ }^{136}$ This William Paley is not to be confused with the same-named CBS president, who was born in 1901 . ${ }^{137}$ Excluded from the present discussion is the X-ray film proper, the actual use of X-ray images in cinematography, pioneered by Scottish scientist James MacIntyre in 1897. See Cartwright (1995 esp. 131141), Tosi (2005 169-71).
} 
And now, that Science may ever keep abreast of literature, comes M. Röntgen's invention to play the part of the psychologist. As M. [Paul] Bourget (shall we say?) uncovers secret and inclinations of his characters, when all you ask of him is a single action, so M. Röntgen bids photography pierce the husk of flesh and blood and reveal to the world the skeletons of living men. In Science the penetration may be invaluable; in literature it destroys the impression, and substitutes pedantry for intelligence. M. Röntgen, however, would commit no worse an outrage than the cure of the sick and advancement of knowledge. Wherefore he is absolved from the mere suspicion of an onslaught upon art. But it is not without its comedy, that photography's last inventions are twin echoes of modern literature. The Cinématograph is but realism reduced to other terms, less fallible and more amusing; while M. Röntgen's rays suggest that, though a too intimate discourse may be fatal to romance, the doctor and the curiosity-monger may find it profitable to pierce through our "too, too solid flesh" and count the rattling bones within. (17)

Where Winter links cinema to the banality he sees in the realist novels of authors like Zola, he links X-rays to psychological literature, which hones in too closely and exposes too much. Both cinema and X-rays, Winter argues, are ultimately artless, but have scientific utility. Lurking behind Winter's words is panic about the ability of new photographic techniques to penetrate the world too clearly, creating a closeness that seems obscene.

It should be no surprise that several practitioners of the nascent cinematic genre of the trick film staged scenes that were, like the theatrical tricks at the Cabaret du Néant, framed around X-rays. Sometimes, the invocation was so general that no skeletal effect need be depicted; Biograph's The X-Ray Mirror (1899) involves a young flâneuse looking into a mirror to see how she looks with a new hat and fainting on seeing herself as a ballerina. Evidently the term "X-ray" could even be used generically for surprising alterations of the human body. Georges Méliès made at least one film clearly about Xrays, known in French as Les Rayons Röntgen (1898) (the same name as the theatrical spectacle he staged the year previous) and in English as A Novice at X-Rays. This lost 
film features a scientist using an X-ray machine on a patient, causing his skeleton to appear to separate from his body and walk away, collapsing in a heap. The scientist reverses the experiment and restores the skeleton to the man's body (Ruffles 2004 14). Near the end of the trick film's popularity, Émile Cohl made The X-Ray Glasses or Les Lunettes Féerique (1909), where a family dons X-ray glasses that reveal the contents of their soul, and the Italian film Un ragno nel cervello (1912) showed X-rays revealing the presence of a spider in a person's brain (Elder 2008 340).

One of the few trick films about X-rays known to survive is George Albert Smith's 1897 The X-Ray Fiend. It plays out against a stark black background. A long shot shows a well-dressed man and a woman on a park bench. She carries a parasol. He flirts with her and she mildly resists his advances. Unseen by the couple, appears a black-clad man at the back right of the frame. This villain has black beard and a top hat and carries a contraption labeled "X RAYS" at shoulder level. Rectangular, with a lens-like protruding front, it is shaped distinctly like a movie camera. The fiend takes off the "lens" and immediately (through a substitution cut, the only type of editing in the film) the man and woman become skeletons, and the parasol turns into a wire-frame parody of itself as well. The man and woman are in fact wearing black costumes with bones painted on them, and their skulls, which are clearly the size of human heads, are particularly unconvincing. The man on the bench gesticulates in a much more exaggerated fashion in skeletal form, his legs bouncing up and down, reminding one of the merry dancing skeletons common in lantern displays. The strange intruder disappears, restoring the couple to their previous forms. She stands from the bench and walks away, though he pathetically falls to his knees in a beggar's posture. He has well and truly been "seen through." 
The comic scene of voyeurism and "undressing" is playfully perverse. The X-Ray Fiend is one of the earliest examples of what Paul Young (2006) calls "media fantasy films," a term adapted from the "media fantasy" of Carolyn Marvin (1988), who looks to the "fantasies" of a given age to help determine "what 'consciousness' was in a particular age, what thoughts were possible and what thoughts could not be entertained yet or anymore" (Young 7-8). Young's focus is on electrical media like the wireless, television and Internet and he makes only a one-line reference to the X-ray, but the label "media fantasy film" perfectly suits The X-Ray Fiend, which evokes various themes associated with the X-ray in its first years: an alteration in human perspective, the potential for an excessive, obscene (and inevitably eroticized) closeness, the gloomy and supernatural implications of transforming human bodies into mementos mori, as well as the fear of the loss of privacy and the rise of voyeuristic new forms of crime. On the latter subject, The X-Ray Fiend has affinities with H.G. Wells's The Invisible Man, published in 1897. Grove writes that Dr. Griffin

acts out the nightmare that X-rays created in the Victorian imagination. He represents the destructive potential of Röntgen's discovery. He is a robber, a spy, and a murderer, not to mention a ghost, who can use his technology of invisibility to commit his crimes undetected. The Invisible Man represents the ultimate threat to the privacy and security of those he encounters. (169)

Wells makes it clear that Dr. Griffin's transparency is not on account of "those Röntgen vibrations" (106), but even this disavowal locates Griffin's science within the same modern alchemy as the X-ray. The X-Ray fiend X-rays other people where his contemporary villain Griffin has pseudo-X-rayed himself, but both are perverse villains using the rays for villainous purposes. ${ }^{138}$

\footnotetext{
${ }^{138}$ If Wells's Dr. Griffin seems remarkably chaste in his use of his powers, at least in comparison with the invisible rapist Sebastian Caine (Kevin Bacon) in Hollow Man (2000) or even the perverse version of
} 
The title The X-Ray Fiend alludes to the "camera fiend" or "Kodak fiend," an amateur obsessed with documenting the world with the newly-portable camera. Between the 1850 s and the $1880 \mathrm{~s}$, photography was generally seen as a tasteful practice, despite the occasion photographer who would put his craft to less than gentlemanly ends (including the pornographer). Things changed in the $1890 \mathrm{~s}$, in part because photography expanded beyond the professional and the well-bred and well-funded amateur and in part because faster shutter speeds allowed a new kind of intrusive photography. As Bill Jay writes, "for the first time people could be photographed surreptitiously... With the snapshot camera, anyone at any time could be the victim of an embarrassing or even incriminating picture ... the snapshooters ignored the restraints of common decency and good manners" (1991 222-3, original emphasis). Writes Robert Mensel: "The amateurs were positively Mephistophelean: they belong to a class of minor demons known as 'camera fiend,' or 'Kodak fiends,' and they were said 'to be in league with some evil spirit.' Their activities were mysterious, seductive and intoxicating" (1991 29). Armed with their weapons, they were thought to go around photographing unsuspecting people and profoundly offending privacy. In 1906, The American Amateur Photographer asked "What is to be Done about the Camera Fiend?", reporting that the President's daughter Alice Roosevelt could not shop for her upcoming wedding without being subject to the flashbulbs of overzealous passersby (the paparazzo is older than we think!). A law

Griffin from Allan Moore's The League of Extraordinary Gentlemen, Grove reminds us of the pedophilic implications of the passage: "I looked about the hillside, with children playing and girls watching them, and tried to think of all the fantastic advantages an invisible man would have in the world" (110). In "Now You See Him: The Invisible Man Revealed" (2002), a special feature for Universal's Legacy Collection of The Invisible Man series, David J. Skal opines that invisible man films are popular because they are covertly about nudity. This claim is particularly borne out with respect to The Invisible Woman (1940), where the transparent titular character (Virginia Bruce) takes a shower on screen. This censor-friendly gag appeared previously with a female ghost in Topper (1937). 
against photography in public places, the article warns, will be forthcoming if the amateurs do not police their own and rebuke the camera fiend.

Camera fiends were constructed as obsessive almost to be point of derangement. The film The Camera Fiend (1903) shows a photographer who is more inclined to take pictures of a drowning boy than to assist in his rescue, only reluctantly helping with his one free hand. Young discusses it as a moralizing allegory for the film industry's fascination with shock: "Its titular devil cares less about human life than about getting a good snapshot of human mortality" (29). In 1911, Arthur Conan Doyle's brother-in-law Ernest Hornung used The Camera Fiend as the title for a sensationalistic novel about a mad scientist obsessed with documenting the human soul. ${ }^{139}$ He murders tramps in Hyde Park to try to photograph the soul as it flees the body, even designing a combined camera-firearm to kill and photograph in the same instant, much like Mark Lewis (Karl Boehm) in Peeping Tom (1960). Unsuccessful, he turns the device on himself, hoping that his suicide will yield the evidence he was unable to obtain in life.

The camera fiend is easily associated with the supernatural both in terms of his nature (a demon) and his twisted objectives. This is doubly true of Smith's X-ray fiend, who covertly transforms the couple into skeletons for his own perverse, voyeuristic reasons. The fiend in Smith's film is, appropriately, Smith himself; the director plays the high-tech criminal. The other man is Tom Green, the Brighton comedian who appeared in numerous of the films of the Hove pioneers before directing dozens of films himself, and the woman is Smith's wife Laura, several years before she would be play a ghost in Mary Jane's Mishap ... another version of the wife as the subject of X-ray photography.

\footnotetext{
${ }^{139}$ Arthur Conan Doyle would defend twentieth century spirit photographers like William Hope and wrote a book defending the infamous Cottingley Fairy Hoax; see Wynne (1998).
} 
The X-Ray Fiend narrativizes anxieties about photography and X-rays, but also has something to say about cinema, in keeping with Young's argument that early cinema was most prone to being reflexive about itself, its depictions of trains, Kodaks, etc., often serving at least in part to comment on cinema (xxxiii). The fiend's X-ray device strongly resembles a film camera and marks him as a kind of a renegade filmmaker, wandering the streets making elicit photographs of courting couples; indeed the "X-ray effect" is achieved cinematically, through the substitution splice that makes the trick film possible, and only mimics the X-ray. It draws cinema and the X-ray together as surely as $\mathrm{O}$. Winter did, and again within the context of excessive and unwanted intimacy with the image.

There is one aesthetic feature of The X-Ray Fiend that fascinates me further. When the fiend activates his machine, Laura Smith and Tom Green are wearing black clothes with bones painted on them, and the edges of their clothing are clearly visible against the black backdrop. This is most visible with respect to her dress, which billows noticeably, shades lighter than the backdrop. Perhaps this overlay is a result of technical limitations; Smith's attempt to match the black of their clothes and the black of the set to create the illusion that they are skeletons does not quite work. The film contains none of the double exposures and other camera tricks that Smith would begin to hone the year after in films like The Mesmerist, Photographing a Ghost, The Corsican Brothers and Santa Claus. But it may contain seeds of Smith's double exposure work, and also might be described as more accurately recreating the X-ray aesthetic than theatricalized imitations generally do. Recall that early spectators were not astonished by X-rays simply because that they showed skeletons but because they also reduced flesh and muscle to a wraithlike parody fluttering half-visible alongside it, reducing depths to surfaces and 
promoting surfaces to depths. The aesthetic principle shared by the spirit photograph, the $\mathrm{X}$-ray and the cinematic double exposure is co-registration, and coming immediately before Smith's successful pioneering of double exposure techniques, The X-Ray Fiend gives us reason to speculate that the aesthetic of the X-ray, with all of its cultural baggage of the supernatural, death and invasion of privacy, played a role in guiding the path of Smith and experimenters like him to the double exposures pioneered by the spiritualists the technique that would shortly become the favoured cinematic means of depicting ghosts. 


\section{Chapter 6: Méliès's Skeleton: Gender and the Danse Macabre}

It is a familiar sight to students of early cinema. The magician steps onto the stage, a set ornately decorated in Louis XV style, from a door at the right of the screen, his female assistant in tow. Both are elegantly dressed in the trappings of wealth and class, the magician in black evening wear, the assistant in a white dress and carrying a white fan. He lays a sheet of newspaper on the floor and he picks up a chair and puts it on top of the paper, first twirling the chair around in a dexterous gesture of the sort that magicians use to deflect audience suspicions of trickery. The assistant sits on the chair and idly fans herself as the magician places a blanket over her. She disappears; the magician beams at his successful trick. He makes an elaborate gesture to rematerialize her, but she instead re-appears a skeleton, blackened and still, sitting upright in the chair. Momentarily horrified, he makes two quick "shooing" gestures in its direction. Picking up the blanket again, he covers the skeleton, pulls back the blanket and finds the lovely assistant in place again. They stand and leave the stage, but then step back to take a bow to the audience, and walk out of door, leaving the stage and the audience's view. The performance was recognized by its first audiences as typical except for in two crucial respects: it occurs not on stage but on the screen, and it adds the skeleton to what had previously been a simpler vanishing act. The magician is Georges Méliès, the director of the film, and the assistant is Jehanne D'Alcy, his usual assistant on both stage and screen. She was also, in a long magic tradition, his mistress, and would become his wife following the death of the first Madame Méliès. 
Few one minute films have attracted as much discussion as this one, Méliès's Escamotage d'une dame chez théâtre Robert Houdin, known in English as The Vanishing Lady (1896). Its disappearances and appearances may not represent the first examples of substitution cutting in cinema history (that honour appears to go to Edison's The Execution of Mary, Queen of Scots the year previous) but rather represent the first places where such a cut was used to approximate an effect from the magical stage. This is the significance of The Vanishing Lady; not the first film containing a trick effect, but nevertheless the first trick film, not only using the magic show as a subject matter but allowing its logic of vanishing and appearance to decide on cinematic technique. In many ways, it set the tone for the rest of Méliès's career in filmmaking. And if imitation is the sincerest form of flattery, The Vanishing Lady was successful indeed: both R.W. Paul and Thomas Edison would produce films of the same title and theme within the next two years. With one foot in the heritage of the magical stage and one in cinema's future, The Vanishing Lady reflects "the defamilization and violent reconstruction of the human subject" (Hurley 1996 4) common to texts of its cultural moment, something we may recognize in the transformation scenes common in the trick film. ${ }^{140}$

This chapter tracks a visual motif, the skeleton (particularly the female skeleton), over a range of time and through a variety of media. Though it discusses a longer history of skeletons in the iconographies in European culture prior to era of cinema's debut (and finally subsequent to it), it focuses on the peculiarities of what I term the "skeleton vogue" of the 1890, when, "formerly [skeletons] were out of the sight in the living world, [but] they were now ever present" (McGrath 2002 191). Even a cursory survey of early

\footnotetext{
${ }^{140}$ For an excellent treatment of transformations in early cinema, see Solomon (2000).
} 
cinema finds that filmmakers were positively fascinated by skeletons: they appear frequently in trick films by Walter R. Booth, Edwin Porter, ${ }^{141}$ Émile Cohl, Segundo de Chomón and others, as well as Méliès and Smith. To explain this phenomenon, we can look in two directions at once: to the traditions of the danse macabre stretching back to the Middle Ages, and to the new context of the X-ray. We need not chose one of these explanations over the other; in fact, a balanced assessment must take them both into account. But what is certain is that, in the $1890 \mathrm{~s}$, something changes with respect to the figure of the skeleton. If it sometimes retains the merry aspect familiar from the dancing skeletons of the magic lantern tradition, something dark and sinister intrudes too. Where the skeleton was once substanceless and ghostly, it could now be corporeal, with a visceral and potentially erotic charge. And, perhaps most strikingly of all, where skeletons were once predominantly genderless, the new skeleton vogue finds them to be female more often than not.

A canonical early film, Méliès's The Vanishing Lady has been the subject of much analysis, especially in terms of gender. I have nonetheless not encountered any scholarship emphasizing the figure of the skeleton, beyond Elizabeth Ezra's astute but passing comment that its "hide and seek anatomy lesson perfectly emblematized the popular combination of masculine scrutiny (masquerading as ' $\mathrm{X}$-ray vision') and sensationalized eroticism" (2006 127). Criticism on gender in trick film goes back at least to Lucy Fischer's “The Lady Vanishes: Women, Magic and the Movies” (1979; a revised version appeared in Fischer's book Cinematernity: Film, Motherhood, Genre (1996)). Fischer argues that trick films, particularly those of Méliès, are premised on the

\footnotetext{
${ }^{141}$ Porter's The Mystic Swing (1900) is an intriguing variation on The Vanishing Lady, where a magician and Mephisto compete to de- and rematerialize a woman. The magician triumphs when he turns her into a skeleton that Mephisto cannot dispel.
} 
relationship of a powerful, authoritative male figure in the magician, and the woman or women upon whom the magic is performed. Women are transformed into decorative objects, are dematerialized and decorporalized and thus transformed into "spirit," and are often envisioned as a figment of the male imagination (31-2). This gender dynamic, argues Fischer, is a holdover from the magical stage. She goes on to interpret the trick films as an expression of a cultural need to contain women that discloses a masculine weakness and fear of female power, and a desire to appropriate female powers of procreation (evident in magic's fondness for fertility symbols like eggs and doves). Perceptive in its observations about the fluid corporeal status of the female assistant on both the stage and the screen, "The Lady Vanishes" was one of the first articles to consider the role of women in early cinema and spotlight the inadequacy of the theories of gender and spectatorship that emerged in the 1970s to deal with cinema's earliest years. ${ }^{142}$ In 1981, Linda Williams argued against the reproductive paradigm in Fischer's argument, suggesting an alternate reading on the status of women in Méliès:

While Lucy Fischer emphasizes the envious male's appropriation of female procreative powers in the construction of this machine that gives 'birth' to women, I would stress instead that this spewing forth of identical female bodies only calls attention even more to the status of these bodies as totally mastered, infinitely reproducible images whose potential threat of castration has been disavowed by the fetish object of the machine with which they are associated. $(527,531)$

Fischer responded to this criticism in Cinematernity, asserting that she and Williams share a common point - the replacement of woman by her male-fabricated image (39). In both Fischer and Williams's approaches, however, the historical specificity of the vanishing woman trick is subjugated to broader theoretical concerns about the nature of

${ }^{142}$ The article has been criticized for not paying enough attention to films with female magicians (Salt 1992 16). A fuller treatment of female conjurers in the trick film would have to wait until Solomon (2010 66-8). 
cinema itself and the status of the female image. My approach will come closer to that of Karen Beckman (2003), who tracks The Vanishing Lady's relationship to a broader fascination with disappearing woman throughout the latter half of the nineteenth century, which she relates to a panic about the surplus female population at a time when census data began to reveal that women outnumbered men. Writes Beckman, "[The vanishing woman trick] exploded onto the cultural scene with a forcefulness and panache unrivalled by other stage tricks at any point in the century. Never had a magic trick been so prominent, so revered" (47-9).

For all the writing about The Vanishing Lady, neither Fischer, Williams, Beckman, nor any other scholar of whom I am aware ${ }^{143}$ has paid much attention to the skeleton and its own gender implications. The skeleton transformations so common in early cinema have a curious relationship to the scenes of animation and the overall obsession with vitalism that Lynda Nead finds everywhere at the time of cinema's debut. Nead states:

At the end of the nineteenth century the search for the spirit or life within the inert art object was evident across all forms of visual media. The exquisite passage from stasis to movement, the hesitation and moment of delay prior to motion, became the fool's gold of representational practices in the period. In an age when lovelorn sculptors could no longer pray to benign goddesses to animate their creations, the power to endow the image with life was handed over to magicians, lanternists and film-makers. (53)

However, these fantasies of animation that cinema seemed to satisfy are haunted by their inverse: the transition from motion to inertia and death. Nead offers one example to which the female body is central:

In the many transformation films of this period, the sexualized female body provides the matter through which the power of film magic is displayed.

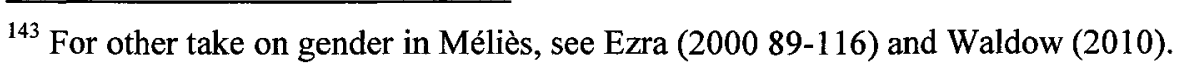


Women's bodies are fragmented and annihilated and their flesh turned to bone. In the American Mutoscope and Biograph Company's The Artist's Dream (1899), a beautiful, fleshy life model in a leotard is transformed into a skeleton, while an artist dozes at his easel. $(90)^{144}$

Early filmmakers were well aware of the paradox that cinema, in its potential for giving life and animating its subjects, even bestowing a sort of immortality, was at the same time a brand of living death. The figure of the skeleton, especially when it is gendered female, can be an emblem for that paradox.

Theatre and Theatricality: Locating the Cinematic in the Skeleton As the first of the trick films that would make him famous, Méliès's The Vanishing Lady is often mentioned as part of longstanding debates about Méliès and intermediality. Academic treatments of Méliès often stress continuities between the theatrical illusions he staged at the Théâtre Robert-Houdin and his filmmaking, arguing that Méliès essentially imported the conventions of the magical theatre into cinematic form, and consequently his work remains essentially rooted in the theatrical (see Vardac (1949), Kovács (1984), Gaudreault (2007), Solomon (2008b, 2010)). His films tend to replicate proscenium staging and his sets often include windows, bookcases, fireplaces, etc. painted onto the walls. Characters frequently address the audience, like a magician bowing to acknowledge applause. But acknowledging the theatrical qualities of Méliès's filmmaking does not mean disparaging him as merely theatrical and therefore uncinematic, as certain early critics did. Elizabeth Ezra's 2000 book on Méliès does a particularly detailed analysis of the varied cinematic techniques throughout Méliès's body of work, concluding that:

Méliès did not merely produce 'filmed theatre' but used a number of cinematic

\footnotetext{
${ }^{144}$ A slightly different gender dynamic is in play in The Startled Lover (1899), where woman seemingly transforms herself into a skeleton to frighten her quarrelling lover.
} 
techniques such as close-ups, multiple exposures and continuity editing. The special effects that he developed were often innovative and always sophisticated . .. In addition, Méliès sometimes used deep staging, with characters moving back and forth along the camera access, and he created the illusion of camera movement through the use of moving backdrops and matte shots of objects approaching the camera. (150)

Few of those innovations are manifest in The Vanishing Lady, which only uses three simple substitution tricks, but through these it accomplishes feats that could not have been done on stage. The film depends on being both theatrical and cinematic for its effect, on both acknowledging a familiar theatrical tradition and departing from it. ${ }^{145}$ As John Frazer writes,

The first part of the trick substituted a film device for a stage device. However, when the skeleton appears out of nowhere, a different order of thinking is involved. There is no longer a stage drape to cover the action. The magical appearance is entirely dependent on the ability of the camera to interrupt and reconstruct time. (60; see also Solomon 2010 34-5).

The film's French title, Escamotage d'une dame au théâtre Robert Houdin, locates it within the heritage of stage magic. ${ }^{146}$ The Vanishing Lady was not filmed in the Theâtre Robert-Houdin, but at Méliès's outdoor studio at Montreuil-de-Bois, ${ }^{147}$ so the name declares a certain relationship to magical traditions, perhaps securing a retroactive imprimatur from Robert-Houdin. The film declares itself as an exact transliteration of a stage act, but, as we shall see, that is not so. The cinematic Méliès lays down the newspaper, which never moves throughout the film, to defray speculation about a trap door, but the film's trick requires no trap door. The convention of the newspaper comes

\footnotetext{
${ }^{145}$ André Gaudreault's useful neologism "trickality" breaks the distinction between narrativity and theatricality (2011 37-8).

146 "Escamotage" comes close to meaning disappearance, but with some untranslatable connotations of thievery and trickery (Beckman 49). In a reflection of the pervasiveness of the vanishing woman trick, "escamoteur" was a key synonym for magician in French. As Solomon notes, part of Méliès's strategy in replicating known tricks on screen was to be able to sell his films to other illusionists and fairground exhibitors, which may explain the presence of his theatre's name in the film's title (2008b 39).

${ }^{147}$ Méliès's first studio was, however, modeled on the Robert-Houdin stage, both in its dimensions and in features like trapdoors, rollers, winches and mattes (Jacobson 2010 195-6).
} 
from the vanishing woman act pioneered by Hungarian-French conjurer Buatier de Kolta in 1886; the newspaper would actually be a rubber sheet carefully split in two to allow the magician to slide through the trapdoor beneath it. But instead Méliès utilizes, in Dan North's apt phrase, "a temporal trap door" (55), depending on an interruption of time rather than the theatrical trick's disjuncture of space.

The presence of the newspaper in The Vanishing Lady is an intriguing vestige of the trick's theatrical roots, remaining as pure adornment, or even misdirection. Audiences by and large understood the basics of the venerable and pervasive vanishing woman act, but would have been surprised by the skeleton's sudden appearance. The cinematic, then, takes as its emblem a (female) skeleton, perhaps in recognition of the current overlap between cinema and the $\mathrm{X}$-ray. So surprising is the appearance of the skeleton that even Méliès's internal conjurer is taken aback. As Gaby Wood writes,

If you play the film again and slow it down at the moment when the skeleton appears, you notice that Méliès, the magician himself, is shocked by its arrival. $\mathrm{He}$ looks surprised shakes his head, and tries to shoo the skeleton away, as if that wasn't supposed to happen. Clearly, even he thinks he has unintentionally killed the woman, instead of simply making her vanish. (2002 194)

I concur with Wood's impression - the effect of the film is indeed predicated on the notion of a "trick gone wrong," which complicates Fischer's claim that the magician in the trick film represents masculine authorial power. ${ }^{148}$

It is worth noting that cinematic substitution tricks such as the one we see in The Vanishing Lady have their own apocryphal origin story, just as cinema has the myth of the Grand Café. As Méliès wrote in 1907:

One day, when I was photographing as usual in the Place de l'Opéra, the camera . .. jammed and produced an unexpected result. It took a minute to disengage the

\footnotetext{
${ }^{148}$ See Lamont and Wiseman (1999 119-20) for staged failure as a tradition in stage magic.
} 
film and to start the camera up again. In the meantime, the passers-by, a horse trolley and other vehicles had, of course, changed positions. When I projected the film strip, which I had glued back together at the point of the break, I suddenly saw a Madeleine-Bastille horse trolley change into a hearse and men become women. The substitution or stop-camera trick had been discovered. Two days later, I produced the first metamorphoses of men into women and the first sudden disappearances which, in the beginning, had such great success. (44)

This story is suspect for a number of reasons, not the least being that Méliès did not invent the substitution cut. Edison's The Execution of Mary, Queen of Scots was filmed in August, 1895, at least fifteen months before The Vanishing Lady was filmed, and there is every reason to believe Méliès was familiar with it. The story is fanciful and improbable (Gaudreault 2007 170-1), and more than a little morbid, and has occasionally been used as evidence of film's ghostliness (Michaels 1998 76-7). The image of the trolley changing into a hearse invokes the danger of modern life, perhaps one of those traffic accidents sent curious spectators flooding into the Paris Morgue (Schwartz 1998 44-88). Scholars like Kristen Whissel (2008) and Ben Singer (2001) have linked the emergence of cinema to traffic as sensationalistic phenomena of urban modernity. ${ }^{149}$ Méliès's mythical, self-aggrandizing, apocryphal yet still foundational "first cut" implicates death; it is perhaps appropriate that the first time he used it in a film, in The Vanishing Lady, it is to slip in death's emblem. As Michael Mangan writes, "The essence of the live trick is maintained but elaborated upon by the camera in the figure of Death" (130). ${ }^{150}$

\footnotetext{
${ }^{149}$ There is a remarkable amount of skeleton imagery in the illustrations of dangerous urban traffic that Singer reproduces in Melodrama and Modernity: skeletons as angels of death perched on trolley cars (80), a deranged skeleton driving a trolley and leaving dozens of dead bodies behind it (79), and even a skeletal representation of Death having a conversation with an allegorical figure of a Trolley Car with the head, arms and legs of a skeleton (76).

${ }^{150}$ We can further note that the use of the substitution cut (pun intended) in The Execution of Mary, Queen of Scots also signifies death, occurring when the executioner's axe strikes the queen's neck.
} 
Skeletons appear with great frequency in Méliès's later trick films. ${ }^{151}$ Sometimes, as in The Haunted Castle (1897), it appears as one of a number of menacing elements in a gothic setting. Sometimes, as in The Wizard, the Prince and the Fairy (1900) and The Doctor and the Monkey (1900), a non-ambulatory skeleton marks the setting as a sorcerer's workplace. In The Magician's Cavern (1901), a display skeleton is given flesh and turned into a young woman by the magician. Like the magician's assistant she is, the newly embodied woman is then subjected to a levitation trick, and turned back into a skeleton in the process. The skeleton then does a lively dance, and though it may be an imperfection in the special effects, the visible outline of the actor surrounding the skeleton heavily suggests an X-ray image akin to The X-Ray Fiend. In The Monster (1903), an Egyptian prince, before an elaborate backdrop of the Sphinx and the pyramids, brings the skeleton of his dead princess and recruits a dervish to restore her to life. The skeleton is garbed in linens and a mask by the dervish and then comes to life, doing a dance, and then growing distended and grotesque. The dervish pulls back the robes and reveals the princess as she was in life, but only for an instant before she turns into skeleton again and collapses in his arms. ${ }^{152}$ As Elizabeth Ezra notes, what we see in The Monster is an inversion of The Vanishing Lady, moving from bone to flesh to bone, instead of flesh to bone to flesh $(200041)$. Without exception, these skeletons are immaculate and white, unlike the charred, brown appearance of their forbearer in The Vanishing Lady, which looks more like an old skeleton from an anatomical collection,

\footnotetext{
${ }^{151}$ Tsivian identifies nine human/skeleton transformation tricks before 1904 (1996 293 n.41); subsequent discoveries such as The Prolific Magical Egg (1902) extend this list.

${ }^{152}$ For the importance of the figure of the mummy in late Victorian fiction and culture, see Daly (1999 84116), Day (2006 19-62), Luckhurst (2006), Briefel (2008) and Macfarlane (2010). For an approach specific to cinema, see Lant (1992).
} 
blackened over time. It is also striking in these films that, the vast majority of the time a skeleton is clearly gendered, it is female. ${ }^{153}$

\section{The Danse Macabre}

Paying attention to the role that the figure of skeleton has traditionally played in Western culture can help us better understand Méliès's skeletons. The skeleton became the preeminent allegorical figure of death in the late medieval period, with the emergence of danse macabre. Death was often figured as a skeleton carrying a scythe or an hourglass, mocking earthly ambitions in the face of the inexorability of death. These images fit into the broader European tradition of the memento mori, where bones and skulls are a reminder of death's inexorability. ${ }^{154}$ Leonard P. Kurtz writes that skeletons were a familiar sight to many at the time, since many cities maintained ossuaries where the bones of the dead were exhibited:

The ossuaries were necessary because of the preference of the people for a particular cemetery, regarded as the holiest burial ground ... The people insisted on being buried there, and hence the skeletons had to be removed to the charnier to make way for new dead. Skeletons were then on general display at all times and the people came to regard them as an integral part of the landscape. (1975 189)

The danse macabre dates back at least to 1376 (Ibid. 178), initially existing in both theatrical forms and visual artistic forms like frescoes in churches. It is thought to initially derive from the deuterocanonical book of 2 Macabees and the martyrdom of a mother and her seven sons, a common artistic subject in the grim Black Plague-ravaged late medieval world. One of the most famous manifestations of the Dance of Death was Hans Holbein's La Danse Macabre, first appearing in 1538. It featured forty-one

\footnotetext{
${ }^{153}$ Exceptions include the aforementioned Les Rayons Röntgen/A Novice at $X$-Rays and The Prolific Magical Egg (1902), where Méliès transforms himself into a skeleton.

${ }^{154}$ See Binion (2004).
} 
woodcuts of Death, figured as a skeleton, visiting a varied series of figures from the Pope to a Peddler, the King to an Old Woman. Friedrich Kittler reproduces the oldest known depiction of a print shop, dating from 1499 (1996 5), featuring a startling danse macabre. A triad of skeletons cavorts around the shop, disturbing a compositor, a bookseller and two men working a printing press; even Guttenberg's invention, promising new permanence for the words of man, is mocked by Death. These images stay with us in the figures of the Grim Reaper and the Death card of the Tarot deck.

The magic lantern became a key venue for images of Death embodied. In 1659, Christiaan Huygens drew the earliest known representation of a moving slide of a magic lantern: ten images of a dancing skeleton. As Laurent Mannoni writes, "paradoxically, the first illuminated artificial recreation of life was a representation of death" (40). One of the images in Kircher's Ars Magna Lucis et Umbra has a skeleton carrying a scythe and an hourglass (Heard 37). These images lasted into the Phantasmagoria era, with Robertson conventionally ending performances with a projection of the skeleton and the words "The fate that awaits us all" (Barnouw 19) and referring to the skeleton as being "the only real horror ... See what is in store for all of you, what each of you will become one day" (Castle 37). Mervyn Heard's Phantasmagoria: The Secret Life of the Magic Lantern (2006) reproduces numerous nineteenth century lantern sides featuring skeletons ... one sitting on a baby, another holding a mirror up to the face of another skeleton, and so on. One skeleton rides a skeletal horse highly reminiscent of the one from Méliès's The Merry Frolics of Satan (1906) (282). In the nineteenth century, the skeleton was a popular figure in new optical technologies of all sorts. The choreutoscope, an improved phenakistiscope invented by L.S. Beale in 1866, often featured a dancing skeleton 
jugging its own detachable head (Heard 236). Indeed, the image of the skeleton seems to have particular utility for such comic effects; the 1833 lantern manual Fun for Winter Evenings says:

A curious effect is produced by drawing out the tube, and slipping it in suddenly to the focus: this is easily done, by holding the tube tight at the proper place, a shivering motion may be given to the figures, by giving the lantern a sudden shake, a skeleton is made to tumble to pieces by means of a slide made for the purpose. By standing at the bottom of the stairs, a figure may be made to appear going up. The figure of a skeleton is a very good one for this purpose. (Herbert 2004 173-4)

Skeletons would also appear in theatrical illusions not dependent on lanterns, such as the elaborate "Black Art," made famous by Harry Kellar and Alexander Herrmann, in which "a life-size skeleton ... appears and dances around the stage, becomes dismembered, the separated parts floating about, but they finally rearticulate themselves, and the skeleton vanishes" (Hopkins 66). In this case, the skeleton is constructed of papier maché and was worked by assistants dressed in dark clothes so as to be unseen against the black drapery. Likewise, J.N. Maskelyne described a trick where "a luminous skeleton appeared; its head came off and floated over the audience, while my organ, with startling electrical effects, would peal out 'Hist, hist, hist! Here comes the bogey man!'” (27). It is on the pervasive image of the dancing and dislocating skeleton that the Lumière brothers would draw for their early stop motion experiment, Le Squelette joyeux (1897), where the dancing skeleton loses limbs and collapses into a pile of bones but always re-forms. ${ }^{155}$ As we have seen, dancing skeletons appear in Méliès's work with considerable frequency, contrasting strongly with to the immobile bones we see in The Vanishing Lady.

In the nineteenth century, the line between the ghost and the ambulatory skeleton was a fine one. Anatomists once drew skeletons standing on terra firma, but by the

${ }^{155}$ See North $(53,190)$, for notes on this and other Lumière trick films 
nineteenth century the convention had shifted to drawing them standing in mid-air, appearing to float in space, like ghosts. The seemingly paradoxical ghostliness of skeletons stems from the fact that "up until the end of the nineteenth century, the notion of 'living bones' was a contradiction in terms. Bones were dead and the skeleton was a relic" (McGrath 2002 111). ${ }^{156}$ As noted, the "ghosts" of Pepper's Ghost were often skeletons as well. The first public presentation, staged by John Henry Pepper at the Polytechnic in 1863 featured "a ghostly skeleton robed in a shroud" that disappears (rather than tumbling into a pile of bones) when attacked with a sword. "The ghost's dramatic appearances and actions were conducted by an assistant clothed from head to foot in black, and holding a white-painted skeleton in his arms" (Lamb 199644$)$. The first ghost to "haunt" the New York stage was the skeleton of an old miser come back to take revenge on his wicked nephew as the spectacular finale of a play called True to the Last (Posner 2007 192-3).

Phantom skeletons, meanwhile, periodically appear in the literature on spiritualism and psychical research; they represent something that people experienced (or at least claimed to). A letter from a Miss Emma Foy of Manor Park, Essex, to the Literary Committee of the Society for Psychical Research appeared in the Jan 1891 issue of the

\section{S.P.R.'s Journal:}

Towards the end of the year 1872, I saw a tall human skeleton enter bedroom, dragging a coffin which it brought close to me. Over its right arm was a pall. Then it pointed to the coffin, it threw the pall over me, causing a feeling of suffocation which left me very weak. Continued its visits almost every night about 10:30 for the space of about two years, then gradually disappeared. Tried in many ways to dispel the illusion; did not believe in supernatural occurrences; have always been of lively disposition; excellent spirits which seemed to affect; never saw a real skeleton; nor up to that time any representation of one; nor had any dread of death.

\footnotetext{
${ }^{156}$ See Ebner and Jenkins (1983) for more on depictions of skeletons in anatomical manuals.
} 
... The phantom appeared again suddenly in August 1879, either the last week in August or the first in September. This time there were eight persons present. Two persons saw the vision besides myself - a poor woman an educated gentleman, the gentleman being thrown into a very nervous state for some time after and experiencing similar sensations to myself. Was out of health this time. Time 9:30 pm. (10, original emphasis)

Here again a skeleton is essentially a ghostly, insubstantial figure, in this case maintaining an ability to disquiet that belies the comic depictions of skeletons we find elsewhere at the time. The fact that it appears in Miss Foy's bedroom and violates her in a strange, phantasmal way, rather like Dracula and other nineteenth century vampires do, would appear to be a reflection of the pervasive sexualisation of the skeleton I will discuss in detail shortly.

Skeletal imagery booms in popularity in the 1890s and 1900 s. This is not only a reaction to the discovery of the X-ray but strangely seems to anticipate it too, allowing us to speculate that the sensation provoked by Röntgen's discovery was nourished by (and in turn fed into) a pre-existing skeleton mania. As seen in the previous chapter, magic acts involving skeletons were now often explicitly framed around X-rays, with the Cabaret du Néant as a key example. If the X-ray did not create the skeleton vogue, it undeniably cemented it and, critically, reshaped it. One obvious change is that, far from the wispy phantom skeletons of previous time, the skeleton could now be a figure of embodied horror. One famous example is Gaston Leroux's The Phantom of the Opera, initially published in serial form in 1909 and 1910 . Erik, the titular phantom, is actually a flesh and blood (if highly disfigured) mad genius living in the opera house's bowels, who poses as the Opera Ghost. His appearance is consistently described as skeletal; as Joseph Buquet, the opera's chief scene setter and major source of conjecture about the Opera 
Ghost, explains: "He is extraordinarily thin and his dress-coat hangs on a skeleton frame. His eyes are so deep you can hardly see the fixed pupils. You just see two big black holes, as in a dead man's skull ... the absence of that nose is a horrible thing to look at" (11, original emphasis). At one point Erik conceals himself amid the skulls in the ossuary of a Breton church, his skull-face at home amid icons of death and decay. A framing device in The Phantom of the Opera deals with Leroux's own (fictional) discovery of Erik's body, now a more conventional skeleton beneath the Opera House, and the book ends with: "And, now, what do they mean to do with that skeleton? Surely they will not bury it in the common grave! ... I say that the place of the skeleton of the Opera ghost is in the archives of the National Academy of Music. It is no ordinary skeleton" (348). This is perfect ending for a novel from a time in which skeletons so rarely seem to be ordinary. ${ }^{157}$

A more literal living skeleton appears in Perceval Landon's 1908 short story "Thurnley Abbey." The ghost of the tale is that of a murdered nun walled up in the abbey, who appears as walking a skeleton that, like the Phantom of the Opera, proves highly material. The narrator's confrontation with the revenant is spectacularly visceral:

I tore at the robed skeleton--how well the whole thing had been carried out, I thought--I broke the skull against the floor, and stamped upon its dry bones. I flung the head away under the bed, and rent the brittle bones of the trunk in pieces. I snapped the thin thigh-bones across my knee, and flung them in different directions. The shin-bones I set up against a stool and broke with my heel. I raged like a Berserker against the loathly thing, and stripped the ribs from the backbone and slung the breastbone against the cupboard ... At last my work was done. There was but a raffle of broken bones and strips of parchment and crumbling wool. (42)

\footnotetext{
${ }^{157}$ For a treatment of The Phantom of the Opera's echoes of the danse macabre, most evident in the famous bal masqué sequence, see Hogle (2002, esp. 5-6, 126-7).
} 
What a change from the skeletal ghosts of earlier periods, who disappeared like vapour when struck by the hero's sword! The one in "Thurnley Abbey" is all corporeal, all bone, and must be violently subdued. If the female skeleton in The Vanishing Lady is less horrific and less animate than the undead nun who haunts Thurnley Abbey, they are on the same lineage, and that this new visibility of female skeletons reveals something about attitudes about death, spirit and sexuality around the turn of the century.

\section{Sexualized Skeletons and Female Assistants}

The significance of the female skeleton has been explored most thoroughly by Roberta McGrath (2002). For the majority of medical history, female skeletons were ignored and never described. Drawings and descriptions of female skeletons began to emerge in the eighteenth century, but female skeletons were rarely collected: only female pelvic bones, understood as the only key point of distinction between the genders on the skeletal level, were studied (105). The fact that the skeleton of the 1890s seems to be predominantly female is a striking change which must have everything to do with changing attitudes towards the female body. Cinema and the X-ray debuted into a society of shifting gender roles and extensive debates over sexual identity, the period of, in Elaine Showalter's famous phrase, "sexual anarchy." The so-called "Woman Question" the 1885 title of a paper by Karl Pearson - was present in most every aspects of life, from politics to education to labour to trade and foreign policy (Showalter $199049-5$ ). A particular flashpoint for all of these issues was women's bodies, in an age when women seem to exist in "surplus," as discovered by census around the mid-nineteenth century (Beckman 19-31). A complex and contradictory set of attitudes towards the female body emerged, turning it into a cultural text caught between antimonies of corporeality and 
incorporeality, and when Méliès invokes in a single motion the vanishing trick and the $\mathrm{X}$ ray in The Vanishing Lady, he exposes an essential connection between both practices: both take their fascination from a new reconfiguration of the nature of corporeality in a world where the line between the visible and the invisible became increasingly uncertain. And while both can be and were used on any subject, it is obviously the case that female subjects, as vanishing women or female skeletons, were understood to be the most effective subjects.

In the previous chapter, I discussed William Crookes as the man who merged spiritualist and scientific sensibilities more clearly than any other figure in Victorian England. His most famous misadventure in psychical research, an investigation of the medium Florence Cook and her famed alter ego Katie King in 1873 and 1874, is relevant to the present discussion of women, spirit and (dis)embodiment. Cook was a teenage medium from London, and King was a "control," a friendly denizen of the Other Side. ${ }^{158}$ British mediums of the 1870 s favoured "full materializations": trumping the previous table-rappings and disembodied voices, a physically embodied ghost would appear to the séance-goers, even as the medium was locked away in a "spirit cabinet," bound and immobilized to prevent any suggestion of fraud. A particularly beautiful and personable spectre, Katie King could manifest physically in the séance room and meet, flirt with and even kiss guests ... even as her medium Florence Cook was (apparently) tucked away in the spirit cabinet. Crookes's 1874 report on mediumship, which so scandalized his scientific peers that there was talk of removing him from the Fellowship of the Royal Society, contained a series of forty-four photos of King, who, despite Crookes's claims to

\footnotetext{
${ }^{158}$ Katie was herself purported to be the daughter of another notable control, a seventeenth-century Welsh pirate named John King.
} 
the contrary, looks much like Cook. Scholarship has generally concluded that Crookes was a willful party in Cook's hoax, most likely because they were having an affair (Crookes being married with eight children, and Cook's senior by decades) (Fischer 2004 172-4, Raia-Green 2008, Lyons 2009 97-105, Lehman 2009 149-159). ${ }^{159}$ Crookes certainly described King with love-struck superlatives: "Photography is inadequate to depict the perfect beauty of Katie's face, as words are powerless to describe her charms of manner. Photography may indeed give a map of her countenance; but how can it reproduce the brilliant purity of her complexion, or the ever varying expressions of her most mobile features?" (qtd. in Hall 1963 86).

In the embarrassment resulting from of the release of a report fully embraced by no one, ${ }^{160}$ Crookes backed away from psychical research for decades. Cook retired Katie King as well, but not before an extensive set of "farewell appearances" (Bennett 2006); King would subsequently re-manifest through other mediums (Lehman 160-7). Crookes composed this poem as a sort of eulogy for Katie on her departure:

Round her she made an atmosphere of life, The very air seemed lighter from her eyes, They were so soft and beautiful, and rife With all we can imagine of the skies; Her overpowering presence made you feel It would not be idolatry to kneel. (qtd. in Hall 1963 86)

Lofty praise indeed, but, as we shall see, such praise was often reserved for dead women. In the assessment of Courtenay Raia-Grean, Crookes started the experiments scientific integrity, but was co-opted by a practiced con woman and manipulator:

\footnotetext{
${ }^{159}$ Some dispute this claim; biographer Brock absolves Crookes of sexual immodesty but concludes that he was at least hoodwinked by a variety of enterprising mediums (203).

${ }^{160}$ It gave considerable ammunition to spiritualism's opponents and debunkers. Magician John Nevil Maskelyne wrote, "The 'scientist' who writes like this - and clasps the beautiful and substantial spirit in his arms - is much too far gone for investigation" (Brock 179).
} 
At some point it seems reasonably clear that Crookes became Cook's collaborator, the passive object of his research coming to fully implement him in an experiment, or rather gamble, of her own ... [Crookes became] more of an "impresario" exhibiting the spirit phenomena in question than a scientist investigating them. (68)

The line between magician and spiritualist has often been a thin one, and in the surviving images of Crookes standing arm in arm with the full materialization of Katie King, we see striking resonances with the duo of the magician and female assistant, and a similar sexual dynamic. It is plainer here than in most cases that, even as the man stands as the embodiment of formal authority, the woman has the real power. As Humphry Osmond writes, Crookes was clearly more in love with King than Cook:

'Katie' was not a woman at all but an eternal, undemanding, sexually flamboyant being, who had nothing to do with the world of Mrs. Crookes (who seems to have had little interest in his work) or Florence Cook (who was manipulating him for his own ends) ... he was 'infatuated' with 'a substantial spirit' and like many men before him, meshed in this massive experience of love, he became wholly responsible. (1963 209)

I would add that Katie King was not just a disembodied, idealized woman but also a dead one. In the last year of his life, Crookes would appear alongside the dead woman again, this time through a spirit photograph (as opposed to a photograph of full materialization). In 1919, spirit photographer William Hope produced an image of him with his own deceased wife (Jolly 102-3). To explain these images of dead women, we must investigate the late Victorian fascination with sexualized female death and in particularly imagery thereof, of which the aforementioned vogue for X-ray images of women's hands was perhaps one of the milder expressions.

Certainly, associations of the X-ray with furtive voyeurism and eroticism emerged almost instantaneously. A contributor to the Pall Mall Gazette wrote in March 1896 wrote: "We are sick of the Röntgen Rays ... you can see other people's bones with the 
naked eye, and also see through eight inches of solid wood. On the revolting indecency of this there is no need to dwell" (qtd. in Goodman 1995 1043). A London firm tried to sell X-ray-proof undergarments (Weart 1998 45). A 1900 German caricature entitled "Declaration of Love, as Photographed with the Röntgen Camera" displayed an image reminiscent of Smith's The X-Ray Fiend: a male skeleton, phallic sword at his belt, kneeling dramatically before a dainty female skeleton, all while a goat-hoofed satyr photographs it from outside of the frame (Tsivian 1996 87-8). The eroticization of the skeleton that runs through the reception of X-ray images was in keeping with the deathobsessed character of Victorian pornography and erotica (Lutz 2011), and we see it in a number of other places. A striking souvenir postcard from the Paris Cabaret du Néant shows a black skeleton against a white background, posed with its arms behind its head and looking (though fleshless) distinctly feminine and distinctly erotic, rather like a skeletal showgirl (see Appendix II). In the less famous of his two articles reviewing the Lumière programme, Maxim Gorky suggested that, "Possible tomorrow X rays will also appear on the screen at Aumond's (sic), used in some way or other for "belly dances"" (1985 231); Gorky endorses a kind of skeleton pornography. A poem by Lawrence K. Russel that appeared in Life magazine on March 12, 1896 facetiously considered the Xray's erotic potential:

She is so tall, so slender, and her bones -Those frail phosphates, those carbonates of lime -Are well produced by cathode rays sublime, By oscillations, amperes and by ohms. Her dorsal vertebrae are not concealed By epidermis, but are well revealed.

Around her ribs, those beauteous twenty-four, Her flesh a halo makes, misty in line, Her noseless, eyeless face looks into mine, 
And I but whisper "Sweetheart, Je t'adore."

Her white and gleaming teeth at me do laugh.

Ah! Lovely, cruel, sweet cathodograph! (191)

The poem describes a skeleton with the erotic care usually reserved for a woman's body, and carries more than a few implications of the fin de siècle fascination with dead and dying women, ${ }^{161}$ the definitive treatment of which is likely Bram Dijkstra's Idols of Perversity: Fantasies of Feminine Evil in Fin-de-siècle Culture (1988).

Dijkstra describes the late Victorian culture of misogyny as a widespread reaction to emerging feminist movements that took Darwinian theory as a pretext for insisting that women's prescribed roles and positions are natural and pre-ordained. Artists were alternatively fascinated by tragic women like Ophelia and Tennyson's Lady of Shallot and vicious and predatory female vampires, Medusas and Sphinxes. "True femininity expresses itself in a vacant stare," writes Dijkstra (219) ... the ideal woman is substanceless, disembodied or dead. An quintessential example is Lucy Westenra in Dracula, who goes from a "horrid flirt" (91) to a vampire who preys on children, but who regains her purity in death after being staked by her husband-to-be Lord Godalming: "There in the coffin lay no longer the foul Thing ... But Lucy as we had seen her in her life, with her face of unequalled sweetness and purity" (255). As Dijkstra writes, Lucy is transformed into "that ideal creature of feminine virtue by the mid-nineteenth century: the dead woman" (346). ${ }^{162}$ One is reminded of William Crookes's insistence that the spectral beauty of the Katie King could not be captured by photography, that she was indeed a kind of Platonic ideal beauty precisely because she was disembodied. Though Dijkstra's explorations do not extend to subjects like magic shows, X-rays or cinema, it is not hard

\footnotetext{
${ }^{161}$ Slightly later, in Mann's The Magic Mountain, we find Hans Castorp making a fetish object of an X-ray image of Clavdia Chauchat, keeping it in his breast pocket near his heart and kissing it frequently.

${ }^{162}$ See also Tracy (1990), Pike (1991), and Christ (1993).
} 
to find echoes of his thesis in The Vanishing Lady and other skeletal transformation scenes. Dijkstra gives extensive treatment to paintings of dead women, often naked. German artist Albert von Keller visited morgues to perfect his photorealistic portraits of corpses, and reported that:

in the case of girls and women who had died a natural death ... [if one] studied their faces intensively one could see them take on an expression of pain so noble and almost so sympathetic by their suffering that it allowed an otherworldly happiness to shine through which could often only be compared to the miraculous expression of a woman who is in love to the point of ecstasy. (56)

Dijkstra notes that von Keller's observation "shows how literal an equation late nineteenth century males made between virtuous passivity, sacrificial ecstasy, and the erotic death as indicative of 'feminine fulfillment"' (56). When one looks at von Keller's 1885 painting "Study of a Dead Woman," every rib of its nude subject bulging through her pallid skin, one sees how the skeleton vogue participated in this culture of necrophilia, and how Dijkstra's premise may easily be extended to the romance of bone.

Further, as Ludmilla Jordanova notes, there is a body of paintings representing the dissection of a beautiful, young, nude woman $(198998-104)^{163}$ with one or more doctor standing around the supine corpse, and often with a symbolic skeleton of death looking on as well. One is again reminded of the staking of Lucy in Dracula, where four male characters crowd around her coffin to drive the stake home. Jordanova reproduces several such images by American anatomist and painter John Wilkes Brodnax, as well as some lines of poetry he wrote:

This comely maiden, once buoyant in life, By the dread hand of disease expires, Is now subject to the dissector's knife,

${ }^{163}$ Elisabeth Bronfen offers an analysis of Gabriel von Max's 1869 painting Der Anatom, where a doctor looks down on a beautiful young female corpse. von Marx, himself a spiritualist, had a special interest in women on the threshold of life and death (1992 3-6). 
To carve and mutilate as he desires. (104)

Jordanova argues that western society consistently genders science (and more broadly, culture itself) as male, with nature gendered female. The statue "Nature Unveiling Herself Before Science," sculpted in 1899, is a famously literal example: a young woman covered in a veil, lifting it to expose her breasts and face, "implies that science is a masculine viewer, who is anticipating full knowledge of nature, which is represented as the naked female body" (87). The relevance of this unveiling metaphor to the transformation of a woman into a skeleton we see in The Vanishing Lady and elsewhere is clear: masculine (scientific) magic transforms into a medical specimen through a process of (profound) unveiling or undressing. ${ }^{164}$ Asks Jordanova,

Why ... it is the female in particular that is to be (un)veiled? First, covering [her] implies shame and modesty ... Modesty was a concept through which ... the contradictory effects of seeing women's bodies were negotiated. Second, veiling implies secrecy. Women's bodies, and by extension feminine attributes, cannot be treated as fully public, something dangerous might happen, secrets might be let out, if they were open to view. Yet, in presenting something as inaccessible and dangerous, an invitation to know and to possess is extended. (92-3)

Indeed, this unveiling may be forced on a woman by masculine science, her inner secrets penetrated and exposed, precisely as a punishment for a breach of modesty. A stunningly misogynistic example is found in "A Photograph of the Invisible" by George Griffith, where the link between the sexualized female skeleton and the X-ray becomes explicit. This hack story appeared in the same April 1896 issue of Pearson's Magazine as a profile of Röntgen entitled "A Wizard of To-day," the text of which even makes reference to "A Photograph of the Invisible" (Dam 414). The story tells of a young man named Denton who speaks with his friend Professor Grantham about his desire for revenge on a woman

\footnotetext{
${ }^{164}$ Rae Beth Gordon notes the frequency of Méliès films in which "the feats of magicians and magnetizers are interchangeable with those of doctors and physicians" (2001 189); see also Frayling (2005 48-55).
} 
named Edith, who jilted him in favour of a millionaire German Jew named Goldsberg, who is described as "phenomenally homely and vulgar" (379). Grantham is the only person in command of a new kind of trick photography that employs a very particular aesthetic of co-registration:

He could photograph people with a ghostly double of themselves looking over their shoulder, and by means of photographs of a man, and his parents, and his grandparents, he had produced a composite picture that was an excellent likeness of a remote ancestor, as proved by an ivory miniature that he had never seen.

Of course he never did this kind of thing for money, but as a matter of favour; and, for the sake of his pet art, he had now and then taken the photographs of some of the most noted beauties of Society by his unknown process, and the results, with their exquisite blending of light and shade and tinting, were the pride and glory of their origins and the envy and despair of every professional in the world. (378)

Grantham is a master of manipulating double exposures in a way that strongly echoes Mumler's art. After educating Denton about X-rays (Denton has been travelling and missed the initial flurry of excitement), Grantham proposes a scheme for revenge against Edith that even Denton finds horrifying and excessive. According to Grantham, the punishment fits the crime:

The woman has committed a crime against herself and all true womanhood, and to punish her you shall wound her in the tenderest spot in such a woman's being, her vanity and the vainglory which she takes in the beauty she has sold. You shall teach her, in a word - yes, and that millionaire purchaser of hers too, that beauty is but skin deep. (379)

Indeed, it is with skin, or lack thereof, that Grantham's plan is concerned. He invites Edith to a session where he photographs her in complete darkness. He then sends the resulting images to her and her husband. What they see causes "the blood [to] rush to his face till it was almost purple, and died out of hers till it was grey and white and ghastly - 
the face of a corpse, but for the two bright glaring eyes that stared out of it" (379). Just what unspeakable horror stared out at them from Grantham's photograph?:

The photograph seemed, as it were, to be in three layers - all transparent save the third. It was a vignette, just showing the head and neck and shoulders. The dress, a most dainty morning costume, in which she had elected to be taken, was perfect in pattern, but diaphanous and transparent. Under this were the skin and flesh, transparent also.

Above were her features, perfect in their likeness, and the wreathed crown of golden brown hair of which she was so proud, but they were the face and hair not of a living woman, but of a ghost, and, beneath all, sharp in outline and perfect in every hideous detail, a fleshless skull - her own skull - poised on the jagged vertebrae of her neck, and supported on the bare bones of her chest and shoulders, grinned at her through the transparent veil of flesh, and seemed to stare at her out of the sockets in which two ghostly eyes seemed to float. (379-80)

Like Smith's X-ray fiend, Grantham's modus operandi is secretly X-raying people for nefarious purposes. Here we see the aesthetic of co-registration taking on its most horrifying aspect. At the sight of this skeletal portrait, both Mr. Goldsberg and his wife go insane. But only her delusion is characterized: "She imagines that she is a skeleton, and that her clothing and skin are nothing more than transparent shadows which everybody can see through" (380). Her physicians confine her to live in total darkness, for she cannot tolerate even the faintest light. Edith's and her feminine vanity is punished by reducing her to her a fleshless wraith of herself, and her "crime against true womanhood" through her sexual betrayal of Denton is repaid with eternity nudity, right down to the bone.

Jehanne D'Alcy in The Vanishing Lady is denied such a fate of living death and eternal nudity, but her transformation into bone has a distinctly sexual edge nonetheless. One review of The Vanishing Lady on the Internet Movie Database, authored by F. Gwynplaine MacIntyre, carries the title, "Now, if he'd made her CLOTHES disappear . . 
." in recognition of the erotic implications of the female skeleton, reminding us of all the nervous reactions to the "indecent" and potentially pornographic X-ray. We may read in the magician's surprised reaction on unveiling the skeleton something the giddy thrill of unexpected, unauthorized voyeurism that connects it with the emerging genre of the stag film, the paradigmatic example of which, Esme Collings's A Victorian Lady in Her Boudoir, was also released in 1896 (see Nead 186-94). Méliès directed at least one stag film himself, After the Ball (1897), very much in the mold of Collings's film. It shows a society woman who sheds her clothes with the help of a maid and, clad only in her fleshcoloured leotard, stands with her back to the camera as the maid pours bathwater down her back. At the end of the scene, the maid looks at the camera, acknowledging her complicity with the viewer's voyeurism; the film suddenly takes place in the same presentational mode that The Vanishing Lady does, in the regime of exhibitionist confrontation. That the undressing woman in After the Ball is the same Jehanne D'Alcy who was Méliès's vanishing woman confirms the link between the two scenes of "undressing."

The fact that D'Alcy was also Méliès's mistress is itself part of a long tradition of the female assistant also being the magician's lover. ${ }^{165}$ Adelaide Herrmann, Gay Blackstone, Nani Darnell and Bess Houdini were notable examples from the early history of stage magic of the combined assistant-lover. The memoirs of Carl Hertz, magician and early cinema exhibitor, describes the beginnings of his relationship with his assistant: "The [oath of secrecy] was duly administered, and the contract signed, and thus Emelie

\footnotetext{
${ }^{165}$ Méliès was apparently a philanderer who engaged in numerous affairs with the young women who are featured in many of his films. Frazer says "One gets the impression that Méliès may have been the most happy when making films such as Ten Ladies in One Umbrella (1903), in which he is the only man on a stage surrounded by his obedient harem" (128).
} 
D'Alton became the original Vanishing Lady, and, a little later, to make my secrets more secure, she became Mrs. Carl Hertz" (1924 29). Hertz here articulates several dimensions of the magician's relationship to his assistant. His description, however facetious it may be, of marrying Mademoiselle D'Alton to secure his secrets, attests to the essential danger women pose to in their ability expose the magician and the need to contain that danger through strictures like marriage. And further, no matter how many illusions she might participate in, her identity is the "vanishing lady."

The vanishing woman trick has a history going back into the eighteenth century, but received a boom in popularity in the 1880 s. Buatier de Kolta premiered his version, “L'Escamotage d'une Dame en Personne Vivante," at the Egyptian Hall on August 6, 1886. It quickly became perhaps the only trick that virtually all magicians performed, and more than any other trick, it was responsible for cementing the convention of the female assistant (Robert-Houdin was generally assisted by his sons). The female assistant is a complex and contradictory figure. Francesca Coppa argues that magic is superficially constructed as an epistemological matter, with the magician as a possessor of secret and rarefied knowledge which the audience is denied. The assistant, especially when she acts as a shill pulled "unexpectedly" onto the stage, must appear as an unschooled in magic as the audience, but in fact she know its secrets intimately and in many cases is as skillful a performer as the magician himself (2008 89-92). Most tricks depend on the illusion of female passivity. In the vanishing woman illusion, the woman must appear still, but actually speedily slips away into a trapdoor, her status as a labouring body concealed. Like a magical sylph, the assistant's corporeality is always fluid and unstable, and she floats between life and death, embodiment and disembodiment. She embodies Kelly 
Hurley's observation that late Victorian thinkers were perfectly capable of "identifying women as dangerously defined by their bodies on the one hand and ethereal, essentially disembodied creatures on the other" (1996 10). The spectacle of thinly-veiled misogynistic violence in the Vanishing Woman trick anticipates the trick that would become perhaps even more emblematic in the twentieth century, Sawing a Woman in Half. Magicians were not subtle about the relish they took in seeming to dismember women: in a 1921 publicity stunt, British magician P.T. Selbit even challenged feminists Christabel and Sylvia Pankhurst to subject themselves to being sawed in half on his stage (Steinmeyer 292-3). ${ }^{166}$

The paradoxes of the female assistant (and more broadly of women in the Victorian imagination) are manifest in The Vanishing Lady, where Jehanne D'Alcy ranges from being extremely disembodied, vanishing into thin air, to being grotesquely embodied as an inert, blackened skeleton. It is worth reiterating that, in this respect, the skeleton in The Vanishing Lady is not like the bulk of the cinematic skeletons that would follow it. It does not get up and dance or bow, tipping its head in the process - rather it sits there, testifying to its deadness. Perhaps this is a simple reflection of the technical limitations placed on Méliès at the time; he certainly wasted no time in creating lively skeletons in his later films. But seen another way, The Vanishing Lady is a meaningful relic of a moment when the skeleton had a particular power to shock and titillate. It accords with Garrett Stewart's points about cinema's tendency to refer to the

\footnotetext{
${ }^{166}$ The ultimate cinematic expression of this misogynistic convention would have to be Hershell Gordon Lewis's The Wizard of Gore (1970). Other films to explore the gender implications of sawing a woman in two trick include Susan Seidelman's Desperately Seeking Susan (1985) and Claude Chabrol's La fille coupée en deux (2007). Warren Zevon would use a magical metaphor to explore his love life in "For My Next Trick, I'll Need a Volunteer," a track off his excellent 2000 album Life'll Kill Ya. Zevon sings "I can saw a woman in two/But you won't want to look in the box when I'm through/I can make love, disappear/For my next trick, I'll need a volunteer."
} 
photographic image, cinema's inert base, to convey the death of a character, either with freeze framing or a photograph within the film: "filmic textuality has one foot in its own graven image as a photogram ... Photography is a death in replica, cinema a dying away process" (1999 152). In this case, the image of death borrows the image of the doublyhaunted X-ray image. At any rate, by the end of the film Jehanne D'Alcy is back in the flesh, restored, the skeleton disavowed ... or is it? Even with her flesh restored, we spectators have seen her in the ultimate state of undress. She carries those bones with her, and to those bones she will return ... the skeleton is, as Robertson told his audiences a century before, "the fate that awaits us all."

The Survival of Skeletons

This dissertation has principally limited its focus to early cinema, but I feel compelled to continue tracking representations of the skeleton throughout the twentieth century and to our contemporary moment, in part because the conventions of the skeleton on display in early cinema so resolutely inform the rest of its history. This narrative culminates with a new version of the sexualized female skeleton which makes Méliès's look modest by comparison but which is still very much on its lineage. If skeletons would never again appear as commonly as in early cinema, the image does persist, often (as in Bergman's Persona (1966)) making reference to early cinema in the process. In D.W. Griffith's fascinating The Avenging Conscience (1914), a bridge between the trick film and the emerging conventions of the silent horror film, a laurelled skeleton appears as the ultimate horrific image conjured by the guilt-ridden unconscious of the murderer (Henry B. Walthall); Walthall again hallucinated a skeletal figure of death while playing Edgar Allan Poe in The Raven (1915). A comparable image appears in Carl Theodor Dreyer's 
Vampyr (1932). Disney’s The Skeleton Dance (1929) and other cartoons would update lanternic traditions of choreographed, self-dislocating skeletons, often with the skeletons playing their ribcages like xylophones (Beghtol 2006 129-30). Indeed, animation, including stop-motion in such films as Jason and the Argonauts (1963), Army of Darkness (1992) and The Nightmare Before Christmas (1993), would keep danse macabre imagery alive all through the twentieth century and beyond. The Oscarnominated animated short This Way Out (2008) provides its own variation on the centuries-old dancing skeletons motif. If Michael Jackson's famous 1983 music video Thriller is another point of continuation for danse macabre traditions, the imagery is even stronger in its less-known follow-up Ghosts (1997), where special effects make Jackson into a literal dancing skeleton (Hogle 2002 221-4).

In my essay "Collective Screams: William Castle and the Gimmick Film" (2011), I contend that Castle's desire to provoke audiences with his sometimes extra-filmic gimmicks led him to cast himself as a new incarnation of early cinema's trick filmmakers, a fact Castle signals through his repeated use of skeletons. The walking skeleton that menaces Annabel Loren (Carol Ohmert) at the climax of House on Haunted Hill (1959), actually a trick rigged by her husband Frederick (Vincent Price), was accompanied by the pop-out skeleton Emergo that flew from the front of the theatre and hover over (hopefully) terrified audiences. Castle consciously drew on the iconographies from the trick film in order to position himself (and Price, his internal avatar) as a master horror showman, albeit with his tongue in his cheek. We find Castle playing Méliès most egregiously during his customary first person appearance in the opening sequence of 13 Ghosts (1960); in this sequence the gendering of the "magician" and the skeleton is 
particularly interesting. We see an office door marked "William Castle," and silhouetted on the other side is the shadow of skeleton's head and upper chest (looking quite like an X-ray image). The skeleton, having made appearances in House on Haunted Hill and The Tingler (1959), was Castle's symbol by this point, and inside the office, we find Castle at a desk alongside hokey horror props like a skull and a bubbling Bunsen burner; the effect is an amusing clash of the gothic and the mundane. The skeleton turns out to be his secretary. He says "No more dictation today" and she obligingly raises her pen. Castle explains the gimmick of 13 Ghosts, "Illusion-O" and its special ghost viewer, and in so doing affects magical changes to the film itself at will (drawing attention to the "magical" qualities of film form generally suppressed by the classical model). At the end of the sequence, he says "Goodbye for now" to the audience, and then turns to the skeleton secretary. "Shall we go?" he asks the female skeleton, and they both vanish. In this sequence, Castle returns to the trope of the vanishing female skeleton in order to make a statement about his own magical powers of authorship, providing strong evidence for the lasting cultural visibility of this trope.

Lest we think of the sexualized skeletons and intrusive $\mathrm{X}$-rays as quaint footnotes from a time long gone, the issues associated with them continue to resonate with debates about corporeality, technology, privacy and exposure. One point of continuity lies with current debates around the use of full-body scanning technology (millimetre wave scanners and backscatter X-ray scanners) in airports in the post-September $11^{\text {th }}$ world. The American Civil Liberties Union condemns these devices as virtual strip searches and The Guardian has claimed that the scanners violate child pornography laws that prohibit 
the creation of indecent images of children (Travis 2010 1). Issues as old as the X-ray's discovery return in full force. Backscatter technology can:

[pinpoint] not only weapons, drugs and contraband, but also the traveler's breasts, buttocks and genitalia. In fact, the resolution is so clear that the operator can literally count the hairs on a man's chest or measure the depth of a woman's navel. At the same time the machines are checking for contraband, they can produce an $\mathrm{X}$-rated image comparable in quality to those found in Playboy magazine. (Murphy and Wilds 2001 334)

The preceding quote comes from an article entitled "X-Rated X-Ray Invades Privacy Rights" ${ }^{\prime 167}$ which argues that these intrusive security scans are unreasonable intrusively and objectifying an airline passenger's body by giving it the same status as a piece of luggage. These debates are important ones, but I find it interesting to find them framed in terms so similar to the moral panic inspired by the arrival of the X-ray more than a century ago. Arguments against full-body scans embrace eroticized language: scanners are "X-rated," expose genitals, breasts and buttocks, produce images which are likened to those in Playboy magazine and are even described as operating with a kind of "voyeur vision" (Ibid. 340). This rhetoric is not so removed from the angry letter in the Pall Mall Gazette in 1896 decrying the X-ray as revolting, indecent and voyeuristic . . but the extent to which such debates are contingent on eroticization helps us see the titillation that underpins moral such outrage. "X-Rated X-Ray Invades Privacy Rights" might work as a subtitle for Smith's The X-Ray Fiend, or even Méliès's The Vanishing Lady.

In the summer 2010, a new lady skeleton caused a stir on the Internet and in the mass media. The monitor manufacturer EIZO put out a calendar to promote the use of their products in medical imaging. It contains twelve pinup images of a female body, all rendered with X-rays, or another method approximating X-ray aesthetics. They all appear

\footnotetext{
${ }^{167}$ This irresistible pun has also been used by David A. Mackey for his article "The 'X-Rated X-Ray': Reconciling Fairness, Privacy, and Security" (2007).
} 
to show the same model wearing nothing but a pair of high heels in a variety of classic pornographic poses: lying with her back arched, or legs splayed with her hands at her crotch. Occasionally she is posed so that the fleshy outline of her breast juts into the frame, or her buttocks appear as a shapely halo framing her pelvic bones. ${ }^{168}$ But little titillation is to be found in that death's head skull starring out at the camera. Writes Phil Plait, blogger for Discover Magazine, in an article waggishly titled "X-rayted pinups":

But seriously, would someone consider these to be racy pictures? ... In many of the pictures, you can see a hint of flesh, and in many cases, those particular body parts are considered to be, um, secondary sexual characteristics - and as it is well known by the lingerie industry, hinting at skin can be more interesting than simply exposing it. In a lot of the pictures the model is posed provocatively. In most of them she's wearing some killer stilettos, which is more of a pinup thing than medical imaging thing.

On the other hand, these are freaking X-rays. (1)

For whatever discussion and titillation EIZO's images might produce (including a presence on sites like MSNBC.com that would certainly not normally reproduce images of a nude woman!), it seems obvious a naked man's skeleton would not have the same impact. In their constellation of nudity, erotic display and "scientific" dismemberment, the images of EIZO's skeleton pinup carry strong echoes of Méliès's The Vanishing Lady and the other sexualized skeletons of the late Victorian skeleton vogue. Whether or not they represent conscious homage, they are evidence of the skeleton vogue's impact lingering on in the twenty-first century, which continues to be felt especially where questions of masculine scientific authority and female corporeality and incorporeality are concerned.

\footnotetext{
${ }^{168}$ Similarly, in 2001 the Belgian neo-conceptualist artist Wim Delvoye produced a series of X-ray images of people having sex.
} 


\section{Conclusion: Lost Worlds, Ghost Worlds}

An early section of Maarten Pereboom's History and Film: Moving Pictures and the Study of the Past (2011), an introductory text for film history students, bears the name "Fin de Siècle and the Early Twentieth Century" and contains a claim representative of the current in thinking on early cinema that I have opposed in my thesis. Pereboom states, "Two recent films that help us to imagine the world into which film would be introduced are Neil Burger's The Illusionist and Christopher Nolan's The Prestige" (17), the two Victorian magician dramas that were released mere months apart in 2006. Pereboom goes on to say that

[b]oth films portray audiences fascinated with magic, eager for innovation, and ever greater thrills, and specifically the tricks that can be played on our eyes and our sense of time, elements key to the 'magic' of motion pictures ... While we can trace the history of cinema in terms of developing technologies and evolving economies, these films remind us of significant aspects of the culture into which film was born: the surprise, wonder and delight of the invention itself. (18)

On some level, it would churlish to disagree with Pereboom. Introductory-level students often find early cinema opaque, alien and impenetrable, so perhaps screening some accessible latter-day film alongside (though surely not in place of!) early films might help open up late Victorian culture and cinema's entry into it. But Pereboom's choices give me pause: both The Illusionist and The Prestige are avowedly fictional, take place in only thinly historical settings (both containing heavily fictionalized versions of historical figures), and contain science fiction/fantasy elements. Further, neither of them is about cinema per se. ${ }^{169}$

\footnotetext{
${ }^{169}$ Cinema does play a passing role in The Illusionist, and both films are certainly amenable to being read self-reflexively, though such a reading would require a level of complexity beyond what Pereboom is presenting.
} 
Pereboom is certainly guilty of treating films about the past like they are actual historical documents, when in fact contemporary reconstructions of any past (including the late Victorian past depicted in contemporary films) serve the needs of the present. But that is not what I find most interesting about his use of them. He says that these films "help us to imagine the world into which film would be introduced," and we can emphasize the word "imagine" in that sentence: to foreground these films is to construct a certain kind of narrative about early cinema being birthed into a haunted, magical moment, a bridge between old and the new eras. I would express caution about Pereboom's exaltation of The Illusionist and The Prestige as texts exemplary of the time when early cinema was invented on much the same grounds that I have challenged the claims that critics linked to the spectral turn have made about early cinema. As I have shown, early cinema had a very real relationship to the supernatural that may be interrogated from a variety of perspectives: the longstanding connection of media of projected light to the supernatural, the broader haunting of media technology in the wake of the spiritualist movement and the deathly qualities of the photographic image, as well as the eccentric career trajectories of individuals like George Albert Smith. No doubt other, equally compelling angles on early cinema and the supernatural have eluded my gaze and may be brought to light by further scholarship. But let us not oversell the idea of early cinema as somehow inherently or essentially supernatural. Such excessive claims retard the flow of nuanced, perceptive scholarship.

The Illusionist and The Prestige (and Pereboom's rhetorical use of them) are of interest to us in another way, as two of the many neo-Victorian texts that emphasize the supernatural in their construction of "Victorianness." It is perhaps a truism that historical 
films tell us more about the time when they were made than the time that they are about, and it is in this spirit that they are among the texts discussed by Ann Heilmann and Mark Llewellyn in their book Neo-Victorianism: The Victorians in the Twenty-First Century, 1999-2009 (2010). Heilmann and Llewellyn include chapters on magic and spiritualism as key threads in neo-Victorian fiction, a term that refers to the widespread cultural fascination with the Victorian period around the beginning of the third millennium. ${ }^{170}$ The collection Haunting and Spectrality in Neo-Victorian Fiction: Possessing the Past (2010) also attests to the special place for the supernatural in the neo-Victorian. In its introduction, Rosario Arias and Patricia Pulham figure the Victorian period itself as ghostly: "one might argue that the Victorian age is spectralized and appears as a ghostly apparition in contemporary literature; in returning as a reverent, it opens up multiple possibilities for re-enactment, reimagining and reinterpretation" (Arias and Pulham 2010: xix). ${ }^{171}$ It seems possible to draw parallels between neo-Victorianism and the spectral turn, which not only seem to come at approximately the same time but to be share a fixation on questions about the supernatural. Certainly, if the Victorian period both was haunted and continues to haunt our present moment, this goes a long way towards explaining why authors like Pereboom and Alan Cholodenko characterize early cinema in supernatural terms. One can further suggest that the marked increase in academic inquiry into the supernatural from a historical perspective and the "rise of the uncanny" in the

\footnotetext{
${ }^{170}$ For other sources on neo-Victorianism, see Stewart (1999 225-44), Joyce (2007), Kaplan (2007), Llewellyn (2008) and Sadoff (2010), as well as the collections Victorian Afterlife: Postmodern Culture Rewrites the Nineteenth Century (2000) and Victorian Turns, NeoVictorian Returns: Essays on Fiction and Culture (2008). For an example placing special emphasis on the supernatural, see Kontou (2009). ${ }^{171}$ Arias and Pulham are here following Julian Wolfreys's Derrida-influenced Victorian Hauntings: Spectrality, Gothic, the Uncanny and Literature (2003), an important reference for many scholars of neoVictorianism.
} 
1990s as described by Martin Jay (1998) are other facets of a broader phenomenon to which the phrase "spectral turn" might not be equal to describing.

An important question that this dissertation has largely postponed is "why now"?

What about the last twenty years or so created the conditions that allowed the spectral turn to come into existence? We can only speculate. One might suggest, following Laura Mulvey, Trond Lundemo and others, that the commercialization of the Internet and the accompanying rise of the digital has confronted us with a new spectral force that inspires reflection on spectrality as it was understood by previous generations. ${ }^{172}$ This is a compelling possibility, but I wish to suggest that the postmodern rethinking of the idea of the archive is as likely a candidate. We certainly need not select one exclusive explanation, I focus on the latter possibility here in part because I do not believe it has even been articulated and in part because of its clear relation to the study of early cinema. The idea of archives as neutral spaces that store the past indiscriminately declined in favour of the interrogation of the power they wield over history, memory and identity on the part of Foucault- and Derrida-influenced scholars. ${ }^{173}$ One fact to which any scholar of early cinema can attest is that film archives are maddeningly incomplete, haunted, as it were, by their gaps, like the bulk of George Albert Smith's trick films. ${ }^{174}$ Further, the films we do have often exist in reconstructed, altered, incomplete and inadequate forms:

\footnotetext{
${ }^{172}$ The aforementioned Martin Jay essay, which argues that our times have seen the uncanny becoming paradoxically domesticated, makes an example of the use of digital imagery of the famous dead "to sell soft drinks and shake the hand of Forrest Gump" (163). Sarah Walters's essay "Ghosting the Interface: Cyberspace and Spiritualism" (1997) marks an early example of appealing to nineteenth century supernatural metaphors to characterize modern technological hauntings; see also Cubitt (1996), Batchen (1999, 2002), Bode (2001), Jones (2004), Edwards (2005), van Efferen (2009) and Drury (2011 257-73), as well as Sconce (201-9).

${ }^{173}$ See Schwartz and Cook (2002), Freshwater (2003) and Manoff (2004). Note too that the art programme and accompanying book Ghosting: The Role of the Archive within Contemporary Artists' Film and Video (2006) takes its title both from "the appearance of an overlapping secondary image on a television or a display screen" - the video age evolution of double exposures - but also from " "the ghost of acidification", the impact that the ravages of time have on nitrate film" (Lanyon 3).

${ }^{174}$ See Usai (2003) for a useful discussion of the archival issues around early and silent cinema.
} 
as Charles Musser has noted, 'Often 'restorations' create synthetic texts that have no historical standing - mishmashes of variant prints that obscure as much as they illuminate" (2004 102).

One recent example perfectly exemplifies how the ghostly character of early cinema manifests through the archive's gaps. The $2006 \mathrm{BBC}$ documentary The Lost World of Mitchell \& Kenyon chronicles the rediscovery of eight-hundred twenty-six films made by Edwardian filmmakers Sagar Mitchell and James Kenyon, a near-miraculous event that has been estimated as increasing the British Film Institute's collection of silent films by somewhere between twenty and twenty-five percent (Carroll 2006 55). ${ }^{175} \mathrm{Much}$ of the documentary concerns modern English people watching films of their ancestors, footage of vanished locations, as well as long-forgotten parades, sports events and other public spectacles. There is almost a spiritualist feel to watching these mediatized communions with their long-departed forbearers and the vanished Edwardian world. Frequently, we are shown how print records, family photos and other documents give names, identities and backstories to the persons recorded by Mitchell and Kenyon's camera, and understand that these tokens of history in turn become more meaningful when coupled with the cinematic records. The documentary thus emphasizes the restoration of effaced continuities as the archive's project.

But one intriguing moment in the first episode shifts the focus onto non-continuity and the archive's ghosts. We see presenter Dan Cruickshank sitting in an editing suite watching one of Mitchell and Kenyon's many street actualities, an image crowded with men leaving work. He notes the appearance of a smartly-dressed young girl looking at the

\footnotetext{
${ }^{175}$ For more on this collection, see Toulmin (2006) and The Lost World of Mitchell \& Kenyon: Edwardian Britain on Film (2004).
} 
camera. She walks directly towards the camera: "Startling, eerie," says Cruickshank as the film, and the girl, slowly advance. The girl's grey silent stare is indeed unnerving, even when the film is played back at the original speed, perhaps reminding one of the ghost girl Sadako emerging from the television set in Nataka Hideo's Ring (1998). One finds oneself experiencing the uncanny of the "Kingdom of Shadows" .. . all the more so for the knowledge that, whomever this girl is, she is long dead. ${ }^{176}$ Where the other cinematic subjects emphasized in the documentary seem more alive on account of their presence on celluloid, this girl somehow seems more dead. "Sadly," Cruickshank's narration tells us, "we weren't able to find anything out about the little girl."

The somber moment hangs over the rest of the documentary, for it reminds us of the archive's limitations. The girl exists now, we understand, merely as a shadow on film, metonymically standing in for all that is lost to collective memory. Even as The Lost World of Mitchell \& Kenyon focuses on continuity and restoration, its project is still haunted by its own gaps and absences. If history has to be haunted, this is more obviously the case when it comes to reconstructing cinema's own fragmentary early history. As Nathan Carroll writes, "Maybe what we are archiving here is a narrative sum total of lost times: accumulations of differentiated film fragments digitally assembled into narrative wholes, whose coalesced remnants map resemblance to the memory of an ever-present 'lost world"” (62).

$$
\text { Or "ghost world." }
$$

\footnotetext{
${ }^{176}$ In one of her essays on the collection, Vanessa Toulmin describes how "these dead souls are now forever captured in a celluloid tapestry of smiles, gestures, motion and poetic grace, ghosts of the past who beckon the modern viewer into the dawn of the twentieth century" (2010, no page number)
} 


\section{Appendix I}

The letter published by Douglas Blackburn in the spiritualist periodical Light, August 28, 1882 (page 392).

\section{THOUGHT-READING EXTRAORDINARY.}

\section{To the Editor of "LIGHT."}

Sir, The following details of the latest and most marketable development of that form of Thought-reading popularised by Mr. Irving Bishop may prove of interest to your readers. In conjunction with Mr. G.A. Smith, a Brighton mesmerist, not unknown to readers of this and other Spiritualist journals, I have had the satisfaction of experiencing some demonstrations of mind-sympathy which are, I believe, almost without precedent. The modus of Mr. Smith's experiment is this: He places himself en rapport with myself by taking my hands; and a strong concentration of will and mental vision on my part has enabled him to read my thoughts with an accuracy that approaches miraculous. Not only can he, with slight hesitation, read numbers, words, and even whole sentences which I alone have seen, but the sympathy between us has been developed to such a degree that he rarely fails to experience the taste of any liquid or solid I choose to imagine. He has named, described, or discovered small articles he has never seen, when they have been concealed by me in the most unusual places, and on two occasions he has successfully described portions of a scene which I either imagined or actually saw.

Mr. Smith has exhibited marked power as a thought-reader through the mediumship of other persons, but on no occasion has he attained to anything like the power he invariably displays when en rapport with myself. I may add that we have for some time been experimenting together with a view of developing one or the other, but until quite recently the results were not of a nature to call for special remark. The results at each sitting have so far shewn such a marked improvement that it may be safely assumed that ere long Mr. Smith will develop a sympathetic power equal to anything shewn by sensitives in the mesmeric or clairvoyant state. The experiments have created great interest in local scientific circles, and we propose giving a series of séances to members of the Sussex National History or other scientific associations.

We shall be happy to receive a visit from any Spiritualist or scientific inquirer who may be at Brighton during the ensuring month, especially as we are about to inaugurate a series of private séances, at which this most interesting phase of psychic force may be investigated and developed.-I am, Sir, yours obediently Douglas Blackburn

\section{Brigtonian Office}

Editor of the Brightonian

24, Duke-street, Brighton 
Appendix II

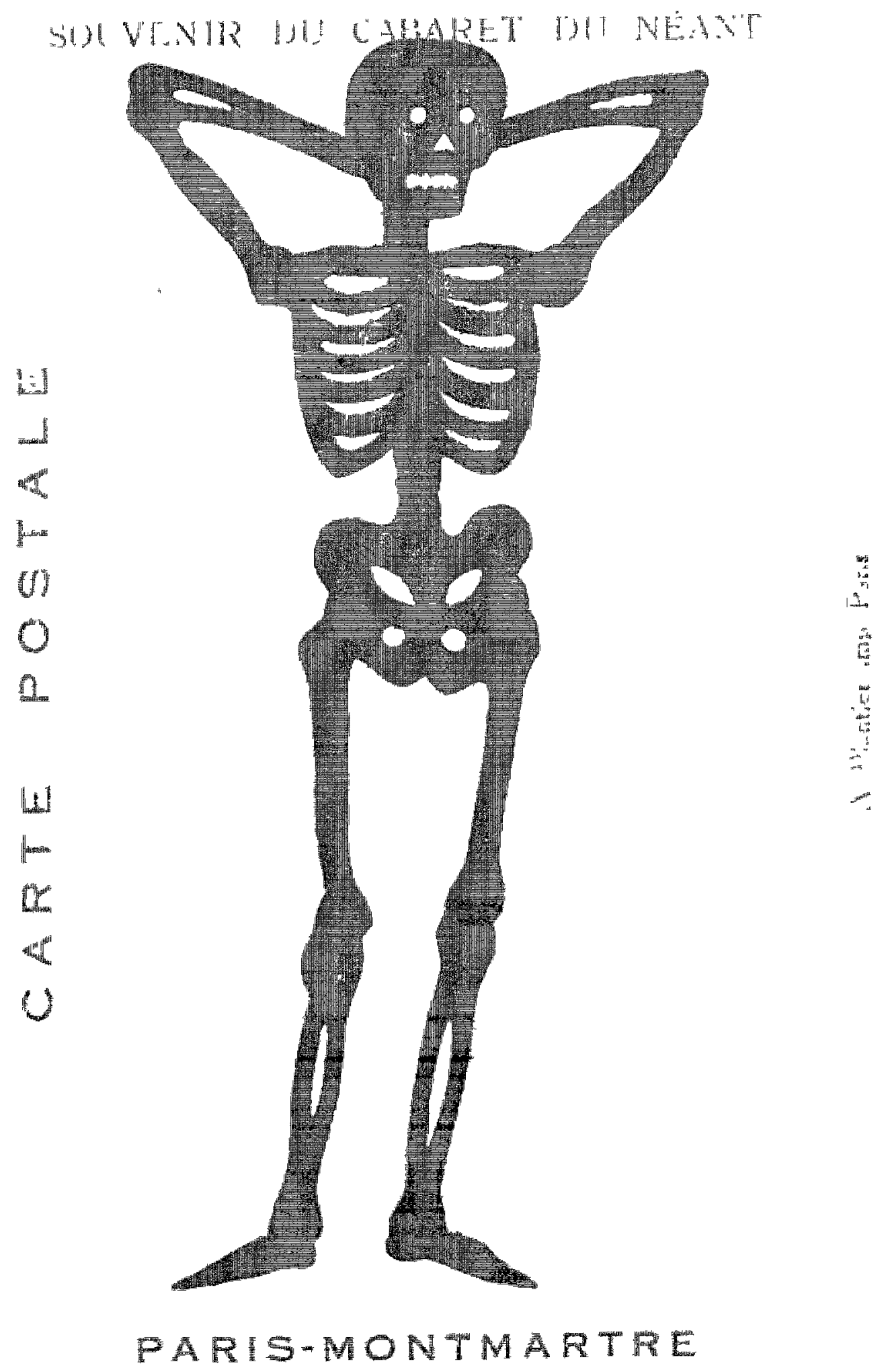




\section{Works Cited}

Abbott, Stacey. Celluloid Vampires: Life After Death in the Modern World. Austin: University of Texas Press, 2007.

Abbott, Stacey. "Spectral Vampires: Nosferatu in the Light of New Technology." Horror Film: Creating and Marketing Fear. Ed. Stefan Hantke. Jackson: University of Mississippi Press, 2004. 3-20.

Adorno, Theodor. In Search of Wagner. London: Verso, 2005.

Allen, Milton. "Electrical Exhibition at Philadelphia." Light 4:205 (1884). 512.

Allen, Richard. "Representation, Illusion, and the Cinema." Cinema Journal 32.2 (Winter 1993): 21-48.

Althans, Katrin. Darkness Subverted: Aboriginal Gothic in Black Australian Literature and Film. Bonn: Bonn University Press, 2010.

Anderson, Joseph D. The Reality of Illusion: An Ecological Approach to Cognitive Film Theory. Carbondale: South Illinois University Press, 1996.

Anderson, Robert. "Defining the Supernatural in Iceland." Anthropological Forum 13.2 (2003): 125-30.

Andriopolous, Stefan. Possessed: Hypnotic Crimes, Corporate Fiction, and the Invention of Cinema. Chicago: University of Chicago Press, 2008.

[Anon] "The Brighton Aquarium." Brighton Herald (July 8, 1882): 2

[Anon] "The Cabaret du Neant." Scientific American (March 7, 1896): 152-3.

[Anon] "Cases Received by the Literary Committee." Journal of the Society for Psychical Research 7:66 (1891): 7-14.

[Anon] "Edison and Rontgen Outdone: A Waipawa Photographer Takes the Picture of Two Phantom Horses and Riders." Borderland 4:3 (October 1896): 446.

[Anon] “A Human X Ray.” Aberdeen Weekly Journal. (July 17, 1899): 6.

[Anon] "Mesmerism." Brighton Herald (September 23, 1882): 3.

[Anon] "Rontgen's Vindication of Reichenbach." Borderland 4:1 (January 1897): 35-6.

[Anon] "What is to be Done about the Camera Fiend?" The American Amateur

Photographer XVIII (March 1906): 4-5. 
Appelbaum, David. Jacques Derrida's Ghost: A Conjuration. Albany: SUNY Press, 2009.

Arias, Rosario and Patricia Pulham. "Introduction." Haunting and Spectrality in NeoVictorian Fiction: Possessing the Past. Eds. Rosario Arias and Patricia Pulham. Houndmills, Basingstoke, Hants: Palgrave Macmillan, 2010. xi-xxvi.

Arias, Rosario. "(Spirit) Photography and the Past in the Neo-Victorian Novel." Literary Interpretation Theory 20 (2009): 92-107.

Arnheim, Rudolf. “Art Today and the Film.” Art Journal 24.3 (Spring 1966): 242-44.

Artaud, Antonin. "Sorcery and the Cinema." The Avant-Garde Film: A Reader of Theory and Criticism. Ed. P. Adams Sitney. New York: New York University Press, 1978. 49-50.

Auerbach, Nina. "Ghosts of Ghosts." Victorian Literature and Culture 32 (4): 277 284.

Bailey, Lee Worth. The Enchantments of Technology. Urbana: University of Illinois Press, 2005.

Balázs, Béla. Béla Balázs: Early Film Theory: Visible Man and The Spirit of Film. New York: Beghahn Books, 2010.

Balázs, Béla. Theory of the Film: Character and Growth of a New Art. New York: Dover, 1970.

Balzac, Honore de. Cousin Pons. London: Penguin, 1978.

Barber, X. Theodore. "Phantasmagorical Wonders: The Magic Lantern Ghost Shows in Nineteenth-Century America." Film History 3 (1989): 73-86.

Barnes, John. Pioneers of the British Film. London: Bishopsgate Press, 1983.

Barnouw, Erik. The Magician and the Cinema. New York: Oxford University Press, 1981.

Barthes, Roland. Camera Lucida: Reflections on Photograph. New York: Hill and Wang, 1981.

Batchen, Geoffrey. "Ectoplasm: Photography in the Digital Age." Over Exposed: Essays on Contemporary Photography. Ed. Carol Squiers. New York: The New Press, 1999. 9-23.

Batchen, Geoffrey. "Spectres of Cyberspace." The Visual Culture Reader. London: 
Routledge, 2002. 237-42.

Baudelaire, Charles. "The Painter of Modern Life." Modern Art and Modernism: A Critical Anthology. Eds. Francis Frascina and Charles Harrison. New York: Harper and Row, 1982. 23-7.

Baudry, Jean-Louis. "Ideological Effects of the Basic Cinematographic Apparatus." Film Quarterly 28.2 (Winter 1974-5): 39-47.

Baumbach, Nico. "Nature Caught in the Act: On the Transformation of an Idea of Art in Early Cinema." Comparative Critical Studies 6.3 (2009): 373-83.

Bazin, André. "The Life and Death of Superimposition." Bazin at Work: Major Essays \& Reviews from the Forties and Fifties. Ed. Bert Cardullo. New York: Routledge, 1997. 73-6.

Bear, Jordan. "From Magician to Metal Brain: The Embodiment of Illusion in Early European Film Theory." Studies in European Cinema 5.1 (2008): 17-29.

Beckman, Karen. Vanishing Women: Magic, Film and Feminism. Durham: Duke University Press, 2003.

Beghtol, L.D. 69 Love Songs: A Field Guide. New York: Continuum, 2006.

Beloff, John. Parapsychology: A Concise History. New York: St. Martin's Press, 1993.

Benjamin, Walter. "The Work of Art in the Age of Mechanical Reproduction." Illuminations. New York: Schocken Books, 1969. 217-51.

Bennett, Bridget. "Spirited Away: The Death of Little Eva and the Farewell Performances of 'Katie King."' Journal of American Studies 40 (2006): 1-16.

Bennett, Bridget. Transatlantic Spiritualism and the Nineteenth-Century American Literature. Houndmills, Basingstoke, Hants: Palgrave Macmillan, 2007.

Bennett, Colin. Handbook of Kinematography. London: Dinematograph Weekly, 1913.

Bergland, Renée L. The National Uncanny: Indian Ghosts and American Subjects. Hanover, NH: University Press of New England, 2000.

Bergson, Henri. Creative Evolution. London: Macmillan, 1913.

Berman, Marshall. All That Is Solid Melts into Air: The Experience of Modernity. London: Verso, 1983.

Berman, Morris. The Reenchantment of the World. Ithaca: Cornell University Press, 
1981.

Bertram, Charles. Isn't It Wonderful? A History of Magic and Mystery. London: Swan Sonnenschein, 1896.

Berthin, Christine. Gothic Hauntings: Melancholy Crypts and Textual Ghosts. Houndmills, Basingstoke, Hants: Palgrave Macmillan, 2010.

Binion, Rudolph. "Europe's Culture of Death." The Psychology of Death in Fantasy and Horror. Ed. Jerry S. Piven. Westport, CN: Greenwood Press, 2004. 119-36.

Blackburn, Douglas. "Thought-Reading Extraordinary." Light 86.2 (1882): 392.

Blanco, María del Pilar and Esther Pereen. "Introduction." Popular Ghosts: The Haunted Spaces of Everyday Culture. Eds. María del Pilar Blanco and Esther Pereen. New York: Continuum, 2010. ix-xxiv.

Blazan, Sladja, ed. Ghost, Stories, Histories: Ghost Stories and Alternate Histories. Newcastle: Cambridge Scholars Publishing, 2007.

Blum, Deborah. Ghost Hunters: William James and the Search for Scientific Proof of Life After Death. New York: Penguin, 2006.

Blümlinger, Christa. "Lumière, the Train and the Avant-Garde." The Cinema of Attractions Reloaded. Ed. Wanda Stauven. Amsterdam: University of Amsterdam Press, 2006. 245-64.

Bode, Lisa. "Ananova in 'the Kingdom of Shadows."” Convergence 7.1 (March 2001): $10-16$.

Bordwell, David. On the History of Film Style. Cambridge: Harvard University Press, 1997.

Bordwell, David and Kristin Thompson. Film Art: An Introduction. Reading MA: Addison-Wesley, 1979.

Bottomore, Stephen. "The Panicking Audience? Early Cinema and the 'Train Effect'." Historical Journal of Film, Radio and Television. 19:2 (1999): 177-216.

Braude, Ann. Radical Spirits: Spiritualism and Women's Writers in Nineteenth-Century America. Bloomington: Indiana University Press, 2001.

Braude, Stephen E. "Peirce on the Paranormal." Transactions of the Charles S. Peirce Society 34.1 (Winter 1998): 203-14.

Braun, Marta. Eadweard Muybridge. London: Reaktion, 2010. 
Braun, Marta. Picturing Time: The Work of Étienne-Jules Marey (1830-1904). Chicago: University of Chicago Press, 1992.

Brecher, Ruth and Edward Brecher. The Rays: A History of Radiology in the United States and Canada. Baltimore: Wilkins \& Wilkins, 1969.

Brewster, Ben. "A Scene at the 'Movies."' Screen 23.2 (1982): 4-15.

Brewster, Ben and Lea Jacobs. Theatre to Cinema: Stage Pictorialism and the Early Feature Film. Oxford: Oxford University Press, 1997. Oxford: Oxford University Press, 1997.

Brewster, David. Letters on Natural Magic. London: Chatto and Windus, 1883.

Brewster, David. The Stereoscope: Its History, Theory and Construction, With Its Application to the Fine and Useful Arts and to Education, Etc. London: John Murray, 1856.

Briefel, Aviva. "Hands of Beauty, Hands of Horror: Fear and Egyptian Art at the Fin de Siècle." Victorian Studies 50.2 (2008): 263-71.

Briggs, Julia. Night Visitors: The Rise and Fall of the English Ghost Story. Faber: London, 1977.

Britzolakis, Christina. "Phantasmagoria: Walter Benjamin and the Poetics of Urban Modernism." Ghosts: Deconstruction, Psychoanalysis, History. Eds Peter Buse and Andrew Stott. New York: St. Martin's Press, 1999. 72-91.

Brock, William H. William Crookes (1832-1919) and the Commercialization of Science. Aldershot, Hants: Ashgate, 2008.

Brogan, Kathleen. Cultural Haunting: Ghosts and Ethnicity in Recent American Literature. Charlottesville, VA: University Press of Virginia, 1998.

Bronfen, Elisabeth. Over Her Dead Body: Death, Femininity and the Aesthetic. Manchester: Manchester University Press, 1992.

Brooker, Jeremy. "The Polytechnic Ghost: Pepper's Ghost, Metempsychosis and the Magic Lantern at the Royal Polytechnic Institution." Early Popular Visual Culture 5.2 (2007): 189-206.

Brown, Nicola, Carolyn Burdett and Pamela Thurschwell. "Introduction." The Victorian Supernatural. Eds. Nicola Brown, Carolyn Burdett and Pamela Thurschwell. Cambridge: Cambridge University Press, 2004. 1-22 
Brown, Simon. "Colouring the Nation: Spectacle, Reality and British Natural Colour in the Silent and Early Sound Era." Film History. 21.2 (2009): 139-49.

Buck-Morss, Susan. "Aesthetics and Anaesthetics: Walter Benjamin's Artwork Essay Reconsidered." October 62 (Autumn 1992): 3-41.

Burch, Noël. Life to Those Shadows. Berkeley: University of California Press, 1990.

Burger, Alissa. "Ghost Hunters: Simulated Participation in Televisual Hauntings." Popular Ghosts: The Haunted Spaces of Everyday Culture. Eds. María del Pilar Blanco and Esther Pereen. New York: Continuum, 2010. 162-74.

Bulwer-Lytton, Edward. "The Haunted and the Haunters, or The House and the Brain." The Caxtons; Zicci; The Haunted and the Haunters, or The House and the Brain. Boston: Aldine Book Publishing, 1980.

Burwick, Frederick. "Science and Supernaturalism: Sir David Brewster and William Scott." Comparative Criticism 13 (1991): 83-114.

Cadava, Eduardo. Words of Light: Theses on the Photography of History. Princeton: Princeton University Press, 1997.

Cadwallader, Jen. "Spirit Photography and the Victorian Culture of Mourning." Modern Language Studies 37.2 (2008): 8-31.

Cahill, James. "and Afterwards ... Matthew Arnold's Phantom Cinema." Spectator 27 (2007): 19-25.

Calinescu, Matei. Five Faces of Modernity: Modernism, Avant-Garde, Decadence, Kitsch, Postmodernism. Durham NC: Duke University Press, 1987.

Cameron, James. "Effects Scene: Technology and Magic." Cinefex 51 (1992): 5-7.

Canguilhem, Denis. "Flammarion and Eusapia Palladino." The Perfect Medium: Photography and the Occult. Eds. Clément Chéroux, Andreas Fischer, Pierre Apraxine, Denis Canguilhem and Sophie Schmit. New Haven: Yale University Press, 2004. 235-7.

Canudo, Ricciotto. "Reflections on the Seventh Art." French Film Theory and Criticism: A History/Anthology, 1907-1939. Volume 1. Ed. Richard Abel. Princeton: Princeton University Press, 1988. 291-302.

Carroll, Nathan. "Mitchell and Kenyon, Archival Contingency, and the Cultural Production of Historical License." The Moving Image 6.2 (2006): 52-76.

Carroll, Noël. "Modernity and the Plasticity of Perception." The Journal of Aesthetics 
and Art Criticism 59.1 (2001): 11-7.

Carroll, Noël. Mystifying Movies: Fads \& Fallacies in Contemporary Film Theory. New York: Columbia University Press, 1988.

Cartwright, Lisa. Screening the Body: Tracing Medicine's Visual Culture. Minneapolis: University of Minnesota Press, 1995.

Cascardi, Anthony J. The Subject of Modernity. Cambridge: Cambridge University Press, 1992.

Castle, Terry. The Female Thermometer: 18th Century and the Invention of the Uncanny. New York: Oxford University Press, 1995.

Castricano, Carla Jodey. Cryptomimesis: The Gothic and Jacques Derrida's Ghost Writing. Montreal: McGill-Queens University Press, 2001.

Chanan, Michael. The Dream that Kicks: The Prehistory and Early Years of Cinema in Britain. London: Routledge, 1996.

Chapman, James. Cinemas of the World: Film and Society from 1895 to Present. London: Reaktion, 2003.

Charney, Leo and Vanessa R. Schwartz, eds. Cinema and the Invention of Modern Life. Berkeley: University of California Press, 1995.

Cholodenko, Alan. "The Crypt, the Haunted House, of Cinema." Cultural Studies Review 10.2. (September 2004): 99-113.

Christ, Carol. "Painting the Dead: Portraiture and Necrophilia in Victorian Art and Poetry." Death and Representation. Eds. Sarah Weber Goodwin and Elisabeth Bronfen. Baltimore: The Johns Hopkins University Press, 1993. 133-151.

Christie, Ian. The Last Machine: Early Cinema and the Birth of the Modern World. London: British Film Institute: BBC Educational Developments, 1994.

Christie, Ian. "Moving-Picture Media and Modernity: Taking Intermediate and Ephemeral Forms Seriously." Comparative Critic Studies 6.3 (2009): 299-318.

Christopher, Milbourne and Maurine Christopher. The Illustrated History of Magic: Updated Edition. New York: Carroll \& Graf, 2006.

Clancy-Smith, Julia A. Rebel and Saint: Muslim Notables, Populist Protest, Colonial Encounters (Algeria and Tunisia, 1800-1904). Berkeley: University of California Press, 1994. 
Clark, T.J. The Painting of Modern Life: Paris in the Art of Manet and his Followers. Princeton: Princeton University Press, 1984.

Clarke, Arthur C. Profiles of the Future: An Inquiry into the Limits of Possibility. London: Victor Gollancz, 1974.

Clery, E.J. The Rise of Supernatural Fiction, 1762-1800. Cambridge: Cambridge University Press, 1995.

Coates, James. Photographing the Invisible: Practical Studies in Spirit Photography, Spirit Portraiture, and Other Rare but Allied Phenomena . . with 90 Photographs. London: L.N. Fowler, 1911.

Coleman, M.H. "The Death of Edmund Gurney." The Journal of the Society for Psychical Research 58 (1993): 194-200.

Collins, Christopher. "Writing and the Nature of the Supernatural Image, or Why Ghosts Float." Languages of Visuality: Crossings Between Science, Art, Politics, and Literature. Detroit: Wayne State University Press, 1996. 242-62.

Collins, Jo and John Jervis. "Introduction." Uncanny Modernity: Cultural Theories, Modern Anxieties. Eds. Jo Collins and John Jervis. Houndmills, Basingstoke, Hants: Palgrave Macmillan, 2008. 1-10.

Comolli, Jean-Louis. "Machines of the Visible." The Cinematic Apparatus. Eds. Teresa de Laurentis and Stephen Heath. London: Macmillan, 1980. 121-42.

Condon, Denis. Early Irish Cinema 1895-1921. Dublin: Irish Academic Press, 2008.

Connor, Steven. "Afterword." The Victorian Supernatural. Eds. Nicola Brown, Carolyn Burdett and Pamela Thurschwell. Cambridge: Cambridge University Press, 2004. 258-77.

Connor, Steven. "The Machine in the Ghost: Spiritualism, Technology and the 'Direct Voice."' Ghosts: Deconstruction, Psychoanalysis, History. Eds Peter Buse and Andrew Stott. New York: St. Martin's Press, 1999. 203-25.

Cook, James W. The Arts of Deception: Playing with Fraud in the Age of Barnum. Cambridge MA: Harvard University Press, 2001.

Cook, Victor W. "The Humours of 'Living Picture' Making." In the Kingdom of Shadows: A Companion to Early Cinema. Eds. Colin Harding and Simon Popple. London: Cyngus Press, 1996. 94-6.

Coppa, Francesca. "The Body Immaterial: Magician's Assistants and the Performance of Labour." Performing Magic on the Western Stage: From the Eighteenth-Century 
to the Present. Eds: Francesca Coppa, Lawrence Hass, James Peck. New York: Palgrave Macmillan, 2008. 85-106.

Cottom, Daniel. Abyss of Reason: Cultural Movements, Revelations, and Betrayals. New York: Oxford University Press, 1991.

Cox, Robert S. Body and Soul: A Sympathetic History of American Spiritualism. Charlottesville: University of Virginia Press, 2003.

Crangle, Richard. "Saturday Night at the X-Rays - The Moving Picture and 'The New Photography' in Britain, 1896." Celebrating 1895: The Centenary of Cinema. Ed. John Fullerton. Sydney: John Libbey \& Company Pty Ltd, 1998. 138-44.

Crary, Jonathan. Techniques of the Observer: On Vision and Modernity in the $19^{\text {th }}$ Century. Cambridge, MA: The MIT Press, 1992.

Crosthwaite, C.H.T. “Rontgen's Curse." Longman's Magazine 28.167 (September 1896): $469-84$.

Cubitt, Sean. "Supernatural Futures: Theses on Digital Aesthetics." FutureNatural: Nature, Science, Culture. Eds. George Robertson, Melinda Mash, Lisa Tickner, Joe Bird, Barry Curtis and Tim Putnam. London: Routledge, 1996. 237-55.

Currie, Gregory. "Film, Reality and Illusion." Post-Theory: Reconstructing Film Studies. Eds. David Bordwell and Noël Carroll. Madison, WI: University of Wisconsin Press, 1996. 325-45.

Curtis, Barry. Dark Places: The Haunted House in Film. London: Reaktion, 2008.

Dalle Vacche, Angela. Diva: Defiance and Passion in Early Italian Cinema. Austin: University of Texas Press, 2008.

Daly, Nicholas. Modernism, Romance and the Fin de Siècle: Popular Fiction and British Culture. Cambridge: Cambridge University Press, 1999.

Dam, H.J.W. “A Wizard of To-Day." Pearson's Magazine. 1.4 (April 1896): 413-9.

Danius, Sara. "Novel Visions and the Crisis of Culture: Visual Technology, Modernism, and Death in The Magic Mountain." Boundary 227.2 (Summer 2000): 177-211.

Daston, Lorraine and Peter Galison. "The Image of Objectivity." Representations 40 (Autumn 1992): 81-128.

Davies, Owen. The Haunted: A Social History of Ghosts. New York: Palgrave Macmillan, 2007. 
Davis, Colin. Haunted Subjects: Deconstruction, Psychoanalysis and the Return of the Dead. Houndmills, Basingstoke, Hants: Palgrave McMillan, 2007.

Davis, Erik. Techgnosis: Myth, Magic and Mysticism in the Age of Information. New York: Harmony, 1998.

Day, Jasmine. The Mummy's Curse: Mummymania in the English-Speaking World. London: Routledge, 2006.

Del Villano, Bianca. Ghostly Alterities: Spectrality and Contemporary Literatures in English. Stuttgart: Ibidem-Verlag, 2007.

Derrida, Jacques. Specters of Marx: The State of Debt, the Work of Mourning and the New International. New York: Routledge, 2006.

Devant, David. My Magic Life. London: Hutchison, 1931.

Dickson, W.K.L and Antonia Dickson. History of the Kinematograph and Kinephonograph. New York: Arno, 1975.

Dijkstra, Bram. Idols of Perversity: Fantasies of Feminine Evil in Fin-de-Siecle Culture. New York: Oxford University Press, 1988.

Dixon, Wheeler Winston. A History of Horror. New Brunswick, NJ: Rutgers University Press, 2010.

Doane, Mary Ann. The Emergence of Cinematic Time: Modernity, Contingency, the Archive. Cambridge, MA: Harvard University Press, 2002.

Doane, Mary Ann. "Information, Crisis, Catastrophe." Logic of Television: Essays in Cultural Criticism. Ed. Patricia Mellencamp. Bloomington: Indiana University Press, 1990. 222-239.

Dolar, Mladen. "II Shall Be With You On Your Wedding-Night': Lacan and the Uncanny." October 58 (1991). 5-23.

Donaldson, Peter S. "Cinema and the Kingdom of Death: Loncraine's Richard III." Shakespeare Quarterly 53.2 (Summer 2002): 241-259.

Donnelly, K.J. "On the Occult Nature of Film-Image Synchronisation." Cinephile: The University of British Columbia's Film Journal. 6.1 (2010): 39-43.

Drury, Nevill. Stealing Fire from Heaven: The Rise of Modern Western Magic. Oxford: Oxford University Press, 2011.

During, Simon. Modern Enchantments: The Cultural Power of Secular Magic. 
Cambridge: Harvard University Press, 2002.

Durovicová, Nataša. "Local Ghosts: Dubbing Bodies in Early Sound Cinema." Film and Its Multiples. Ed. Anna Antonioni. Udine, Italy: Forum, 2003. 83-98.

Dyson, Linda. "The Return of the Repressed? Whiteness, Femininity and Colonialism in The Piano." Screen 36.3 (1995): 267-76.

Ebner, Ingrid D and Glen P. Jenkins. Skeletons in Our Closet: Skeletal Illustration as Represented in the Rare Book Collection of the Cleveland Health Sciences Library. Cleveland: History Division, the Cleveland Health Sciences Library. 1983.

Eggleston, Thomas. "Is He Not a Medium?" Banner of Light. May 2, 1896. 1.

Edwards, Emily D. Metaphysical Media: The Occult Experience in Popular Culture. Carbondale: Southern Illinois University Press, 2005.

Eisenstein, Sergei. The Film Sense. London: Harcourt, 1947.

Eisner, Lotte. The Haunted Screen: Expressionism in the German Cinema and the Influence of Max Reinhardt. London: Thames \& Hudson, 1969.

Elder, R. Bruce. Harmony + Dissent: Film and Avant-Garde Movements in the Early Twentieth Century. Waterloo: Wilfred Laurier University Press, 2008.

Elsaesser, Thomas. "Archaeologies of Interactivity: Early Cinema, Narrative and Spectatorship." Film 1900: Technology, Perception, Culture. Eds. Annemone Ligensa and Klaus Kreimeier. New Barnet, Herts: John Libbey Publishing, 2009. 9-22.

Epperson, Gordon. The Mind of Edmund Gurney. Madison, NJ: Fairleigh Dickinson University Press, 1994.

Epstein, Jean. "Bonjour cinéma and Other Writings." Afterimage. 10 (1981). 2-39.

Epstein, Jean. "The Senses of I (b)." French Film Theory and Criticism: A History/Anthology, 1907-1939. Volume 1. Ed. Richard Abel. Princeton: Princeton University Press, 1988. 291-302. 241-5.

Evans, Henry Ridgely. "Introduction: The Mysteries of Modern Magic." Magic: Stage Illusions, Special Effects, and Trick Photography. New York: Dover, 1976. 1-26.

Evans, Nicola Jean. "Undoing the Magic? DVD Extras and the Pleasure Behind the Scenes." Continuum: Journal of Media \& Cultural Studies 24.4 (August 2010): 587-600. 
Ezra, Elizabeth. "Becoming Woman: Cinema, Gender and Technology." $A$ "Belle Epoque"?: Women in French Society and Culture, 1890-1914. Eds. Diana Holmes and Carrie Tarr. New York: Berghahn Books, 2006. 125-36.

Ezra, Elizabeth, Georges Méliès and the Birth of the Auteur. Manchester: Manchester University Press, 2000.

Fairservice, Don. Film Editing: History, Theory and Practice. New York: Manchester University Press, 2001.

Fechner, Christian. The Magic of Robert-Houdin (Two Volumes). Boulounge, France: Edition F.C.F., 2002.

Finucane, R.C. Appearances of the Dead: A Cultural History of Ghosts. London: Junction Books, 1982.

Fischer, Andreas. "“The Reciprocal Adaptation of Optics and Phenomena': The Photographic Recording of Materializations." The Perfect Medium: Photography and the Occult. Eds. Clément Chéroux, Andreas Fischer, Pierre Apraxine, Denis Canguilhem and Sophie Schmit. New Haven: Yale University Press, 2004. 17189.

Fischer, Lucy. Cinematernity: Film, Motherhood, Genre. Princeton: Princeton University Press, 1996.

Fischer, Lucy. "The Lady Vanishes: Women, Magic, and the Movies." Film Quarterly 33 (Fall 1979): 30-40.

Fowkes, Katherine A. Giving Up the Ghost: Spirits, Ghosts and Angels in Mainstream Comedy Films. Detroit: Wayne State University Press, 1998.

Fowkes, Katherine A. "Melodramatic Specters: Cinema and The Sixth Sense." Spectral America: Phantoms and the National Imagination. Ed. Jeffrey Andrew Weinstock. Madison, WI: University of Wisconsin Press, 2004. 185-206.

Frampton, Daniel. Filmosophy. London: Wallflower, 2006.

Frayling, Christopher. Mad, Bad and Dangerous?: The Scientist and the Cinema. London: Reaktion, 2005.

Frazer, John. Artificially Arranged Scenes: The Films of Georges Méliès. Boston: G. K. Hall, 1979.

Freshwater, Helen. "The Allure of the Archive." Poetics Today 24.4 (Winter 2003): 729758. 
Freud, Sigmund. "The 'Uncanny'." The Standard Edition of the Complete Psychological Works of Sigmund Freud. Vol. XVII (1917-1919). London: Hogarth, 1964. 219-56.

Friedberg, Anne. The Virtual Window: From Alberti to Microsoft. Cambridge: The MIT Press, 2006.

Friedberg, Anne. Window Shopping: Cinema and the Postmodern. Berkeley: University of California Press, 1993.

Furstenau, Marc and Kerstin Hasslöcher. "Cinema/Modernism/Modernity: Towards an Archaeology of the Cinema." European Journal for Semiotic Studies 6.1,2 (1994): 253-305.

Furstenau, Marc. "Introduction-Film Theory: A History of Debates." The Film Theory Reader: Debates and Arguments. Ed. Marc Furstenau. London: Routledge, 2010. $1-20$.

Gaudreault, André. "Méliès the Magician: The Magical Magic of the Magic Image." Early Popular Visual Culture 5.2 (July 2007): 167-74.

Gaudreault, André. "Theatricality, Narrativity, and Trickality: Reevaluating the Cinema of Georges Méliès."Fantastic Voyages of the Cinematic Imagination: Georges Méliès's Trip to the Moon. Ed. Matthew Solomon. Albany: SUNY Press, 2011. $31-48$.

Gauld, Alan. The Founders of Psychical Research. New York: Schocken, 1968.

Gay, Penny, Judith Johnston and Catherine Waters, eds. Victorian Turns, NeoVictorian Returns: Essays on Fiction and Culture. Cambridge: Scholars Publishing, 2008.

Gay, Volney Patrick. Understanding the Occult: Fragmentation and Repair of the Self. Philadelphia: Fortress Press, 1989.

Gelder, Ken. Reading the Vampire. London: Routledge, 1994.

Genelli, Tom and Lynn Davis Genelli. Journal of Popular Film. 12.3 (Fall 1984): 10011.

Gibbons, Tom H. "Cubism and 'The Fourth Dimensions' in the Context of the Late Nineteenth-Century and Early Twentieth-Century Revival of Occult Idealism." Journal of the Warburg and Courtauld Institutes. 44 (1981): 130-47.

Gifford, Denis. A Pictorial History of Horror Movies. London: Hamlyn, 1973.

Glasser, Otto. Wilhelm Conrad Rontgen and the Early History of the Roentgen Rays. San 
Francisco: Norman, 1934.

Glendinning, Andrew. "Psychic Photography." Borderland. 3.3 (July 1896): 313-321.

Goddu, Teresa A. Gothic America: Narrative, History, and Nation. New York: Columbia University Press, 1997.

Goldstein, Diane F, Sylvia Ann Grider and Jeannie Banks Thomas. Haunting Experiences: Ghosts in Contemporary Folklore. Logan, Utah: Utah State University Press, 2007.

Gomel, Elana. "Spirits in the Material World': Spiritualism and Identity in the Fin De Siècle." Victorian Literature and Culture. 35.1 (2007): 189-213.

Goodman, Philip C. "The New Light: Discovery and Introduction of the X-Ray." American Journal of Roentgenology 165 (1995): 1041-45.

Gordon, Avery F. Ghostly Matters: Haunting and the Sociological Imagination. Minneapolis: University of Minnesota Press, 1997.

Gordon, Rae Beth. Why the French Love Jerry Lewis: From Cabaret to Early Cinema. Stanford: Stanford University Press, 2001.

Gordon, Suzy. "I I Clipped Your Wing, That's All': Auto-Erotism and the Female Spectator in The Piano Debate." Screen 37.2 (1996): 193-205.

Gorky, Maxim. "Gorky on the Films, 1896." New Theatre and Film 1934 to 1937. Ed. Herbert Kline. San Diego: Harcourt Brace Jovanovich, 1985. 227-31.

Gorky, Maxim. "A review of the Lumière programme at the Nizhni-Novgorod Fair, as printed in the Nizhegorodski listok, newspaper, July 4, 1986, and signed "I.M. Pacatus." Jay Leyda, A History of the Russian and Soviet Film. London: Unwin House, 1960. 407-9.

Gray, Frank. "From Mesmerism to Moving Pictures in Natural Colours - The Life of G. Albert Smith." The Hove Pioneers and the Arrival of Cinema. Ed. Frank Gray. Brighton: University of Brighton, Faculty of Art, Design and Humanities, 1996. 27-31.

Gray, Frank. "George Albert Smith's Visions and Transformations: The Films of 1898." Visual Delights: Essays on the Popular Projected Image in the $19^{\text {th }}$ Century. Eds. Simon Popple and Vanessa Toulmin. Trowbridge, Wiltshire: Flicks Books, 2000. $170-80$.

Gray, Frank. "The Kiss in the Tunnel (1899), G.A. Smith and the Emergence of the 
Edited Film in England." The Silent Cinema Reader. London: Routledge, 2004. 51-62.

Gray, Frank. "Smith the Showman: The Early Years of George Albert Smith." Film History 10.1 (1998): 8-20.

Gray, Stephen. Free-Lancers and Literary Biography in South America. Amsterdam: Rodopi, 1999.

Grieveson, Lee and Peter Krämer, eds. The Silent Cinema Reader. New York: Routledge, 2004.

Griffith, George. “A Photograph of the Invisible.” Pearson's Magazine 1.4 (April 1896): $376-80$.

Griffiths, Kate and David Evans, eds. Haunting Presences: Ghost in French Literature and Culture. Cardiff: University of Wales Press, 2009.

Groth, Helen. "Reading Victorian Illusions: Dickens's Haunted Man and Dr. Pepper's 'Ghost'." Victorian Studies 5.10 (Autumn 2007): 43-65.

Grove, Allen W. “Röntgen's Ghosts: Photography, X-Rays and the Victorian Imagination." Literature and Medicine 16.2 (Fall 1997): 141-73.

Guerin, Frances. A Culture of Light: Cinema and Technology in 1920s Germany. Minneapolis: University of Minnesota Press, 2005.

Gunn, Joshua. Modern Occult Rhetoric: Mass Media and the Drama of Secrecy in the Twentieth Century. Tuscaloosa: University of Alabama Press, 2011.

Gunn, Joshua. "Review Essay: Mourning Humanism, or, the Idiom of Haunting." Quarterly Journal of Speech 92. 1 (February 2006): 77-102.

Gunning, Tom. "An Aesthetic of Astonishment: Early Film and the (In)Credulous Spectator." Viewing Positions: Ways of Seeing Film. Ed. Linda Williams. New Brunswick, NJ: Rutgers University Press, 1995. 114-33.

Gunning, Tom. "The Cinema of Attractions: Early Film, Its Spectator and the AvantGarde." Early Cinema: Space, Frame, Narrative. Eds. Thomas Elsaesser and Adam Barker. London: British Film Institute, 1990a. 56-62.

Gunning, Tom. D.W. Griffith and the Origins of American Film: The Early Years at Biograph. Urbana: University of Illinois Press, 1991.

Gunning, Tom. "Flickers: On Cinema's Power for Evil." Bad: Infamy, Darkness, Evil 
and Slime on Screen. Ed. Murray Pomerance. Albany: State University Press, 2004a. 21-38.

Gunning, Tom. "The Ghost in the Machine: Animated Pictures at the Haunted Hotel of Early Cinema." Living Pictures 1.1 (2001): 3-17.

Gunning, Tom. "Haunting Images: Ghosts, Photography and the Modern Body." The Disembodied Spirit. Brunswick, Maine: Bowdoin College Museum or Art, 2003a. 8-19.

Gunning, Tom. "Invisible Worlds, Visible Media." Brought to Light: Photography and the Invisible, 1840-1900. San Francisco: San Francisco Museum of Modern Art, 2008a. 51-63.

Gunning, Tom. "Modernity and Cinema: A Culture of Shocks and Flows." Cinema and Modernity. Ed. Murray Pomerance. New Brunswick, NJ: Rutgers University Press, 2007. 297-315.

Gunning, Tom. "Phantasmagoria and the Manufacturing of Illusions and Wonder: Towards a Cultural Optics of the Cinematic Apparatus." The Cinema, A New Technology for the $20^{\text {th }}$ Century. Eds. André Gaudreault, Catherine Russell and Pierre Veronneau. Lausanne, Switzerland: Editions Payot Lausanne, 2004b. 3144.

Gunning, Tom. "Phantom Images and Modern Manifestations: Spirit Photography, Magic Theatre, Trick Films and Photography's Uncanny." Fugitive Images: From Photography to Video. Ed. Patrice Petro. Bloomington: Indiana University Press, 1995a. 42-71.

Gunning, Tom. “'Primitive' Cinema: A Frame-Up? Or, the Trick's on Us." Early Cinema: Space, Frame, Narrative. Eds. Thomas Elsaesser and Adam Barker. London: British Film Institute, 1990b. 95-103.

Gunning, Tom. "Re-Newing Old Technologies: Astonishment, Second Nature and the Uncanny in Technology from the Previous Turn-of-the-Century." Rethinking Media Change: The Aesthetics of Transition. Eds. David Thorburn and Henry Jenkins. Cambridge: MIT Press, 2003b. 39-60.

Gunning, Tom. "To Scan a Ghost: The Ontology of Mediated Vision." Grey Room 26 (Winter 2007): 94-127.

Gunning, Tom. "Uncanny Reflections, Modern Illusion: Sighting the Modern Optical Uncanny." Uncanny Modernity: Cultural Theories, Modern Anxieties. Eds. Jo Collins and John Jervis. Houndmills, Basingstoke, Hants: Palgrave Macmillan, 2008b. 68-90. 
Gurney, Edmund, F.W.H. Myers and Frank Podmore. Phantasms of the Living (Two Volumes). London: Trübner, 1886.

Hall, Trevor H. The Spiritualists: The Story of Florence Cook and William Crookes. New York: Helix Press, 1963.

Hall, Trevor H. The Strange Case of Edmund Gurney. London: Duckworth, 1964.

Hamilton, Trevor. Immortal Longings: F.W.H. Myers and the Victorian Search for Life after Death. Exeter: Imprint Academic, 2009.

Hankins, Thomas L. and Robert J. Silverman. Instruments and the Imagination. Princeton: Princeton University Press, 1995.

Hansel, Charles Edward Mark. ESP: A Scientific Investigation. New York: Scribner, 1966.

Hansen, George. "Magicians Who Endorsed Psychic Phenomena." The Linking Ring 70.8 (August 1990): 52-54.

Hansen, Miriam. Babel and Babylon: Spectatorship in American Silent Film. Cambridge, MA: Harvard University Press, 1991.

Hansen, Miriam. "The Mass Production of the Senses: Classical Cinema as Vernacular Modernism." Modernism/Modernity 6.2 (1999) 59-77

Harding, Colin and Simon Popple, eds. In the Kingdom of Shadows: A Companion to Early Cinema. London: Cyngus Press, 1996.

Harrington, Curtis. "Ghoulies and Ghosties." Horror Film Reader. Eds. Alain Silver and James Ursini. New York: Limelight Editions, 2000. 9-20.

Harvey, John. Photography and Spirit. London: Reaktion Books, 2007.

Heard, Mervyn. Phantasmagoria: The Secret Life of the Magic Lantern. Hastings: The Projection Box, 2006.

Heilmann, Ann and Mark Llewellyn. Neo-Victorianism: The Victorians in the TwentyFirst Century, 1999-2009. Houndmills, Basingstoke, Hants: Palgrave Macmillan, 2009.

Henderson, Linda Dalrymple. "X Rays and the Quest for Invisible Life in the Art of Kupka, Duchamp, and the Cubists." Art Journal 47 (Winter 1988). 323-340.

Herbert, Stephen. A History of Pre-Cinema. Volume 2. London: Routledge, 2004. 
Herman, Daniel. "Whose Knocking? Spiritualism as Entertainment and Therapy in Nineteenth-Century San Francisco." American Nineteenth Century History 7.3 (September 2006): 417-42.

Hertz, Carl. A Modern Mystery Merchant: The Trials, Tricks and Travels of Carl Hertz, the Famous American Illusionist. London: Hutchinson, 1924.

Herzig, Rebecca M. Suffering for Science: Reason and Sacrifice in Modern America. New Brunswick, NJ: Rutgers University Press, 2005.

Hill, Annette. Paranormal Media: Audiences, Spirits and Magic in Popular Culture. London: Routledge, 2011.

Hill, Marylu. "'Shadowing Sense at War with Soul": Julia Margaret Cameron's Photographic Illustrations of Tennyson's 'Idylls of the King." Victorian Poetry 40.4 (Winter 2002): 445-62.

Hills, Matt. The Pleasures of Horror. London: Continuum, 2005.

Hogle, Jerrold E. The Undergrounds of The Phantom of the Opera: Sublimation in Leroux's Novel and its Progeny. New York: Palgrave, 2002.

Hopkins, Albert. A. Magic: Stage Illusions and Scientific Diversions Including Trick Photography. New York: Munn \& Co., 1897.

Hornung, Ernest. The Camera Fiend. Champagne, IL: Project Gutenberg. $<$ http://www.gutenberg.org/files/30096/30096-h/30096-h.htm>. Accessed June $12,2010$.

Houdini, Harry. The Unmasking of Robert-Houdin. London: George Routledge and Sons, 1909.

Howell, Joel. Technology in the Hospital: Transforming Patient Care in the Early Twentieth Century. Baltimore: The Johns Hopkins University Press, 1995.

Hurley, Kelly. The Gothic Body: Sexuality, Materialism, and Degeneration at the Fin de Siecle. Cambridge: Cambridge University Press, 1996.

Huyssen, Andreas. Across the Great Divide: Modernism, Mass Culture, Postmodernism. Bloomington: Indiana University Press, 1986.

Jackson, Russell. "Victorian and Edwardian Stagecraft: Technologies and Issues." The Cambridge Companion to Victorian and Edwardian Theatre. Ed. Kerry Powell. Cambridge: Cambridge University Press, 2004. 52-69.

Jacobson, Brian R. “The 'Imponderable Fluidity’ of Modernity: Georges Méliès and the 
Architectural Origins of Cinema." Early Popular Visual Culture. Early Popular Visual Culture 8.2 (May 2010): 189-207.

Jay, Bill. Cyanide \& Spirits: An Inside-Out View of Early Photography. Munich: Nazraeli Press, 1991.

Jay, Martin. Cultural Semantics: Keywords of Our Time. Amherst, University of Massachusetts Press, 1998.

Jay, Martin. Downcast Eyes: The Denigration of Vision in Twentieth-Century French Thought. Berkeley: University of California Press, 1993.

Jenkins, Richard. "Disenchantment, Enchantment and Re-Enchantment: Max Weber at the Millennium." Max Weber Studies 1 (2003): 11-32.

Johnson, V.E. "The Kinematograph from a Scientific Point of View." In the Kingdom of Shadows: A Companion to Early Cinema. Eds. Colin Harding and Simon Popple. London: Cygnus Press, 1996, 25.

Jolly, Martyn. Faces of the Dead: The Belief in Spirit Photography. London: British Library, 2006.

Jones, Graham M. "The Family Romance of Modern Magic: Contesting Robert-Houdin's Cultural Legacy in Contemporary France." Performing Magic on the Western Stage From the Eighteenth Century to the Present. Ed: Francesca Coppa, Lawrence Hass and James Peck. New York: Palgrave McMillan, 2008. 33-60.

Jones, Graham M. "Modern Magic and the War of Miracles in French Colonial Culture." Comparative Studies in Society and History 52.1 (2010): 66-99.

Jones, Steve. "404 Not Found: The Internet and the Afterlife." Omega: The Journal of Death and Dying 49.1 (2004): 83-88.

Jordan, David Starr. "The Sympsychograph: A Study in Expressionist Physics." Appleton's Popular Science Monthly 49 (Sept. 1896): 597-602.

Jordanova, Ludmilla. Sexual Visions: Images of Gender in Science and Medicine between the Eighteenth and Twentieth Centuries. Madison, WI: University of Wisconsin Press, 1989.

Joyce, Simon. Victorians in the Rearview Mirror. Athens: Ohio University Press, 2007.

Jülich, Solveig. "Media as Modern Magic: Early X-ray Imaging and Cinematography in Sweden." Early Popular Visual Culture 6.1 (April 2008): 18-33.

Jülich, Solveig. "Seeing in the Dark: Early X-ray Imaging and Cinema. Moving Images: 
From Edison to the Webcam. Eds. John Fullerton and Astrid Söderbergh Widding. London: John Libbey, 47-58.

Kaes, Anton. Shell Shock Cinema: Weimar Culture and the Wounds of War. Princeton: Princeton University Press, 2009.

Kania, Andrew. "The Illusion of Realism in Film." British Journal of Aesthetics 42 (2002): 243-58.

Kaplan, Cora. Victoriana: Histories, Fictions, Criticisms. Edinburgh: Edinburgh University Press, 2007.

Kaplan, Fred. Dickens and Mesmerism: The Hidden Spring of Fiction. Princeton: Princeton University Press, 1975.

Kaplan, Louis. The Strange Case of William Mumler, Spirit Photographer. Minneapolis: Minnesota University Press, 2008.

Kara, Ashok, The Ghosts of Justice: Heidegger, Derrida and the Fate of Deconstruction. San José: iUniversity Press, 2001.

Kasson, John F. Houdini, Tarzan and the Perfect Man: The White Male Body and the Challenge of Modernity in America. Hill and Wang: New York, 2003.

Keil, Charlie. Early American Cinema in Transition: Story, Style, and Filmmaking, 19071913. Madison, WI: University of Wisconsin Press, 2001.

Keil, Charlie. "'To Here From Modernity': Style, Historiography, and Transitional Cinema." American Cinema's Transitional Era: Audiences, Institutions, Practices. Ed. Charlie Keil and Shelley Stamp. Berkeley: University of California Press, 2004. 51-75.

Kember, Joe. Marketing Modernity: Victorian Popular Shows and Early Cinema. Exeter: University of Exeter Press, 2009.

Kember, Joe. "Productive Intermediality and the Expert Audiences of Magic Theatre and Early Film." Early Popular Visual Culture. 8.1 (February 2010): 31-46.

Kern, Stephen. The Culture of Time and Space 1880-1918. Cambridge, MA: Harvard University Press, 1983.

Khair, Tabish. The Gothic, Postcolonialism and Otherness: Ghosts from Elsewhere. Houndmills, Basingstoke, Hants: Palgrave Macmillan, 2009.

Kirby, Lynne. "Death and the Photographic Body." Fugitive Images: From 
Photography to Video. Ed. Patrice Petro. Bloomington: Indiana University Press, 1995. 72-84.

Kirby, Lynne. "Male Hysteria and Early Cinema." Camera Obscura 17 (May 1988): 11331.

Kirby, Lynne. Parallel Tracks: The Railroad and Silent Cinema. Durham: Duke University Press, 1997.

Kittler, Friedrich A. Gramophone, Film, Typewriter. Stanford, CA: Stanford University Press, 1999.

Klass, Morton. Ordered Universes: Approaches to the Anthropology of Religion. Boulder: Westview Press, 1995

Knight, David. The Age of Science: The Scientific World-view in the Nineteenth Century. Oxford: Blackwell, 1986.

Knight, Nancy. “"The New Light': X-Rays and Medical Futurism.” Imagining Tomorrow: History, Technology, and the American Future. Ed. Joseph J. Corn. Cambridge, MA: The MIT Press, 1986. 10-30.

Kochhar-Lindgren, Gray. TechnoLogics: Ghosts, the Incalculable, and the Suspension of Animation. Albany: SUNY Press, 2005.

Kontou, Tatiana. Spiritualism and Women's Writing: From the Fin de Siècle to the NeoVictorian. Houndmills, Basingstoke, Hants: Palgrave Macmillan, 2009.

Kovács, Katherine Singer. "Georges Méliès and the Féerie." Film Before Griffith. Ed. John Fell. Berkeley: University of California Press, 1984. 244-57.

Krauss, Rolf H. Beyond Light and Shadow: The Role of Photography in Certain Paranormal Phenomena: A Historical Survey. Portland, OR: Nazraeli Press, 1995.

Krauss, Rosalind. "Tracing Nadar." October 5 (Summer 1978): 29-47.

Kucich, John and Dianne F. Sadoff. Victorian Afterlife: Postmodern Culture Rewrites the Nineteenth Century, eds. Minneapolis: University of Minnesota Press, 2000.

Kurtz, Leonard P. The Dance of Death and the Macabre Spirit in European Literature. Geneva, Switzerland: Slatkine Reprints, 1975.

Lachapelle, Sofie. "From the Stage to the Laboratory: Magicians, Psychologists, and the Science of Illusion," Journal of the History of the Behavioral Sciences 44.4 (Autumn 2008): 319-34. 
Lamb, Geoffrey Frederick. Victorian Magic. London: Routledge \& Kegan Paul, 1976.

Lamont, Peter and Richard Wiseman. Magic in Theory: An Introduction to the Theoretical and Psychological Elements of Conjuring. Hatfield: University of Hertfordshire Press, 1999.

Landon, Perceval. "Thurnley Abbey." The Dark Horse Book of Hauntings. Ed. Scott Allie. Milwaukie: Dark Horse, 2003. 32-46.

Landy, Joshua and Michael Saler. "Introduction: The Varieties of Modern Enchantment." The Re-Enchantment of the World. Eds. Joshua Landy and Michael Saler. Stanford: Stanford University Press, 2009. 1-14.

Landy, Joshua. "Modern Magic: Jean Eugene Robert-Houdin and Stephane Mallarme." The Re-Enchantment of the World. Eds. Joshua Landy and Michael Saler. Stanford: Stanford University Press, 2009. 102-29.

Lant, Antonia. "The Curse of the Pharaoh, or How Cinema Contracted Egyptomania." October 59 (Winter 1992). 86-112.

Lanyon, Josephine. "Foreword." Ghosting: The Role of the Archive within Contemporary Artists' Film and Video. Eds. Jane Connarty and Josephine Lanyon. Bristol: Picture This, 2006. 3-11.

Latour, Bruno. We Have Never Been Modern. Cambridge, MA: Harvard University Press, 1993.

Ledger, Sally and Roger Luckhurst. "Psychical Research." The Fin de Siecle: A Reader in Cultural History, c. 1880-1900. Eds. Sally Ledger and Roger Luckhurst. Oxford: Oxford University Press, 2000. 269-70.

Leeder, Murray. "Collective Screams: William Castle and the Gimmick Film." Journal of Popular Culture 44.4 (2011): 774-96.

Leeder, Murray "M. Robert-Houdin Goes to Algeria: Spectatorship and Panic in Illusion and Early Cinema." Early Popular Visual Culture. 8.2 (2010): 187-203.

Lehman, Amy. Victorian Women and the Theatre of Trance: Mediums, Spiritualists and Mesmerists in Performance. Jefferson, NC: McFarland, 2009.

Leja, Michael. Looking Askance: Skepticism and American Art from Eakins to Duchamp. Berkeley: University of California Press, 2006.

Leroux, Gaston. The Phantom of the Opera. Charlottesville, VA: University of Virginia Library, 1994. 
Leyda, Jay. "Prologue to the Russian Film." Hollywood Quarterly 2.1 (Oct. 1946): 3541.

Lightman, Bernard. Victorian Popularizers of Science: Designing Nature for New Audiences. Chicago: University of Chicago Press, 2007.

Lim, Bliss Cua. Translating Time: Cinema, the Fantastic and Temporal Critique. Durham: Duke University Press, 2009.

Limon, John. The Place of Fiction in the Time of Science: A Disciplinary History of American Writing. New York: Cambridge University Press, 1990.

Lindskoog, Kathryn Ann. Fakes, Frauds and Other Malarkey. Grand Rapids, MI: Zondervan Publishing House, 1992.

Lippit, Akira Mizuta. Atomic Light (Shadow Optics). Minneapolis: University of Minnesota Press, 2005.

Llewellyn, Mark. "What is Neo-Victorian Studies?" Neo-Victorian Studies 1.1 (Autumn 2008): 164-85.

Loiperdinger, Martin. "Lumière's Arrival of a Train: Cinema's Founding Myth." The Moving Image 4.1. (Spring 2004): 89-118.

Low, Rachael and Roger Manvell. The History of the British Film, 1896-1906. London: Allen, 1948.

Lowenstein, Adam. "Living Dead: Fearful Attractions of Film." Representations 110 (Spring 2010): 105-28.

Luckhurst, Roger. "Introduction." Late Victorian Gothic Tales. Ed. Roger Luckhurst. Oxford: Oxford University Press, 2005. ix-xxxi.

Luckhurst, Roger. "The Contemporary London Gothic and the Limits of the 'Spectral Turn."” Textual Practice 16.3. (2002): 527-46.

Luckhurst, Roger. The Invention of Telepathy. Oxford: Oxford University Press, 2002.

Luckhurst, Roger. "The Mummy's Curse: A Genealogy." Magic, Science, Technology and Literature. Eds. Jarmila Mildorf, Hans Ulrich Seeber and Martin Windisch. Berlin: LIT Verlag, 2006. 123-38.

Luckhurst, Roger. "'Something Tremendous, Something Elemental': On the Ghostly Origins of Psychoanalysis." Ghosts: Deconstruction, Psychoanalysis, History. Eds Peter Buse and Andrew Stott. New York: St. Martin's Press, 1999. 50-71. 
Lundemo, Trond. "In the Kingdom of Shadows: Cinematic Movement and Its Digital Ghost." The YouTube Reader. Eds. Pelle Snickars and Patrick Vonderau. Stockholm: National Library of Sweden, 2009. 314-29.

Lutz, Deborah. Pleasure Bound: Victorian Sex Rebels and the New Eroticism. New York: Norton, 2011.

Lyons, Sherrie Lynne. Species, Serpents, Spirits, and Skulls: Science at the Margins in the Victorian Age. Albany: SUNY Press, 2009.

Ma, Jean. "Photography's Absent Times." Still Moving: Between Cinema and Photography. Eds. Karen Beckman and Jean Ma. Durham: Duke University Press, 2008. 98-118.

Macfarlane, Karen E. "Mummy Knows Best: Knowledge and the Unknowable in Turn of the Century Mummy Fiction." Horror Studies 1.1 (2010): 5-24.

MacIntyre, F. Gwynplaine. "Now, if only he'd made her CLOTHES disappear..." Internet Movie Database. July 5, 2005. $<$ http://www.imdb.com/title/tt0000075/usercomments> Accessed June 18, 2009.

Mackey, David A. "The 'X-Rated X-Ray': Reconciling Fairness, Privacy, and Security." Criminal Justice Studies. 20.2 (June 2007): 149-59.

Maddern, Jo Frances and Peter Adey. "Editorial: Spectro-Geographies." Cultural Geographies 15 (2008): 291-295.

Mak, Monica. "East-West Movie Magic: Shadow Magic as Hybrid Art in the Third Space." Yishu: Journal of Contemporary Chinese Art. 1.1 (2002): 68-82.

Mangan, Michael. Performing Dark Arts: A Cultural History of Conjuring. Bristol: Intellect, 2007.

Manoff, Marlene. "Theories of the Archive from Across the Disciplines." portral: Libraries and the Academy 4.1 (2004): 9-25.

Mann, Thomas. The Magic Mountain. New York: Alfred A. Knopf, 1997.

Mannoni, Laurent. The Great Art of Light and Shadow: The Archaeology of Cinema. Exeter: University of Exeter Press, 2000.

Marcus, Laura. The Tenth Muse: Writing About Cinema in the Modernist Period. New York: Oxford University Press, 2007.

Marvin, Carolyn. When Old Technologies Were New: Thinking About Electric 
Communication in the Late Nineteenth Century. New York: University of Oxford Press, 1988.

Marx, Karl. Capital V.1. Harmondsworth: Penguin, 1976.

Masschelein, Anneleen. The Unconcept: The Freudian Uncanny in Late-TwentiethCentury Theory. Albany: SUNY Press, 2011.

Mayer, David. Stagestruck Filmmaker: D.W. Griffith \& the American Theatre. Iowa City: University of Iowa Press, 2009.

McCorristine, Shane. Specters of the Self: Thinking about Ghosts and Ghost-Seeing in England, 1750-1920. Cambridge: Cambridge University Press, 2010.

McEwan, Cheryl. "A Very Modern Ghost: Postcolonialism and the Politics of Enchantment." Environment and Planning D: Society and Space. 26 (2008): 2946.

McGarry, Molly. Ghosts of Futures Past: Spiritualism and the Cultural Politics of Nineteenth-Century America. Berkeley: University of California Press, 2008.

McGrath, Roberta. "Natural Magic \& Science Fiction: Instruction, Amusement \& the Popular Show 1795-1895." Cinema: The Beginnings and the Future. Essays Marking the Centenary of the First Film Show Projected to a Paying Audience in Britain. Ed. Christopher Williams. London: University of Westminster Press, 1996. 13-23.

McGrath, Roberta. Seeing Her Sex: Medical Archives and the Female Body. New York: Manchester University Press, 2002.

McIlhany, Bill. "The Magical Origins of Movies." Magic (January 1996). 46-51.

McKernan, Luke. "The Brighton School and the Quest for Natural Colour." Visual Delights Two: Exhibition and Reception. Eds. Vanessa Toulmin and Simon Popple. Eastleigh: John Libbey, 2005. 205-18.

Melechi, Antonio. Servants of the Supernatural: The Night Side of the Victorian Mind. London: William Heinemann, 2008.

Méliès, Georges. "Cinematographic Views." French Film Theory and Criticism Vol. 1, 1907-1939. Volume 1. Ed: Richard Abel. Princeton: Princeton University Press, 1988. 35-46.

Mensel, Robert E. "'Kodakers Lying in Wait: Amateur Photography and the Right of Privacy in New York, 1885-1915." American Quarterly 43.1 (Mar 1991): 24-45. 
Merck, Mandy. "The Medium of Exchange." Ghosts: Deconstruction, Psychoanalysis, History. Eds. Peter Buse and Andrew Stott. New York: St. Martin's Press, Macmillan Press, 1999. 163-78.

Metz, Christian. The Imaginary Signifier: Psychoanalysis and the Cinema. Bloomington, Indiana: Indiana University Press, 1982.

Metzner, Paul. Crescendo of the Virtuoso: Spectacle, Skill, and Self-Promotion in Paris During the Age of Revolution. Berkeley: University of California Press. 1998.

Meyer, Birgit. "Ghanaian Popular Cinema and the Magic in and of Film." Magic and Modernity: Interfaces of Revelation and Concealment. Eds. Birgit Meyer and Peter Pels. Stanford: Stanford University Press, 2003. 200-222.

Michaels, Lloyd. The Phantom of the Cinema: Character in Modern Film. Albany: SUNY Press, 1998.

Milbank, Alison. "The Victorian Gothic in English Novels and Stories, 1830-1880." The Cambridge Companion to Gothic Fiction. Ed. Jerrold E. Hogle. Cambridge: Cambridge University Press, 2002. 145-65.

Mildorf, Jarmila, Hans Ulrich Seeber and Martin Windisch, eds. Magic, Science, Technology and Literature. Berlin: LIT Verlag, 2006.

Mimura, Glen M. Ghostlife of Third Cinema: Asian American Film and Video. Minneapolis: University of Minnesota Press, 2009.

Mitry, Jean. Semiotics and the Analysis of Film. Bloomington: Indiana University Press, 2000.

Monroe, John Warne. "Flammarion." Email to Murray Leeder. May 27, 2009.

Monroe, John Warne. Laboratories of Faith: Mesmerism, Spiritism and Occultism in Modern France. Ithaca: Cornell University Press, 2002.

Moore, Alan and Kevin O'Neil. League of Extraordinary Gentlemen. V1. La Jolla, CA: American's Best Comics, 2000.

Moore, Paul S. Now Playing: Early Moviegoing and the Regulation of Fun. Albany: State University of New York Press, 2008.

Moore, Rachel O. Savage Theory: Cinema as Modern Magic. Durham: Duke University Press, 2000.

Morgan, Daniel. "The Afterlife of the Superimposition." Opening Bazin: Postwar Film 
Theory and Its Afterlife. Eds. Dudley Andrew and Hervé Joubert-Laurencin. Oxford: Oxford University Press, 2011. 127-141.

Morita, Sally. "Unseen (and Unappreciated) Matters: Understanding the Reformative Nature of $19^{\text {th }}$-Century Spiritualism." American Studies 3.2 (Fall 1999): 99-135.

Morris, Peter. Embattled Shadows: A History of Canadian Cinema, 1895-1939. Montréal: McGill-Queens University Press, 1978.

Morrisson, Mark S. Modern Alchemy: Occultism and the Emergence of Atomic Theory. Oxford: Oxford University Press, 2007.

Morrow, W.C. Bohemian Paris of To-day. London: Chatto and Windus, 1899.

Mulvey, Laura. Death $24 x$ a Second: Stillness and the Moving Image. London: Reaktion, 2006.

Münsterberg, Hugo. The Photoplay: A Psychological Study. New York: D. Appleton and Company, 1916.

Münsterberg, Hugo. "Psychology and Mysticism." Atlantic Monthly 83 (January 1899): 67-85.

Murdock, Graham. "Re-enchantment and the Popular Imagination: Fate, Magic and Purity." Northern Lights 6 (2008): 27-44.

Murphet, Julian. "Film and (as) Modernity." The SAGE Handbook of Film Studies. Eds. James Donald and Michael Renov. Los Angeles: Sage, 2008. 343-60.

Murphy, Michael C. and Michael R. Wilds. "X-Rated X-Ray Invades Privacy Rights." Criminal Justice Policy Review 12.4 (December 2001): 333-343

Mussell, James. Science, Time and Space in the Late Nineteenth-Century Periodical Press: Movable Types. Aldershot, Hants: Ashgate: 2007.

Musser, Charles. The Emergence of Cinema: The American Screen to 1907. New York: Maxwell Macmillan International, 1990.

Musser, Charles. "Historiographic Method and the Study of Early Cinema." Cinema Journal 44.1 (Fall 2004): 101-7.

Nadis, Fred. Wonder Shows: Performing Science, Magic and Religion in America. New Brunswick, NJ: Rutgers University Press, 2005.

Natale, Simone. "Le specttacolari origini di cinema e radiografia." Mondo Niovo. 2 (2006). 55-62. 
Natale, Simone. "Spiritualism Exposed: Scepticism, Credulity and Spectatorship in Endof-the-Century America." European Journal of American Culture 29.2 (2010), 131-144.

Nead, Lynda. The Haunted Gallery: Painting, Photography, Film c. 1900. New Haven: Yale University Press, 2007.

Nelms, Henning. Magic and Showmanship: A Handbook for Conjurers. New York: Dover, 1969.

Nicol, Fraser. "The Silences of Mr. Trevor Hall." International Journal of Parapsychology 8 (1966): 3-59.

Noakes, Richard. "Spiritualism, Science and the Supernatural in Mid-Victorian Britain." The Victorian Supernatural. Eds. Nicola Brown, Carolyn Burdett and Pamela Thurschwell. Cambridge: Cambridge University Press, 2004. 23-43.

North, Dan. Performing Illusions: Cinema, Special Effects and the Virtual Actor. London: Wallflower, 2008.

O'Brien, Charles. "Motion Picture Colour and the Institutionalization of the Cinema." The Blackwell Companion to Early Cinema. Ed. André Gaudreault. London: Blackwell. Forthcoming.

O'Hara, Jessica. "Making Their Presence Known: TV's Ghost-Hunter Phenomenon in a 'Post-' World." The Philosophy of Horror. Ed. Thomas Fahy. Lexington: University of Kentucky Press, 2010. 72-85.

Onians, John. "II Wonder . . ': A Short History of Amazement." Sight \& Insight: Essays on Art and Culture in Honour of E.H. Gombrich at 85. London: Phaidon, 1994. 11-34.

Oppenheim, Janet. The Other World: Spiritualism and Psychical Research in English, 1850-1914. Cambridge: Cambridge University Press, 1985.

Osmond, Humphry. "Victorian Imborglio." International Journal of Parapsychology 5.2 (Spring 1963): 203-12.

Owen, Alex. The Darkened Room: Women, Power, and Spiritualism in Late Nineteenth Century England. London: Virago Press, 1989.

Owen, Alex. The Place of Enchantment: British Occultism and the Culture of the Modern. Chicago: University of Chicago Press, 2004.

Pamboukian, Sylvia. “'Looking Radiant': Science, Photography and the X-ray Craze of 
1897." Victorian Review 27.2 (2001): 56-74.

Pankratz, Loren. "Magician Accuses Faith Healers of Hoax." Journal of Religion and Health. 26.2 (Summer 1987): 115-24.

Parham, Marisa. Haunting and Displacement in African American Literature and Culture. New York: Routledge, 2009.

Parssinen, Terry M. "Mesmeric Performers." Victorian Studies 21.1 (1977): 87-104.

Pels, Peter. "Introduction: Magic and Modernity." Magic and Modernity: Interfaces of Revelation and Concealment. Eds. Birgit Meyer and Peter Pels. Stanford: Stanford University Press, 2003. 1-38.

Pence, Jeffrey. "Cinema of the Sublime: Theorizing the Ineffable." Poetics Today. 25:1 (Spring 2004): 29-66.

Pepper, John Henry. The True History of the Ghost and All About Metempsychosis. London: Cassell \& Company, 1890.

Pereboom, Maarten. History and Film: Moving Pictures and the Study of the Past. Columbus: Prentice Hall, 2011.

Perez, Gilberto. The Material Ghost: Films and their Medium. Baltimore: The Johns Hopkins University Press. 1998.

Peters, John Durham. Speaking into the Air: A History of the Idea of Communication. Chicago: University of Chicago Press, 1999.

Pick, Daniel. Svengali's Web: The Alien Enchanter in Modern Culture. New Haven, CT: Yale University Press, 2000.

Pierson, Michele. Special Effects: Still in Search of Wonder. New York: Columbia University Press, 2002.

Pike, Judith Eloise. Exquisite Corpses: The Fetish of the Female Dead Body in Late Eighteenth and Nineteenth Century Literature. Diss. University of California, Irvine, 1991.

Pimple, Kenneth D. "Ghosts, Spirits and Scholars: The Origins of Modern Spiritualism." Out of the Ordinary: Folklore and the Supernatural. Barbara Walker, ed. Logan: Utah State University Press, 1995. 75-89.

Plaitt, Phil. "X-rayted pinup." Discover Magazine. June 21, 2010. $<\mathrm{http} / / /$ blogs.discovermagazine.com/badastronomy/2010/06/21/x-rayted-pinup $>$. Accessed June 23, 2011. 
Polan, Dana B. “"Above All Else to Make You See': Cinema and the Ideology of Spectacle." Boundary 2. 11.1/2 (August 1982 - Winter 1983): 129-44.

Popple, Simon and Joe Kember. Early Cinema: From Factory Gates to Dream Factory. New York: Wallflower, 2004.

Posner, Dassia N. "Spectres on the New York Stage: The (Pepper's) Ghost Craze of 1863." Representations of Death in Nineteenth Century U.S. Writing and Culture. Ed. Lucy Elizabeth Frank. Aldershot, Hants: Ashgate, 2007. 189-204.

Potts, John. "The Idea of the Ghost." Technologies of Magic: A Cultural Study of Ghosts, Machines and the Uncanny. Eds. John Potts and Edward Scheer. Power Publications: Sydney, 2006. 78-91.

Pringle, Patricia. "The Spatial Implication of Stage Magic." Technologies of Magic: A Cultural Study of Ghosts, Machines and the Uncanny. Eds. John Potts and Edward Scheer. Power Publications: Sydney, 2006. 48-61.

Punt, Michael. "What the Film Archive Can Tell Us About Technology in the Postdigital Era." Design Issues 21.2 (2005): 48-62.

Rabaté, Jean-Michel. The Ghosts of Modernity. Gainsville: University of Florida Press, 1996.

Raia-Grean, Courtenay. "Picturing the Supernatural: Spirit Photography, Radiant Matter, and the Spectacular Science of Sir William Crookes." Visions of the Industrial Age, 1830-1914: Modernity and the Anxiety of Representation in Europe. Eds. Minsoo Kang and Amy Woodson-Boutlon. Aldershot, Hants: Ashgate, 2008. 5580 .

Rayner, Alice. Ghosts: Death's Double and the Phenomena of Theatre. Minneapolis: University of Minnesota Press, 2006.

Richardson, Nathan E. “A Kingdom of Shadows: Muñoz Molina's Beltenbros, Film Theory, and Spain, 1944-1989." Anales de la literature española contemporánea. 29.1 (2004): 257-81.

Rigby, Jonathan. English Gothic: A Century of Horror Cinema. Richmond, Surrey: Reynolds \& Hearn, 2006.

Riskin, Jessica. "The Defecating Duck, Or, The Ambiguous Origins of Artificial Life." Critical Inquiry. 20.4 (Summer 2003): 599-633.

Robert-Houdin, Jean Eugène. Memoirs of Robert-Houdin, Author, Conjurer, Ambassador. Philadelphia: G.G. Evans, 1859. 
Robert-Houdin, Jean Eugène. The Secrets of Stage Conjuring. London: George Routledge and Sons, 1900.

Robinson, David. "Realising the Vision: 300 Years of Cinematography." Cinema: The Beginnings and the Future. Essays Marking the Centenary of the First Film Show Projected to a Paying Audience in Britain. Ed. Christopher Williams. London: University of Westminster Press, 1996. 33-40.

Rorty, Richard. Philosophy and the Mirror of Nature. Princeton: Princeton University Press, 1979.

Rossell, Deac. Living Pictures: The Origins of the Movies. Albany: SUNY Press, 1998.

Ruffles, Tom. Ghost Images: Cinema of the Afterlife. Jefferson, NC: McFarland, 2004.

Russel, Lawrence K. "Lines on an X-ray Portrait of a Lady." Life 27.689 (March 12, 1896): 191.

Rutter, Gordon. "Magic Goes to War." Fortean Times July 2004.

$<\mathrm{http}: / /$ www.forteantimes.com/features/articles/151/magic_goes_to_war.html $>$. Accessed August 21, 2008.

Sadoff, Dianne F. Victorian Vogue: British Novels on Screen. Minneapolis: University of Minnesota Press, 2010.

Sadoul, Georges and Yvonne Templin. "Early Film Production in England: The Origin of Montage, Close-Ups and Chase Sequence." Hollywood Quarterly 1.3 (Apr. 1946): 249-259.

Said, Edward. Orientalism. New York: Vintage, 1977.

Salt, Barry. "The Evolution of Film Form up to 1906." Cinema 1900-1906: An Analytical Study. Ed. Roger Holman. Brussels: FIAF, 1982. 281-96.

Salt, Barry. Film Style \& Technology: History \& Analysis. Second Edition. London: Starword, 1992.

Schaffer, Simon. "Enlightened Automata." The Sciences in Enlightened Europe. Eds. William Clark, Jan Golinski and Simon Schaffer. Chicago: University of Chicago Press, 1999. 126-167.

Schedel, Angelika. "An Unprecedented Sensation - Public Reaction to the Discovery of X-Rays." Physics Education 30.6 (1995): 342-47.

Schivelbusch, Wolfgang. The Railway Journey: The Industrialization of Time and Space 
in the $19^{\text {th }}$ Century. Berkeley: University of California Press, 1986.

Schmidt, Johann N. "Magic and the Film: The Enchantments of a Modern Medium." Magic, Science, Technology and Literature. Eds. Jarmila Mildorf, Hans Ulrich Seeber and Martin Windisch. Berlin: LIT Verlag, 2006. 239-48.

Schoonover, Karl. "Ectoplasms, Evanescence, and Photography." Art Journal 63.3 (Autumn 2003): 30-43.

Schwab, Gabriele. Haunting Legacies: Violent Histories and Transgenerational Trauma. New York: Columbia University Press, 2010.

Schwartz, Joan M and Terry Cook. "Archives, Records, and Power: The Making of Modern Memory." Archival Science 2:1-2 (2002): 1-19.

Schwartz, Louis-Georges. "Cinema and the Meaning of Life." Discourse 28.2 and 3 (Spring and Fall 2006): 7-27.

Schwartz, Vanessa. Spectacular Realities: Early Mass Culture in Fin-de-Siècle Paris. Berkeley: University of California Press, 1998.

Sconce, Jeffrey. Haunted Media: Electronic Presence from Telegraphy to Television. Durham: Duke University Press, 2000.

Sered, Susan. "Afterword: Lexicons of the Supernatural." Anthropological Forum 13.2 (2003): 213-8.

Sharpe, Sam H. Salutations to Robert-Houdin. Calgary: Mickey Hades International, 1983.

Shaviro, Steven. "SCMS08Response.pdf." $<$ http://www.shaviro.com/Othertexts/SCMS08Response.pdf $>$. Accessed October $16,2009$.

Showalter, Elaine. Sexual Anarchy: Gender and Culture at the Fin de Siecle. New York: Viking, 1990.

Simon, Linda. Dark Light: Electricity and Anxiety from the Telegraph to the X-Ray. Orlando: Harcourt, 2004.

Singer, Ben. "The Ambimodernity of Early Cinema: Problems and Paradoxes in the Film-and-Modernity Discourse." Film 1900: Technology, Perception, Culture. Eds. Annemone Ligensa and Klaus Kreimeier. New Barnet, Herts: John Libbey, 2009. 37-52.

Singer, Ben. Melodrama and Modernity: Early Sensational Cinema and Its Contexts. 
New York: Columbia University Press, 2001.

Skoller, Jeffrey. Shadows, Specters, Shards: Making History in Avant-Garde Film. Minneapolis: University of Minnesota Press, 2005.

Smajić, Srdjan. Ghost-Seers, Detectives and Spiritualists: Theories of Vision in Victorian Literature and Science. New York: Cambridge University Press, 2010

Smith, Andrew. The Ghost Story, 1840-1920: A Cultural History. Manchester: Manchester University Press, 2010.

Smith, George Albert. "Report on a Haunted House in Norwich." Journal of the Society for Psychical Research 1 (1885): 313-17.

Smith, George Albert. Untitled. Journal of the Society for Psychical Research 11 (1895): 225-8.

Solomon, Matthew. "The 'Chinese' Conjurer: Orientalist Magic in Variety Theater and the Trick Film." Early Cinema and the "National." Ed. Richard Abel, Giorgio Bertellini and Rob King. New Barnet, Herts: John Libbey, 2008a. 248-57.

Solomon, Matthew. Disappearing Tricks: Silent Film, Houdini, and the New Magic of the Twentieth Century. Iowa City: University of Iowa Press, 2010.

Solomon, Matthew. "Fairground Illusions and the Magic of Méliès." Travelling Cinema in Europe: Source and Perspectives. Ed. Martin Loiperdinger. Frankfurt: Stæmfeld/Roter Stern, 2008b. 35-46.

Solomon, Matthew. "Magicians and Hollywood in the 1920s." Performing Magic on the Western Stage: From the Eighteenth Century to the Present. Ed: Francesca Coppa, Lawrence Hass and James Peck. New York: Palgrave McMillan, 2008c. 61-84.

Solomon, Matthew. "Twenty-Five Heads under One Hat: Quick-Change in the 1890s." Meta Morphing: Visual Transformation and the Culture of Quick-Change. Ed. Vivian Sobchack. Minneapolis: University of Minnesota Press, 2000. 3-20.

Spadoni, Robert. Uncanny Bodies: The Coming of Sound Film and the Origins of the Horror Genre. Berkeley: University of California Press, 2007.

Spitz, Herman. Nonconscious Movements: From Mystic Messages to Facilitated Communication. Mahwah, NJ: Erlbaum, 1997.

Spivak, Gayatri Chakravorty. "Ghostwriting." Diacritics 25.2 (1995): 65-84.

Stahl, Christopher. "Taking Bullets." Anamesia: An Interdisciplinary Journal 2.1 (Spring 
2004).

$<$ http://www.nyu.edu/pubs/anamesa/archive/spring_2004_violence/06_stahl.htm> Accessed January 25, 2011.

Stead, W.T. "Suggestions from Science for Psychic Students: Useful Analogies from Recent Discoveries and Inventions." Borderland 3.4 (October 1896): 400-11.

Steinmeyer, Jim. Hiding the Elephant: How Magicians Invented the Impossible and Learned to Disappear. New York: Carol \& Graf Publishers, 2003.

Stewart, Garrett. Between Film and Screen: Modernism's Photo Synthesis. Chicago: University of Chicago Press, 1999.

Stoker, Bram. Bram Stoker's Notes for Dracula. Eds. Robert Eighteen-Bisang and Elizabeth Miller. Jefferson NC: McFarland, 2008.

Stoker, Bram. The Annotated Dracula. Ed. Leonard Wolf. New York: Ballantine, 1975.

Sugars, Cynthia and Gerry Turcotte, eds. Unsettled Remains: Canadian Literature and the Postcolonial Gothic. Waterloo, ON: Wilfred Laurier University Press, 2009.

Swatos, William H. "Spiritualism as a Religion of Science." Social Compass 37.4 (1999): 471-82.

Swingewood, Alan. Cultural Theory and the Problem of Modernity. New York: St. Martin's Press, 1998.

Sword, Helen. Ghostwriting Modernism. Ithaca: Cornell University Press, 2002.

Tatar, Maria M. Spellbound: Studies on Mesmerism and Literature. Princeton: Princeton University Press, 1978.

Terpak, Frances. "Objects and Contexts." Devices of Wonder: From the World in a Box to Images on a Screen. Los Angeles: Getty Publications, 2001. 142-364.

Thomas, D.B. The First Colour Motion Pictures. London: Her Majesty's Stationery Office, 1983.

Thomas, Ronald R. "Specters of the Novel: Dracula and the Cinematic Afterlife of the Victorian Novel." Victorian Afterlife: Postmodern Culture Rewrites the Nineteenth Century. Eds. John Kucich and Dianne F. Sadoff. Minneapolis: University of Minnesota Press, 2000. 288-310.

Thornton, E.H. "Ghosts Have No Thickness." The Sphinx 2.10 (December 1903): 111.

Thouless, Robert Henry. From Anecdote to Experiment in Psychical Research. 
Routledge: London, 1972.

Thurschwell, Violet. Literature, Technology and Magical Thinking, 1880-1920.

Cambridge: Cambridge University Press, 2001.

Tiedemann, Rolf. "Dialectics at a Standstill: Approaches to the Passagen-Werk." On Walter Benjamin: Critical Essays and Recollections. Ed. Gary Smith. Cambridge MA: The MIT Press, 1988. 260-91.

Todorov, Tzvetan. The Fantastic: A Structural Approach to a Literary Genre. Ithaca, NY: Cornell University Press, 1975.

Tosi, Virgilio. Cinema Before Cinema: The Origins of Scientific Cinematography. London: British Universities Film \& Video Council, 2005.

Toulmin, Vanessa. Electric Edwardians: The Story of the Mitchell \& Kenyon Collection. London: British Film Institute, 2006.

Toulmin, Vanessa. Randall Williams: King of Showmen. From Ghost Show to Bioscope. London: The Projection Box, 1998.

Toulmin, Vanessa. “"This is a local film: The Cultural and Social Impact of the Mitchell \& Kenyon Film Collection." The Public Value of the Humanities. Ed. Jonathan Bate. London: Bloomsbury Academic, 2010. No page numbers.

Toulmin, Vanessa, Simon Popple and Patrick Russell, eds. The Lost World of Mitchell \& Kenyon: Edwardian Britain on Film. London: British Film Institute, 2004.

Tracy, Robert. "Loving Your All Ways: Vamps, Vampires, Necrophiles and Necrofiles in Nineteenth-Century Fiction." Sex and Death in Victorian Literature. Ed. Regina Barreca. Bloomington: Indiana University Press, 1990. 9-31.

Travis, Alan. "New scanners break child porn laws." guardian.co.uk. January 4, 2010. $<$ http://www.guardian.co.uk/politics/2010/jan/04/new-scanners-child-porn-laws $>$ Accessed June 29, 2010.

Tromp, Marlene. Altered States: Sex, Nation, Drugs and Self-Transformation in Victorian Spiritualism. Albany: SUNY Press, 2006.

Tsivian, Yuri. Early Cinema in Russia and Its Reception. New York: Routledge, 2004.

Tsivian, Yuri. "Media Fantasies and Penetrating Vision: Some Links Between X-Rays, the Microscope, and Film." Laboratory of Dreams: The Russian Avant-Garde and Cultural Experiment. Eds. John E. Bowlt and Olga Matich. Stanford: Stanford University Press, 1996. 81-99. 
Tucker, Jennifer. Nature Exposed: Photography as Eyewitness in Victorian Science. Baltimore: The Johns Hopkins University Press, 2005.

Turcotte, Gerry. Peripheral Fear: Transformations of the Gothic in Canadian and Australian Fiction. Brussels: Peter Lang, 2009.

Turvey, Malcolm. Doubting Vision: Film and the Revelationist Tradition. Oxford: Oxford University Press, 2008.

Tyler, Parker. "Supernaturalism in the Movies." Theatre Arts 26.6 (June 1945): 362-9.

Urban, Charles. "Terse History of Natural Colour Kinematography." Living Pictures 2.2 (2003): 59-68.

Usai, Paolo Cherchi. Silent Cinema: An Introduction. London: BFI, 2003.

Valenti, Peter L. The Film Blanc: Suggestions for a Variety of Fantasy, 1940-45." Journal of Popular Film. 6.4 (1978): 294-304.

van Efferen, Isabella. "Dances with Spectres: Theorising the Cybergothic." Gothic Studies 11.1 (2009): 99-112.

Vanderbeke, Dirk. "'Science is Magic that Works': The Return of Magic in Literature on Science." Magic, Science, Technology and Literature. Eds. Jarmila Mildorf, Hans Ulrich Seeber and Martin Windisch. Berlin: LIT Verlag, 2006. 209-24.

Vardac, A. Nicholas. Stage to Screen: Theatrical Method from Garrick to Griffith. Cambridge: Harvard University Press, 1949.

Vermier, Koen. "The Magic of the Magic Lantern (1660-1700): On Analogical Demonstration and the Visualization of the Invisible." British Journal for the History of Science 38.2 (June 2005): 127-59.

Vinitsky, Ilya. Ghostly Paradoxes: Modern Spiritualism and Russian Culture in the Age of Realism. Toronto: University of Toronto Press, 2009.

Virilio, Paul. War and Cinema: The Logistics of Perception. London: Verso, 1989.

Waldow, Stephen. "Women Objectified, Manipulated, and Exploited: The Central Attractions in the "Cinema of Attractions." Film Matters. 1.3 (July 2010): 20-5.

Walters, Sarah. "Ghosting the Interface: Cyberspace and Spiritualism." Science as Culture. 6.33 (1997): 414-43.

Ward, H. Snowdon. "Marvels of New Light: Notes on the Rontgen Rays." Windsor Magazine 16 (April 1896): 372. 
Warner, Marina. Phantasmagoria: Spirit Visions, Metaphors and Media into the Twentyfirst Century. Oxford: Oxford University Press, 2006.

Washington, Peter. Madame Blavatsky's Baboon: A History of the Mystics, Mediums and Misfits Who Brought Spiritualism to America. New York: Schocken Books, 1995.

Wayne, Mike. "Spectres, Marx's Theory of Value and the Ghost Film." Film International 10 (2004): 4-13.

Weart, Spencer R. Nuclear Fear: A History of Images. Cambridge, Harvard University Press, 1988.

Weber, Max. "Science as a Vocation." From Max Weber: Essays in Sociology. Eds. H.H. Gerth and C. Wright Mills. London: Routledge, 1967. 129-158.

Weeden, Brenda. The Education of the Eye: History of the Royal Polytechnic Institution 1838-1881. Chesterton, Cambridge: University of Westminster, 2008.

Weinstein, Sheri. "Technologies of Vision: Spiritualism and Science in NineteenthCentury America." Spectral America: Phantoms and the National Imagination. Ed. Jeffrey Andrew Weinstock. Madison, WI: University of Wisconsin Press, 2004. 124-40.

Weinstock, Jeffrey Andrew. "Introduction: The Spectral Turn." Spectral America: Phantoms and the National Imagination. Ed. Jeffrey Andrew Weinstock. Madison, WI: University of Wisconsin Press, 2004. 3-17.

Weisberg, Barbara. Talking to the Dead: Kate and Margaret Fox and the Rise of Spiritualism. San Francisco: Harper, 2004.

Wells, H.G. The Invisible Man. New York: Signet, 2002.

West, Nancy M. "Camera Fiends: Early Photography, Death, and the Supernatural." The Centennial Review. 40.1 (1996): 170-206.

Wetmore, Alex. "Sympathy Machines: Men of Feeling and the Automaton." EighteenthCentury Studies. 43.1 (Fall 2009): 37-54.

Whissel, Kristen. Picturing American Modernity: Traffic, Technology, and the Silent Cinema. Durham: Duke University Press, 2008.

Willemen, Paul. Looks and Frictions: Essays in Cultural Studies and Film Theory. Bloomington: Indiana University Press, 1994.

Williams, Karen. "The Liveness of Ghosts: Haunting and Reality TV." Popular Ghosts: 
The Haunted Spaces of Everyday Culture. Eds. María del Pilar Blanco and Esther Pereen. New York: Continuum, 2010. 149-61.

Williams, Keith. H.G. Wells, Modernity and the Movies. Liverpool: Liverpool University Press, 2007.

Williams, Linda. "Film Body: An Implantation of Perversions." Cinétracts 12 (Winter 1981): 19-35.

Willis, Martin and Catherine Wynne, eds. Victorian Literary Mesmerism. Amsterdam. Rodopi, 2006.

Winston, Brian. Technologies of Seeing: Photography, Cinematography and Television. London: BFI, 1996.

Winter, Alison. Mesmerized: Powers of the Mind in Victorian Britain. Chicago: University of Chicago Press, 1998.

Winter, O. "The Cinematograph." In the Kingdom of Shadows: A Companion to Early Cinema. Eds. Colin Harding and Simon Popple. London: Cyngus Press, 1996. 137.

Wojcik, Daniel. "Spirits, Apparitions, and Traditions of Supernatural Photography." Visual Resources 25.1-2 (2009): 109-136.

Wolfreys, Julian. Victorian Hauntings: Spectrality, Gothic, the Uncanny and Literature. Houndmills, Basingstoke, Hants: Palgrave Macmillan, 2002.

Wood, Gaby. Edison's Eve: A Magical History of the Quest for Mechanical Life. New York: Alfred A. Knopf, 2002.

Wynne, Catherine. "Arthur Conan Doyle and Psychic Photographs." History of Photography 22.4 (1998): 385-92.

Young, Paul. The Cinema Dreams Its Rivals: Media Fantasy Films from Radio to the Internet. Minneapolis: University of Minnesota Press, 2006. 